EDUARDO JUNCA

RECICLAGEM DE POEIRA DE ACIARIA: ESTUDO DA REDUÇÃO DA POEIRA DE ACIARIA LD, ELÉTRICA E FERRITA DE ZINCO 
EDUARDO JUNCA

\section{RECICLAGEM DE POEIRA DE ACIARIA: ESTUDO DA REDUÇÃO DA POEIRA DE ACIARIA LD, ELÉTRICA E FERRITA DE ZINCO}

Tese apresentada à Escola Politécnica da Universidade de São Paulo para obtenção do título de Doutor em Engenharia.

Área de concentração:

Engenharia Metalúrgica e de Materiais.

Orientador:

Prof. Dr. Jorge Alberto Soares Tenório

Coorientador:

Prof. Dr. Denise Crocce Romano Espinosa 
Este exemplar foi revisado e corrigido em relação à versão original, sob responsabilidade única do autor e com a anuência de seu orientador.

São Paulo, de junho de 2014.

Assinatura do autor

Assinatura do orientador

Catalogação-na-publicação

Junca, Eduardo

Reciclagem de poeira de aciaria: estudo da redução da poeira de aciaria LD, elétrica e ferrita de zinco / E. Junca. -versão corr. -- São Paulo, 2014.

$143 \mathrm{p}$.

Tese (Doutorado) - Escola Politécnica da Universidade de São Paulo. Departamento de Engenharia Metalúrgica e de Materiais.

1.Resíduos sólidos 2.Cinética 3.Termogravimetria 4.Redução I.Universidade de São Paulo. Escola Politécnica. Departamento de Engenharia Metalúrgica e de Materiais II.t. 


\section{AGRADECIMENTOS}

Primeiramente a Deus, por todas as oportunidades concedidas.

A minha mãe Delza, e minha irmã Danúbia, pelo incentivo em todos os momentos da minha vida, sendo eles fáceis ou difíceis.

Ao Prof. Dr. Titular Jorge Alberto Soares Tenório, pela orientação e oportunidade oferecida para o desenvolvimento deste trabalho.

À Prof. Dr. Denise Crocce Romano Espinosa pela coorientação e pelas dicas dadas ao longo desta caminhada.

Aos Professores Claudio Parra De Lazzari, Jefferson Caponero, José Roberto de Oliveira e Thomaz Augusto Guisard Restivo, membros da banca avaliadora, pelo tempo e disponibilidade para avaliar e enriquecer este trabalho.

Aos amigos de laboratório Adriana, Ana, Carlos, Dani, Denis, Felipe, Fernando, Flávia, Hugo, Jorge, Marcos, Monica, Priscila, Solange, Tatiana, Victor e Viviane pelo companheirismo, momentos de diversão, tempo e apoio dedicados dentro e fora do ambiente de trabalho.

Aos amigos de Marilândia pelos momentos de alegria e diversão e que mesmo de longe sempre me incentivaram nesta difícil caminhada.

Aos técnicos do Departamento de Engenharia Metalúrgica e de Materiais Danilo, Livio, Rubens e Veríssimo pela ajuda durante o desenvolvimento do trabalho.

À USP e seus funcionários, que me ajudaram no desenvolvimento deste trabalho.

À FAPESP, pelo apoio financeiro concedido pelo projeto número 11/51638-0. 
À CAPES pela bolsa de estudos.Ao CNPq 245470/2012-3, pela bolsa de doutorado sanduiche.

Ao Prof. Dr. Hong Young Sohn da Universidade de Utah pela disponibilidade em me receber e ajudar no desenvolvimento deste trabalho.

Aos amigos feitos nos Estados Unidos Eddy, Mustafa, Gustavo e Miguel, pelos bons momentos passados nos 6 meses que estive fora.

À Tatiana Scortecci por me acompanhar e me ouvir na maior parte desta caminhada.

A minha filha Giovanna por fazer a minha vida mais feliz.

Em especial, ao meu pai, Sérgio João Junca, que infelizmente me deixou no meio desta jornada, mas que sempre me incentivou em todos os momentos em que esteve presente e que aonde esteja, sempre estará presente por onde eu for.

Enfim, a todos que direta ou indiretamente contribuíram para a realização deste trabalho. 


\section{RESUMO}

Este trabalho teve como objetivo estudar a redução de poeira de aciaria LD, elétrica e ferrita de zinco utilizando duas composições diferentes de gases redutores. Inicialmente foram realizadas as caracterizações das matérias primas. Esta etapa foi executada através de análise química, difração de raios- $X$, microscopia eletrônica de varredura, análise granulométrica e densidade aparente. Foi feita também a caracterização térmica das poeiras de aciaria elétrica e LD. Na próxima etapa, pelotas foram confeccionadas a partir das matérias primas em estudo. Em seguida, foram realizadas as etapas de redução. Esta etapa foi desenvolvida com o uso de uma mistura redutora com 90\% Argônio com 10\% hidrogênio e outra simulando gás natural reformado (utilizando-se a primeira composição de gás redutor mais $\mathrm{CO}$, na proporção de $75 \%$ de $\mathrm{H}_{2}$ e $25 \%$ de $\mathrm{CO}$ ). Foram utilizadas vazões de 50, 100, 150 e $200 \mathrm{~mL} /$ minuto de gás redutor para ambos os gases. Com os dados de perda de massas, partiu-se para a investigação cinética. Esta foi desenvolvida através de uma derivação do método conhecido por Stepwise Isothermal Analysis, onde ao invés da taxa de reação controlar o salto entre os patamares de temperatura, este é gerenciado pelo usuário. Os resultados de caracterização mostraram que a poeira de aciaria elétrica é composta por ferro e zinco e a poeira de aciaria LD é composta principalmente por ferro e cálcio. Na PAE, o ferro apresentou-se como magnetita e o zinco como zincita e franklinita. A poeira de aciaria LD apresentou como principais fases a base de ferro a wustita e a magnetita. Com relação à cinética de redução, foi notado que para as pelotas de poeira de aciaria LD, utilizando mistura gasosa, a etapa inicial de redução $\left(550\right.$ a $\left.650^{\circ} \mathrm{C}\right)$ foi controlada pela etapa de nucleação e a partir de $700^{\circ} \mathrm{C}$, para ambos os gases, a reação passou a ser controlada pela difusão. No caso da redução da ferrita de zinco, foi notado que a etapa inicial de redução (entre 550 a $650^{\circ} \mathrm{C}$ ) foi controlada por reação química. Após $700^{\circ} \mathrm{C}$, foi concluído que a reação passou a ser controlada por difusão para ambos gases. Por fim, na redução das pelotas de poeira de aciaria elétrica foi observado que no estágio inicial, a redução foi controlada por nucleação. A partir de $700^{\circ} \mathrm{C}$ foi visto que a reação apresentou um controle misto entre nucleação e difusão.

Palavras-chave: Resíduo sólido; cinética; Termogravimetria; Redução. 


\section{ABSTRACT}

The aim of this work was study of the reduction of basic oxygen furnace dust (BOFD), electric arc furnace dust (EAFD) and zinc ferrite. To do this, two different reducing gases were used. Initially, the raw materials were characterized by chemical analysis, X-ray, scanning electron microscope, size analysis and bulk density. Furthermore, thermal characterization was also performed in both BOFD and EAFD. The next step, pellets were made using the raw materials. The reduction tests were carried out on the pellets through two different reducing gases. The first gas used was a mixture between argon (90wt.\%) and hydrogen (10wt.\%). The last one was a gas simulating reformed natural gas. In this case, it was accomplished a mixture between the first gas with CO. Fluxes at 50,100, 150 and $200 \mathrm{~mL} /$ minute were used in this study in both reducing gas. The kinetic investigation was executed through loss mass curve obtained from reduction tests. The method used for kinetic analysis is a method derived from Stepwise Isothermal Analysis (SIA) where the isothermals are controlled by user. The results from characterization showed that EAFD is composed mainly of iron and zinc. The iron's phase found was magnetite while zinc's phases detected were zincite and franklinite. The BOFD is composed by iron and calcium. It was verified that the main iron's phases encountered were wustite and magnetite. The kinetic analysis showed that pellets of BOFD reduced by gaseous mixture at 550 to $650^{\circ} \mathrm{C}$ was controlled by nucleation. After $700^{\circ} \mathrm{C}$, in both reducing gases, the reactions were controlled by diffusion. To zinc ferrite, it was checked out that initially $\left(550\right.$ to $\left.650^{\circ} \mathrm{C}\right)$ the reaction was controlled by phase boundary reaction. After $700^{\circ} \mathrm{C}$, it was concluded that reaction of reduction for zinc ferrite switched to diffusion in both reducing gases. Lastly, reduction of BOFD's pellet was noted $\left(550\right.$ to $\left.650^{\circ} \mathrm{C}\right)$ that the reduction was controlled by nucleation. Further $700^{\circ} \mathrm{C}$, it was observed that the reaction showed a mix control between nucleation and diffusion.

Key-words: Solid waste; Kinetic; Thermogravimetry; Reduction. 


\section{LISTA DE FIGURAS}

Figura 1 - Processo de geração de partículas em conversor LD...........................2 Figura 2 - Imagem obtida por microscópio eletrônico de varredura de partículas de poeira de aciaria LD.

Figura 3 - Partículas formadas a partir de aglomeração de partículas menores na

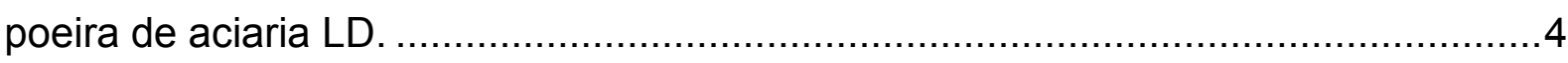

Figura 4 - Processo de formação de poeira no forno elétrico a arco........................5

Figura 5 - Imagem obtida por microscopia eletrônica de varredura da poeira de aciaria elétrica.

Figura 6 - Análise granulométrica realizada através do equipamento Malvern com poeira de aciaria elétrica.

Figura 7 - Diagrama de estabilidade de óxidos de ferro em função da temperatura $x$ porcentagem de oxigênio

Figura 8 - Diagrama de Bell dos óxidos de ferro para diferentes temperatura e pressões de gases redutores.

Figura 9 - Efeito da composição do gás redutor sobre a redução de minério de ferro a $900^{\circ} \mathrm{C}$.

Figura 10 - Representação esquemática do processo de sinterização.

Figura 11 - Arranjo cristalina da hematita $\alpha$.

Figura 12 - Grau de conversão versos tempo para diferentes temperaturas de redução.

Figura 13 - Comparação de dados experimentais utilizando os modelos de controle por limite de fases e Avrami-Erofeyev de mudança de fases em temperatura de $700^{\circ} \mathrm{C}$.

Figura 14 - Comparação de dados experimentais utilizando os modelos de controle por limite de fases e Avrami-Erofeyev de mudança de fases em temperatura de $910^{\circ} \mathrm{C}$

Figura 15 - Representação esquemática das etapas de redução de $\mathrm{Fe}_{2} \mathrm{O}_{3}$ para $\mathrm{Fe}$ em temperaturas entre 250 a $300^{\circ} \mathrm{C}$. .26

Figura 16 - Representação da estrutura cristalina da magnetita. 27

Figura 17 - Grau de redução em função do tempo para a redução de magnetita. ....28 
Figura 18 - Representação do modelo estrutural da wustita.

Figura 19 - Micrografias de wustita em atmosfera de hidrogênio: A) Temperaturas de 700; B) Temperatura de $890^{\circ} \mathrm{C}$.

Figura 20 - Representação esquemática da estrutura cristalina da ferrita de zinco. .33

Figura 21 - Redução de ferrita de zinco em diferentes temperaturas com hidrogênio puro.

Figura 22 - Redução de ferrita de zinco pura com diferentes misturas redutoras para a temperatura de $900^{\circ} \mathrm{C}$. 36

Figura 23 - Adaptação dos estágios de nucleação e crescimento sobre a superfície da wustita durante da reação de redução sugerida por John, Matthew e Hayes . 38 Figura 24 - Adaptação da representação esquemática do mecanismo de bursting para formação de poros. 40

Figura 25 - Fluxograma esquemático do processo MIDREX. .43

Figura 26 - Fluxograma esquemático do processo HyL III. .44

Figura 27 - Processo FIOR de redução direta de minério de ferro. .45

Figura 28 - Pilha alongada para realização do quarteamento das amostras. .48

Figura 29 - Forno mufla utilizada na síntese da Ferrita de zinco. 49

Figura 30 - Termobalança utilizada nos ensaios de redução. .57

Figura 31 - Programação de temperatura utilizada na realização das análises termogravimétricas. 58

Figura 32 - Difratograma obtido da poeira de aciaria LD.

Figura 33 - Imagem de elétrons secundários obtida por microscópio eletrônico de varredura da poeira de aciaria LD 66

Figura 34 - Espectro de EDS da poeira de aciaria LD. .66

Figura 35 - Análise granulométrica da poeira de aciaria LD. 67

Figura 36 - Caracterização térmica da poeira de aciaria LD entre as temperaturas de 30 a $1100^{\circ} \mathrm{C}$ com atmosfera de nitrogênio. 68

Figura 37 - Curva DTG obtida da caracterização térmica da poeira de aciaria LD utilizando atmosfera inerte. 68

Figura 38 - Difratograma obtido da poeira de aciaria elétrica. 70

Figura 39 - Análise granulométrica da poeira de aciaria elétrica. 72

Figura 40 - Imagens de elétrons retro-espalhados obtidas por microscopia eletrônica de varredura da poeira de aciaria elétrica. .73

Figura 41 - Espectro de EDS obtido da poeira de aciaria elétrica. 
Figura 42 - Perda de massa da poeira de aciaria elétrica em atmosfera inerte.

Figura 43 - Curva de DTG obtida na análise térmica da poeira de aciaria elétrica com atmosfera inerte.

Figura 44 - Difratograma obtido da ferrita de zinco sintetizada.

Figura 45 - Imagem de elétrons retro-espalhados obtidos por microscópio eletrônico de varredura da ferrita de zinco sintética. .77

Figura 46 - Espectro de EDS da ferrita de zinco sintetizada.

Figura 47 - Curva de porcentagem acumulada obtida na análise granulométrica da ferrita de zinco sintetizada

Figura 48 - Análises de perda de massa das pelotas de poeira de aciaria LD utilizando mistura redutora.

Figura 49 - Curvas de Arrhenius obtidas utilizando as equações para reações do tipo gás-sólido na redução de pelotas de poeira de aciaria LD reduzidas por mistura gasosa com fluxo de $200 \mathrm{~mL} / \mathrm{minuto}$.

Figura 50 - Imagem retro-espalhada obtida por microscópio eletrônico de varredura da pelota de poeira de aciaria LD reduzida com mistura gasosa interrompida a $900^{\circ} \mathrm{C}$

Figura 51 - Espectro de EDS obtida na região apresentada na Figura 50.

Figura 52 - Difratograma obtido da pelota de poeira de aciaria LD reduzida com mistura redutora.

Figura 53 - Análise termogravimétrica com pelotas feitas com poeira de aciaria LD utilizando gás natural simulado como agente redutor para diferentes fluxos.

Figura 54 - Espectro de difração de raios-X obtido da camada externa da pelota de poeira de aciaria LD reduzida até a temperatura de $600^{\circ} \mathrm{C}$ com uso de gás natural simulado.

Figura 55 - Curvas de Arrhenius obtidas para a redução de pelotas feitas com de poeira de aciaria LD reduzida com gás natural simulado.

Figura 56 - Imagem obtida por microscópio eletrônico de varredura da pelota de poeira de aciaria LD reduzida por gás natural simulado com fluxo de $200 \mathrm{~mL} /$ minuto.

Figura 57 - Espectros de EDS obtida na pelota de poeira de aciaria LD reduzida por gás natural simulado com fluxo de $200 \mathrm{~mL} /$ minuto.

Figura 58 - Curvas de perda de massa das pelotas de poeira de aciaria elétrica em função do tempo para diferentes fluxos de mistura gasosa. 
Figura 59 - Curvas de Arrhenius obtidas para a redução de pelotas de poeira de aciaria elétrica reduzidas por mistura gasosa.

Figura 60 - Imagem de elétrons retro-espalhados obtido por microscópio eletrônico de varredura da pelota de poeira de aciaria elétrica reduzida com mistura redutora até o patamar de $700^{\circ} \mathrm{C}$ com mistura redutora

Figura 61 - Espectro de EDS da borda da pelota de poeira de aciaria elétrica reduzida com mistura redutora até o patamar de $700^{\circ} \mathrm{C}$ 102

Figura 62 - Imagem de elétrons retro-espalhados obtido por microscópio eletrônico de varredura da pelota de poeira de aciaria elétrica reduzida com mistura redutora até o patamar de $900^{\circ} \mathrm{C}$ com mistura redutora

Figura 63 - Espectro de EDS obtido do ponto A da pelota de poeira de aciaria elétrica reduzida com mistura redutora até o patamar de $900^{\circ} \mathrm{C}$ mostrada na Figura 62. 103

Figura 64 - Difratograma obtido na pelota de poeira de aciaria elétrica reduzida com mistura redutora com fluxo de $200 \mathrm{~mL} /$ minuto.

Figura 65 - Análise termogravimétrica das pelotas feitas com poeira de aciaria elétrica reduzidas com gás natural simulado para fluxos de 50, 100, 150 e $200 \mathrm{~mL} / \mathrm{minuto}$.

Figura 66 - Difratograma obtido na camada externa da pelota de poeira de aciaria elétrica reduzida com gás natural simulado interrompida na isoterma de $550^{\circ} \mathrm{C} \ldots 106$ Figura 67 - Curvas de Arrhenius obtidas para a redução de pelotas de poeira de aciaria elétrica utilizando gás natural simulado. 108

Figura 68 - Imagens de elétrons retro-espalhados obtidas por microscópio eletrônico de varredura nas pelotas de poeira de aciaria elétrica em diferentes instantes de redução. A) interrompia a $700^{\circ} \mathrm{C}$; B) interrompida a $900^{\circ} \mathrm{C}$

Figura 69 - Espectro de EDS obtido da região apresentada na Figura 68B.

Figura 70 - Curvas de perda de massa realizada nas pelotas feitas com ferrita de zinco sintética utilizando mistura gasosa como agente redutor em diferentes fluxos.

Figura 71 - Curvas de Arrhenius obtidas para a redução de pelotas de ferrita de zinco reduzidas com mistura redutora.

Figura 72 - Imagens obtidas por microscópio eletrônico de varredura da pelota de ferrita de zinco reduzida por mistura redutora até $700^{\circ} \mathrm{C}$. 
Figura 73 - Difratograma obtido da pelota de ferrita de zinco sintética reduzida até a temperatura de $700^{\circ} \mathrm{C}$ com mistura gasosa.

Figura 74 - Análise termogravimétrica das pelotas de ferrita de zinco reduzida por gás natural simulado para fluxos de 50,100, 150 e $200 \mathrm{~mL} /$ minuto.

Figura 75 - Curvas de Arrhenius obtidas para a redução de pelotas de ferrita de zinco reduzidas por gás natural simulado.

Figura 76 - Imagem de elétrons retro-espalhados obtido por microscópio eletrônico de varredura da pelota de ferrita de zinco reduzida com gás natural simulado após a completa redução.

Figura 77 - Espectro de EDS da pelota de ferrita de zinco reduzida com gás natural simulado após completa redução 123

Figura 78 - Difratograma obtido da pelota de ferrita de zinco reduzida por gás natural reformado após a completa redução. 


\section{LISTA DE TABELAS}

Tabela 1 - Composições típicas de poeira de aciaria LD. ........................................

Tabela 2 - Composição química de diferentes poeiras de aciarias elétricas. ...............6

Tabela 3 - Principais fases cristalinas encontradas na poeira de aciaria elétrica........7

Tabela 4 - Sugestões matemáticas para modelamento cinético para reações heterogêneas do tipo gás-sólido.

Tabela 5 - Compilação de valores de energia de ativação e mecanismos envolvidos na redução de óxidos de ferro

Tabela 6 - Análise química da poeira de aciaria LD.

Tabela 7 - Quantificação das fases presentes na poeira de aciaria LD pelo método Rietveld.

Tabela 8 - Análise química da poeira de aciaria elétrica.

Tabela 9 - Quantificação das fases pelo método Rietveld na poeira de aciaria elétrica.

Tabela 10 - Análises de densidade da ferrita de zinco, poeira de aciaria LD e poeira de aciaria elétrica e porosidades das pelotas para cada material. 79

Tabela 11 - Coeficientes de correlação para as funções citadas como possíveis controladoras para a redução de pelotas de poeira de aciaria LD reduzida com mistura redutora.

Tabela 12 - Valores de Energia de ativação aparente obtidas para as possíveis funções controladoras.

Tabela 13 - Quantificação de fases pelo método Rietveld da pelota de poeira de aciaria LD reduzida com mistura redutora.

Tabela 14 - Coeficientes de correlação para as funções citadas como possíveis controladoras para a redução de pelotas de poeira de aciaria LD reduzida com gás natural simulado.

Tabela 15 - Energias de ativação aparente e fatores de correlação obtidos a partir das curvas de Arrhenius para a redução de pelotas de poeira de aciaria LD reduzida por gás natural reformado.

Tabela 16 - Fatores de correção obtidos para as relações $d(\alpha) / d t \times f(\alpha)$ e $g(\alpha) \times t$ para a redução de pelotas de poeira de aciaria elétrica reduzida com mistura redutora...98 
Tabela 17 - Compilação dos valores de energia de ativação aparente e fatores de correlação das funções utilizadas nos cálculos cinéticos para as pelotas de poeira de aciaria elétrica reduzidas com mistura redutora. 100

Tabela 18 - Aplicação do método Rietveld de quantificação de fases no difratograma obtido na pelota de poeira de aciaria elétrica reduzida com mistura redutora. .......104 Tabela 19 - Fatores de correção obtidos para as relações $d(\alpha) / d t \times f(\alpha)$ e $g(\alpha) \times t$ para a redução de pelotas de poeira de aciaria elétrica reduzida com gás natural simulado. 107

Tabela 20 - Compilação dos valores de energia de ativação aparente e fatores de correlação das funções utilizadas nos cálculos cinéticos para as pelotas de poeira de aciaria elétrica reduzidas com gás natural simulado. 109

Tabela 21 - Fatores de correção obtidos para a redução de pelotas de ferrita de zinco sintética com uso de mistura gasosa.

Tabela 22 - Compilação dos valores de energia de ativação aparente e fatores de correlação obtidos nas curvas de Arrhenius para a redução de pelotas de ferrita de zinco reduzidas com mistura gasosa.

Tabela 23 - Fatores de correção obtidos para a redução de pelotas de ferrita de zinco sintética com uso de gás natural simulado.

Tabela 24 - Compilação dos valores de energia de ativação aparente e fatores de correlação obtidos nas curvas de Arrhenius para a redução de pelotas de ferrita de zinco reduzidas com gás natural simulado. 


\section{SUMÁRIO}

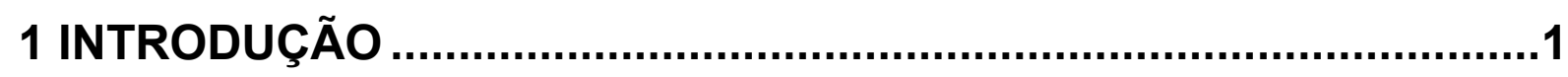

2 REVISÃO BIBLIOGRÁFICA ..........................................................

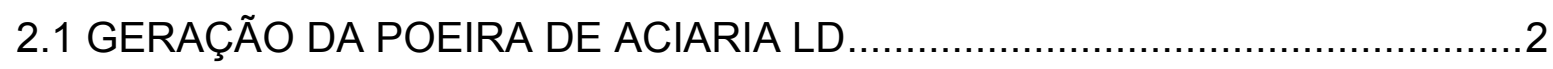

2.2 CARACTERIZAÇÃO DA POEIRA DE ACIARIA LD..................................

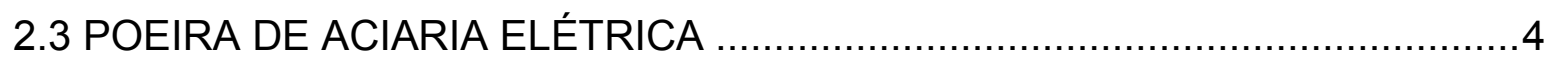

2.4 CARACTERIZAÇÃO DA POEIRA DE ACIARIA ELÉTRICA ...........................6

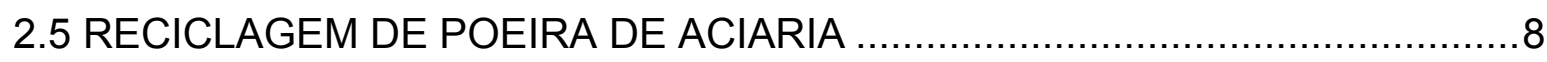

2.6 TERMODINÂMICA DE REDUÇÃO DE ÓXIDOS DE FERRO …....................10

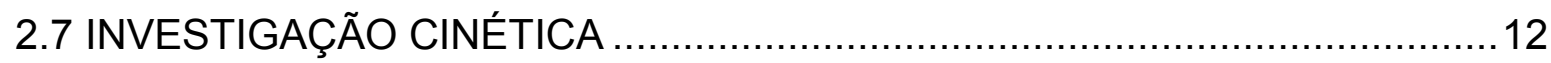

2.8 REAÇÕES DE REDUÇÃO DE ÓXIDOS DE FERRO ….............................15

2.8.1 Hematita .......................................................................................21

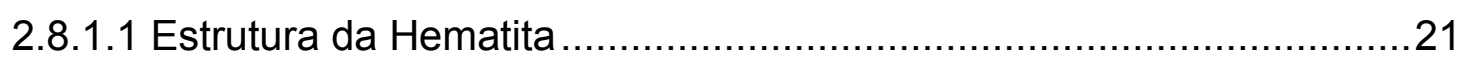

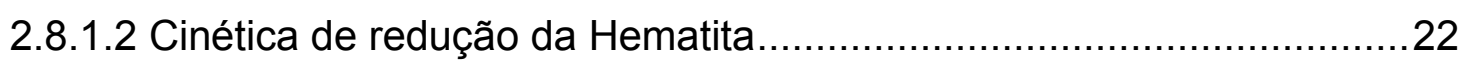

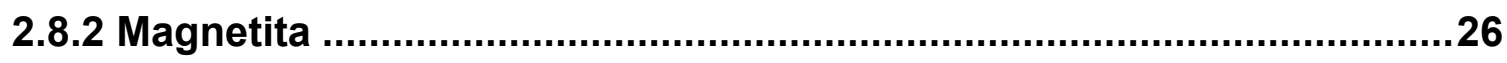

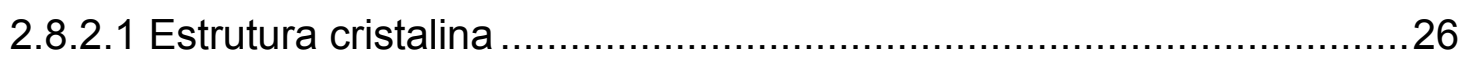

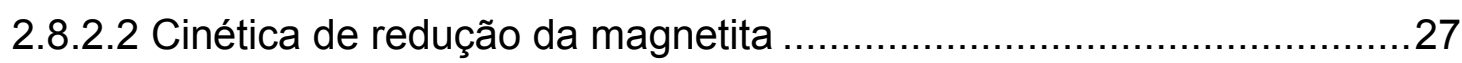

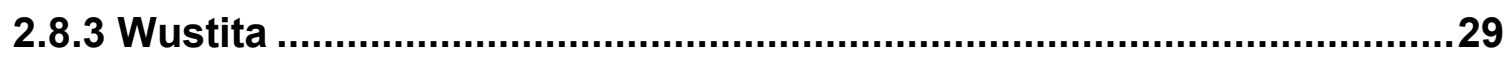

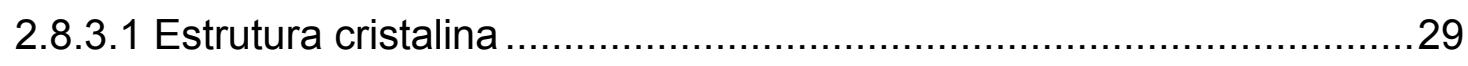

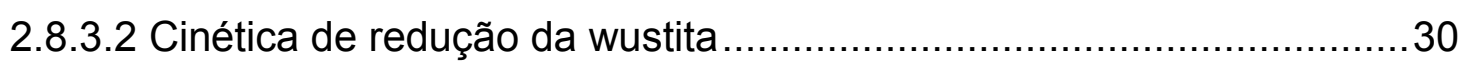

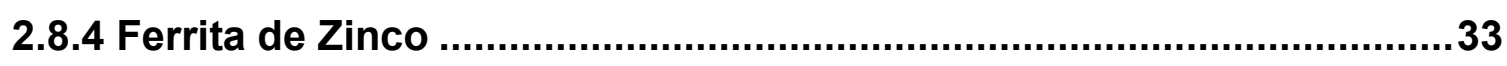

2.8.4.1 Cinética de redução de ferrita de zinco ..........................................33

2.9 MECANISMO DE NUCLEAÇÃO E CRESCIMENTO ........................................38

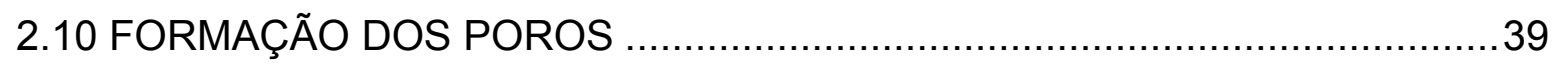

2.11 PROCESSOS DE REDUÇÃO DIRETA ………...................................42

2.11.1 Processos em reatores verticais ...............................................42

2.11.2 Processos em leitos fluidizados ..................................................44

3 OBJETIVOS ............................................................................46

4 MATERIAIS E MÉTODOS ...........................................................47

4.1 PREPARAÇÃO DAS POEIRAS DE ACIARIA LD E ELÉTRICA …..................47

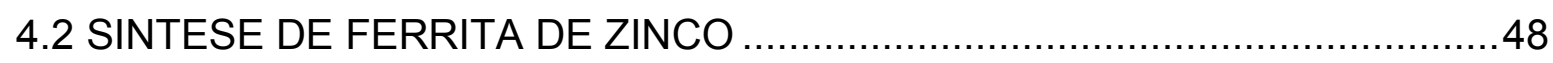

4.3 CARACTERIZAÇÃO DAS MATERIAS PRIMAS ….................................50 


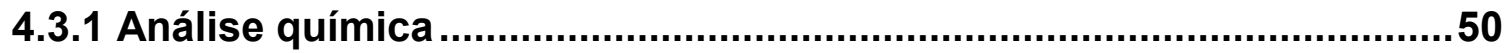

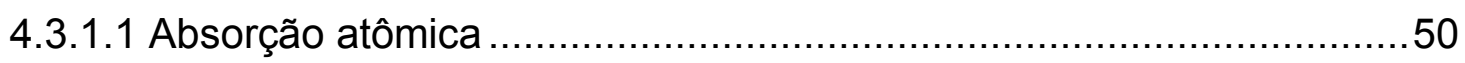

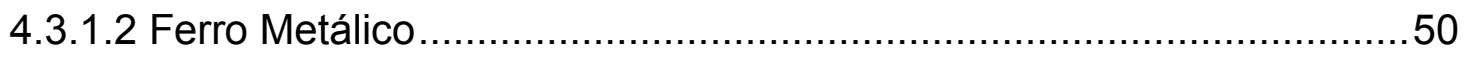

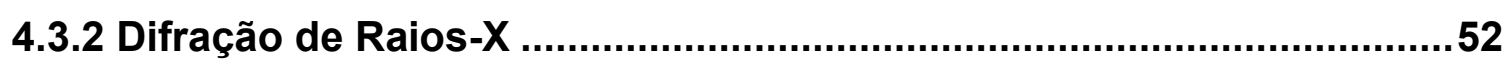

4.3.3 Microscópio eletrônico de varredura ………....................................52

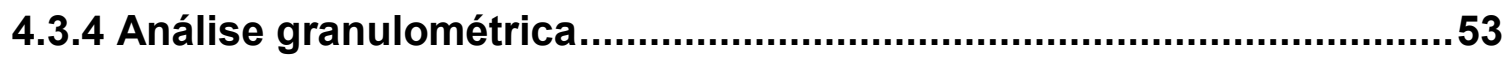

4.3.5 Análise de densidade por picnometria.............................................53

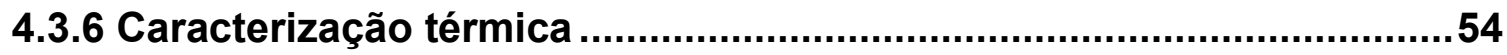

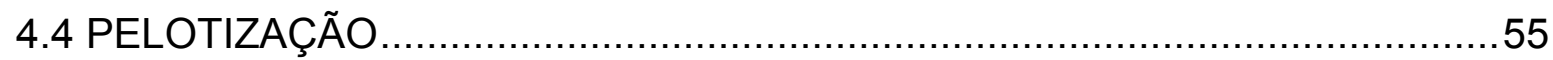

4.5 DETERMINAÇÃO DA POROSIDADE DAS PELOTAS …….........................56

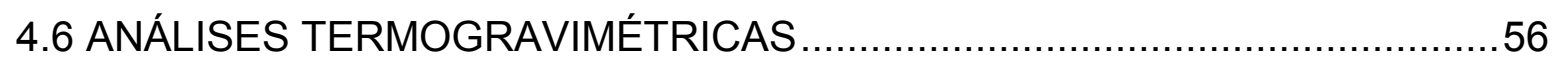

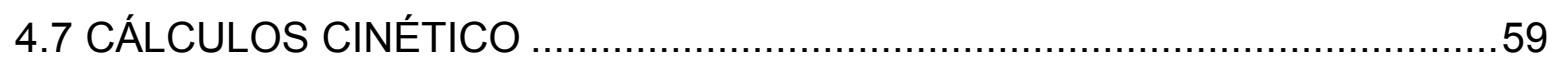

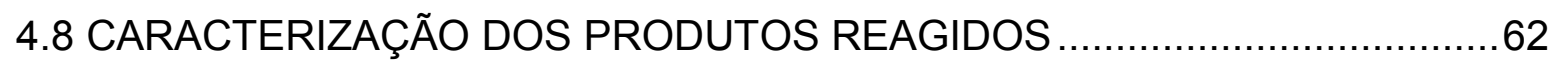

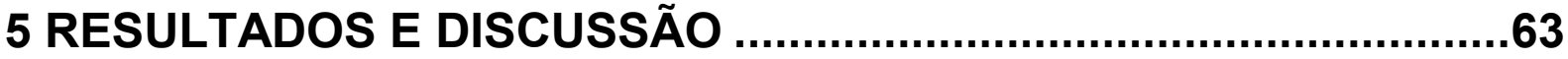

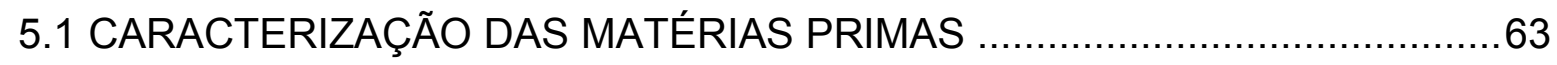

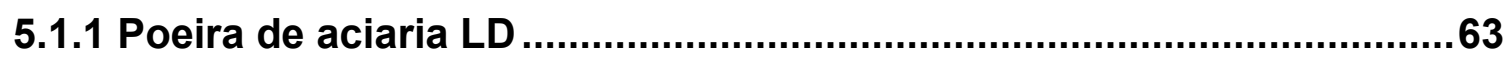

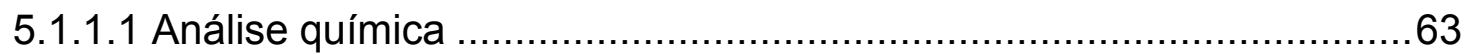

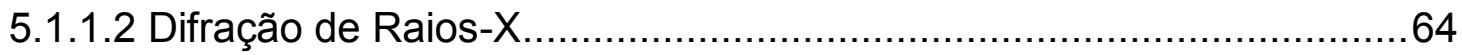

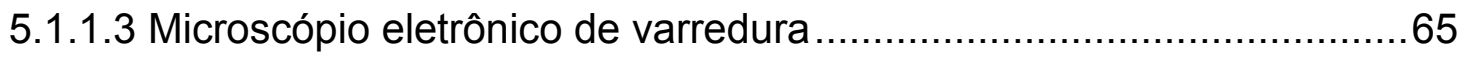

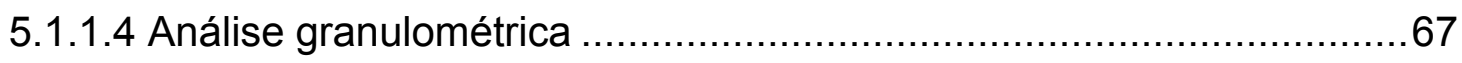

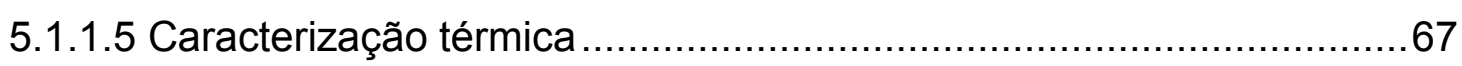

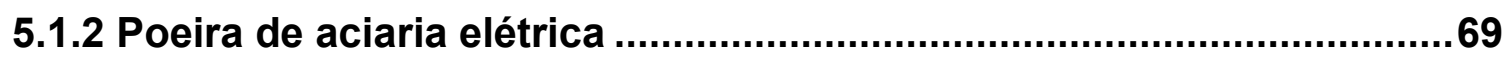

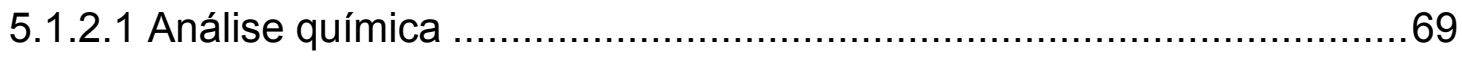

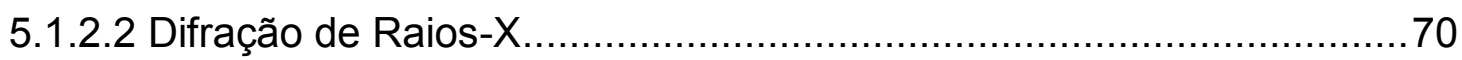

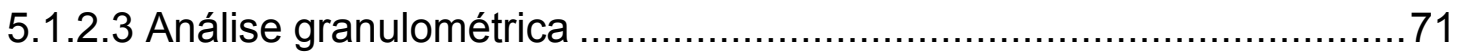

5.1.2.4 Microscópio eletrônico de varredura .............................................. 72

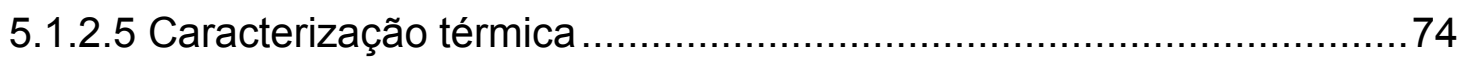

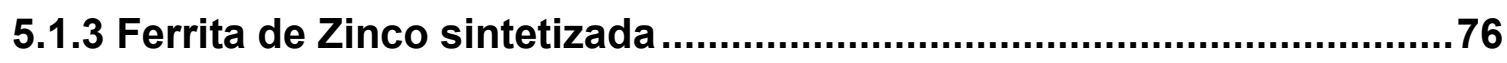

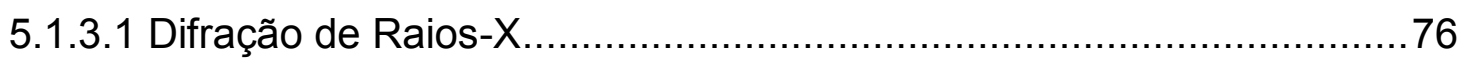

5.1.3.2 Microscópio eletrônico de varredura ............................................... 77

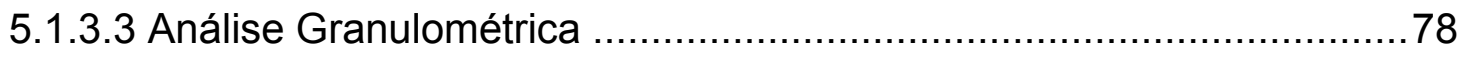

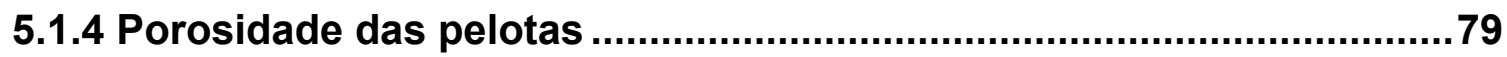

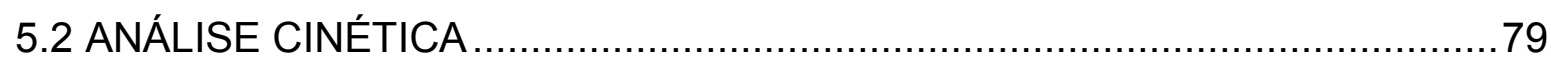




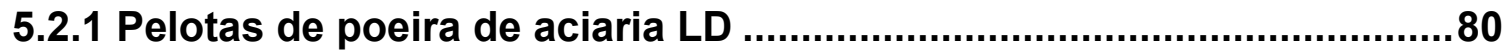

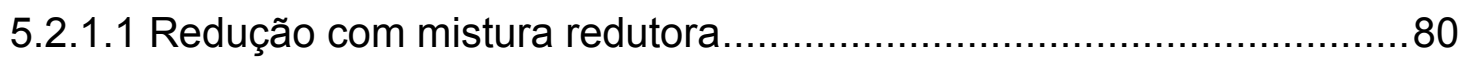

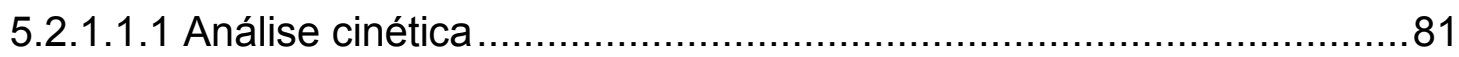

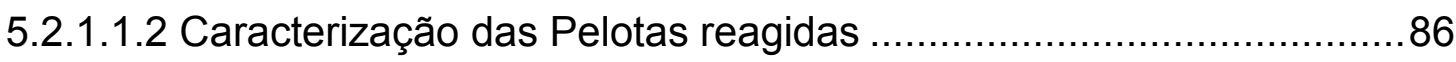

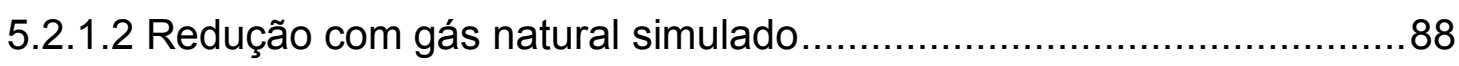

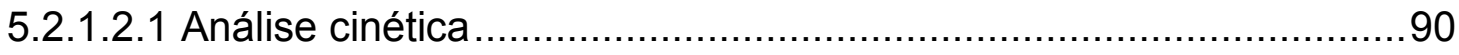

5.2.2 Pelotas de poeira de aciaria Elétrica ……...........................................

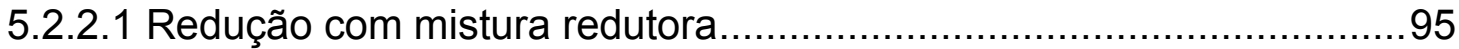

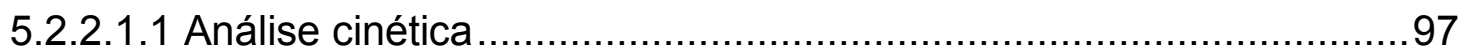

5.2.2.1.2 Caracterização dos produtos reagidos ......................................101

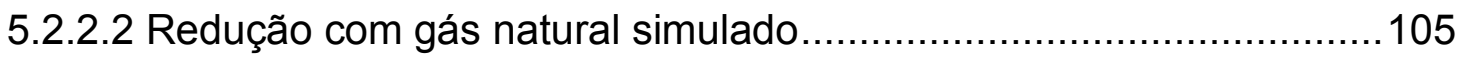

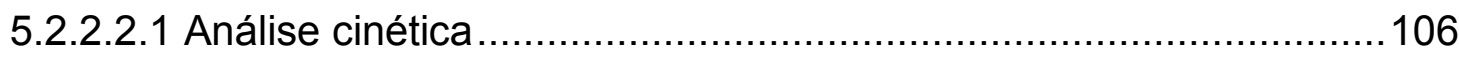

5.2.2.2.2 Caracterização dos produtos reagidos .....................................110

5.2.3 Pelotas de Ferrita de zinco ...............................................................111

5.2.3.1 Redução com mistura redutora.................................................111

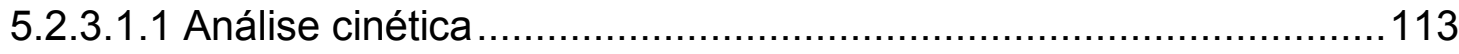

5.2.3.2 Redução com gás natural simulado..............................................118

5.2.3.2.1 Caracterização dos produtos reagidos .......................................123

6 CONCLUSÕES ............................................................................125

REFERENCIAS BIBLIOGRÁFICAS .............................................128 


\section{INTRODUÇÃO}

O setor siderúrgico é responsável pela geração de resíduos sólidos, efluentes líquidos e gasosos. Os resíduos sólidos são predominantemente compostos por escória, poeiras, lamas e sucatas ${ }^{(1)}$. Estes resíduos quando depositado em aterros, podem causar a degradação do solo, contaminação do lençol freático e do ar, gerando custos adicionais e problemas ambientais ${ }^{(2)}$.

O reuso destes produtos é importância para o setor, devido a aspectos econômicos e ambientais. São gerados aproximadamente 650 a $700 \mathrm{~kg}$ de resíduo sólido por tonelada de aço ${ }^{(3,4)}$.

De acordo com Cunha et al. (2006) ${ }^{(3)}$, numa indústria siderurgia, os principais resíduos recicláveis são: pós de sinterização, pós e lama de alto-forno, lamas de aciaria, carepas de lingotamento continuo, lamas de laminação e os finos de coque.

A indústria siderúrgica recupera cerca de $80 \%$ dos resíduos contendo ferro através de sinterização. Porém, a rota de reciclagem destes resíduos por sinterização não é a prática mais recomendada, pois de acordo com Takano et al. (2000) ${ }^{(5)}$, diminui a permeabilidade do leito da carga e consequentemente a perda da produtividade da sinterização.

$\mathrm{Na}$ aciaria, para cada tonelada de aço produzida, a quantidade de lama gerada nestas etapas é variável, podendo situar-se entre 0,5 a $3 \%$ da quantidade de aço produzida. Valores iguais a $8 \%$ já foram registrados em algumas usinas siderúrgicas ${ }^{(6)}$. Autores ${ }^{(7,8)}$ têm citado que a geração de poeira para cada tonelada de aço produzida é de aproximadamente 10 a 20kg.

A produção de aço bruto no Brasil no ano de 2013 foi de aproximadamente 34,1 milhões de toneladas de aço bruto ${ }^{(9)}$. Levando-se em conta os dados citados acima, é possível estimar que a quantidade de poeira gerada nos conversores foi de aproximadamente 340 mil toneladas no último ano.

A lama bruta é um resíduo siderúrgico classe II $A$, não inerte e não perigoso ${ }^{(13)}$. 


\section{REVISÃO BIBLIOGRÁFICA}

\subsection{GERAÇÃO DA POEIRA DE ACIARIA LD}

A aciaria LD é responsável pela produção de $60 \%$ do total de aço produzido sendo o segundo maior gerador de resíduos sólidos de uma usina siderúrgica integrada, contribuindo com $27 \%$ do resíduo sólido gerado numa planta, o que representa um total de 5 a 7 milhões de toneladas de resíduos gerados mundialmente por ano ${ }^{(10,11,12)}$.

A poeira na aciaria LD é gerada através do sopro de oxigênio no ferro gusa. Quando o oxigênio soprado entra em contato com o banho de ferro gusa, gotas são geradas. Estas são arrastadas para fora pelo sistema de saída de gás. A Figura 1 mostra o processo de geração de partículas no conversor LD.

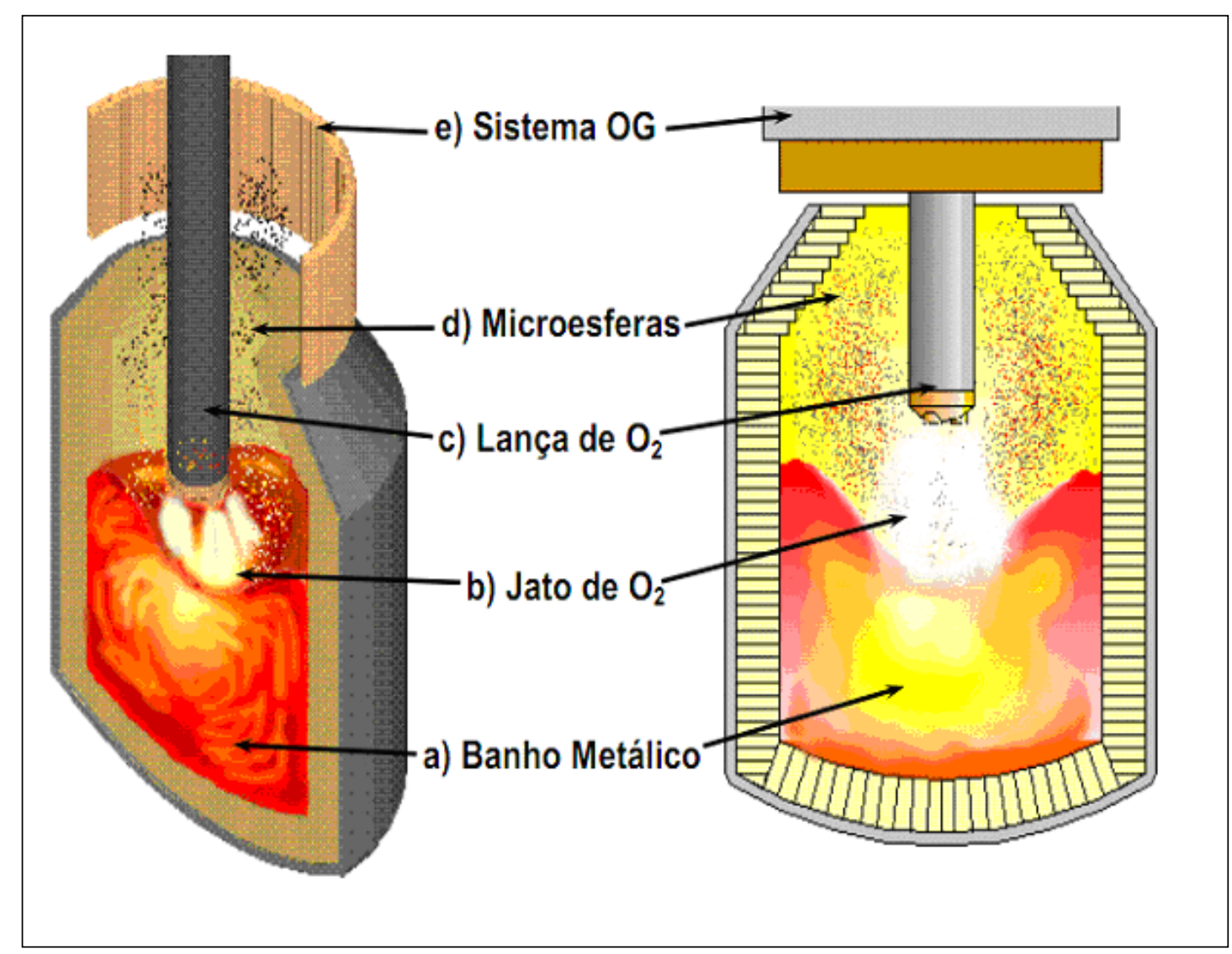

Figura 1 - Processo de geração de partículas em conversor LD ${ }^{(13)}$. 
Ao mesmo tempo, pequenas partículas contendo ferro e outras impurezas são geradas. Devido à reação do oxigênio com o carbono, ocorre a geração de $\mathrm{CO}$ e $\mathrm{CO}_{2}$. Estes gases geram um fluxo que arrasta as partículas formadas para fora do conversor. O pó gerado neste processo é composto principalmente por óxidos, nos quais pode citar óxidos de ferro, cálcio e silício.

\subsection{CARACTERIZAÇÃO DA POEIRA DE ACIARIA LD}

A característica da poeira gerada na aciaria pode variar de siderúrgica para siderúrgica. A Tabela 1 apresenta composições de diferentes poeiras geradas em conversores LD.

Tabela 1 - Composições típicas de poeira de aciaria LD ${ }^{(14,15)}$.

\begin{tabular}{c|c|c}
\hline Componentes & \% em Peso & \% em peso \\
\hline Total Fe & 55,4 & 47,9 \\
\hline $\mathrm{SiO}_{2}$ & 2,3 & 1,4 \\
\hline $\mathrm{MnO}$ & 1,8 & 0,3 \\
\hline $\mathrm{CaO}$ & 10,6 & 13,0 \\
\hline $\mathrm{MgO}$ & 3,7 & 0,5 \\
\hline $\mathrm{ZnO}$ & 1,7 & 6,7 \\
\hline $\mathrm{Pb}$ & - & 0,5 \\
\hline $\mathrm{Na}_{2} \mathrm{O}$ & 0,3 & 0,7 \\
\hline
\end{tabular}

Pode-se observar que a poeira de aciaria LD é composta principalmente por ferro. No caso dos exemplos citados, as proporções de ferro encontradas foram de 55,4 e $47,9 \%$ respectivamente. $O$ teor de zinco presente na poeira é geralmente em torno de $2 \%{ }^{(16)}$.

Com relação às características físicas da poeira de aciaria LD, Kelebek, Yörük e Davis (2004) ${ }^{(11)}$ realizaram análises no microscópio eletrônico de varredura. Em seu trabalho, os autores comentam que as partículas estão entre 3 a 100 $\mu \mathrm{m}$. Outra observação levantada pelos autores é que a poeira apresenta partículas esféricas. A Figura 2 apresenta uma imagem obtida por microscopia eletrônica de varredura, onde pode ser observado a presença de partículas esféricas na poeira de aciaria LD. 


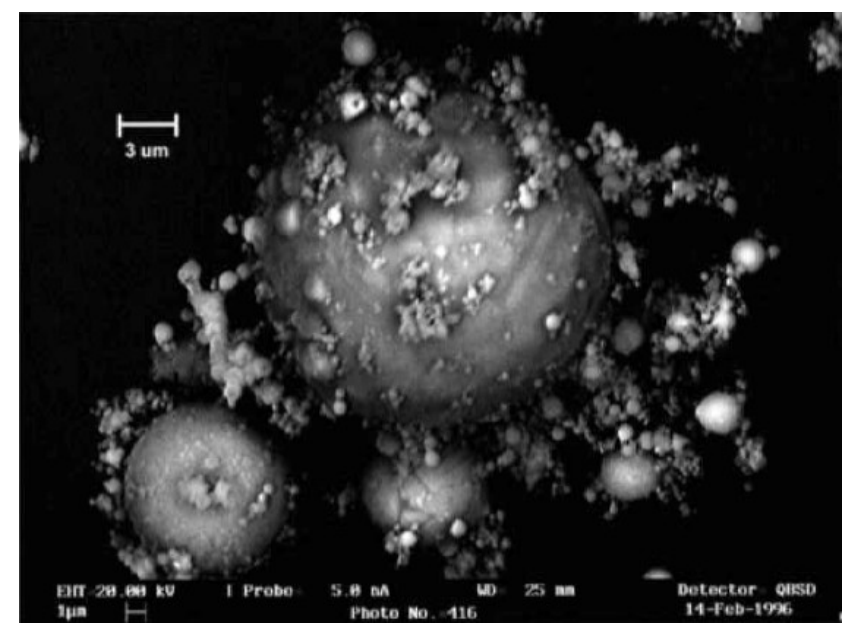

Figura 2 - Imagem obtida por microscópio eletrônico de varredura de partículas de poeira de aciaria LD ${ }^{(17)}$.

Algumas partículas maiores, não esféricas e porosas também foram encontradas, sendo essas partículas formadas por aglomeração de partículas menores, como pode ser observado na Figura 3.

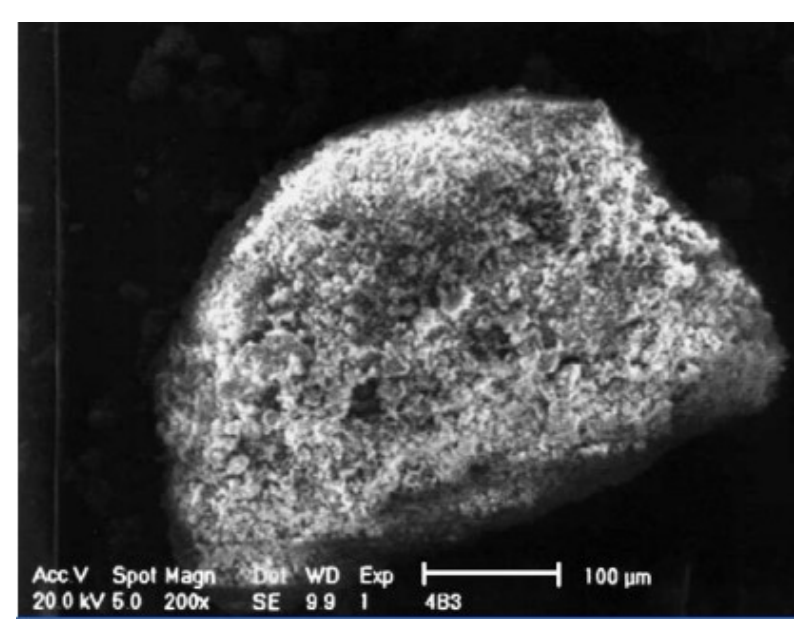

Figura 3 - Partículas formadas a partir de aglomeração de partículas menores na poeira de aciaria LD ${ }^{(11)}$.

\subsection{POEIRA DE ACIARIA ELÉTRICA}

De acordo com Oustadakis et al. ${ }^{(18)}$, a geração mundial de poeira de aciaria elétrica é de aproximadamente 3,7 milhões de toneladas anualmente. Nos Estados Unidos, o custo para processar esta poeira é US\$150 a 200 por tonelada ${ }^{(19)}$. 
Aproximadamente $70 \%$ da poeira de aciaria elétrica são enviadas para aterros e o restante (30\%) é destinado a processos de recuperação de zinco ${ }^{(20,21)}$.

A geração da poeira nos fornos elétricos a arco ocorre principalmente pela explosão de bolhas de $\mathrm{CO}$ e volatilização de elementos como $\mathrm{Zn}, \mathrm{Pb}$ e $\mathrm{Cd}$, por exemplo. Estes dois mecanismos têm sido mencionados como sendo os principais métodos de formação da poeira ${ }^{(22,23,24)}$. A Figura 4 apresenta o processo de formação da poeira nos fornos elétricos a arco.

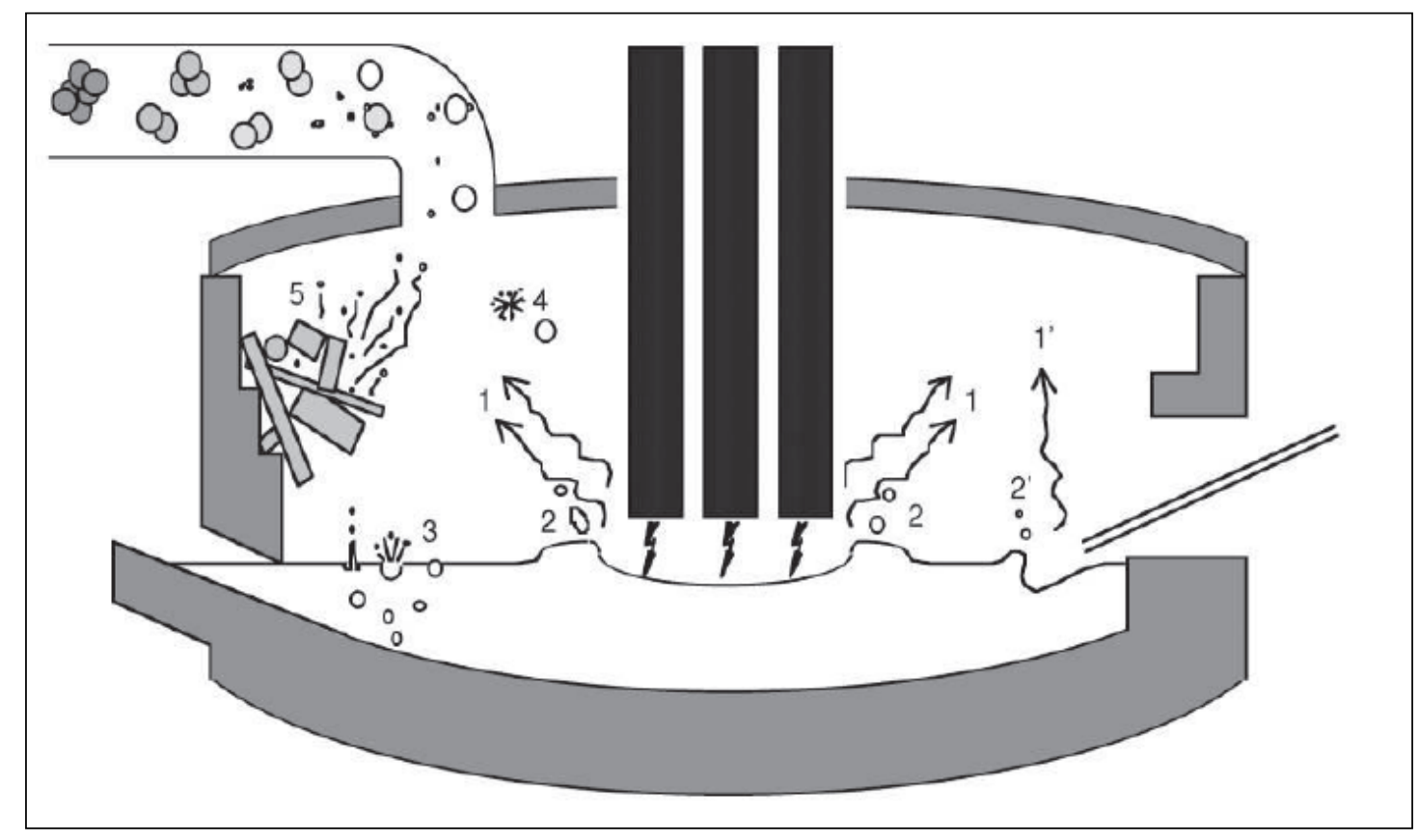

Figura 4 - Processo de formação de poeira no forno elétrico a arco ${ }^{(25)}$.

Nos pontos 1 e 2 são representados as regiões onde ocorre o processo de volatilização. No ponto 2 também ocorre o processo de explosão das bolhas de $\mathrm{CO}$, junto com o ponto 3. O ponto 4 representa a oxidação das partículas ejetadas. No ponto 5 , ocorre o desprendimento de partículas diretamente das materiais primas que são introduzidas no forno elétrico a arco ${ }^{(26)}$. 


\subsection{CARACTERIZAÇÃO DA POEIRA DE ACIARIA ELÉTRICA}

Os principais elementos encontrados na poeira de aciaria são: ferro, zinco, cálcio e chumbo. Na Tabela 2 são apresentas diferentes composições de poeira de aciaria elétrica.

Tabela 2 - Composição química de diferentes poeiras de aciarias elétricas ${ }^{(22,27,28)}$.

\begin{tabular}{c|c|c|c}
\hline Elementos & \% em peso & \% em peso & $\%$ em peso \\
\hline $\mathrm{Fe}$ & 39,3 & 46,6 & 33,6 \\
\hline $\mathrm{Ca}$ & 1,9 & 4,0 & 9,3 \\
\hline $\mathrm{Si}$ & 16 & 1,9 & 2,3 \\
\hline $\mathrm{Zn}$ & 23,5 & 4,8 & 10,7 \\
\hline $\mathrm{Pb}$ & 4,5 & 1,8 & 1,3 \\
\hline $\mathrm{Cd}$ & 0,01 & 0,019 & 0,0004 \\
\hline $\mathrm{Mg}$ & 0,2 & 2,3 & 2,3 \\
\hline $\mathrm{Mn}$ & 2,39 & 5,4 & 1,8 \\
\hline
\end{tabular}

A diferença de composição química entre as poeiras se deve ao uso de diferentes sucatas, ou seja, sucatas que apresentam diferentes composições químicas, e também devido à prática operacional que cada empresa realiza ${ }^{(29)}$.

Os elementos presentes na poeira de aciaria elétrica podem apresentar várias formas estruturais. Um exemplo disso é o ferro, que pode está presente na forma de magnetita, wustita ou Fe metálico. O zinco é outro exemplo desse fenômeno, que pode está na forma de zincita $(\mathrm{ZnO})$ ou de franklinita (ferrita de zinco, $\mathrm{Fe}_{2} \mathrm{ZnO}_{4}$ ).

Para ilustrar esta variação de formas morfológicas em que os elementos químicos podem apresentar, a Tabela 3 mostra as principais fases encontradas em algumas amostras de poeira de aciaria elétrica. 
Tabela 3 - Principais fases cristalinas encontradas na poeira de aciaria elétrica.

\begin{tabular}{c|c|c|c}
\hline Fases & $\begin{array}{c}\text { Machado et al. } \\
(2006))^{(30)}\end{array}$ & Telles (2010) ${ }^{(31)}$ & $\begin{array}{c}\text { Vargas, Masuero } \\
\text { e } \\
\text { Vilela (2006) })^{(32)}\end{array}$ \\
\hline Franklinita & $\mathrm{X}$ & $\mathrm{X}$ & $\mathrm{X}$ \\
\hline Magnetita & $\mathrm{X}$ & $\mathrm{X}$ & $\mathrm{X}$ \\
\hline Magnesio-ferrita & $\mathrm{X}$ & $\mathrm{X}$ & - \\
\hline Periclase & $\mathrm{X}$ & - & - \\
\hline Óxido de manganês & $\mathrm{X}$ & - & $\mathrm{X}$ \\
\hline Quartzo & $\mathrm{X}$ & $\mathrm{X}$ & $\mathrm{X}$ \\
\hline Zincita & $\mathrm{X}$ & $\mathrm{X}$ & $\mathrm{X}$ \\
\hline Ferro metalico & - & - & $\mathrm{X}$ \\
\hline Pirolusita & - & - & $\mathrm{X}$ \\
\hline Cromita & $\mathrm{X}$ & - & - \\
\hline Cálcio e Óxido de ferro & - & - & \\
\hline Mangnesio-cromita & - & - & - \\
\hline Calcio-magnetita & $\mathrm{X}$ & - & \\
\hline
\end{tabular}

A ferrita de zinco, de acordo com Menad (2003) ${ }^{(33)}$, depende do teor de zinco e ferro presente na poeira. Tem sido reportado que 50 a $80 \%$ do zinco presente na poeira de aciaria é observada na forma de $\mathrm{ZnO}$, sendo o restante do zinco, podendo está combinado com o ferro formando ferrita de zinco $\left(\mathrm{ZnO} . \mathrm{Fe}_{2} \mathrm{O}_{3}\right){ }^{(33,34)}$.

A caracterização física da poeira de aciaria elétrica foi realizada por Lee e Song (2007) ${ }^{(35)}$ através de microscopia eletrônica de varredura. A Figura 5 apresenta uma imagem obtida por microscópio eletrônico de varredura da poeira de aciaria elétrica.

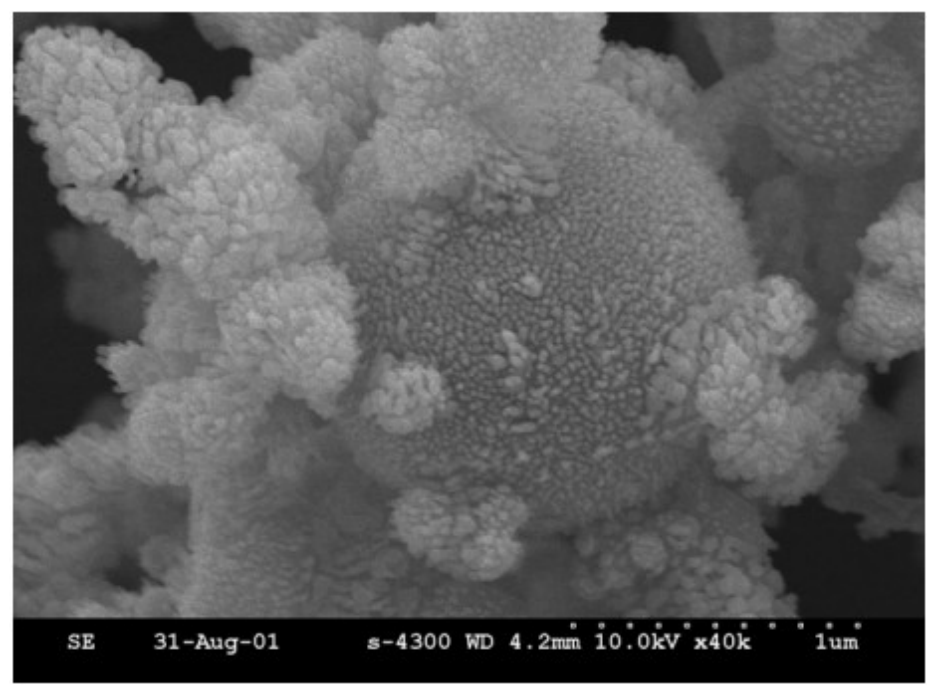

Figura 5 - Imagem obtida por microscopia eletrônica de varredura da poeira de aciaria elétrica $^{(35)}$. 
Através da Figura 5, os autores concluíram que a poeira de aciaria elétrica apresenta partículas esféricas com diâmetros de aproximadamente $1 \mu \mathrm{m}$. Ainda complementam dizendo que partículas maiores do que $9 \mu \mathrm{m}$ foram encontradas, sendo estas resultantes da aglomeração de partículas menores.

Para complementar a caracterização física da poeira de aciaria elétrica, a Figura 6 apresenta a análise granulométrica utilizando o equipamento mastersizer 2000 realizada por Grillo (2011) ${ }^{(36)}$.

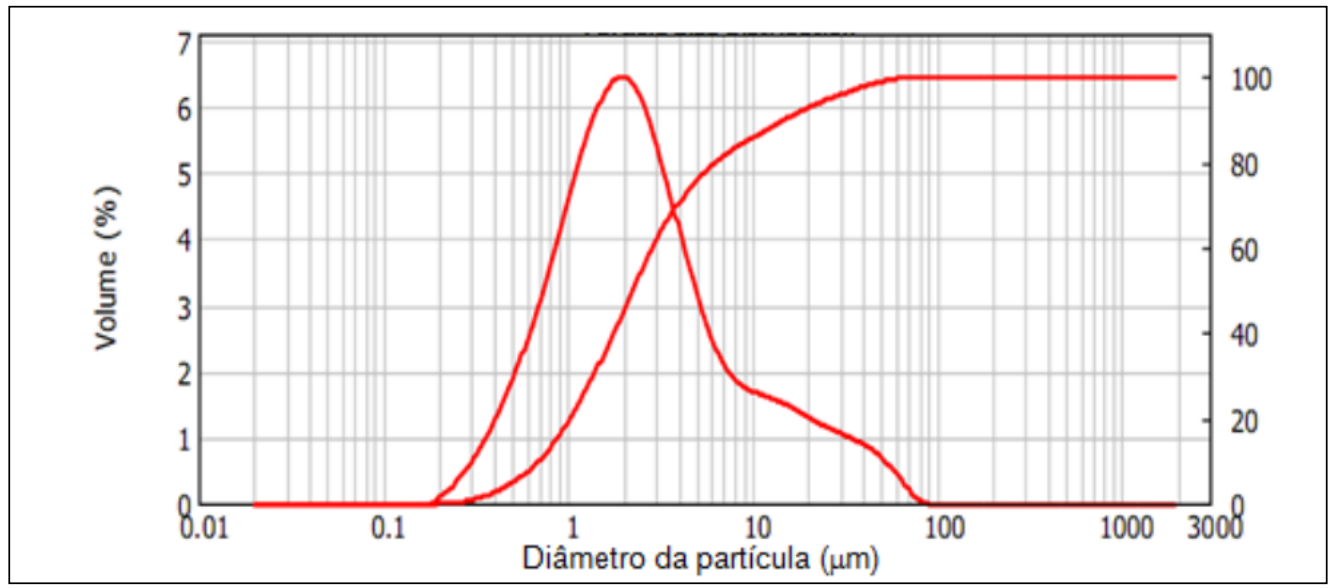

Figura 6 - Análise granulométrica realizada através do equipamento Malvern com poeira de aciaria elétrica ${ }^{(36)}$.

Com auxilio da análise granulométrica, o autor chegou a conclusão que cerca de $85 \%$ das partículas da poeira são menores do que $10 \mu \mathrm{m}$.

Telles $(2010)^{\left({ }^{(31)}\right.}$ em seu trabalho também realizou análise granulométrica utilizando o mesmo equipamento. No seu trabalho, o autor chegou à conclusão de que $90 \%$ das partículas da poeira de aciaria elétrica estão abaixo de $8,21 \mu \mathrm{m}$.

\subsection{RECICLAGEM DE POEIRA DE ACIARIA}

Como foi observado nas sessões anteriores, as poeiras geradas tanto na aciaria LD como na aciaria elétrica são constituídas principalmente por ferro, na forma de óxidos. Além disso, a poeira de aciaria elétrica apresenta em sua composição zinco. Deste modo, diversos trabalhos têm sido desenvolvidos com 
estas poeiras, principalmente para a poeira gerada na aciaria elétrica, para o seu reaproveitamento ou recuperação do zinco $(31,36,37,38)$. Como será reportado neste item, é observado que os métodos de reciclagem estudados, visam a utilização das poeiras em métodos já conhecidos, havendo a incorporação das poeiras no processos.

Telles $(2010)^{(31)}$, em seu trabalho, adicionou poeira de aciaria elétrica, na forma de micropelotas, no processo de sinterização de minério de ferro com o intuito de eliminar o zinco presente na poeira de aciaria elétrica. $O$ autor chegou a eliminação de aproximadamente $92 \%$ de zinco no processo com adição de $10 \%$ de micropelotas na carga de sinterização.

Grillo (2011) ${ }^{(36)}$ estudou a recuperação de zinco e ferro da poeira de aciaria elétrica, na forma de briquetes no gusa liquido. Neste trabalho, foi possível a recuperação de até $98 \%$ do ferro contido na poeira. O autor também realizou a coleta dos pós gerado neste processo, onde foi possível obter uma poeira com até $68 \%$ de zinco.

Marques Sobrinho $(2012)^{(37)}$ realizou a incorporação de poeira de aciaria elétrica na forma de briquetes em gusa liquido. Neste trabalho, o autor fez variações nos teores de poeira adicionada ao banho. O autor chegou a conclusão de que aumentando a massa de poeira de aciaria elétrica no banho de ferro gusa, favoreceu a remoção do silício do banho.

Shawabkeh $(2010)^{(38)}$ realizou a extração de zinco da poeira de aciaria elétrica por lixiviação com ácido clorídrico, nítrico e sulfúrico. O autor diz que valores de extração maior do que $70 \%$ de zinco foram obtidos com uso de ácido sulfúrico.

Mantovani (1998) ${ }^{(24)}$ realizou em seu trabalho o reaproveitamento de poeira de aciaria elétrica, na forma de pelota, em banho de gusa liquido. O autor coletou o pó gerado nas análises e fez a caracterização da mesma, obtendo um pó com aproximadamente $55,8 \%$ de zinco.

Marroquín (2008) ${ }^{(39)}$ estudou o comportamento da redução de ferrita de zinco sintética e a contida na poeira de aciaria elétrica por agentes gasosos, neste caso, com misturas de $\mathrm{CO} / \mathrm{CO}_{2}$ e $\mathrm{CO}$ puro, onde chegou a conclusão que a redução da ferrita de zinco é similar a redução dos óxidos de ferro. 


\subsection{TERMODINÂMICA DE REDUÇÃO DE ÓXIDOS DE FERRO}

O ferro pode apresentar três tipos de óxidos: hematita, magnetita e wustita, onde o óxido mais estável é a hematita. Partindo-se deste principio, a redução de hematita ocorre conforme pode ser visto na Equação 1:

$$
\mathrm{Fe}_{2} \mathrm{O}_{3}+3 \mathrm{H}_{2}=2 \mathrm{Fe}+3 \mathrm{H}_{2} \mathrm{O}
$$

Equação 1

$\mathrm{Na}$ Figura 7 é apresentado um diagrama de temperatura versos a porcentagem de oxigênio que indica a estabilidade do óxido de ferro com relação a estes dois parâmetros.

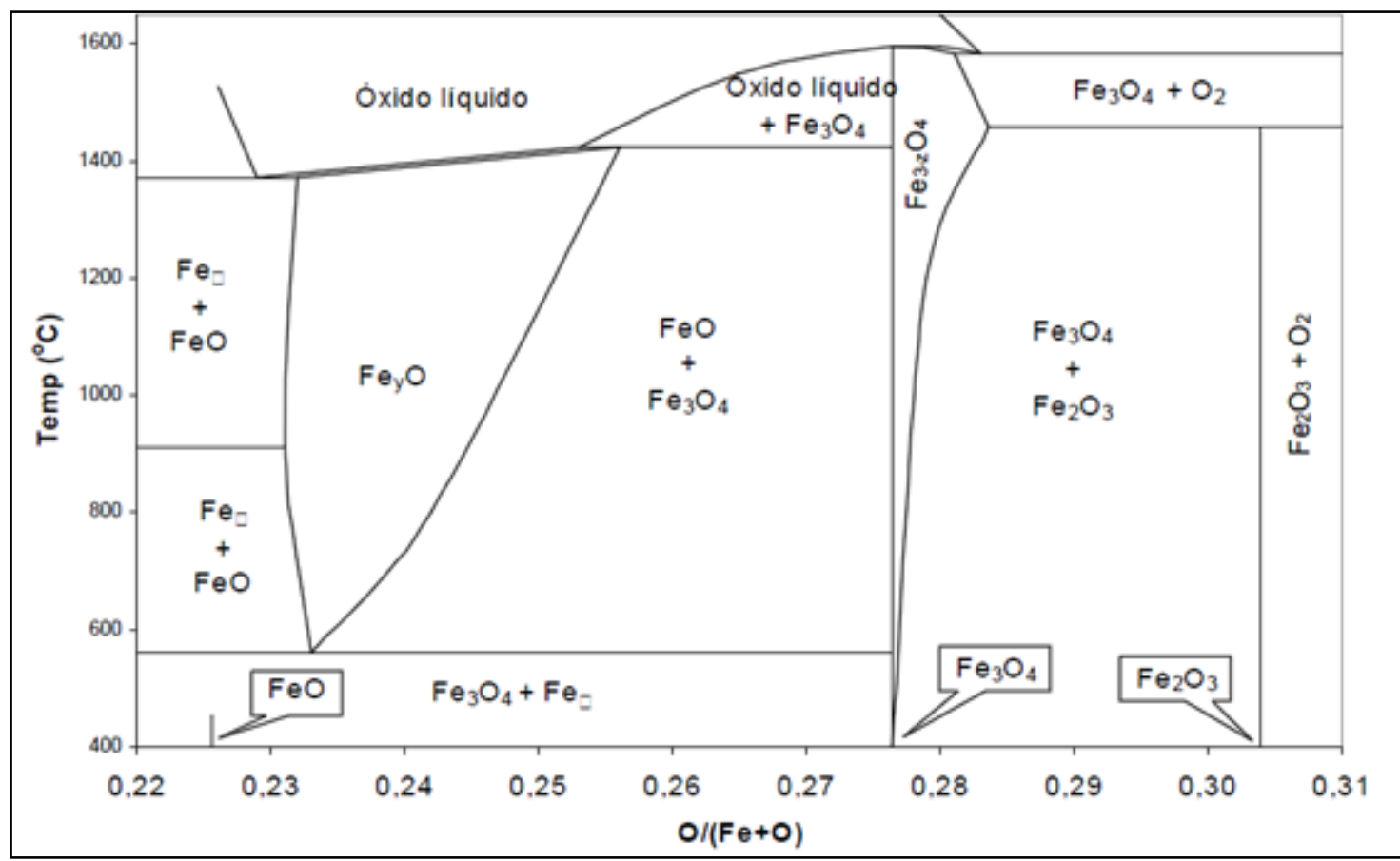

Figura 7 - Diagrama de estabilidade de óxidos de ferro em função da temperatura $x$ porcentagem de oxigênio ${ }^{(40)}$

O diagrama apresentado na Figura 7, chamados de diagramas de Chaudron, é possível se obter, com uma determinada temperatura em função do potencial redutor da atmosfera gasosa, a estabilidade dos óxidos de ferro e do metal.

Pode-se observar que em temperaturas abaixo de $570^{\circ} \mathrm{C}$ a wustita é instável, assim, pode-se ter dois caminhos para a redução do óxido de ferro ${ }^{(40,41,42)}$. As 
Equações 2 e 3 ocorrem para temperaturas menores do que $570^{\circ} \mathrm{C}$, e Equações 4,5 e 6 ocorrem para temperaturas maiores do que $570^{\circ} \mathrm{C}$.

$\checkmark$ Para redução com temperaturas menor ou igual a $570^{\circ} \mathrm{C}$ :

$$
\begin{array}{ll}
3 \mathrm{Fe}_{2} \mathrm{O}_{3(\mathrm{~s})}+\mathrm{H}_{2(\mathrm{~g})}=2 \mathrm{Fe}_{3} \mathrm{O}_{4(\mathrm{~s})}+\mathrm{H}_{2} \mathrm{O}_{(\mathrm{g})} & \text { Equação 2 } \\
\mathrm{Fe}_{3} \mathrm{O}_{4(\mathrm{~s})}+4 \mathrm{H}_{2(\mathrm{~g})}=3 \mathrm{Fe}+4 \mathrm{H}_{2} \mathrm{O}_{(\mathrm{g})} & \text { Equação 3 }
\end{array}
$$

$\checkmark$ Para redução com temperaturas maiores do que $570^{\circ} \mathrm{C}$ :

$$
\begin{array}{ll}
3 \mathrm{Fe}_{2} \mathrm{O}_{3(\mathrm{~s})}+\mathrm{H}_{2(\mathrm{~g})}=2 \mathrm{Fe}_{3} \mathrm{O}_{4(\mathrm{~s})}+\mathrm{H}_{2} \mathrm{O}_{(\mathrm{g})} & \text { Equação 4 } \\
\mathrm{Fe}_{3} \mathrm{O}_{4(\mathrm{~s})}+\mathrm{H}_{2(\mathrm{~g})}=3 \mathrm{Fe}_{1-\mathrm{x}} \mathrm{O}_{(\mathrm{s})}+\mathrm{H}_{2} \mathrm{O}_{(\mathrm{g})} & \text { Equação 5 } \\
\mathrm{Fe}_{1-\mathrm{x}} \mathrm{O}_{(\mathrm{s})}+\mathrm{H}_{2(\mathrm{~g})}=\mathrm{Fe}_{(\mathrm{s})}+\mathrm{H}_{2} \mathrm{O}_{(\mathrm{g})} & \text { Equação 6 }
\end{array}
$$

A Figura 8 apresenta o diagrama de Bell. Este diagrama indica que a wustita pode ser um produto intermediário durante a redução de hematita por hidrogênio em temperaturas menor do que $570^{\circ} \mathrm{C}$.

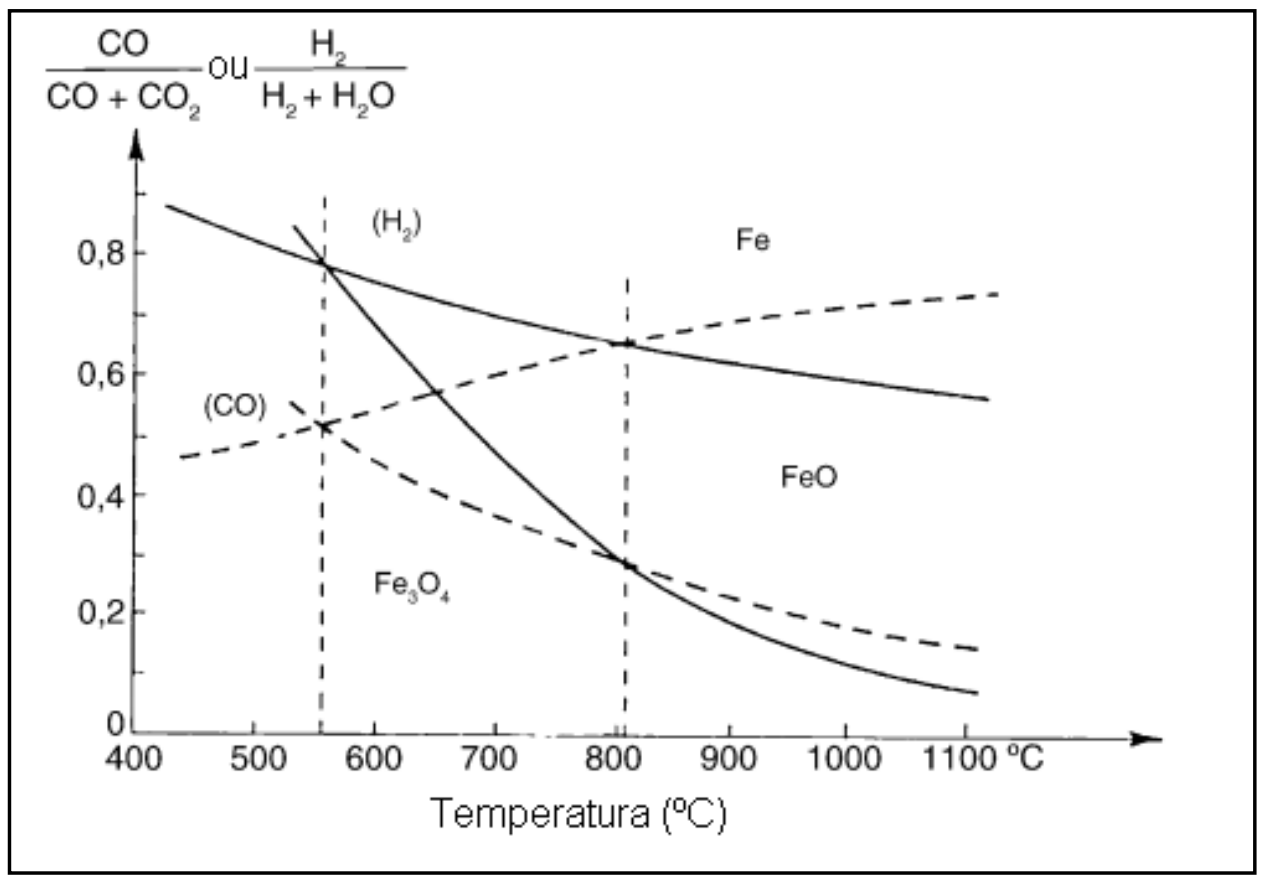

Figura 8 - Diagrama de Bell dos óxidos de ferro para diferentes temperatura e pressões de gases redutores ${ }^{(43)}$.

A Figura 8 também mostra que a partir de $810^{\circ} \mathrm{C}$ a redução de óxidos de ferro por hidrogênio é termodinamicamente mais favorável do que por $\mathrm{CO}$. 


\subsection{INVESTIGAÇÃO CINÉTICA}

A investigação cinética é uma importante ferramenta para a determinação das velocidades de reação e dos parâmetros cinéticos, como por exemplo, energias de ativação, coeficiente pré-exponencial e ordem de reação. Além disso, com o estudo cinético, podem ser obtidos os mecanismos que estão envolvidos numa reação, incluindo o reconhecimento dos mecanismos controladores ${ }^{(44)}$.

A energia de ativação é o parâmetro mais estudado numa investigação cinética. O conceito de energia de ativação de acordo com Atkins e De Paula $2006{ }^{(45)}$ é: energia cinética mínima que o reagente deve ter para formar o produto.

Algumas técnicas são bastantes empregadas no estudo de investigação cinética, principalmente as que utilizam isotermas. Uma destas técnicas é a descrita nos trabalhos de Soresen ${ }^{(46,47)}$, que trabalha com isotermas durante a evolução da reação. Esta técnica é conhecida como Stepwise Isothermal Analysis (SIA). Nesta técnica, a programação de aquecimento é controlada pela taxa da reação ${ }^{(48)}$.

Uma análise realizada pelo método SIA ocorre, inicialmente, com a predeterminação de valores mínimos e máximos da taxa de reação. Com estes valores predefinidos, é dado inicio à análise. A temperatura da primeira isoterma é aquela aonde é obtido o valor máximo da taxa de reação preestabelecido. Neste momento, o aquecimento é cessado e a temperatura é mantida até se atingir o valor mínimo preestabelecido para a taxa de reação. Quando este valor mínimo é atingido, ocorre um novo aquecimento até a obtenção da taxa de reação máxima preestabelecida no inicio do ensaio. Este processo é repetido até o fim da reação de redução.

O método SIA permite a determinação de modelos cinéticos mais precisos para reações do estado sólido do que as técnicas que não utilizam isotérmicas (49). Algumas vantagens são apresentadas utilizando este método, tais como ${ }^{(44)}$ :

$\checkmark$ Reações consecutivas e sobrepostas podem ser separadas;

$\checkmark$ Permite a obtenção da energia de ativação e dos mecanismos envolvidos em uma reação sem sobreposição; 
$\checkmark$ A utilização de isotermas para obtenção de dados permite a obtenção de dados mais confiáveis para a análise cinética, assim como temperaturas de reação mais exatas;

$\checkmark$ A análise pode ser realizada em apenas um ensaio.

Para o caso de óxidos de ferro, a literatura cita que a reação de redução é heterogênea do tipo sólido-gás ${ }^{(50,51)}$. Neste tipo de processo, diversos mecanismos têm sido propostos, entre os quais se podem citar ${ }^{(52)}$ :

$\checkmark$ Transferência de massa por convecção do reagente gasoso do fluxo para a pelota;

$\checkmark$ Difusão dos reagentes gasosos através da camada sólida porosa;

$\checkmark$ Reação química com o reagente sólido na interface de reação;

$\checkmark$ Difusão do produto para fora da superfície de reação através da camada sólida porosa;

$\checkmark$ Transferência de massa do produto por convecção através do filme de gás em torno da pelota sólida no fluxo de gás.

Onde cada uma dessas etapas supracitadas tem sua própria cinética e pode limitar ou ajudar a limitar a taxa global de redução.

A literatura cita que a investigação cinética pode ser efetuada pelo método diferencial ou pelo método integral ${ }^{(53,54)}$.

O método diferencial é descrito pela Equação 7:

$\frac{d \propto}{d t}=k \cdot f(\propto)$

Equação 7

Já o método integral é descrito pela Equação 8:

$g(\propto)=k \cdot t$

Equação 8

sendo $g(\propto)$ descrita pela Equação 9: 
$g(\propto)=\int \frac{1 \cdot d \propto}{f(\propto)}$

Equação 9

Onde:

$\propto$ é a fração reagida.

$t$ é o tempo.

$k$ é a constante de velocidade que obedece a lei de Arrhenius, descrita pela Equação 10:

$k=A \exp \left(-\frac{E a}{R T}\right)$

Equação 10

Onde

$A$ é o coeficiente pré-exponencial;

$E a$ é a energia de ativação para a reação;

$R$ é a constante dos gases;

$T$ é a temperatura absoluta.

A Tabela 4 apresenta algumas sugestões de modelagem matemática para o método diferencial e integral para algumas reações cinéticas citadas pela literatura como sendo as principais funções controladoras para reações do tipo gás-sólido. Cada função aqui descrita carrega em si própria os mecanismos controladores. 
Tabela 4 - Sugestões matemáticas para modelamento cinético para reações heterogêneas do tipo gás-sólido ${ }^{(55,56)}$.

\begin{tabular}{c|c|c|c}
\hline Mecanismo & Símbolo & $\mathrm{f}(\alpha)$ & $\mathrm{g}(\alpha)$ \\
\hline $\begin{array}{c}\text { Reação controlada por } \\
\text { limite de fases }\end{array}$ & $\mathrm{R} 2$ & $(1-\propto)^{1 / 2}$ & $\frac{-1}{2(1-\alpha)^{1 / 2}}$ \\
\hline $\begin{array}{c}\text { Reação controlada por } \\
\text { limite de fases }\end{array}$ & $\mathrm{R} 3$ & $\frac{-2}{3(1-\propto)^{1 / 3}}$ \\
\hline Difusão unidimensional & $\mathrm{D} 1$ & $\frac{1}{\alpha}$ & $\frac{\alpha^{2}}{2}$ \\
\hline Difusão bidimensional & $\mathrm{D} 2$ & $\frac{1}{-\ln (1-\alpha)}$ & $(1-\propto) \ln (1-\propto)+\propto$ \\
\hline $\begin{array}{c}\text { Difusão tridimensional } \\
\text { (equação de Jander) }\end{array}$ & $\mathrm{D} 3$ & $\frac{(1-\propto)^{2 / 3}}{1-(1-\propto)^{1 / 3}}$ & $3 / 2\left[1-(1-\propto)^{1 / 3}\right]^{2}$ \\
\hline $\begin{array}{c}\text { Difusão tridimensional } \\
\text { (equação de Ginstling- } \\
\text { Brounshtein) }\end{array}$ & $\mathrm{D} 4$ & $\frac{1}{\left[(1-\propto)^{-1 / 3}-1\right]}$ & $3 / 2\left[(1-2 / 3 \propto)-(1-\propto)^{2 / 3}\right]$ \\
\hline $\begin{array}{c}\text { Crescimento de núcleo } \\
\text { bidimensional }\end{array}$ & $\mathrm{A} 2$ & $(1-\propto)[-\ln (1-\propto)]^{1 / 2}$ & $2[-\ln (1-\propto)]^{1 / 2}$ \\
\hline $\begin{array}{c}\text { Crescimento de núcleo } \\
\text { tridimensional }\end{array}$ & $\mathrm{A} 3$ & $(1-\propto)[-\ln (1-\propto)]^{2 / 3}$ & $3[-\ln (1-\propto)]^{1 / 3}$ \\
\hline
\end{tabular}

Brown et al. ${ }^{(57)}$ citam também a equação de Sestak-Berggren (Equação 11), no qual os autores dizem que esta equação acomodaria a maioria dos modelos cinéticos.

$D \alpha / d t=k \cdot \alpha^{m} \cdot(1-\alpha)^{n} \cdot[-\ln (1-\alpha)]^{p}$

\subsection{REAÇÕES DE REDUÇÃO DE ÓXIDOS DE FERRO}

A reação de um gás com uma matriz sólida gerando um gás e um sólido diferente dos iniciais é observado em processos metalúrgicos, por exemplo. Tais reações são conhecidas como reações do tipo sólido-gás. A Equação $12^{(58)}$ apresenta a equação genérica para este tipo de reação.

$$
\mathrm{A}_{(\mathrm{g})}+b \mathrm{~B}_{(\mathrm{s})}=c \mathrm{C}_{(\mathrm{g})}+d \mathrm{D}_{(\mathrm{s})}
$$


Onde $b, c$ e $d$ são os coeficientes estequiométricos da reação.

Dentre estas reações está a redução do óxido de ferro por reagentes gasosos. Esta reação é dita como sendo um processo complexo, pois é uma reação heterogênea em que várias reações ocorrem simultaneamente ${ }^{(59,60)}$.

De acordo com Bessières, Bessières e Heizmann $(1980)^{(61)}$ a redução de óxidos de ferro pode ocorrer de três diferentes maneiras:

$\checkmark \quad$ Uma cadeia de reações simples, Equação 13:

$$
\mathrm{Fe}_{2} \mathrm{O}_{3} \rightarrow \mathrm{Fe}_{3} \mathrm{O}_{4} \rightarrow \mathrm{FeO} \rightarrow \mathrm{Fe} \quad \text { Equação } 13
$$

Combinações de reações simples e duplas, Equações 14 e 15:

$$
\begin{array}{ll}
\mathrm{Fe}_{2} \mathrm{O}_{3} \rightarrow \mathrm{Fe}_{3} \mathrm{O}_{4} \rightarrow \mathrm{Fe} & \text { Equação } 14 \\
\mathrm{Fe}_{2} \mathrm{O}_{3} \rightarrow \mathrm{FeO} \rightarrow \mathrm{Fe} & \text { Equação } 15
\end{array}
$$

$\checkmark \quad$ Ou uma reação tripla, Equação 16:

$$
\mathrm{Fe}_{2} \mathrm{O}_{3} \rightarrow \mathrm{Fe}
$$

Assim, na redução de óxidos de ferro por agentes gasosos, pode-se encontrar diferentes valores de energia de ativação e mecanismos controladores. A variação tanto dos valores de energia de ativação como dos mecanismos controladores estão ligados aos parâmetros utilizados nos ensaios, como por exemplo, material inicial, a natureza do gás redutor, a faixa de temperatura utilizada e impurezas na amostra $^{(62)}$.

Para exemplificar a interferência destes parâmetros sobre a redução, Valipour, Hashemi e Saboohi (2006) ${ }^{(52)}$ realizaram testes somente com variação na composição do gás redutor, utilizando o mesmo tipo de minério de ferro na temperatura de $900^{\circ} \mathrm{C}$. A Figura 9 mostra os resultados obtidos pelos autores com a variação da composição dos gases redutores. 


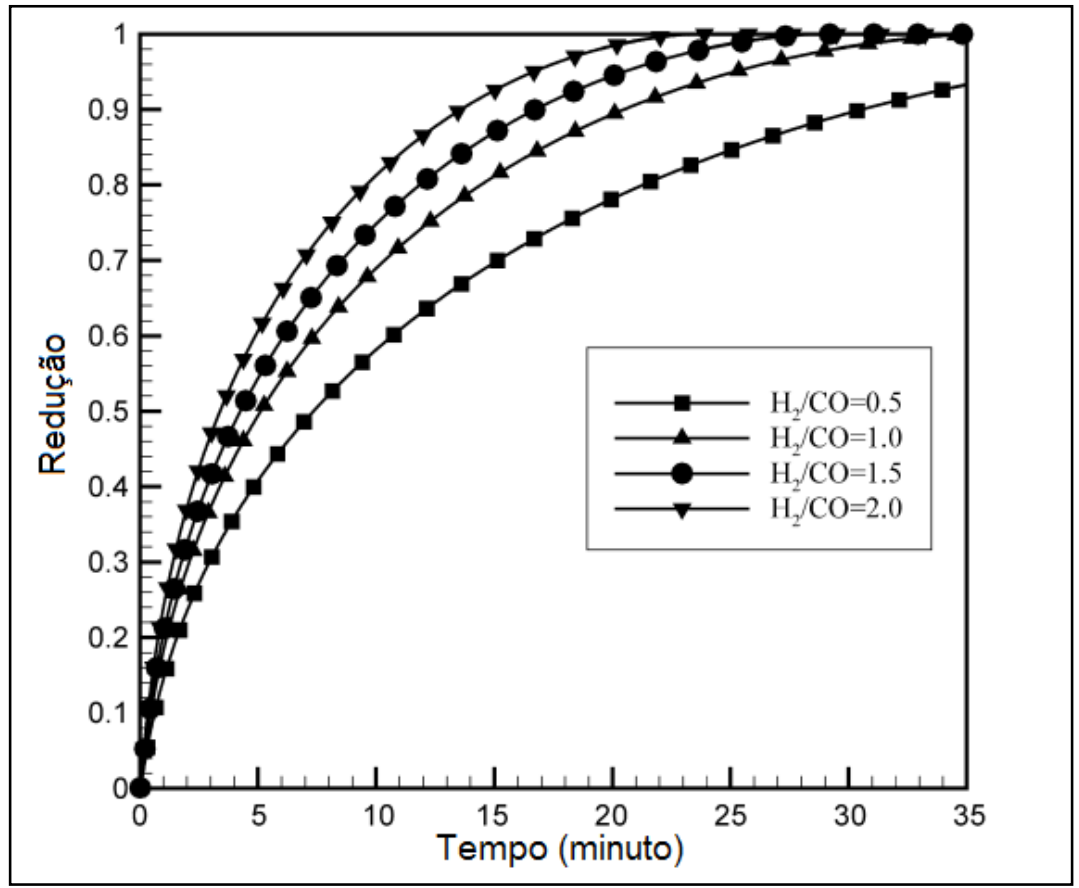

Figura 9 - Efeito da composição do gás redutor sobre a redução de minério de ferro a $900^{\circ} \mathrm{C}^{(52)}$.

Como pode ser observado na Figura 9, o aumento da proporção de $\mathrm{CO}$ no gás redutor ocasionou um aumento no tempo de redução do minério de ferro. Além dos fatores ligados a análise, a mudança estrutural que ocorre durante a etapa de redução também influencia na redução, onde a principal mudança é o fenômeno de sinterização.

O processo de sinterização geralmente está associado a três estágios, como pode ser visto na Figura 10. 


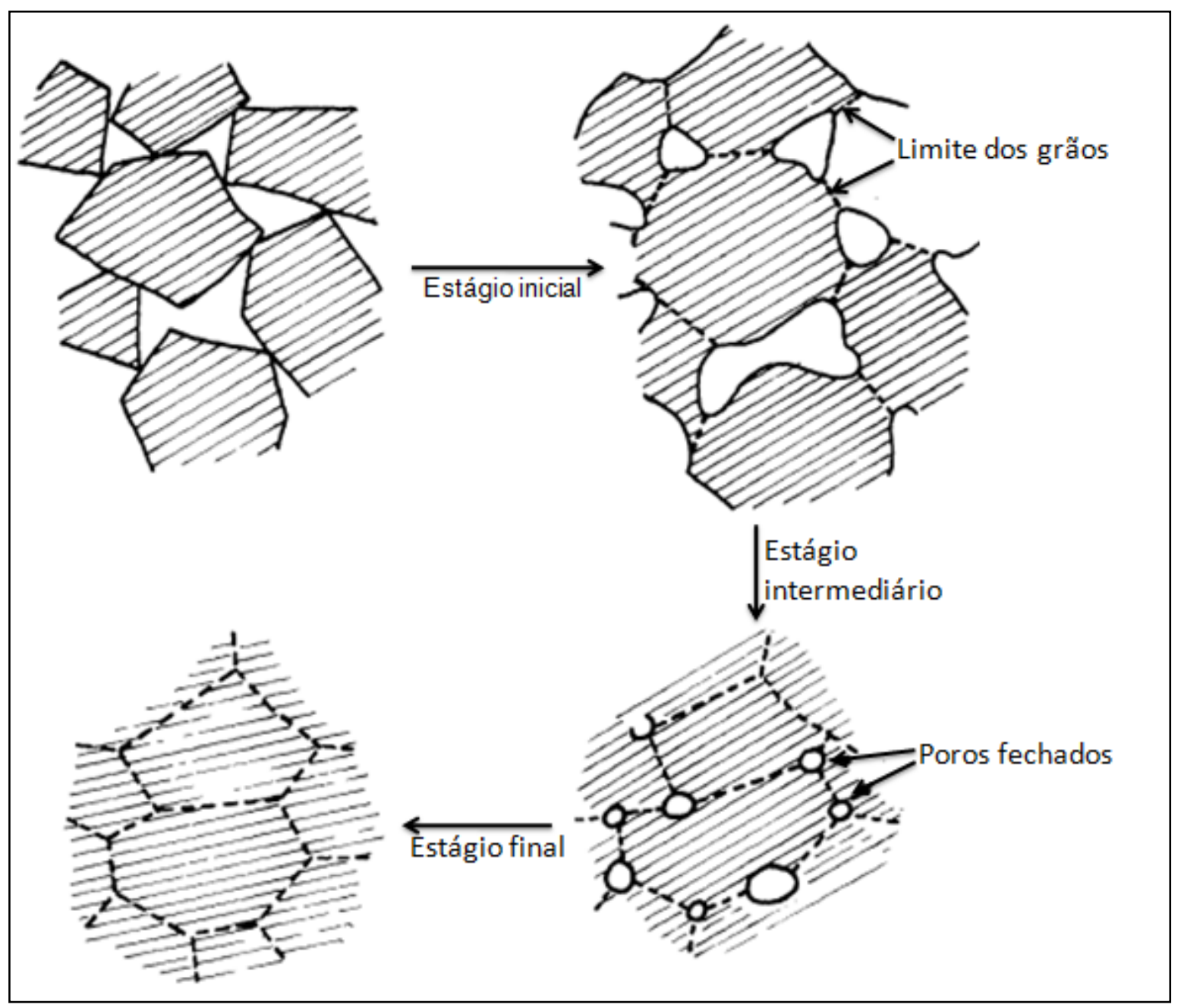

Figura 10 - Representação esquemática do processo de sinterização ${ }^{(58)}$.

O estágio inicial envolve o crescimento de pequenas áreas de contato entre os grãos, denominadas pescoços. O estágio inicial juntamente com o estágio intermediário, envolve o encolhimento global do sólido. O estágio intermediário envolve a interseção dos pescoços até a formação de poros fechados. O último estágio é o fechamento dos poros.

Szekely, Evans e Sohn (1976) ${ }^{(58)}$ introduziram uma expressão para a generalização modular para a reação do tipo gás-sólido, $\hat{\sigma}$, que é apresentada na Equação 17.

$$
\hat{\sigma} \equiv \frac{V_{p}}{A_{p}} \sqrt{\frac{(1-\varepsilon) k F_{p}}{2 D_{e}}\left(\frac{A_{g}}{F_{g} \cdot V_{g}}\right)\left(1+\frac{1}{K_{E}}\right)}
$$


Sendo:

$V_{p}$ e $V_{g}=$ Volume da pelota e do grão;

$F_{p}$ e $F_{g}=$ Fator de forma da pelota e do grão;

$A_{p}$ e $A_{g}=$ Área superficial da pelota e do grão;

$K_{E}=$ Constante de equilíbrio para a reação;

$D_{e}=$ Difusividade efetiva do reagente gasoso na camada do produto para cada grão;

$k=$ Constante da taxa de reação.

Através da análise do parâmetro $\hat{\sigma}$ da Equação 17, pode-se medir a magnitude relativa da taxa de reação química ou difusão de uma reação através de propriedades cinéticas e estruturais. Quando $\hat{\sigma}$ torna-se maior que $3(\hat{\sigma}>3)$, o processo global pode ser controlado por difusão no estado sólido. Isto tem sido observado, por exemplo, quando o produto de reação formado não apresenta porosidade. Por outro lado, se o produto de reação formado apresenta-se com algum grau de porosidade, então, o valor de $\hat{\sigma}$ torna-se menor, $\hat{\sigma}<0,3$, sendo o efeito da difusão, neste caso, podendo ser negligenciado. Outra observação feita pelo autor é que quando uma reação é irreversível, o valor de $K_{E}$ tende ao infinito, ou seja, o termo $\left(1+\frac{1}{K_{E}}\right)$ da Equação 17 pode ser desconsiderado ${ }^{(58,63)}$.

Através da Equação 17, pode-se observar a relação da porosidade neste parâmetro. É observado que com a diminuição do volume de poros na amostra, ocorre um aumento do valor de $\hat{\sigma}$, ou seja, o processo global tende a ser controlado por difusão.

A difusividade efetiva é outro parâmetro que aparece na Equação 17. A Equação 18 descreve a difusividade efetiva para um par de gases.

$D_{e}=\left(\frac{\varepsilon}{\tau}\right) D_{A B}$ Equação 18

Onde:

$\varepsilon$ é a porosidade do sólido;

$\tau$ é a tortuosidade característica do sólido;

$D_{A B}$ é a difusividade molecular do par de gases redutores. 
Onde $D_{A B}$ é definido pela Equação $19^{(64)}$ :

$D_{A B}=\frac{a}{p}\left(\frac{T}{\left(T_{C A} \cdot T_{C B}\right)^{1 / 2}}\right)^{b}\left(\frac{1}{M_{A}}+\frac{1}{M_{B}}\right)^{1 / 2}\left(T_{C A} \cdot T_{C B}\right)^{5 / 12} \cdot\left(P_{C A} \cdot P_{C B}\right)^{1 / 3} \quad$ Equação 19

Sendo:

$a$ e $b$ são valores constantes que para pares de gases não polares valem $2,745 \times 10^{-4}$ e 1,823 respectivamente;

$T_{C A}$ e $T_{C B}$ são as temperaturas criticas para os gases A e B respectivamente;

$M_{A}$ e $M_{B}$ são as massas moleculares;

$P_{C A}$ e $P_{C B}$ são as pressões críticas dos gases A e B;

$p$ é a pressão (atm).

A Equação 19 mostra que a difusividade de um par gasoso aumenta com o aumento da temperatura e é quase que independente da composição do par gasoso.

Pode-se observar a relação dos valores de porosidade e difusividade efetiva com relação ao parâmetro. É observado que com o aumento da difusividade efetiva e a diminuição da porosidade, ocorre um aumento do valor de $\hat{\sigma}$, ou seja, o processo global tende a ser controlado por difusão.

Deste modo, devido a presença de vários fatores que podem interferir na redução, diferentes mecanismos e valores de energia de ativação têm sido encontrados na literatura para redução de óxidos de ferro por reagentes gasoso ${ }^{(62,65,66,67)}$. A Tabela 5 mostra alguns valores de energia de ativação e mecanismos controladores encontrados por pesquisadores, em seus trabalhos, para redução de óxidos de ferro para diferentes gases redutores. 
Tabela 5 - Compilação de valores de energia de ativação e mecanismos envolvidos na redução de óxidos de ferro ${ }^{(62,68)}$.

\begin{tabular}{|c|c|c|c|c|}
\hline $\begin{array}{l}\text { Gás } \\
\text { redutor }\end{array}$ & $\begin{array}{l}\text { Matéria } \\
\text { nrima }\end{array}$ & $\mathrm{Ea}(\mathrm{kJ} / \mathrm{mol})$ & Temperatura & Mecanismos \\
\hline $\mathrm{H}_{2}$ & $\mathrm{Fe}_{3} \mathrm{O}_{4}$ & 88 & $\mathrm{~T}<417^{\circ} \mathrm{C}$ & $\begin{array}{l}\text { Crescimento de núcleos } \\
\text { bidimensionais e } \\
\text { tridimensionais }\end{array}$ \\
\hline $\mathrm{H}_{2}$ & $\mathrm{Fe}_{3} \mathrm{O}_{4}$ & 39 & $\mathrm{~T}>417^{\circ} \mathrm{C}$ & $\begin{array}{c}\text { Reação por limites de } \\
\text { fases }\end{array}$ \\
\hline $5 \% \mathrm{H}_{2} / \mathrm{N}_{2}$ & $\mathrm{Fe}_{3} \mathrm{O}_{4}$ & 70,4 & $\begin{array}{c}\text { Não } \\
\text { especificada }\end{array}$ & $\begin{array}{c}\text { Crescimento de núcleo } \\
\text { bidimensional }\end{array}$ \\
\hline $\mathrm{H}_{2}$ & $\mathrm{Fe}_{3} \mathrm{O}_{4}$ & 200 & $\mathrm{~T}<250^{\circ} \mathrm{C}$ & $\begin{array}{l}\text { Reação por limite de } \\
\text { fases }\end{array}$ \\
\hline $\mathrm{H}_{2}$ & $\mathrm{Fe}_{3} \mathrm{O}_{4}$ & 71 & $250-390$ & $\begin{array}{l}\text { Reação por limite de } \\
\text { fases }\end{array}$ \\
\hline $\mathrm{H}_{2}$ & $\mathrm{Fe}_{3} \mathrm{O}_{4}$ & 44 & $\mathrm{~T}>390^{\circ} \mathrm{C}$ & $\begin{array}{l}\text { Reação por limite de } \\
\text { fases }\end{array}$ \\
\hline $\mathrm{CO}$ & $\mathrm{Fe}_{3} \mathrm{O}_{4}$ & 64 & $T>428$ & Controle por difusão \\
\hline
\end{tabular}

Do mesmo modo, alguns autores ${ }^{(62,66)}$ também realizaram compilações dos valores de energia de ativação para a redução de óxidos de ferro, onde foi observado que os valores de energia de ativação variam desde 13,4 a $246 \mathrm{~kJ} / \mathrm{mol}$ para redução de óxidos de ferro por agentes gasosos.

\subsubsection{Hematita}

\subsubsection{Estrutura da Hematita}

A hematita tem a composição química de $\mathrm{Fe}_{2} \mathrm{O}_{3}$, correspondendo a $69,94 \%$ de ferro e $30,06 \%$ de oxigênio. Possui duas estruturas cristalinas, a e y. A primeira é uma estrutura cristalina romboédrica onde os íons $\mathrm{O}^{2-}$ obedecem a um arranjo hexagonal e $2 / 3$ dos interstícios octaédricos estão ocupados por íons $\mathrm{Fe}^{3+}$. No caso da estrutura da hematita $\mathrm{\gamma}$, está é obtida pela oxidação de $\mathrm{Fe}_{3} \mathrm{O}_{4}$ em temperaturas menores do que $400^{\circ} \mathrm{C}{ }^{(69,70)}$. A estrutura cristalina do $\mathrm{Fe}_{2} \mathrm{O}_{3}$ a pode ser observada na Figura 11. 


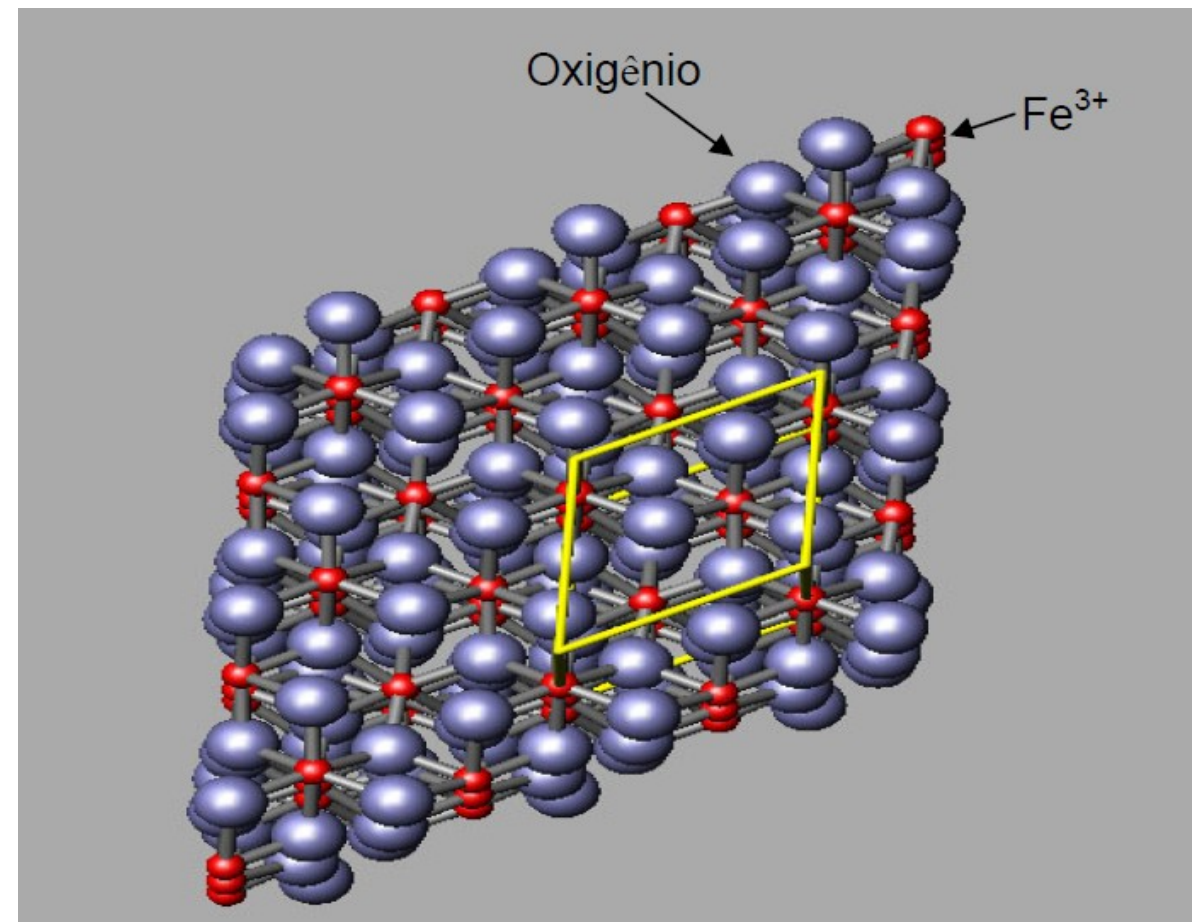

Figura 11 - Arranjo cristalina da hematita $\alpha^{(71)}$.

\subsubsection{Cinética de redução da Hematita}

Piotrowski et al. (2005) ${ }^{(72)}$ desenvolveu um estudo sobre a redução da hematita. No trabalho, os autores consideram a redução da hematita diretamente para wustita $\left(\mathrm{Fe}_{2} \mathrm{O}_{3} \rightarrow \mathrm{Fe}_{\mathrm{x}} \mathrm{O}\right)$ para temperaturas entre 700 a $900^{\circ} \mathrm{C}$ utilizando mistura de nitrogênio com hidrogênio $\left(90 \% \mathrm{~N}_{2}+10 \% \mathrm{H}_{2}\right)$.

Os autores plotaram uma curva com o grau de conversão versos o tempo para diferentes temperaturas (Figura 12). Através desta curva, é possível observar a influência da temperatura sobre a fração reagida. Neste caso, foi observado que o aumento da temperatura implicou na diminuição do tempo para atingir um valor de fração reagida $(\alpha)$ igual a um. 


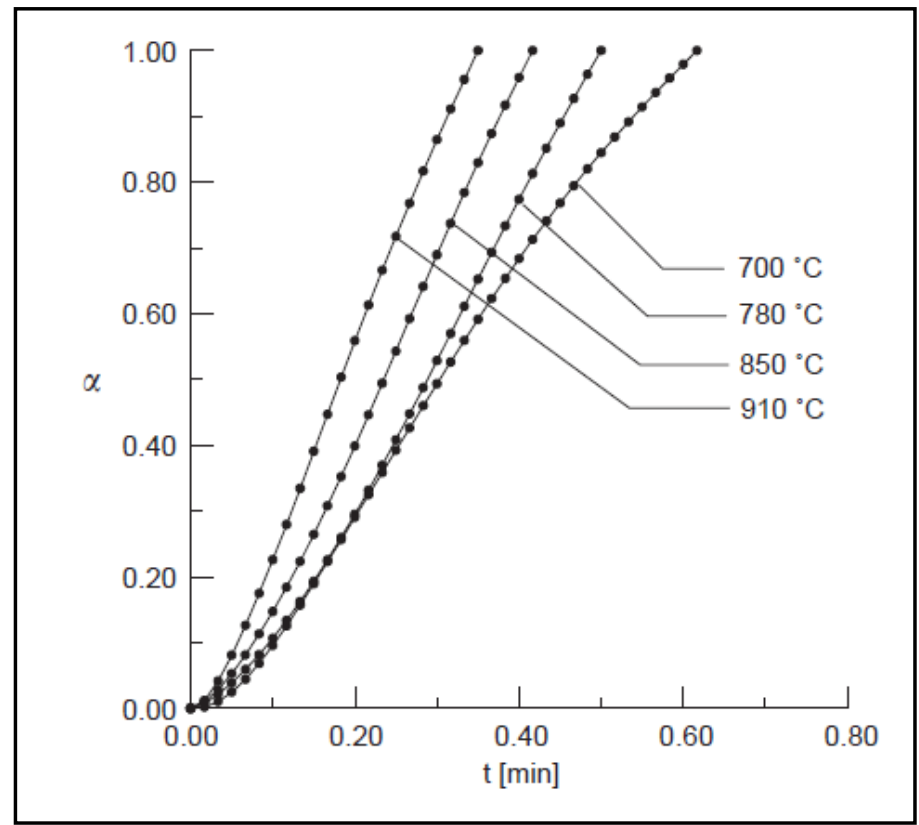

Figura 12 - Grau de conversão versos tempo para diferentes temperaturas de redução ${ }^{(72)}$.

Os autores também realizaram uma comparação dos resultados obtidos experimentalmente com alguns modelos teóricos. Na Figura 13 são apresentados os dados experimentais obtidos a $700^{\circ} \mathrm{C}$ e na Figura 14 os dados experimentais obtidos a $910^{\circ} \mathrm{C}$. A comparação foi realizada utilizando dois modelos teóricos, o modelo de controle por limite de fases e o modelo de Avrami-Erofeev de mudança de fases.

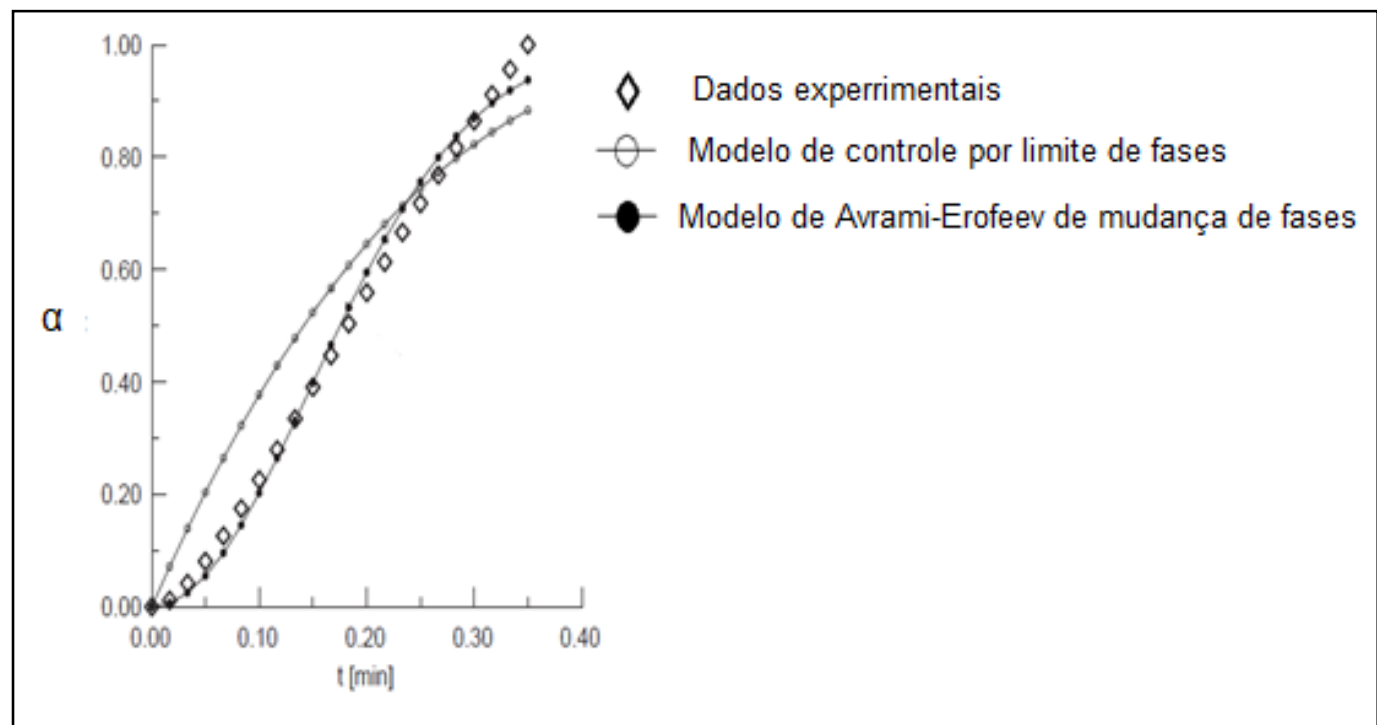

Figura 13 - Comparação de dados experimentais utilizando os modelos de controle por limite de fases e Avrami-Erofeyev de mudança de fases em temperatura de $700^{\circ} \mathrm{C}^{(72)}$. 


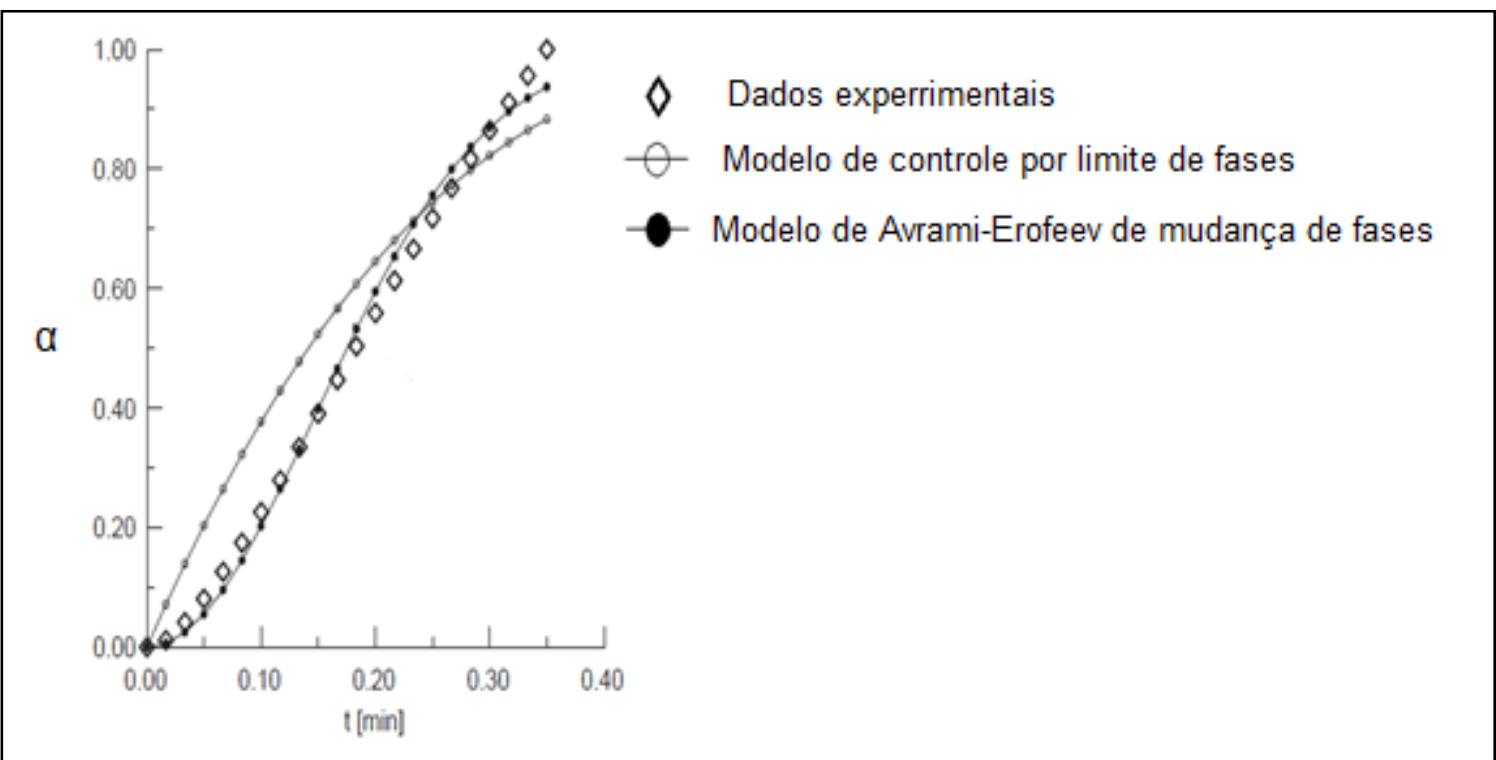

Figura 14 - Comparação de dados experimentais utilizando os modelos de controle por limite de fases e Avrami-Erofeyev de mudança de fases em temperatura de $910^{\circ} \mathrm{C}^{(72)}$.

Assim, os autores chegaram à conclusão de que o modelo de Avrami-Erofeev é o que melhor que se enquadra na redução de hematita para wustita.

Gaviría et al. (2007) ${ }^{(73)}$ estudaram a redução de hematita para magnetita monitorada por espectro de Mössbauer e difração de raios-X utilizando uma mistura com $5 \%$ de $\mathrm{H}_{2}$. Os autores encontraram uma energia de ativação de $98 \mathrm{~kJ} / \mathrm{mol}$, podendo variar \pm 4 . Os autores não citam em seu trabalho os mecanismos controladores.

Estudos realizados por Shimokawabe, Furuichi e Ishii (1979) ${ }^{(74)}$ mostram que para temperaturas menores do que $700^{\circ} \mathrm{C}$, a redução de $\mathrm{Fe}_{2} \mathrm{O}_{3}$ ocorre via duas diferentes etapas $\left(\mathrm{Fe}_{2} \mathrm{O}_{3}\right.$ para $\mathrm{Fe}_{3} \mathrm{O}_{4}$ e $\mathrm{Fe}_{3} \mathrm{O}_{4}$ para $\left.\mathrm{Fe}\right)$. Para temperaturas superiores a $900^{\circ} \mathrm{C}$, ambas as etapas ocorrem simultaneamente. O autor reportou que valores de energia de ativação foram encontrados na faixa de 33,27 a $74 \mathrm{~kJ} / \mathrm{mol}$.

Wiltowski et al. ${ }^{(75)}$ estudaram a cinética de redução de $\mathrm{Fe}_{2} \mathrm{O}_{3}$ para $\mathrm{FeO}$ entre 700 a $900^{\circ} \mathrm{C}$. Nas análises, foram utilizadas misturas de $\mathrm{N}_{2}+\mathrm{CO}$ e $\mathrm{N}_{2}+\mathrm{H}_{2}$. Os autores encontraram que a redução inicial de hematita é um processo controlado pela superfície. Entretanto, uma vez que uma fina camada de magnetita ou wustita é formada sobre a superfície, o processo passa a ser controlado por difusão. Valores de energia de ativação de 104 e $24 \mathrm{~kJ} / \mathrm{mol}$ para as misturas redutoras de $\mathrm{N}_{2}+\mathrm{CO}$ e $\mathrm{N}_{2}+\mathrm{H}_{2}$, respectivamente, foram encontradas. Piotrowski et al. (2005) ${ }^{(72)}$ 
complementa dizendo que o estágio final do processo de redução de hematita para magnetita, o acesso de gás redutor é limitado por difusão nos poros.

Outro trabalho de redução de hematita para magnetita foi realizado por Swann e Tighe $(1979)^{(76)}$. Foi observado que para temperaturas de redução menores que $650^{\circ} \mathrm{C}$, a magnetita formada apresenta uma estrutura porosa. Os autores também dizem que para temperaturas de redução acima de $850^{\circ} \mathrm{C}$, magnetitas na forma de ripas foram formadas.

Baguley et al. (1983) ${ }^{(77)}$ dizem que magnetita na forma de ripas foram observadas nos estágios iniciais de redução em $400^{\circ} \mathrm{C}$, e que as ripas de magnetitas atuam como locais para subsequentes crescimento de magnetita porosa.

Microscópio eletrônico de varredura também tem sido usado para estudar a relação entre a microestrutura e a taxa de redução na redução de hematita. $A$ redução de hematita ocorre mais rapidamente quando há formação de poros, já na etapa inicial, no produto de reação sólida. É observado também que a temperatura tem influência sobre os poros formados durante a redução. Poros esféricos distribuídos aleatoriamente podem ser encontrados para temperaturas de reação entre 400 a $700^{\circ} \mathrm{C}$. Para temperaturas entre 700 a $900^{\circ} \mathrm{C}$, poros alongados podem ser encontrados ${ }^{(78)}$.

Wang et al. (2009) ${ }^{(79)}$ sugere que a redução de $\mathrm{Fe}_{2} \mathrm{O}_{3}$ para temperaturas entre 250 a $300^{\circ} \mathrm{C}$ ocorre do modo apresentado na Figura 15. 


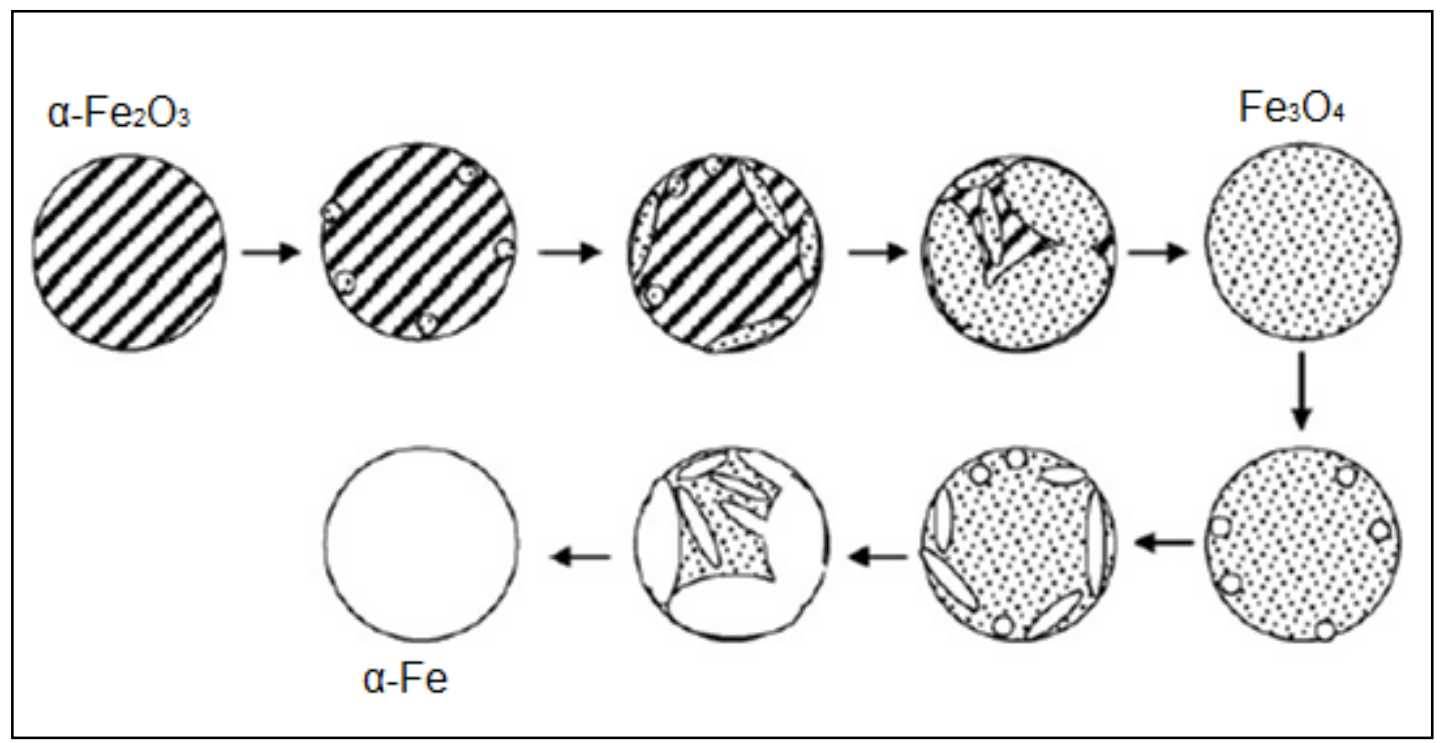

Figura 15 - Representação esquemática das etapas de redução de $\mathrm{Fe}_{2} \mathrm{O}_{3}$ para $\mathrm{Fe}$ em temperaturas entre 250 a $300^{\circ} \mathrm{C}^{(79)}$.

Primeiramente, núcleos de $\mathrm{Fe}_{3} \mathrm{O}_{4}$ são formados aleatoriamente nos limites dos grãos e/ ou nas imperfeições do cristal de $\mathrm{Fe}_{2} \mathrm{O}_{3}$. Com a continuidade da reação, o crescimento unidirecional de $\mathrm{Fe}_{3} \mathrm{O}_{4}$ torna-se a etapa controladora de redução, e a taxa de redução acelera. Então, ocorre à sobreposição de núcleos de $\mathrm{Fe}_{3} \mathrm{O}_{4}$ e uma desaceleração na taxa de redução é observada. Após a completa conversão de $\mathrm{Fe}_{2} \mathrm{O}_{3}$ para $\mathrm{Fe}_{3} \mathrm{O}_{4}$, núcleos de $\mathrm{Fe}$ são formados aleatoriamente nos limites do grão de $\mathrm{Fe}_{3} \mathrm{O}_{4}$, assim, a taxa de redução é controlada sucessivamente por crescimento e sobreposição dos núcleos de Fe.

\subsubsection{Magnetita}

\subsubsection{Estrutura cristalina}

A magnetita apresenta uma estrutura cristalina conhecida com espinel inverso. Possuí 08 sítios tetraédricos ocupados por $\mathrm{Fe}^{3+}$ e 16 sítios octaédricos ocupados por íons $\mathrm{Fe}^{2+}$ e $\mathrm{Fe}^{3+(80,81)}$ que pode ser observada na Figura 16. 


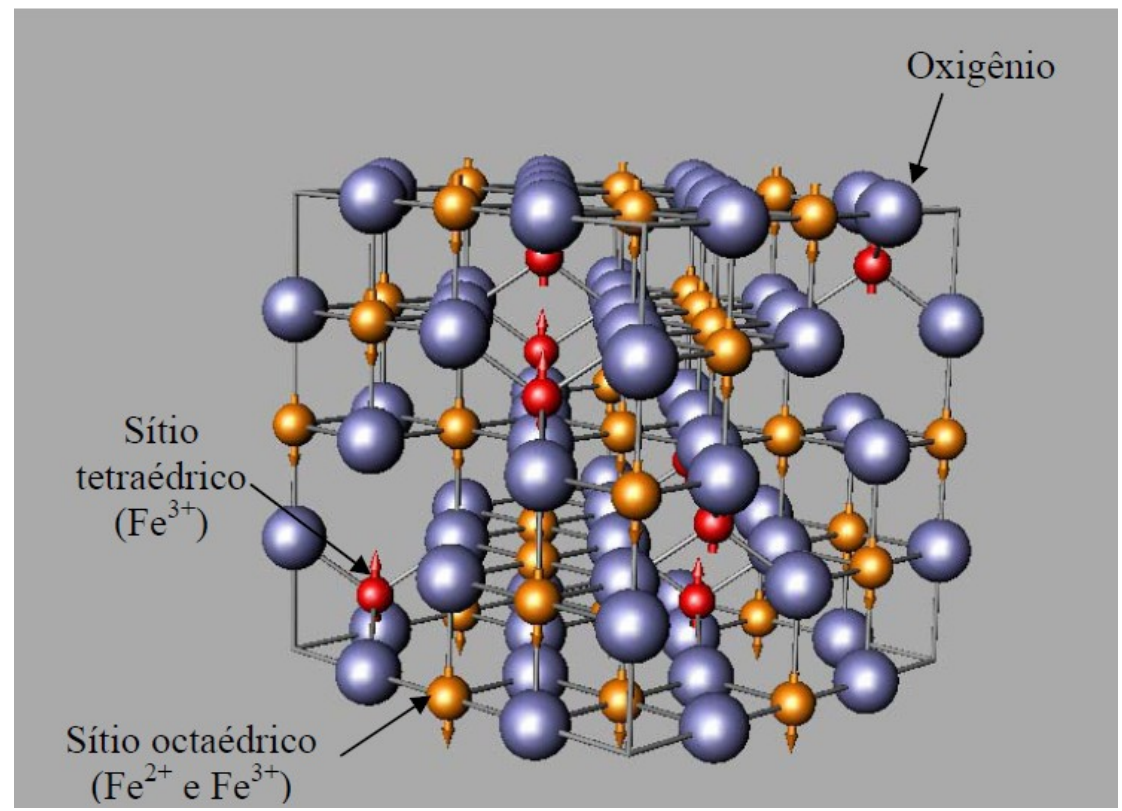

Figura 16 - Representação da estrutura cristalina da magnetita ${ }^{(71)}$.

Sua formula química pode ser escrita como $\mathrm{Y}(\mathrm{XY}) \mathrm{O}_{4}$, onde $\mathrm{Y}$ é o $\mathrm{Fe}^{3+}$ e o $\mathrm{X}$ é o $\mathrm{Fe}^{2+}$. Sendo assim, pode-se observar que a estrutura da magnetita apresenta aproximadamente $67 \%$ dos íons de ferro na forma de $\mathrm{Fe}^{3+}$ e $33 \%$ de $\mathrm{Fe}^{2+(82)}$. Outra forma de se dizer é que a magnetita apresenta $72,36 \%$ de ferro e $27,64 \%$ de oxigênio ${ }^{(83)}$.

2.8.2.2 Cinética de redução da magnetita

Caceres e Behbehani (1994) ${ }^{(84)}$ realizaram a redução de magnetita pura por hidrogênio. A Figura 17 apresenta as curvas de grau de redução versos tempo para diferentes temperaturas para a redução de magnetita. 


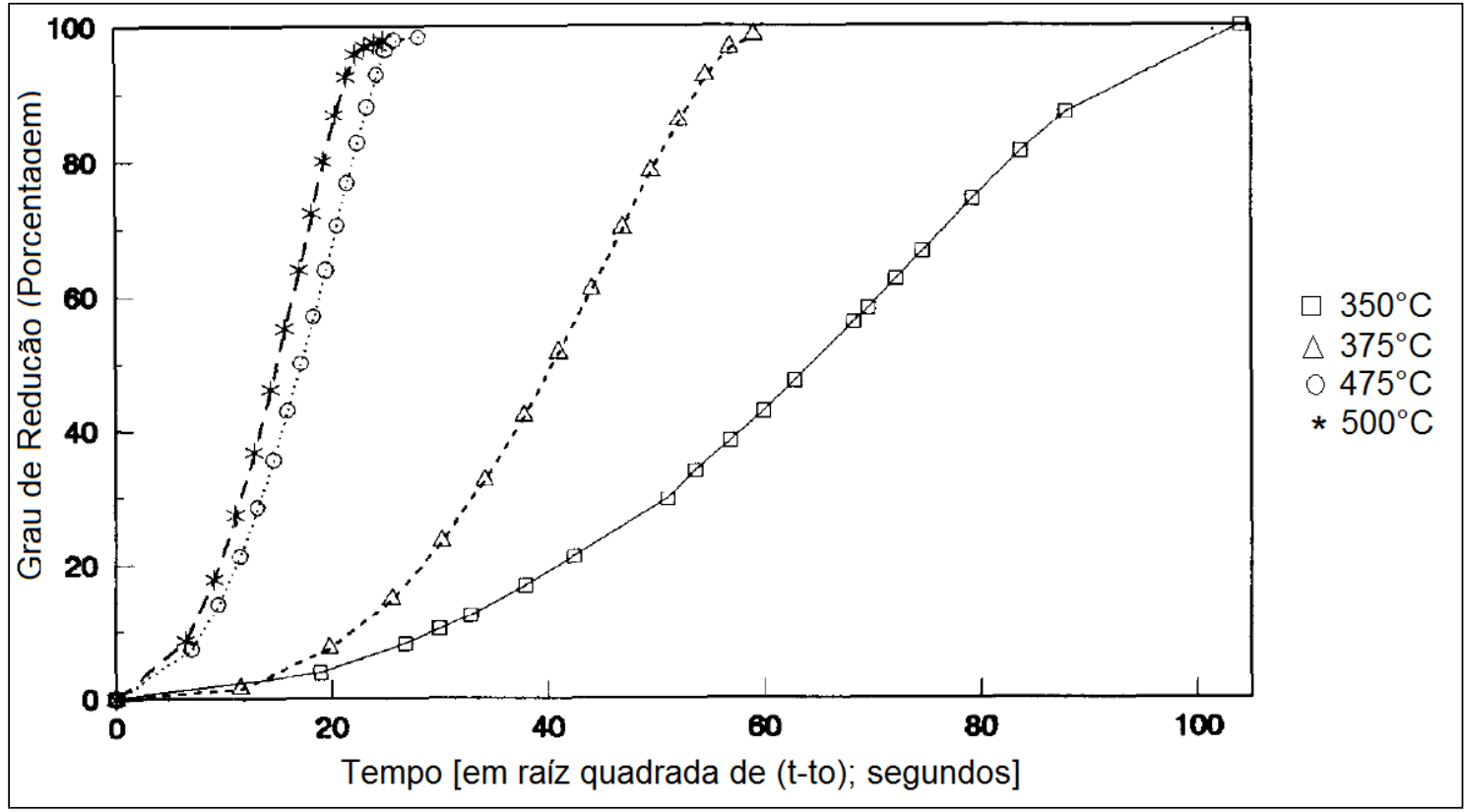

Figura 17 - Grau de redução em função do tempo para a redução de magnetita ${ }^{(84)}$.

Os autores chegaram à conclusão de que a energia de ativação da redução de magnetita para temperaturas entre 325 a $500^{\circ} \mathrm{C}$ foi de $69,3 \mathrm{~kJ} / \mathrm{mol}$.

Outros valores de energia de ativação são citados por Tiernan, Barnes e Parkes (2001) ${ }^{(42)}$ onde foi observado que o valor da energia de ativação da redução da magnetita para ferro pode variar de $54 \mathrm{~kJ} / \mathrm{mol}$ a valores de até $111 \mathrm{~kJ} / \mathrm{mol}$.

Bahgat e Khedr (2007) ${ }^{(85)}$ citam em seu trabalho que a redução de magnetita para wustita é controlada por reação química para temperaturas menores do que $800^{\circ} \mathrm{C}$. Para temperaturas acima de $800^{\circ} \mathrm{C}$, o mecanismo controlador é uma mistura entre reação química e difusão gasosa. Ainda segundo os autores, em seus estudos, a redução de um cristal simples de magnetita apresentou uma energia de ativação de 99,2kJ/mol, apresentando como mecanismo controlador a difusão no estado sólido.

Viswanath, Viswanathan e Sastri (1977) ${ }^{(86)}$ estudaram a redução de $\mathrm{Fe}_{3} \mathrm{O}_{4}$ a $505^{\circ} \mathrm{C}$, utilizando hidrogênio como agente redutor. Os autores encontraram que o mecanismo controlador foi por reação topoquímica.

Lina, Chena e $\mathrm{Li}^{(65)}$ realizaram a redução de $\mathrm{Fe}_{2} \mathrm{O}_{3}$ entre as temperaturas de 300 a $900^{\circ} \mathrm{C}$ utilizando uma mistura de $5 \% \mathrm{H}_{2}-95 \% \mathrm{~N}_{2}$. $\mathrm{Na}$ etapa de redução de $\mathrm{Fe}_{3} \mathrm{O}_{4}$ para Fe, foi obtida uma energia de ativação de $70,4 \mathrm{~kJ} / \mathrm{mol}$, onde a etapa controladora foi modelo de nucleação bidimensional sugerido por Avrami-Erofeev. 
Edstrom (1953) ${ }^{(87)}$ realizou o estudo da microestrutura da redução de magnetita para wustita, onde o autor utilizou misturas contendo $\mathrm{CO}, \mathrm{H}_{2}$ e $\mathrm{CO} / \mathrm{CO}_{2}$ entre as temperaturas de 800 a $1000^{\circ} \mathrm{C}$ como parâmetros durante a redução. $\mathrm{Na}$ redução de magnetita por $\mathrm{CO}$ a $1000^{\circ} \mathrm{C}$, o autor observou que após a redução, a wustita apresentou uma estrutura densa. Para a redução de magnetita na mesma temperatura supracitada, porém utilizando $\mathrm{H}_{2}$, o autor encontrou que a wustita apresentou após a redução, uma estrutura porosa. Assim, foi observado que, o aumento do potencial redutor da mistura redutora gera preferencialmente uma estrutura mais porosa na wustita. A mesma afirmação é dita por Mattew e Hayes $(1990)^{(88)}$ onde comentam que o aumento do potencial redutor do gás redutor favorece a formação de microestruturas porosas.

\subsubsection{Wustita}

\subsubsection{Estrutura cristalina}

A wustita apresenta estrutura cristalina do tipo cúbica de face centrada (CFC), com o íon de ferro arranjado nos interstícios octaédricos entre os íons de oxigênio. A Figura $18^{(89)}$ apresenta o modelo estrutural da wustita onde se pode observar a presença de vacâncias na estrutura.

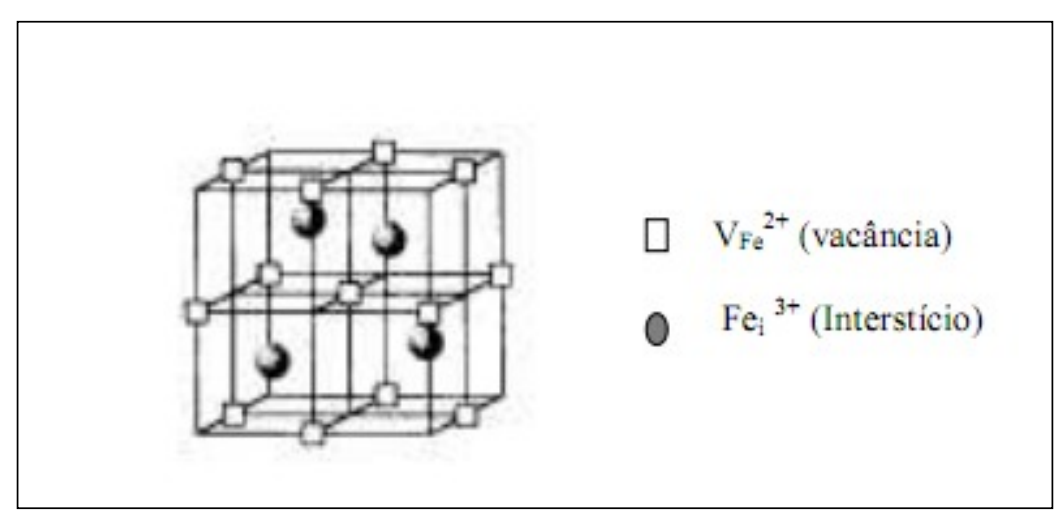

Figura 18 - Representação do modelo estrutural da wustita ${ }^{(89)}$. 
Em sua estrutura somente é encontrado $\mathrm{Fe}^{2+}$. Apresenta uma estrutura normalmente não estequiométrica, onde frequentemente é representada pela formula $\mathrm{Fe}_{(1-\mathrm{X})} \mathrm{O}$, com $x$ podendo variar de 0,83 a $0,96^{(90,91)}$. A ausência da estequiometria deve-se à oxidação de parte dos íons de ferro e da criação de vacâncias catiônicas ${ }^{(71,92)}$.

\subsubsection{Cinética de redução da wustita}

A redução de wustita para ferro é a última etapa do processo de redução e a mais lenta. Gaballah et al. (1972) ${ }^{(93)}$ realizou ensaios de redução de pó de wustita com temperaturas entre 680 a $900^{\circ} \mathrm{C}$. De acordo com os autores, a difusão sólida de oxigênio através da camada densa de ferro foi o passo limitante da reação.

Outra importante pesquisa foi desenvolvida por Pescott (1976) ${ }^{(94)}$. O autor cita que existe uma desaceleração na reação de redução da wustita. De acordo com o autor, esta desaceleração é devido à mudança alotrópica que ocorre na redução de FeO para ferro. Em adição, Moukassi et al. (1983) ${ }^{(95)}$, realizou observações no microscópio eletrônico de varredura durante a redução de wustita. Foi observado que com o andamento da redução, a estrutura se torna cada vez mais densa, assim, atuando como uma barreira para a difusão de gás nos poros. A Figura 19, mostra duas micrografias de wustita utilizando hidrogênio como agente redutor, em temperaturas de 700 e $890^{\circ} \mathrm{C}$. 


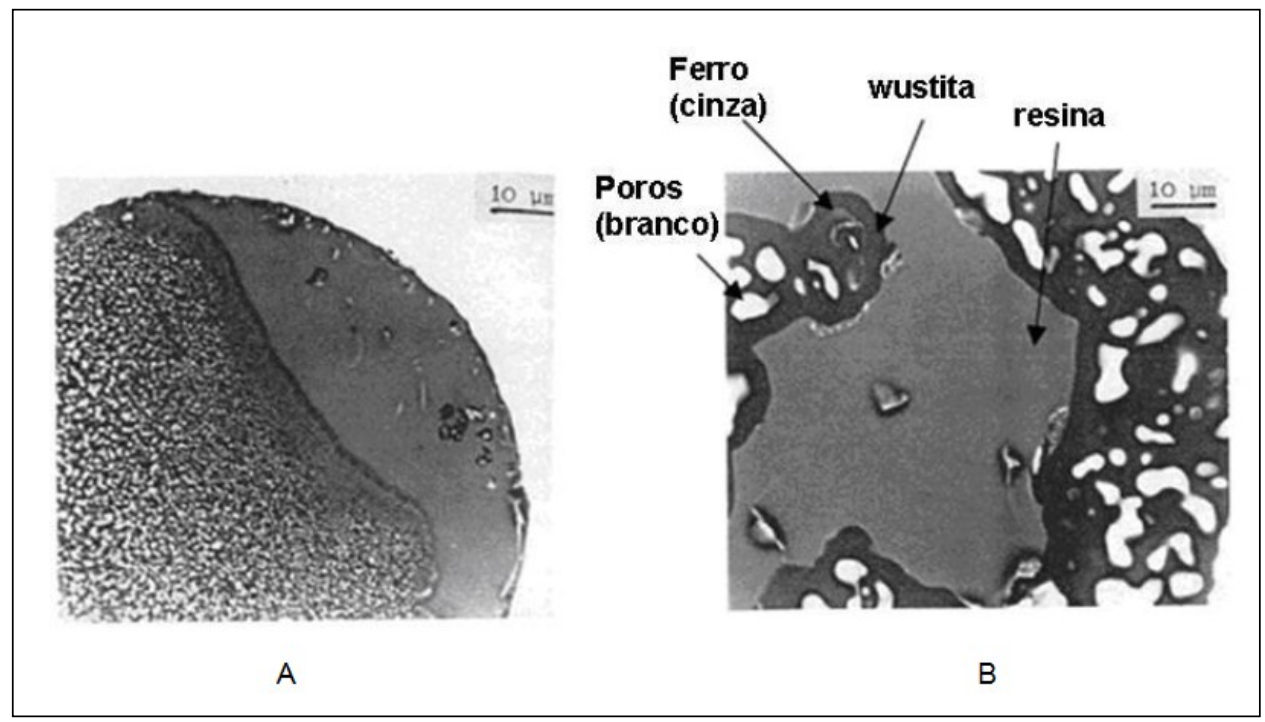

Figura 19 - Micrografias de wustita em atmosfera de hidrogênio: A) Temperaturas de 700 ; B) Temperatura de $890^{\circ} \mathrm{C}^{(95)}$.

Em $700^{\circ} \mathrm{C}$, as amostras têm porosidade mais fina do que a $890^{\circ} \mathrm{C}$, enquanto que a $890^{\circ} \mathrm{C}$, as amostras contêm um menor número de poros (com relação a amostras obtidas a $700^{\circ} \mathrm{C}$ ), porém estes são maiores, tornando assim, a camada de ferro uma barreira densa.

Estudo de redução de wustita também foi realizado por El-Rahaiby e Rao $(1979)^{(96)}$. Neste trabalho, os autores realizaram análises entre as temperaturas de 238 a $417^{\circ} \mathrm{C}$. Foi utilizado como agente redutor hidrogênio puro. Para as referidas condições, foi encontrada uma energia de ativação de $71,5 \mathrm{~kJ} / \mathrm{mol}$. Para os autores, em nível microscópico, o processo de redução de wustita envolve a formação de um núcleo de ferro e em seguida, o crescimento dos núcleos sobre a matriz de óxido de ferro. A nucleação de ferro é favorável a aparecer nos limites dos grãos e em outras imperfeições presentes nas amostras policristalinas.

Fruehan et al. (2005) ${ }^{(97)}$ diz que quando uma camada sólida de ferro é formada, a difusão do hidrogênio torna-se impossível. Deste modo, o átomo de oxigênio é que deve se difundir da interface $\mathrm{Fe} / \mathrm{FeO}$ para a interface Fe/gás, onde a reação com o hidrogênio ocorre.

A morfologia que o ferro apresenta está diretamente ligada aos mecanismos de redução. Assim, vale fazer um breve comentário sobre as morfologias encontradas durante a redução. 
Três diferentes morfologias podem ser encontradas na redução de wustita para ferro quando se usa misturas redutos $\mathrm{CO} / \mathrm{CO}_{2}$ e $\mathrm{H}_{2} / \mathrm{H}_{2} \mathrm{O}$, são elas: ferro poroso, wustita porosa recoberta com ferro denso e wustita densa recoberta com ferro denso ${ }^{(98,99)}$, sendo que estas estruturas estão ligadas diretamente as condições de análises, ou seja, estão ligadas a temperatura em que a reação está ocorrendo e do tipo de agente redutor utilizado.

El Moujahid e Rist $(1988){ }^{(100)}$ realizaram estudos da morfologia de redução de $\mathrm{FeO}$ denso para ferro utilizando diferentes misturas redutoras. As investigações foram realizadas entre as temperaturas de 430 a $1100^{\circ} \mathrm{C}$. Foi observado pelos autores que o uso de hidrogênio como agente redutor propicia a formação de um ferro com morfologia mista e ou porosa quando comparado ao $\mathrm{CO}$.

St John, Matthew e Hayes (1984) ${ }^{(99)}$ complementam dizendo que em misturas gasosas contendo mais que $7,5 \%$ de $\mathrm{CO}_{2}$ ou mais de $25 \%$ de $\mathrm{H}_{2} \mathrm{O}$, uma densa camada de ferro é mantida durante a reação. Para menores valores de $\mathrm{CO}_{2} \mathrm{e}$ $\mathrm{H}_{2} \mathrm{O}$, os autores comentam que apesar de haver a formação de uma camada densa de ferro no inicio da redução, a estrutura final consiste de uma morfologia porosa. Ou seja, o aumento do potencial redutor do gás redutor gera a formação de uma estrutura porosa.

Estudos de redução de wustita com hidrogênio entre temperaturas de 238 a $417^{\circ} \mathrm{C}$ foram realizados por El-Rahaiby e Rao $(1979)^{(96)}$. Os autores observaram que a redução da wustita ocorre em três fases. O período de incubação, período de aceleração e o período de desaceleração. O período de incubação corresponde a formação dos núcleos de ferro, onde a temperatura tem efeito direto sobre este fenômeno. Na aceleração, ocorre o crescimento dos núcleos formados na primeira etapa. Por último, ocorre a etapa de desaceleração, que ocorre quando os grãos formados entram em contado uns com os outros podendo gerar até sobreposições, ocasionado um desaceleração na taxa de redução neste momento. 


\subsubsection{Ferrita de Zinco}

A ferrita de zinco está presente em sólidos como poeira de aciaria elétrica ou resíduo de lixiviação de zinco ustulado. É formada em temperaturas que variam de 800 a $1300^{\circ} \mathrm{C}^{(101)}$.

Apresenta uma estrutura em espinélio normal, em que os cátions de $\mathrm{Zn}^{2+}$ ocupam os espaços tetraédricos, enquanto que os cátions $\mathrm{Fe}^{3+}$ ocupam as posições octaédricas ${ }^{(102,103)}$. A Figura $20^{(104)}$ traz a representação esquemática da estrutura cristalina da ferrita de zinco.

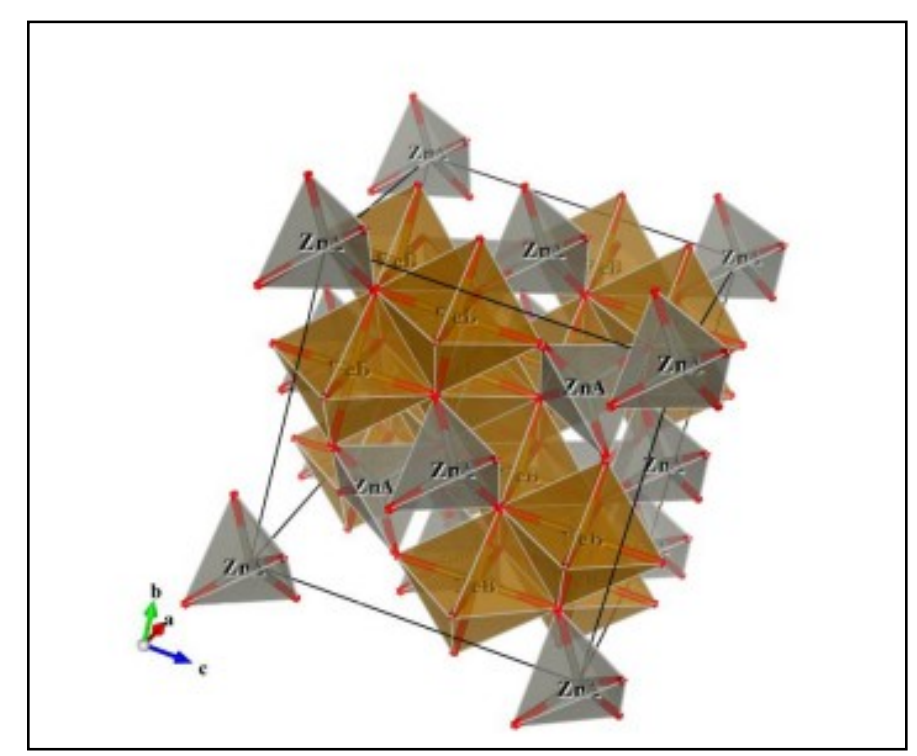

Figura 20 - Representação esquemática da estrutura cristalina da ferrita de zinco ${ }^{(104)}$.

\subsubsection{Cinética de redução de ferrita de zinco}

O estudo cinético da redução de ferrita de zinco não é uma prática corriqueira. Os trabalhos apresentados, na maioria dos casos, refere-se à redução carbotérmica ${ }^{(105)}$.

É citado que a primeira etapa que ocorre na redução da ferrita de zinco é a sua dissociação em óxido de zinco $(\mathrm{ZnO})$ e óxido de ferro $\left(\mathrm{Fe}_{2} \mathrm{O}_{3}\right)$. A partir deste 
momento, os dois óxidos são reduzidos simultaneamente ${ }^{(105)}$. Tong $2001{ }^{(106)}$, por sua vez, também cita que os mecanismos de redução de ferrita de zinco podem ser comparados com os dos óxidos de ferro.

Deste modo, a reação de redução de ferrita de zinco, por $\mathrm{CO}$, pode apresentar três diferentes sequencias, como pode ser observado nas equações 20 , 21 e $22^{(39)}$ :

$$
\begin{array}{ll}
\mathrm{ZnFe}_{2} \mathrm{O}_{4} \rightarrow \mathrm{FeO} \rightarrow \mathrm{Fe} & \text { Equação } 20 \\
\mathrm{ZnFe}_{2} \mathrm{O}_{4} \rightarrow(\mathrm{Fe}, \mathrm{Zn}) \mathrm{O} \rightarrow \mathrm{Fe} & \text { Equação } 21 \\
\mathrm{ZnFe}_{2} \mathrm{O}_{4} \rightarrow \mathrm{Fe}_{3} \mathrm{O}_{4} & \text { Equação 22 }
\end{array}
$$

Parâmetros, como por exemplo, temperaturas de redução e composição do gás redutor irão influenciar na sequência de reação. Pela Equação $23^{\left({ }^{(39)}\right.}$ pode ser observado o processo de redução de ferrita de zinco por CO. Pela equação, é possível observar que a redução tem como característica a remoção do oxigênio e do zinco proveniente da ferrita de zinco.

$$
\mathrm{ZnFe}_{2} \mathrm{O}_{4(\mathrm{~s})}+2 \mathrm{CO}_{(\mathrm{g})}=\mathrm{Zn}_{(\mathrm{g})}+2 \mathrm{FeO}_{(\mathrm{s})}+2 \mathrm{CO}_{2}
$$

Porém, quando o potencial de oxigênio na mistura redutora não estabiliza o $\mathrm{FeO}$, tem-se a produção de ferro metálico, de acordo com a Equação $24{ }^{(39)}$.

$$
\mathrm{ZnFe}_{2} \mathrm{O}_{4(\mathrm{~s})}+4 \mathrm{CO}_{(\mathrm{g})}=\mathrm{Zn}_{(\mathrm{g})}+2 \mathrm{Fe}_{(\mathrm{s})}+4 \mathrm{CO}_{2}
$$

Tong e Hayes (2007) ${ }^{(107)}$, citam que a sequencia de redução de ferrita de zinco por gases redutores contendo $\mathrm{CO}$ e $\mathrm{H}_{2}$ podem seguir as etapas descritas pelas Equações 25 e 26:

$$
\begin{array}{ll}
\mathrm{ZnFe}_{2} \mathrm{O}_{4(\mathrm{~s})} \rightarrow(\mathrm{Fe}, \mathrm{Zn}) \mathrm{O} \rightarrow \mathrm{FeO} \rightarrow \mathrm{Fe}\left(\mathrm{T}>700^{\circ} \mathrm{C} \text { para } \mathrm{H}_{2} / \mathrm{N}_{2}\right) & \text { Equação } 25 \\
\mathrm{ZnFe}_{2} \mathrm{O}_{4(\mathrm{~s})} \rightarrow \mathrm{FeO} \rightarrow \mathrm{Fe}\left(\mathrm{T}<700^{\circ} \mathrm{C} \text { para } \mathrm{CO} / \mathrm{N}_{2}, \mathrm{CO} / \mathrm{CO}_{2} \text { e } \mathrm{H}_{2} / \mathrm{N}_{2}\right) & \text { Equação } 26
\end{array}
$$


Tong e Hayes (2007) ${ }^{(107)}$ realizaram estudos de redução de ferrita de zinco pura utilizando como agente redutor hidrogênio puro e misturas de nitrogênio e hidrogênio em temperaturas entre 700 a $900^{\circ} \mathrm{C}$. A Figura 21 apresenta as curvas de porcentagem de redução versos o tempo, obtidas pelos autores na redução de ferrita de zinco pura utilizando hidrogênio puro como agente redutor.

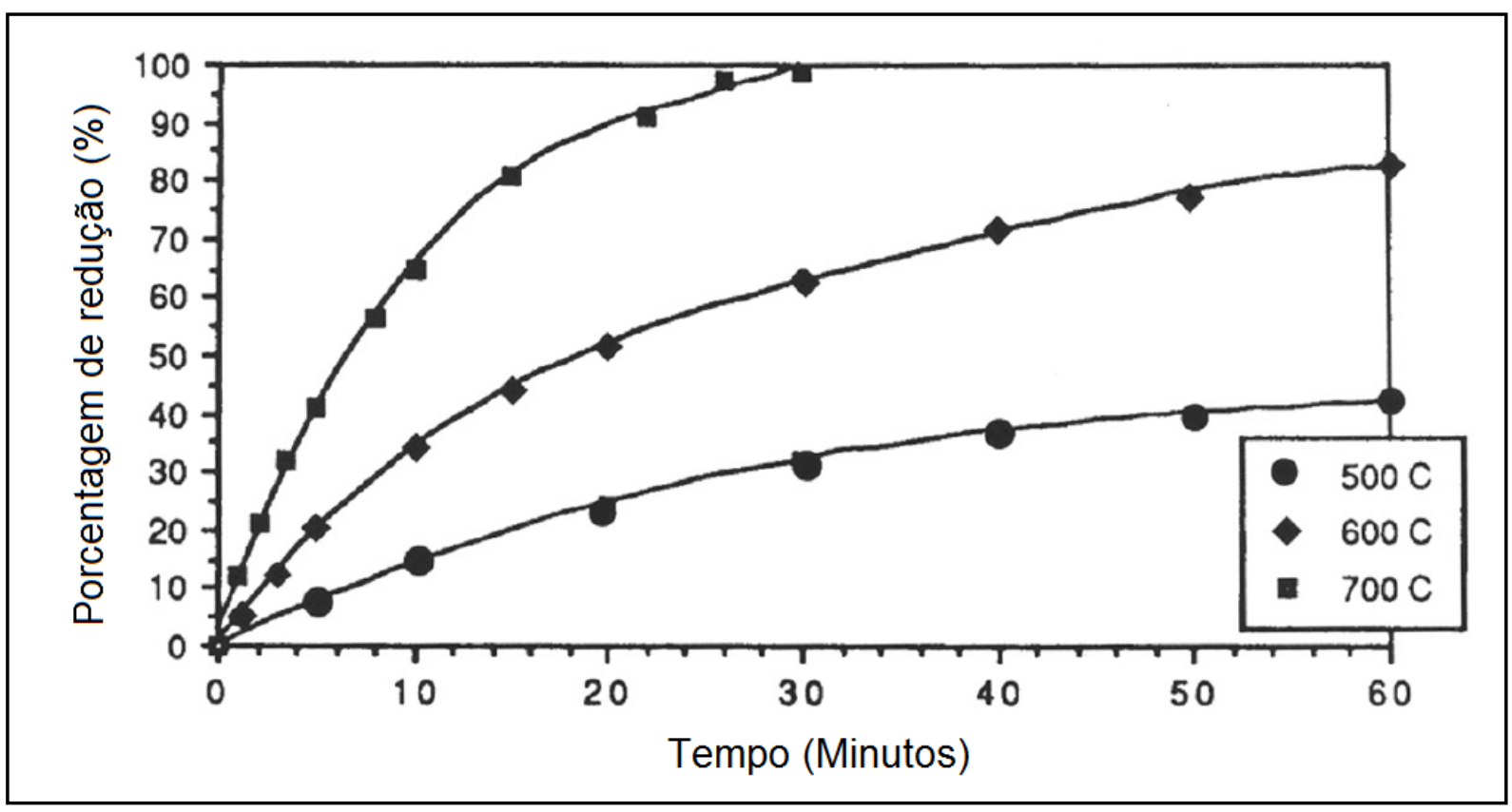

Figura 21 - Redução de ferrita de zinco em diferentes temperaturas com hidrogênio puro ${ }^{(107)}$.

Os autores também realizaram ensaios com mistura redutora contendo diferentes porcentagens de hidrogênio $(10 \%, 20 \%, 50 \%$ e $100 \%)$ em temperaturas de 800 e $900^{\circ} \mathrm{C}$. A Figura 22 apresenta os resultados obtidos a $900^{\circ} \mathrm{C}$. 


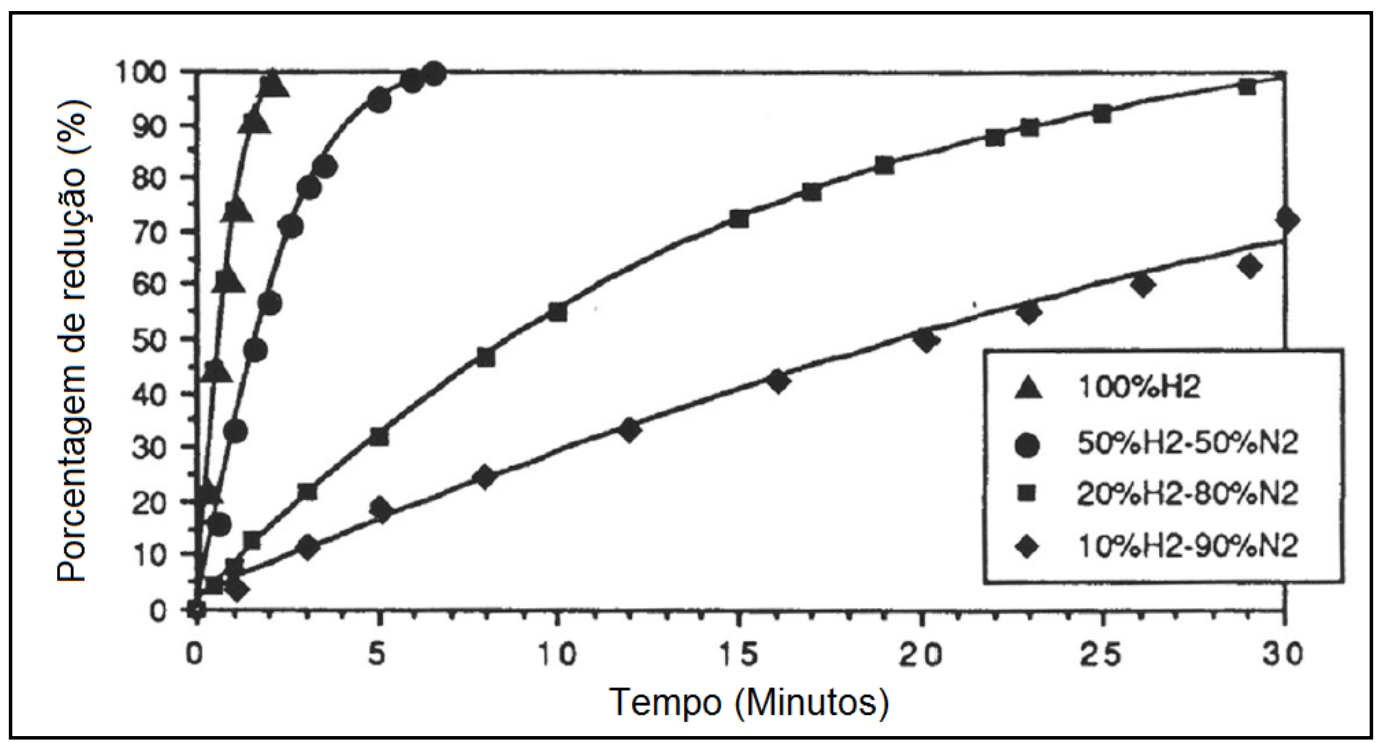

Figura 22 - Redução de ferrita de zinco pura com diferentes misturas redutoras para a temperatura de $900^{\circ} \mathrm{C}^{(107)}$.

As curvas de redução apresentam uma taxa linear inicial constante, o que, em seguida, diminui com o aumento tempo de reação. Os autores dizem que a redução da ferrita de zinco ocorre em duas etapas. A primeira etapa é a conversão da ferrita de zinco em wustita e a segunda é uma reação lenta que envolve a redução da wustita para ferro.

Liang, Kang e Xié (2009) ${ }^{(108)}$ também realizaram estudos de redução de ferrita de zinco utilizando hidrogênio como gás redutor. Neste trabalho, o estudo de redução foi realizado partindo-se da temperatura ambiente até $800^{\circ} \mathrm{C}$. Os autores ${ }^{(108)}$ comentam que a redução da ferrita de zinco por hidrogênio ocorre em três etapas. Na primeira, a ferrita de zinco é reduzida para magnetita $\left(\mathrm{Fe}_{3} \mathrm{O}_{4}\right)$, na segunda, a magnetita é reduzida para wustita (FeO) e na terceira, a wustita é reduzida para ferro. Os autores também calcularam a energia de ativação envolvida em cada uma das etapas, aonde chegaram a valores de 118,02kJ/mol na primeira etapa, $174 \mathrm{~kJ} / \mathrm{mol}$ na segunda e $92,48 \mathrm{~kJ} / \mathrm{mol}$ na terceira etapa. Também foram calculados os valores das constantes pré-exponenciais de cada etapa. Os valores obtidos foram de $9,06 \times 10^{7} / \mathrm{s}, 2,32 \times 10^{9} / \mathrm{s}$ e $1480,7 / \mathrm{s}$ respectivamente.

Tong $(2001)^{(106)}$ realizou estudos de redução de ferrita de zinco pura utilizando misturas de $\mathrm{CO}$ com $\mathrm{CO}_{2}$ e argônio. As seguintes condições experimentais foram usadas: temperatura entre 800 a $1100^{\circ} \mathrm{C}$ para $\mathrm{CO}$ puro a $10 \% \mathrm{CO}-90 \% \mathrm{CO}_{2}$, e temperaturas de 900 a $1100^{\circ} \mathrm{C}$ para CO puro a $20 \% \mathrm{CO}-80 \% \mathrm{~N}_{2}$. 
Segundo o autor ${ }^{(106)}$, a redução de $\mathrm{ZnFe}_{2} \mathrm{O}_{4}$ com $\mathrm{CO}$ puro prossegue por meio de um fase de wustita intermediária e não diretamente para a fase de ferro.

Ainda segundo o autor ${ }^{(106)}$, a redução de ferrita de zinco para ferro com misturas de $\mathrm{CO}-\mathrm{CO}_{2}$ e CO- $\mathrm{N}_{2}$, para temperaturas acima de $570^{\circ} \mathrm{C}$ ocorre em dois estágios. O primeiro estágio é a conversão rápida de ferrita de zinco para wustita. $\mathrm{O}$ segundo estágio é uma lenta reação envolvendo a redução da wustita para ferro poroso ou denso. $\mathrm{O}$ autor diz que a fase intermediaria de wustita é formada como uma fase estável "protetiva" (não porosa) sobre a fase de ferrita de zinco.

Durante a redução de ferrita de zinco por misturas redutoras contendo $\mathrm{CO}$ $\mathrm{CO}_{2}$, CO-N $\mathrm{N}_{2}$ e $\mathrm{CO}$ puro, cinco diferentes tipos de microestruturas foram encontradas, que foi nomeado pelo autor ${ }^{(106)}$ como estruturas A, B, C, D e E. A microestrutura do tipo A apresenta uma microestrutura de ferro poroso, sendo esta obtida com o uso de $100 \%$ de CO como gás redutor. A morfologia do ferro poroso também foi observada para todas as amostras reduzidas em misturas contendo $\mathrm{CO}-\mathrm{N}_{2}$ (misturas com $90 \% \mathrm{CO}, 75 \% \mathrm{CO}, 50 \%$ CO e $20 \% \mathrm{CO}$ ) em temperaturas de $800-1100^{\circ} \mathrm{C}$. $\mathrm{Na}$ estrutura $\mathrm{B}$, o ferro apresenta uma densa camada de ferro cobrindo uma superfície da wustita porosa. Para este caso, o autor diz que os poros crescem para dentro da wustita, onde as paredes são recobertas com uma camada densa de ferro. Em alguns casos, esta camada densa de ferro pode ser rompida, expondo o óxido da matriz. Para condições aproximadas do equilíbrio entre $\mathrm{FeO}-\mathrm{Fe}$, a estrutura tipo $\mathrm{C}$ foi a predomina. Neste caso, uma superfície densa de wustita é completamente coberta com uma camada densa de ferro, que persiste ao longo de todo o restante da reação. A formação de uma camada densa de ferro não permite o contado direto entre o gás redutor e o óxido de ferro, levando a uma diminuição da taxa de redução. Nesta situação, a redução é limitada por difusão no estado sólido de oxigênio através da densa camada de ferro. Redução sobre estas condições tornam-se mais lentas com o aumento da espessura da camada de ferro.

A estrutura tipo D são formadas para misturas contendo $50 \% \mathrm{CO}_{2}-50 \% \mathrm{CO}$ para temperaturas entre 800 a $1100^{\circ} \mathrm{C}$.

Estrutura do tipo $\mathrm{E}$ (grãos de magnetita) são formados quando a amostra de ferrita de zinco é reduzida com gás redutor contendo $10 \% \mathrm{CO}-90 \% \mathrm{CO}_{2}$ na temperatura de $1000^{\circ} \mathrm{C}$. 


\subsection{MECANISMO DE NUCLEAÇÃO E CRESCIMENTO}

A partir do momento em que uma nova fase é formada através de uma reação, inicialmente deve haver a formação de um núcleo. O núcleo da nova fase formada cresce, tanto individualmente, ou pode se juntar com outros núcleos formando uma nova fase. Deste modo, a definição de nucleação torna-se importante no processo de redução e pode ser definido como o processo de formação de um embrião (ou núcleo) de uma nova fase que tenha capacidade de crescer ${ }^{(109)}$.

O estágio de nucleação e crescimento do ferro sobre a superfície da wustita durante da reação de redução por um reagente gasoso podem ser observados na Figura $23^{(110)}$.

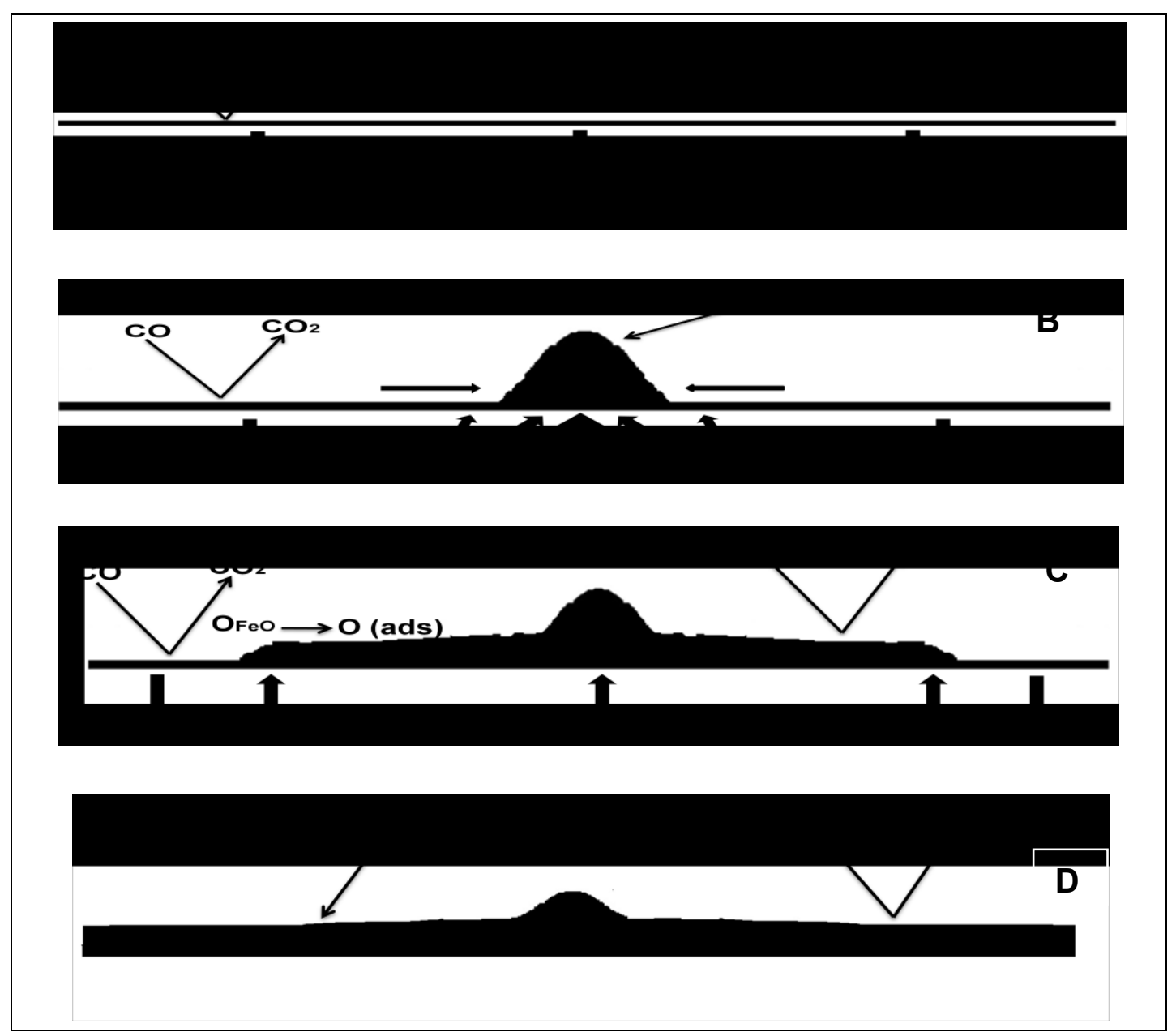

Figura 23 - Adaptação dos estágios de nucleação e crescimento sobre a superfície da wustita durante da reação de redução sugerida por John, Matthew e Hayes ${ }^{(110)}$. 
Na Figura 23A, mostra que o gás redutor ao entrar em contato com a superfície sólida, ocorre a remoção de átomos de oxigênio da superfície da wustita, aumentando assim a concentração de átomos de ferro na superfície.

A reação química e transporte de massa determina o acumulo de íons de ferro e a distribuição dos mesmos na superfície. Com o prosseguimento da reação, a composição da wustita em contato com o gás redutor torna-se mais rica em ferro, até eventualmente se tornar supersaturada com íons de ferro. Neste ponto, o óxido de ferro, neste caso a wustita, é metaestável e eventualmente será decomposto para a forma de ferro metálico, e consequentemente, uma wustita com menor concentração de íons de ferro. Quando a nucleação de ferro ocorre, o excesso de íns de ferro na wustita supersaturada nas proximidades do núcleo resultará num fluxo de íons de ferro para o núcleo via difusão de massa e na superfície (Figura 23B).

Em seguida, ocorre a difusão dos íons de oxigênio para a junção FeO-Fe-Gás, e remoção do oxigênio adsorvido na fase metálica. A remoção do oxigênio adsorvido ocorre pela superfície do núcleo de ferro por reação química (Figura 23C). Por fim, ocorre o crescimento da camada densa de ferro que pode ser vista na Figura 23D.

É importante ressaltar que o fenômeno de nucleação é favorecido pela presença de defeitos tais como contornos de grãos e impurezas ${ }^{(96)}$. Alguns elementos químicos são conhecidos como fomentadores de nucleação, dos quais, pode-se citar o cálcio, enxofre e álcalis ${ }^{(111)}$.

O fenômeno de nucleação e crescimento não ocorre somente para a redução de wustita. Este fenômeno pode estar presente em todas as etapas de redução dos óxidos de ferro.

\subsection{FORMAÇÃO DOS POROS}

John, Matthew e Hayes (1984) ${ }^{(99)}$ estudaram a formação de poros a partir da redução de wustita densa utilizando misturas contendo $\mathrm{CO} / \mathrm{CO}_{2}$ e $\mathrm{H}_{2} / \mathrm{H}_{2} \mathrm{O}$. Os 
autores utilizaram microscópio eletrônico de varredura para verificar a mudança microestrutural que ocorre durante a redução.

Os autores ${ }^{(99)}$ iniciam dizendo que a formação de poros durante a redução de wustita parte de uma estrutura densa de ferro. O mecanismo descrito para a formação dos poros é denominado mecanismo de bursting e pode ser visto na Figura $24^{(99)}$, que descreve o mecanismo de bursting para gases redutores contendo $\mathrm{CO} / \mathrm{CO}_{2}$.

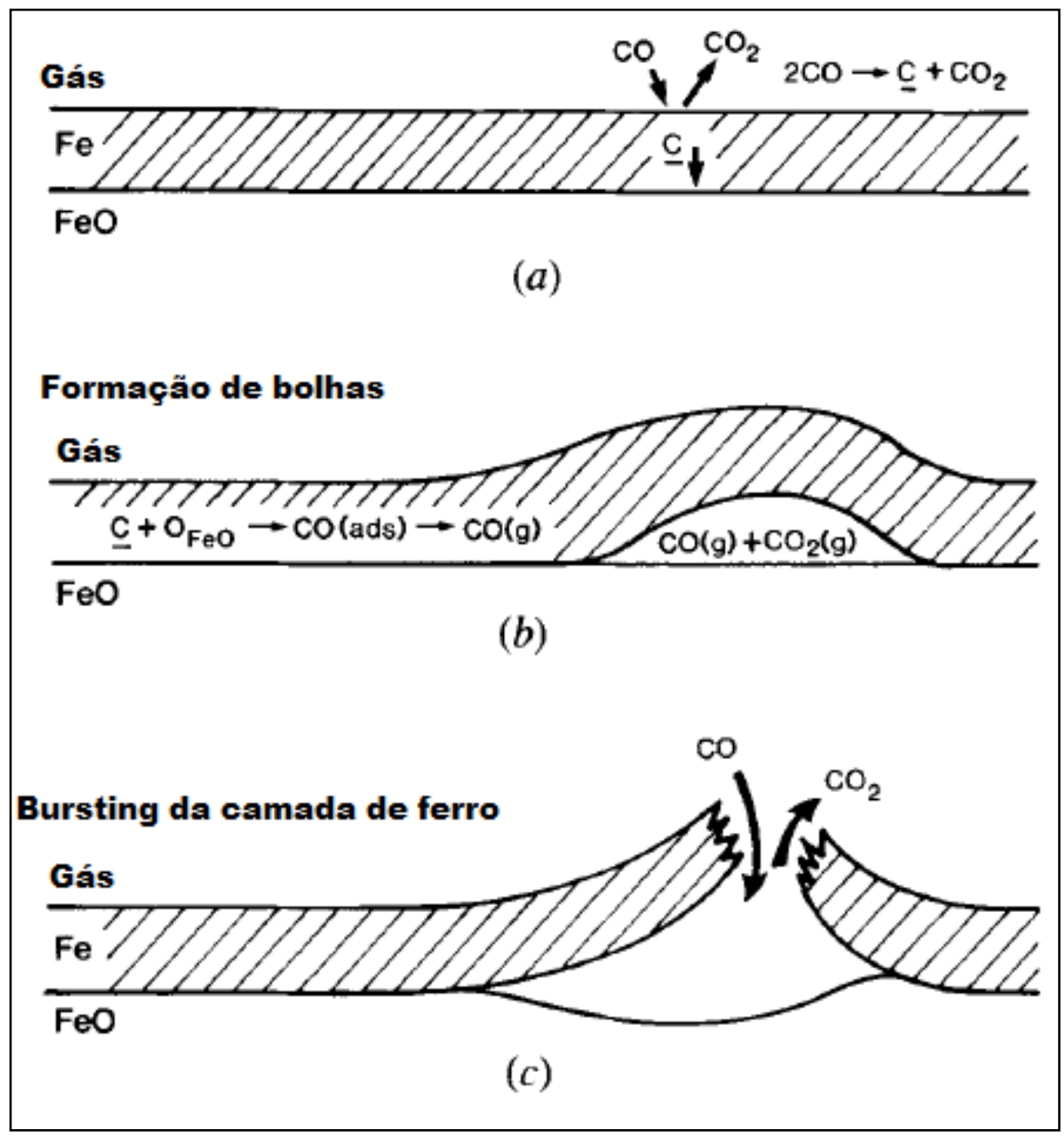

Figura 24 - Adaptação da representação esquemática do mecanismo de bursting para formação de poros ${ }^{(99)}$.

O inicio do mecanismo se dá com a dissolução do carbono, procedente do $\mathrm{CO}$, na camada densa do ferro. Esta carburação da camada densa de ferro acontece de acordo com a Equação $27^{(99)}$ : 


$$
2 \mathrm{CO}_{(\mathrm{g})}=\mathrm{CO}_{2(\mathrm{~g})}+\underline{\mathrm{C}}
$$

Na próxima etapa, o carbono dissolvido reage com o oxigênio, procedente do $\mathrm{FeO}$. Neste momento, $\mathrm{CO}$ e/ ou $\mathrm{CO}_{2}$ é formado, conforme é mostrado nas Equações 28 e $29^{(99)}$. Os gases formados são aprisionados e bolhas são formadas, como pode ser observado na Figura 24b.

$$
\begin{aligned}
& \mathrm{FeO}_{(\mathrm{s})}+\underline{\mathrm{C}}=\mathrm{Fe}_{(\mathrm{s})}+\mathrm{CO}_{(\mathrm{g})} \\
& 2 \mathrm{FeO}_{(\mathrm{s})}+\underline{\mathrm{C}}=2 \mathrm{Fe}_{(\mathrm{s})}+\mathrm{CO}_{2(\mathrm{~g})}
\end{aligned}
$$

Por fim, pode ocorrer a expansão das bolhas formadas causando a ruptura da camada densa de ferro. Processo que pode ser visualizado na Figura 24c.

O mecanismo de bursting é descrito para a formação de poros quando o gás redutor é composto por $\mathrm{CO} / \mathrm{CO}_{2}$. John, Matthew e Hayes $(1984)^{\left({ }^{(9)}\right.}$ também demonstram em seu artigo, que o mesmo mecanismo pode ser aplicado quando o gás redutor é composto por $\mathrm{H}_{2} / \mathrm{H}_{2} \mathrm{O}$.

Para gases redutores, o oxigênio procedente da wustita se difunde através da interface ferro/wustita para a interface ferro/gás. Então o mecanismo para a remoção do oxigênio na superfície de ferro pode ser representada pela Equação $30{ }^{(99) \text { : }}$

$$
\begin{aligned}
& \mathrm{H}_{2(\mathrm{~g})} \\
& \mathrm{CO}_{(\mathrm{g})}
\end{aligned}+\mathrm{O}_{(\mathrm{ads})}=\begin{aligned}
& \mathrm{H}_{2} \mathrm{O}_{(\mathrm{g})} \\
& \mathrm{CO}_{2(\mathrm{~g})}
\end{aligned} \quad \text { Equação } 30
$$

Em misturas gasosas contendo $\mathrm{H}_{2} / \mathrm{H}_{2} \mathrm{O}$, o dissolução do hidrogênio no ferro é dado através da Equação $31^{\left({ }^{99}\right)}$, ocorrendo, em seguida, difusão para a interface ferro/wustita.

$$
\mathrm{H}_{2(\mathrm{~g})}=2 \underline{\mathrm{H}}
$$

O hidrogênio, agora dissolvido no ferro, reage com o oxigênio da wustita produzindo vapor de água através da Equação $32{ }^{(99)}$ :

$$
\mathrm{FeO}_{(\mathrm{s})}+2 \underline{\mathrm{H}}=\mathrm{Fe}_{(\mathrm{s})}+\mathrm{H}_{2} \mathrm{O}_{(\mathrm{g})}
$$


Novamente, as bolhas geradas podem expandir e explodir, resultando na ruptura da camada densa de ferro. Em ambos os sistemas, $\mathrm{CO} / \mathrm{CO}_{2}$ e $\mathrm{H}_{2} / \mathrm{H}_{2} \mathrm{O}$, a atividade máxima de gás no ferro é determinada pela mistura de gás redutor. $A$ atividade máxima do $\underline{\mathrm{C}}$ e $\underline{\mathrm{H}}$ no ferro é determinada pela mistura de gás redutor, através da Equação 27 e da Equação 31.

\subsection{PROCESSOS DE REDUÇÃO DIRETA}

Conforme será visto nos capítulos seguintes, este trabalho apresenta como base o processo de redução direta, ou seja, tratamento químico de redução, geralmente um óxido, para a obtenção de um metal, através de um agente redutor, que podem ser tanto sólido, por exemplo, o carvão, ou gasosos, como o gás natural, por exemplo, onde não ocorre a fusão da carga ${ }^{(112)}$.

Assim, torna-se necessário a apresentação dos principais processos de redução direta para óxidos de ferro.

\subsubsection{Processos em reatores verticais}

No processo em reatores verticais, os principais processos são o MIDREX e HyL III. Estes processos são, respectivamente, responsáveis por aproximadamente $60,5 \%$ e $15,2 \%$ da produção mundial de ferro esponja ${ }^{(113)}$.

Geralmente o gás redutor é constituído de uma mistura de $95 \% \mathrm{H}_{2}$ e CO ${ }^{(114)}$. Segundo Araújo ${ }^{(115)}$, o gás redutor deve conter uma mistura de $53 \%$ de $\mathrm{H}_{2}$ e $34,5 \%$ de CO. Já para Cheeley ${ }^{(116)}$ é desejável que a razão entre $\mathrm{H}_{2} / \mathrm{CO}$ seja maior 0,5 .

O gás é introduzido na parte inferior do reator, assim, o gás apresenta um fluxo ascendente dentro do mesmo. A carga, em contrapartida, apresenta um fluxo descendente. Ao encontrar com o gás em uma temperatura de aproximadamente 860 a $900^{\circ} \mathrm{C}$, a carga é aquecida e reduzida de acordo com as Equações 33 e $34^{(115)}$. 
$\mathrm{Fe}_{2} \mathrm{O}_{3}+3 \mathrm{H}_{2}=2 \mathrm{Fe}+3 \mathrm{H}_{2} \mathrm{O}$

$\mathrm{Fe}_{2} \mathrm{O}_{3}+3 \mathrm{CO}=2 \mathrm{Fe}+3 \mathrm{CO}_{2}$

Equação 34

A Figura 25 apresenta o processo MIDREX de redução ${ }^{(117)}$.

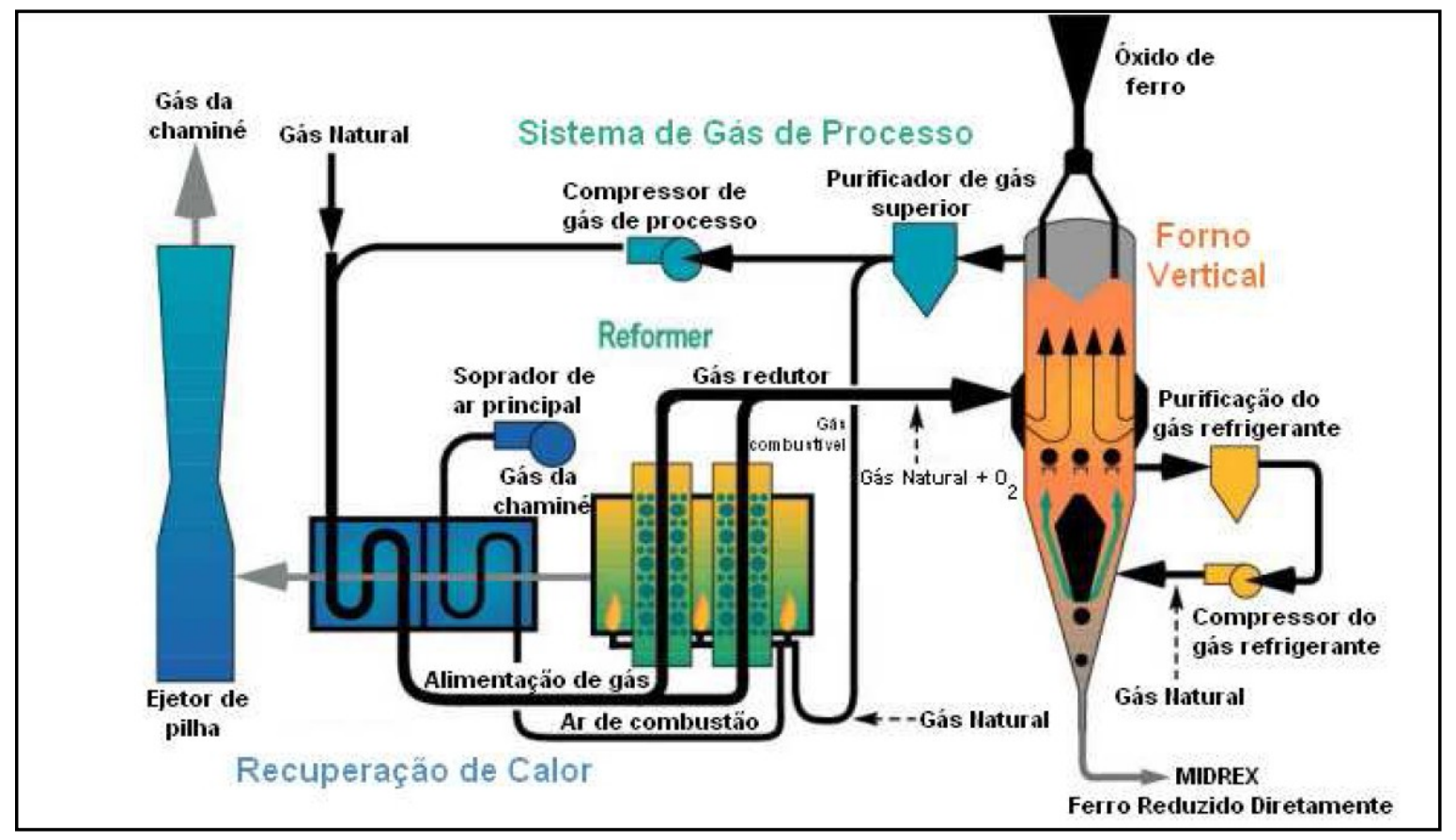

Figura 25 - Fluxograma esquemático do processo MIDREX ${ }^{(117)}$.

No processo HyL III, o gás obtido na unidade de reforma tem como principais constituintes o $\mathrm{H}_{2}(74-76 \%)$, $\mathrm{CO}(13-16 \%), \mathrm{CH}_{4}(4-5 \%)$ e $\mathrm{CO}_{2}(7-8 \%)^{(115)}$.

$\mathrm{O}$ gás redutor contendo principalmente $\mathrm{H}_{2}$ e CO é injetado no forno entre 900 a $950^{\circ} \mathrm{C}$, com pressão acima de 6,5atm. Este gás atravessa o forno em contracorrente à carga removendo o oxigênio e formando $\mathrm{H}_{2} \mathrm{O}$ e $\mathrm{CO}_{2}$. As reações são as mesmas que ocorrem no processo MIDREX (Equações 33 e 34$)^{(115)}$. A Figura 26 apresenta o fluxograma do processo HyL III. 


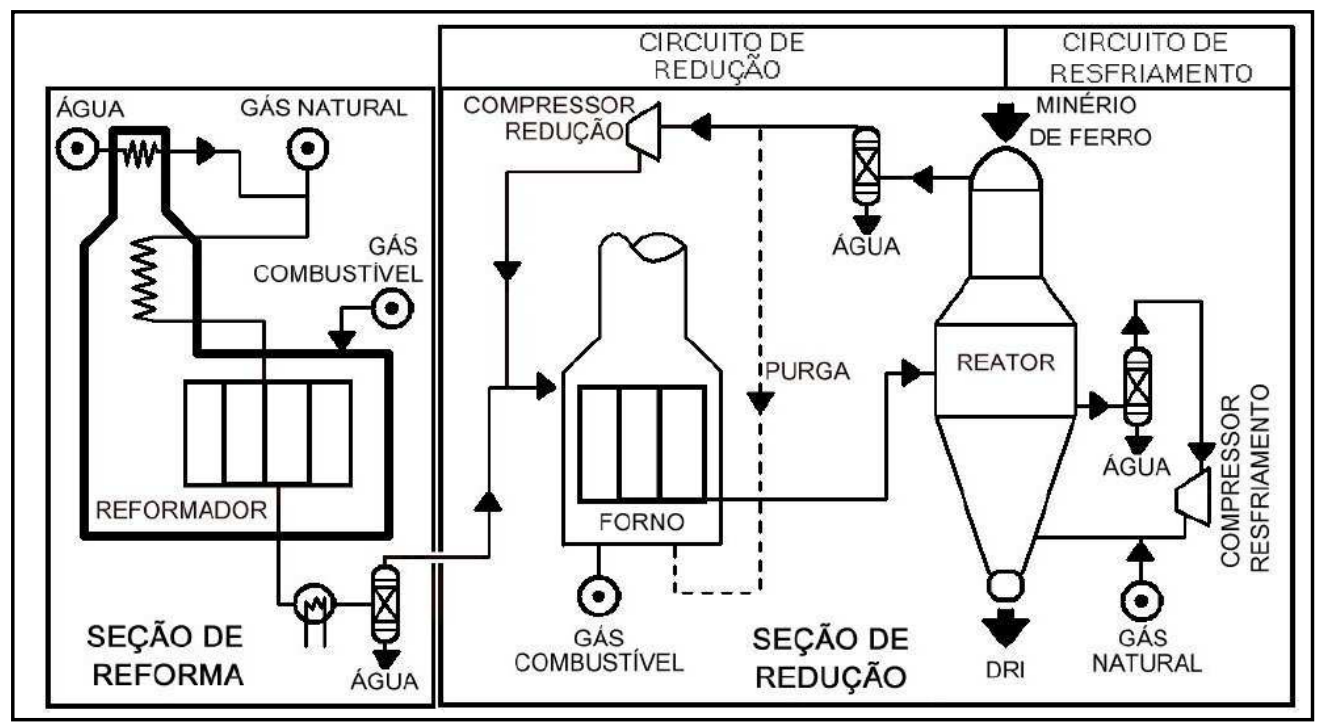

Figura 26 - Fluxograma esquemático do processo HyL III ${ }^{(112)}$.

\subsubsection{Processos em leitos fluidizados}

Os reatores em leito fluidizado podem ser utilizados em beneficiamentos de minérios finos sem uma aglomeração previa. São geralmente aplicados em temperaturas acima de $900^{\circ} \mathrm{C}$ e pressão de 10 bar. Utilizam como gás redutor misturas de $\mathrm{H}_{2}, \mathrm{H}_{2} \mathrm{O}, \mathrm{CO}, \mathrm{CO}_{2}, \mathrm{CH}_{4}{ }^{(118)}$

A produção de ferro-esponja por processos em leito fluidizado chegou a aproximadamente $8,9 \%$ entre os processos que utilizam gás como agente redutor. Os principais processos são FIOR e FINMET, onde a produção é de aproximadamente de $0,7 \%$ e $8,2 \%{ }^{(119)}$. Além destes processos, pode-se citar também o Circored, H-Iron e HIB ${ }^{(120)}$.

No processo FIOR, o minério é carregado no primeiro reator onde é aquecido a uma temperatura de aproximadamente $800^{\circ} \mathrm{C}$. Neste, o minério é pré-aquecido e ocorre uma redução de aproximadamente 10\%. Em seguida, o minério é encaminhado para os próximos reatores onde é realizada a etapa final de redução. Nesta etapa, a temperatura é de aproximadamente 700 a $750^{\circ} \mathrm{C}$. Neste processo pode-se obter um grau de metalização de aproximadamente $92 \%{ }^{(114)}$. Um esquema do processo FIOR é apresentado na Figura 27. 


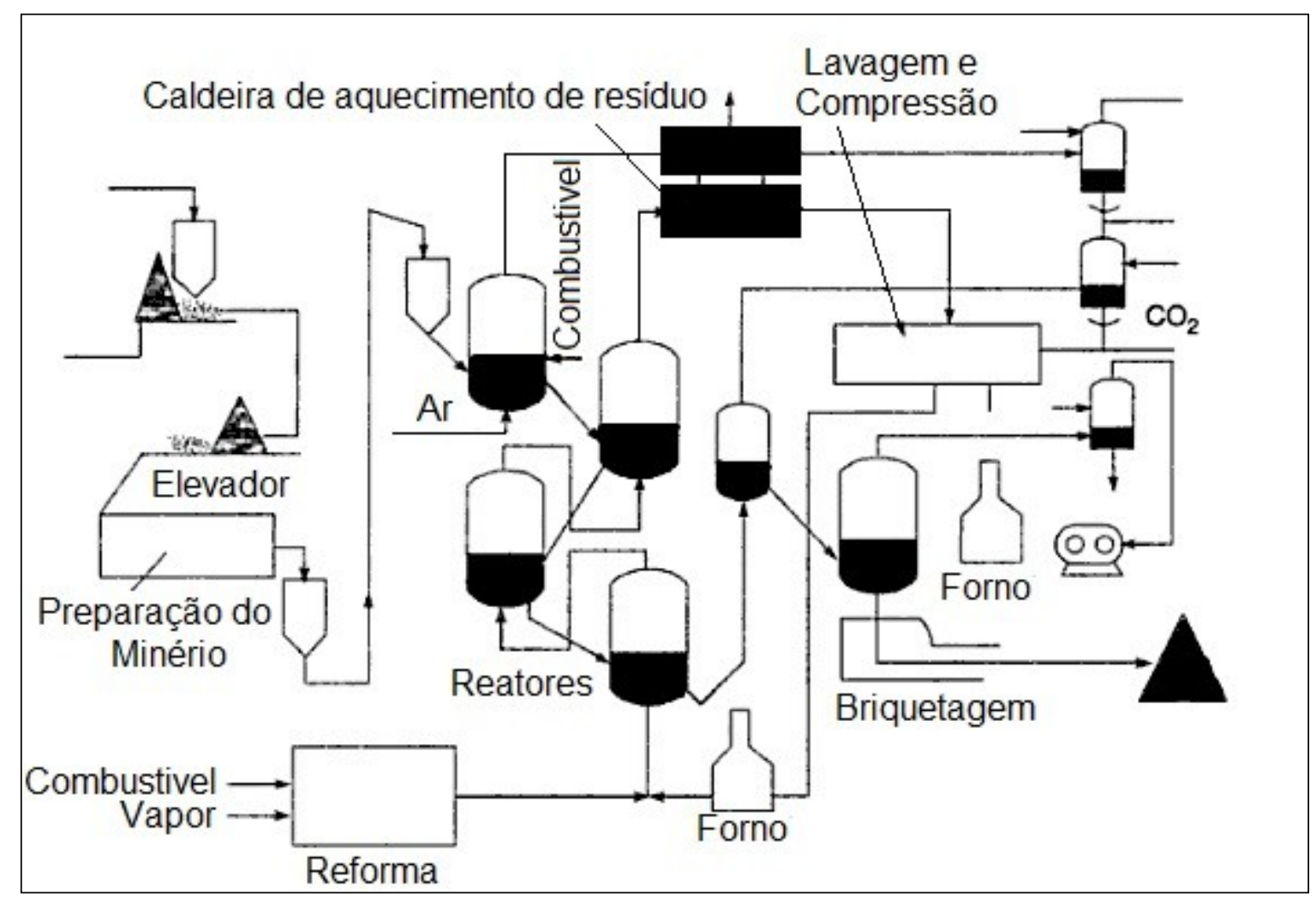

Figura 27 - Processo FIOR de redução direta de minério de ferro ${ }^{(121)}$.

O processo FINMET é derivado do processo FIOR. Este processo consiste de quatro reatores instalados em série. O minério apresenta um fluxo descendente dentro do reator, enquanto que o gás redutor apresenta um fluxo ascendente.

O minério de ferro é introduzido no primeiro reator onde é iniciado o processo de aquecimento do minério. Neste reator, a temperatura se encontra na faixa de 550 a $570^{\circ} \mathrm{C}$. O minério pré-aquecido é então transferido para os outros reatores onde acontece à redução. A temperatura de redução é de aproximadamente 780 a $800^{\circ} \mathrm{C}$ com uma pressão de $10 \mathrm{~atm}^{(114,122)}$.

Neste processo, é obtido um produto com aproximadamente $92-93 \%$ de ferro total com aproximadamente $84-85 \%$ de Fe metálico ${ }^{(123)}$. 


\section{OBJETIVOS}

Objetivo geral:

$\checkmark$ Estudar a cinética de redução de pelotas de poeiras de aciaria, com e sem a presença de ferrita de zinco, e de ferrita de zinco sintética, utilizando misturas contendo hidrogênio e outra simulando gás natural reformado através do método Forced Stepwise Isothermal Analysis.

Objetivos específicos:

$\checkmark$ Caracterização química e física da poeira de aciaria LD e elétrica;

$\checkmark$ Sintetizar Ferrita de zinco a partir de $\mathrm{ZnO}$ e $\mathrm{Fe}_{2} \mathrm{O}_{3}$ e realizar a sua caracterização;

$\checkmark$ Ensaios de redução das pelotas feitas com poeira de aciaria LD, elétrica e ferrita de zinco em termobalança utilizando mistura contendo hidrogênio e outra simulando gás natural reformado;

$\checkmark$ Determinação das etapas controladoras e cálculo das energias de ativação aparente dos processos de redução das três matérias primas utilizadas.

$\checkmark$ Obter produtos ricos em ferro metálico e livres de zinco a partir de resíduos siderúrgicos e ferrita de zinco sintética. 


\section{MATERIAIS E MÉTODOS}

Para a realização deste trabalho, foram utilizadas três diferentes matérias primas para a confecção das pelotas: poeira de aciaria LD, poeira de aciaria elétrica e ferrita de zinco sintética.

As seguintes etapas foram realizadas neste trabalho:

$\checkmark$ Preparação das poeiras de aciaria LD e elétrica.

$\checkmark$ Síntese de ferrita de zinco.

$\checkmark$ Caracterização das matérias primas.

$\checkmark$ Pelotização.

$\checkmark$ Determinação da porosidade das pelotas.

$\checkmark$ Análises termogravimétricas.

$\checkmark$ Cálculos cinéticos.

$\checkmark$ Caracterização dos produtos reagidos.

Onde cada etapa será explicada detalhadamente no decorrer deste capitulo.

\subsection{PREPARAÇÃO DAS POEIRAS DE ACIARIA LD E ELÉTRICA}

Foram obtidos aproximadamente $20 \mathrm{~kg}$ de cada poeira (poeira de aciaria LD e elétrica) para o desenvolvimento deste trabalho. Estas poeiras são procedentes de empresas siderúrgicas do estado do Espírito Santo.

Após a chegada das poeiras, foi feito o quarteamento de cada amostra. Foi utilizado o método de quarteamento por pilhas alongadas, que pode ser vista na Figura 28. 


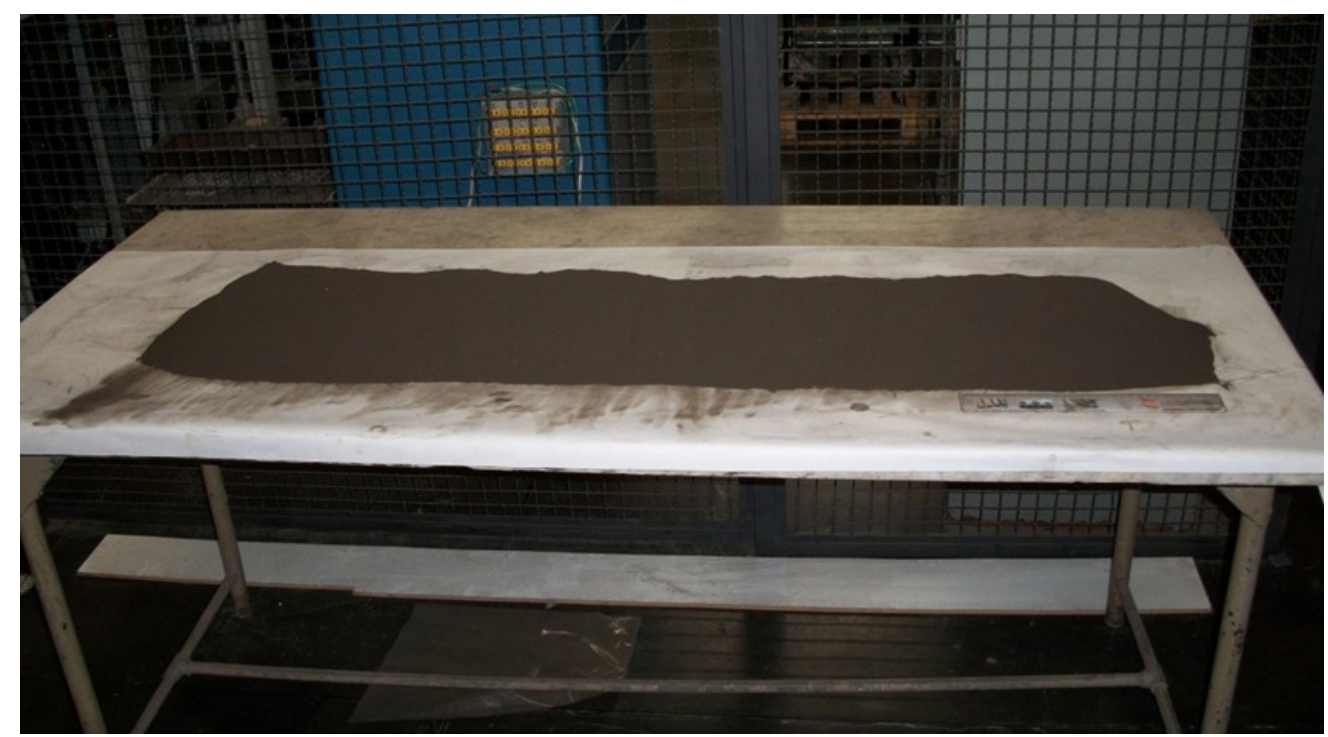

Figura 28 - Pilha alongada para realização do quarteamento das amostras.

A partir das pilhas, as amostras foram divididas em dois lotes. O primeiro foi utilizado para a realização dos ensaios de caracterização e produção das pelotas para os ensaios de redução. O segundo lote foi armazenado em um saco plástico para o caso de necessidade de repetir as análises.

Para a etapa de caracterização foram retiradas alíquotas de aproximadamente $20 \mathrm{~g}$ para cada análise. Para isso, a amostra foi novamente quarteada até a obtenção da massa de amostra necessária para a realização dos ensaios de caracterização. Foram realizadas análises químicas, microscopia eletrônica de varredura com EDS acoplado, difração de raios-X, análise granulométrica, análise térmica e densidade real por picnometria.

\subsection{SINTESE DE FERRITA DE ZINCO}

Para a síntese da ferrita de zinco, foi utilizado o método descrito por Marroquín, D’Abreu e Kohler (2006) ${ }^{(124)}$.

Foram utilizados $200 \mathrm{~g}$ de óxido de zinco e $400 \mathrm{~g}$ de hematita. Após a pesagem, foi feita a homogeneização dos reagentes. Os dois reagentes foram colocados em um saco plástico de amostras e foi feita a homogeneização 
manualmente. Em seguida, o material foi encaminhado ao forno mufla (Figura 29).

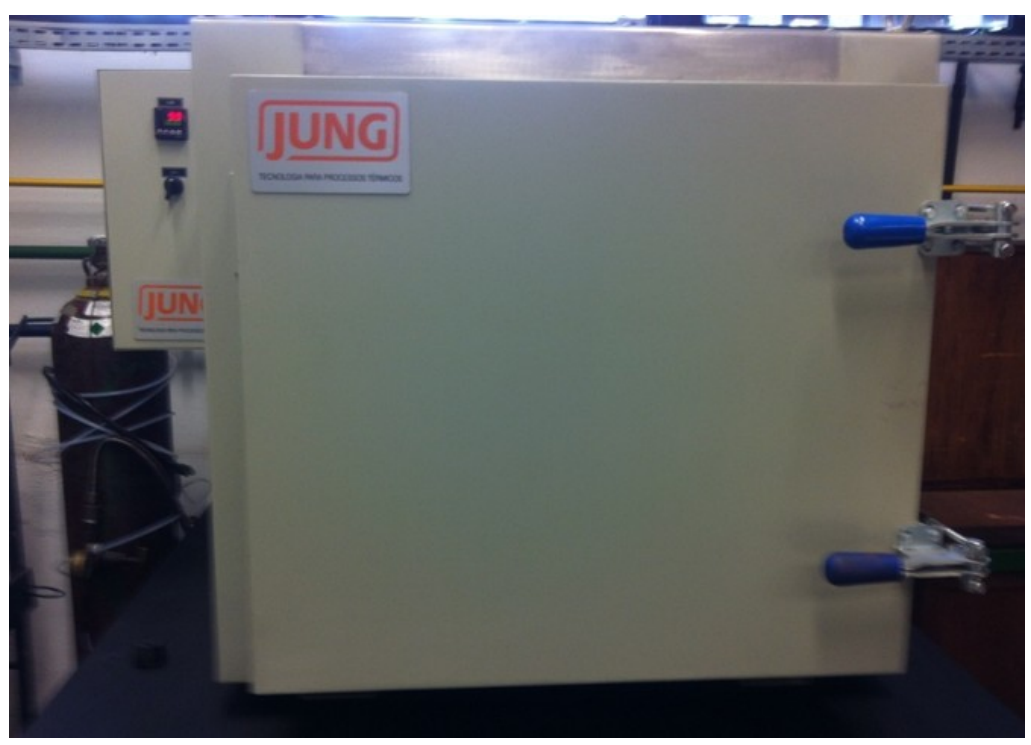

Figura 29 - Forno mufla utilizada na síntese da Ferrita de zinco.

Para a síntese da ferrita de zinco, partiu-se da temperatura ambiente (aproximadamente $25^{\circ} \mathrm{C}$ ) até $1000^{\circ} \mathrm{C}$ a uma taxa de aquecimento de $15^{\circ} \mathrm{C} /$ minuto. Ao atingir a temperatura final, esta foi mantida por um período de 4 horas. Ao término deste tempo, o forno foi desligado e esperou-se chegar à temperatura ambiente (aproximadamente $25^{\circ} \mathrm{C}$ ). Não foi utilizado nenhum gás específico na atmosfera do forno, ou seja, foi utilizado o ar da atmosfera ambiente tanto no aquecimento quanto no resfriamento.

Após o resfriamento, a ferrita de zinco sintetizada foi submetida a análises de microscopia eletrônica de varredura com EDS, análise granulométrica, difração de raios- $X$ e densidade real por picnometria. 


\subsection{CARACTERIZAÇÃO DAS MATERIAS PRIMAS}

\subsubsection{Análise química}

\subsubsection{Absorção atômica}

A análise química foi realizada utilizando a técnica de absorção atômica. A análise foi realizada no laboratório do LACOR (Laboratório de Corrosão, Proteção e Reciclagem de Materiais) da Universidade Federal do Rio Grande do Sul.

Para a realização da análise, foi necessário realizar a abertura (digestão) da amostra. Esta etapa foi feita utilizando água régia (mistura de ácido nítrico e ácido clorídrico concentrados, na proporção de 1 para 3, respectivamente).

O procedimento iniciou-se com a pesagem de $10 \mathrm{~g}$ da amostra. Esta foi transferida para um béquer de $500 \mathrm{~mL}$. Em seguida, foi adicionado $150 \mathrm{~mL}$ de água régia. Deixou-se a amostra em repouso para a realização da digestão por um período de 24 horas.

Após o término da digestão, foi realizada a filtragem da solução. Em seguida, foi feita a diluição das amostras utilizando água destilada. A diluição é necessária, pois o equipamento de absorção atômica trabalha com valores específicos de concentração para cada elemento. Feita a diluição, as amostras foram enviadas ao equipamento de absorção atômica para leitura do valor de concentração.

\subsubsection{Ferro Metálico}

O procedimento utilizado neste trabalho para a determinação do ferro metálico é descrito no trabalho de Junca $(2009)^{(125)}$. O procedimento foi 
realizado em triplicata e o resultado adotado no trabalho é a média das três análises.

Neste procedimento, os seguintes reagentes foram utilizados:

$\checkmark$ Solução de sulfato de cobre $\left(\mathrm{CuSO}_{4}\right)$ a $10 \%$.

$\checkmark$ Solução de acido sulfúrico $\left(\mathrm{H}_{2} \mathrm{SO}_{4}\right)$ com água destilada na proporção de 1:1.

$\checkmark$ Alumínio metálico.

$\checkmark$ Solução de permanganato de potássio $\left(\mathrm{KMnO}_{4}\right)$ a $0,25 \mathrm{~mol} / \mathrm{L}$.

Inicialmente, alíquotas de $1 \mathrm{~g}$ foram obtidas das amostras de poeira de aciaria LD e elétrica. Estas amostras foram transferidas para um béquer de $400 \mathrm{~mL}$ e adicionou-se aproximadamente $200 \mathrm{~mL}$ de água na temperatura de aproximadamente $70^{\circ} \mathrm{C}$. Em seguida, adicionou-se $30 \mathrm{~mL}$ da solução de sulfato de cobre no béquer contendo água e amostra. $\mathrm{O}$ conjunto foi mantido em aquecido na temperatura de $100^{\circ} \mathrm{C}$ até a redução do volume para $70 \mathrm{~mL}$. Em seguida, foi feita a filtragem utilizando filtro de faixa preta.

Na solução filtrada, foi adicionado $10 \mathrm{~mL}$ de solução de ácido sulfúrico e alumínio metálico. A solução foi novamente aquecida a uma temperatura de aproximadamente $100^{\circ} \mathrm{C}$ e esperou-se que a coloração azul proveniente do sulfato de cobre fosse eliminada. Após isto, foi feita uma nova filtragem, utilizando filtro de faixa preta e esperou-se a solução chegar à temperatura ambiente.

A última etapa foi a titulação da solução com permanganato do potássio. A titulação foi interrompida quando a solução em analise apresentou uma coloração rosa pálida.

Para se chegar ao valor de ferro metálico, utilizou-se a Equação 35

$\% F e=\frac{V 1 \times 0,25 \times \text { Fator } \times 5,584}{p . a}$

onde:

$\%$ Fe: porcentagem em massa de Fe metálico presente na amostra;

$V 1$ : volume gasto $(\mathrm{mL})$ de permanganato de potássio $0,25 \mathrm{~mol} / \mathrm{L}$; 
0,25: concentração da solução de $\mathrm{KMnO}_{4} 0,25 \mathrm{~mol} / \mathrm{L}$;

Fator: fator de correção do $\mathrm{KMnO}_{4}$ 0,25 mol/L;

5,584: miliequivalente grama do ferro $\times 100$;

p.a.: peso da amostra.

\subsubsection{Difração de Raios-X}

Com o objetivo de caracterizar as fases presentes nas amostras, foi realizada a difração de Raios-X. Como as amostras se encontravam na forma de pó, não foi preciso cominuir as mesmas. As amostras foram colocadas por 24 horas numa estufa, $60^{\circ} \mathrm{C}$, para a secagem antes das análises.

O equipamento utilizado foi um Rigaku, modelo Miniflex 300, com radiação cobre $\mathrm{Ka}(\lambda=1,5418 \AA \AA)$, potência de $30 \mathrm{kV}$ e $8 \mathrm{~mA}$. As análises foram realizadas entre 10 a $100^{\circ}$, com passos de $0,02^{\circ}$ e tempo de passo de 5 segundos.

\subsubsection{Microscópio eletrônico de varredura}

O Microscópio Eletrônico de Varredura utilizado foi da marca Philips, modelo XL-30, que possui uma microssonda EDAX para análise espectrométrica de raios-X e também câmera EBSD (Electron Backscattered Diffraction) para difração de elétrons retro-espalhados.

Tanto para a caracterização das poeiras de aciaria LD e elétrica como para a ferrita de zinco sintética, as amostras, em forma de pó, foram colocadas numa fita dupla faces em porta amostra e recobertas com ouro. 


\subsubsection{Análise granulométrica}

A análise granulométrica foi feita utilizando o equipamento Mastersizer 2000. O equipamento Mastersizer 2000 utiliza a difração de raio laser para definir a distribuição do tamanho das partículas do material. $O$ equipamento possui um sistema de detectores com luz vermelha, que detecta 0 espalhamento frontal, lateral e posterior. A fonte de luz vermelha é o laser néon de hélio, cujo comprimento de onda define a faixa de tamanho de partícula que o aparelho mede. No caso do equipamento utilizado na pesquisa, a faixa de

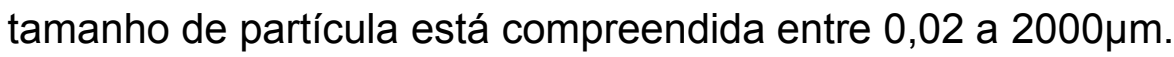

Foi utilizada água destilada como meio dispersante e o ultrassom foi acionado por um período de 5 minutos. A quantidade de amostra utilizada nesta técnica vária de amostra para amostra. O parâmetro que foi adotado igualmente para todas as análises foi o grau de obscuridade ou índice de obscuração. Este índice indica a concentração de partículas no meio dispersivo. Para este trabalho, adotou-se a faixa padrão de obscuridade que é entre 10 a $20 \%$.

A análise granulométrica foi realizada nas três matérias primas deste trabalho (poeira de aciaria LD, elétrica e ferrita de zinco sintética). A curva utilizada como resultado para cada material foi à média obtida de três leituras.

\subsubsection{Análise de densidade por picnometria}

A densidade real representa a massa da amostra por unidade de volume real, incluindo o volume interno de poros. As análises de densidades reais das poeiras de aciaria $L D$, elétrica e da ferrita de zinco sintética foram determinadas utilizando-se um picnômetro. As etapas que consiste este procedimento foram:

$\checkmark \quad$ Pesou-se a massa do picnômetro vazio com tampa;

$\checkmark \quad$ Adicionou-se água destilada ao picnômetro, tomando o cuidado para evitar a formação de bolhas de ar; 
$\checkmark \quad$ Tampou-se o picnômetro para remoção do excesso de água (foi feita a secagem da parede externa do picnômetro);

$\checkmark \quad$ Pesagem do conjunto completo (picnômetro, tampa e água);

$\checkmark \quad$ Pesagem da massa da amostra utilizada para a análise (foram utilizadas massas entre 0,15 a 0,16g de amostra);

$\checkmark \quad$ Transfere-se a amostra para o picnômetro;

Tampa-se o picnômetro e seca-se a parede externa do mesmo;

Pesagem de todo o conjunto (água, picnômetro, amostra e tampa).

Para o cálculo da densidade real foi utilizada a Equação 36.

$\rho=\frac{m}{m^{\prime}}$

Equação 36

Onde:

$\rho$ é a densidade $\left(\mathrm{g} / \mathrm{cm}^{3}\right)$;

$m$ massa da amostra que pretende determinar a densidade;

$m^{\prime}$ é a massa da água deslocada pelo sólido $\left(m^{\prime}=M 1-M 2\right)$;

M1 é a massa do conjunto picnômetro + água e massa da amostra;

M2 é a massa do conjunto picnômetro + água + amostra.

As análises foram feitas em triplicata e os valores utilizados foram a média dos resultados.

\subsubsection{Caracterização térmica}

A caracterização térmica foi realizada nas amostras de poeira de aciaria elétrica e LD. Nesta análise, foi utilizado a termobalança Netzsch. Foi utilizado um fluxo de gás inerte (nitrogênio) de $40 \mathrm{~mL} /$ minuto durante o ensaio. A temperatura inicial foi de $30^{\circ} \mathrm{C}$ e a final de $1100^{\circ} \mathrm{C}$. Uma taxa de aquecimento de $10^{\circ} \mathrm{C} /$ minuto foi utilizada. Para a poeira de aciaria LD, um espectrômetro de massas, modelo QMS 403C, foi utilizado no decorrer do ensaio. Para as 
análises com poeira de aciaria elétrica não foi utilizado espectrômetro de massas devido à volatilização do zinco presente na amostra. A volatilização do zinco pode causar o entupimento do capilar do espectrômetro de massas, consequentemente, inviabilizando a análise.

A caracterização térmica teve o objetivo de identificar os gases eliminados durante a análise, auxiliando assim, na escolha de temperatura para realização da secagem das pelotas.

\subsection{PELOTIZAÇÃO}

Para a confecção das pelotas, foi utilizada uma betoneira com um disco pelotizador adaptado em sua extremidade.

O processo iniciou-se com a adição manual de poeira no disco pelotizador. A água também foi adicionada manualmente com auxilio de um borrifador.

Os aglomerados eram retirados do disco com auxilio de uma pá. As pelotas formadas apresentaram um diâmetro de aproximadamente $13 \mathrm{~mm}$. Em seguida, as pelotas foram acomodadas numa bandeja e encaminhas a um forno tipo mufla para a etapa de secagem.

A secagem ocorreu em duas etapas. Na primeira, partiu-se da temperatura ambiente $\left(25^{\circ} \mathrm{C}\right)$ até $200^{\circ} \mathrm{C}$ com uma taxa de aquecimento de $10^{\circ} \mathrm{C} /$ minuto. Esta temperatura foi mantida por um período de 12 horas. $\mathrm{Na}$ segunda etapa, a temperatura do forno foi elevada de $200^{\circ} \mathrm{C}$ para $700^{\circ} \mathrm{C}$ (taxa de aquecimento de $10^{\circ} \mathrm{C} /$ minuto). Esta temperatura foi mantida por 24 horas.

Ao final do ciclo, esperou-se o forno mufla atingir a temperatura ambiente (aproximadamente $25^{\circ} \mathrm{C}$ ) para retirada das pelotas, em seguida armazenando-as em sacos plásticos.

A utilização das pelotas aqui fabricadas destina-se a utilização em processos de redução direta. Nestes processos, a temperatura de redução é entre 700 a $900^{\circ} \mathrm{C}$. Desta forma, optou-se por não sinterizar as pelotas, e realizar a secagem até a temperatura de $700^{\circ} \mathrm{C}$. 


\subsection{DETERMINAÇÃO DA POROSIDADE DAS PELOTAS}

A determinação da porosidade das pelotas foi efetuada pela diferença entre a densidade volumétrica e a sua densidade real. Ambas as medições foram realizadas utilizando um picnômetro.

A análise de densidade real do pó foi descrito anteriormente. Para o caso da densidade volumétrica da pelota, o procedimento foi o mesmo realizado para densidade real, porém, ao invés de usar o pó, foi utilizado uma pelota. A razão entre a densidade volumétrica e a densidade real é a porosidade da pelota, que pode ser observada na Equação 37.

$\varepsilon=\left[1-\left(\frac{\rho_{V}}{\rho_{R}}\right)\right] x 100$

Onde:

$\varepsilon$ é a porosidade da pelota;

$\rho_{V}$ é a densidade volumétrica da pelota;

$\rho_{R}$ é a densidade real do material que constitui a pelota.

Os ensaios de picnometria foram repetidos três vezes e a média obtida nestas análises foi o valor utilizado.

\subsection{ANÁLISES TERMOGRAVIMÉTRICAS}

Os ensaios de análises termogravimétricas foram realizados numa termobalança Setaram. Neste equipamento, a pelota é pendurada na balança, com auxilio de um arame, onde que na extremidade deste arame, foi acoplada uma cesta, onde a pelota era alocada. A vantagem deste método é que a reação pode ocorrer em toda a pelota homogeneamente, em outras palavras, 0 
gás redutor tem acesso a todas as partes da pelota. $O$ aparato instrumental para realização das análises termogravimétricas é mostrado na Figura 30.

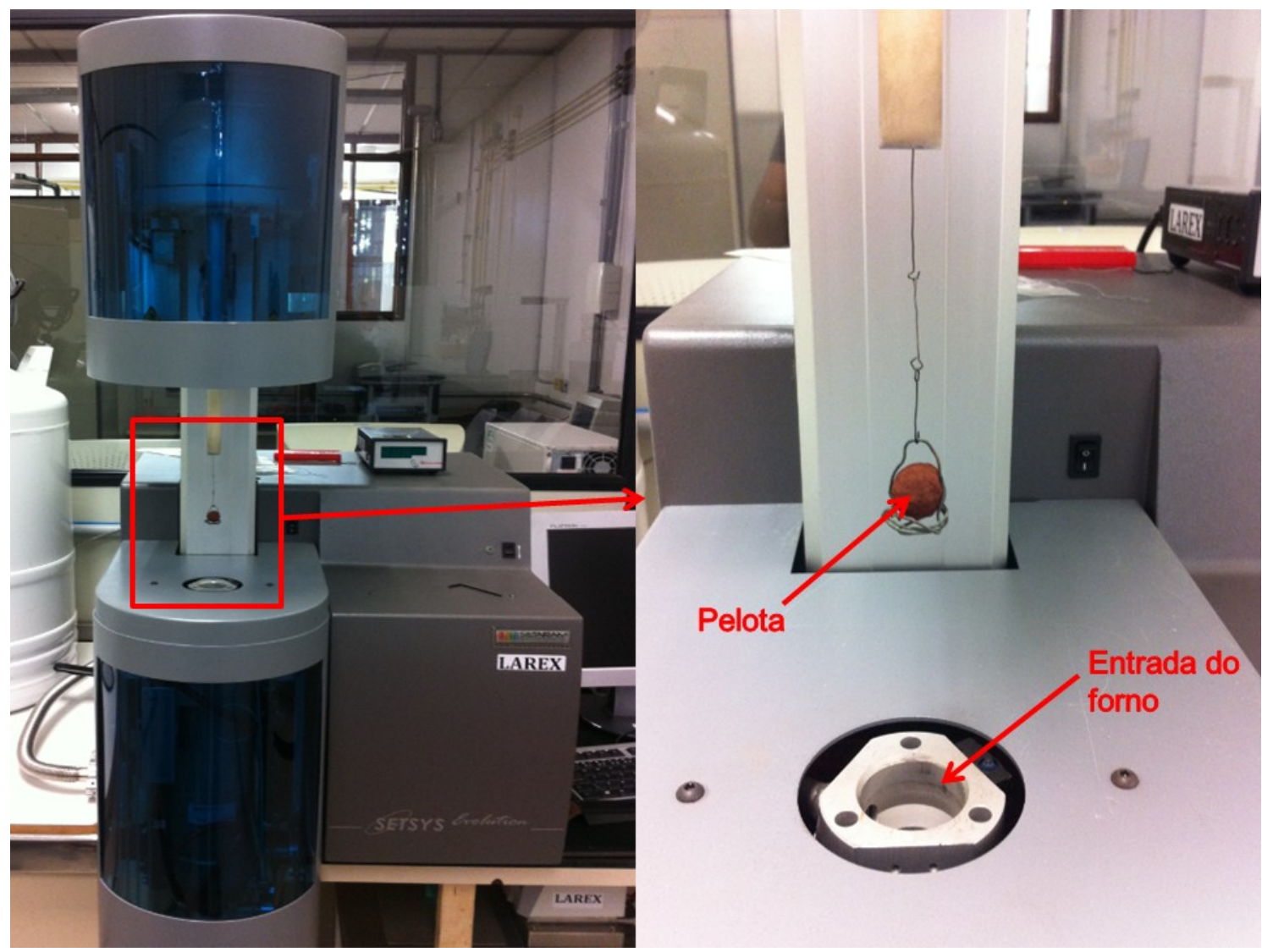

Figura 30 - Termobalança utilizada nos ensaios de redução.

Foram realizados estudos de redução utilizando duas composições diferentes de gases redutores. O primeiro gás estudado foi uma mistura gasosa contendo $10 \%$ de hidrogênio $\left(\mathrm{H}_{2}\right)$ e $90 \%$ de argônio $(\mathrm{Ar})$, nomeada mistura redutora. $\mathrm{Na}$ segunda composição, acrescentou-se $\mathrm{CO}$, respeitando a proporção de $75 \%$ de $\mathrm{H}_{2}$ e $25 \%$ de $\mathrm{CO}$, com o objetivo de simular gás natural reformado. Esta última mistura foi nomeada gás natural simulado.

No caso deste trabalho, optou-se pela proporção $75 \%$ de $\mathrm{H}_{2}$ e $25 \%$ de $\mathrm{CO}$, pois é a proporção gerada pela reforma do gás natural $\left(\mathrm{CH}_{4}\right)$ com vapor de água $\left(\mathrm{H}_{2} \mathrm{O}\right)$, que pode ser observada pela Equação $38^{(126)}$ :

$$
\mathrm{CH}_{4}+\mathrm{H}_{2} \mathrm{O}=3 \mathrm{H}_{2}+1 \mathrm{CO}
$$


As análises foram realizadas utilizando uma variação do método descrito por Sorensen ${ }^{(127)}$, no qual várias isotermas são programadas durante a realização das análises, tal método é conhecido por Forced stepwise isothermal analysis (FSIA). Neste método, o tempo em cada isotérmica é predefinido pelo operador e não definido pela diminuição da taxa de redução, como é o método tradicional.

Para facilitar o entendimento da programação térmica realizada neste trabalho, é apresentado na Figura 31, um exemplo da programação térmica realizada.

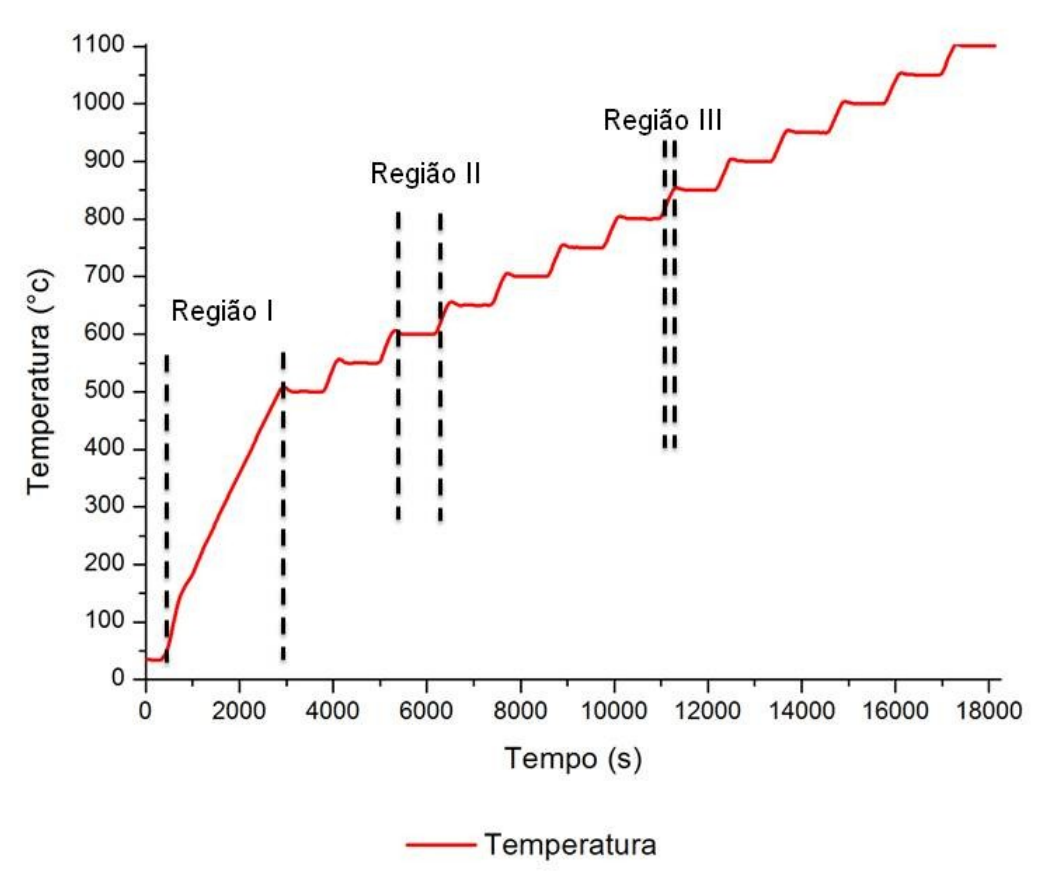

Figura 31 - Programação de temperatura utilizada na realização das análises termogravimétricas.

Na região I, é a região onde é feito o aquecimento para se obter a temperatura de inicio das isotérmicas, neste caso, $500^{\circ} \mathrm{C}$. Nesta região, foi adotada uma taxa de aquecimento de $10^{\circ} \mathrm{C} /$ minuto. $\mathrm{O}$ gás redutor já é liberado desde o inicio desta região, em outras palavras, o gás redutor é liberado desde o inicio da análise, de $30^{\circ} \mathrm{C}$ até $500^{\circ} \mathrm{C}$.

$\mathrm{Na}$ região II, são descritas as isotermas. Estas têm duração de 15 minutos cada e foram realizadas a cada $50^{\circ} \mathrm{C}$ até se atingir a temperatura final 
de análise $\left(1100^{\circ} \mathrm{C}\right)$. Deste modo, isotermas foram realizadas em 500,550 , $600,650,700,750,800,850,900,950,1000,1050$ e $1100^{\circ} \mathrm{C}$.

A região III é a região de aquecimento entre uma isoterma a outra. Nesta região foi utilizada uma taxa de aquecimento de $10^{\circ} \mathrm{C}$ /minuto com o gás redutor passando pelo sistema.

Para cada amostra, foram realizadas quatro análises variando a vazão de gás redutor. Foram utilizadas as vazões de 50, 100, 150 e 200mL/minuto.

Ao fim dos ensaios, as amostras foram identificadas, colocadas dentro de um saco plástico e encaminhadas para um dessecador, onde foram deixadas no vácuo até 0 momento da realização das análises de caracterização.

\subsection{CÁLCULOS CINÉTICO}

Os cálculos cinéticos foram realizados com os dados obtidos com os melhores resultados obtidos nos ensaios de perda de massa, ou seja, onde a perda de massa foi completada mais rapidamente.

Foi adotada esta metodologia na escolha das curvas de perda de massa pois são as curvas que apresentaram maior taxa de reação. No caso deste trabalho, as curvas analisadas para a realização dos cálculos cinéticos foram as obtidas utilizando o fluxo de $200 \mathrm{~mL} /$ minuto, tanto de mistura gasosa quanto de gás natural simulado.

A partir destes dados, foi possível calcular a fração reagida $(\alpha)$ com auxilio da Equação $39^{(128,129,130)}$.

$\propto=\frac{m_{0}-m_{T}}{m_{0}-m_{f}}$

Equação 39

onde:

$\alpha$ é a fração reagida;

$\mathrm{m}_{0}$ é a massa inicial da amostra; 
$\mathrm{m}_{\mathrm{T}}$ é a massa da amostra na temperatura $\mathrm{T}$;

$m_{f}$ é a massa final da amostra.

Tendo em mãos os valores da fração reagida, foram levantadas as curvas $\frac{d(\alpha)}{d t} x f(\alpha)$ e $g(\alpha) x t$ para as funções citadas pela literatura (Tabela 4 ), em seguida, comparou-se os valores dos fatores de correlação de cada equação. Neste trabalho, a análise dos fatores de correlação das funções $g(\alpha) x t$ somente foi utilizada para auxilio na escolha de possíveis funções controladoras.

Os cálculos realizados para se chegar à energia de ativação aparente foram:

Reescrevendo a Equação 7 citada anteriormente:

$\frac{d \alpha}{d t}=k \cdot f(\alpha)$

Equação 7

Aplicando logaritmo natural na Equação 7, tem-se a Equação 40:

$\ln \frac{d \propto}{d t}=\ln k+\ln f(\propto)$

Equação 40

A próxima etapa foi levantar as retas para a relação $\ln d(\propto) / d t x \ln f(\propto)$ para todas as funções citadas pela literatura (Tabela 4). O coeficiente linear obtidos destas retas é o valor de lnk da Equação 40, onde o valor de $k$ obedece à lei de Arrhenius. Reescrevendo a Equação 10 para a lei de Arrhenius, tem-se:

$k=A \cdot \exp \left(-\frac{E_{a}}{R T}\right)$

Equação 10

Aplicando-se logaritmo natural na Equação 10, tem-se a Equação 41: 
$\ln k=\ln A-\frac{E_{a}}{R} \frac{1}{T}$

Equação 41

Deste modo, levantando-se a reta para a relação $\operatorname{lnk}$, obtida pela Equação 40, e o inverso da temperatura (em Kelvin) de cada patamar, chega-se a relação $-\frac{E_{a}}{R}$ através do coeficiente angular da reta obtida.

Deste modo, o modelamento cinético foi elaborado adotando os seguintes critérios:

a) Análise do fator de correlação $\left(\mathrm{R}^{2}\right)$ das funções $d(\propto) / d t x f(\propto)$ e $g(\propto) x t$ em cada patamar para cada função sugerida na literatura.

b) Construção das curvas de Arrhenius para as funções escolhidas.

c) Cálculo da energia de ativação aparente através das curvas de Arrhenius.

d) Comparação dos valores de energia de ativação aparente encontradas para as funções escolhidas.

e) Comparação dos modelos e valores de energia de ativação aparente obtido neste trabalho com os obtidos na literatura.

Alguns critérios foram adotados para ajudar na interpretação dos resultados. Quando duas ou mais funções apresentarem o mesmo fator de correlação, a energia de ativação aparente que comandará o processo será a de maior valor. Além disso, valores de energia de ativação aparente menores do que $13 \mathrm{~kJ} / \mathrm{mol}$ e maiores do que $250 \mathrm{~kJ} / \mathrm{mol}$ não foram aceitos.

Além dos critérios adotados na determinação dos parâmetros cinéticos, é importante destacar os critérios utilizados para a interpretação dos dados de termogravimetria, uma vez que utilizando diferentes abordagens na exportação dos dados, diferentes resultados são obtidos. Deste modo, os seguintes critérios foram empregados: Sempre o primeiro e último patamar em cada análise termogravimétrica foi descartado. Nos primeiros patamares das análises de redução foi observado que a reação ainda não havia iniciado. No caso dos últimos patamares, foi observado que as reações de redução se encerravam durante o patamar, portando, não sendo possível realizar os cálculos cinéticos com os dados de perda de massa obtidos. 
Além disso, foi observado que no inicio de cada isoterma, ocorria um extrapolação da temperatura, ou seja, as temperaturas ultrapassavam o valor de temperatura predeterminado para o patamar. Assim, os dados utilizados na investigação cinética foram aqueles obtidos após a estabilização da temperatura em cada patamar. Ademais, o último ponto em cada isoterma também foi descartado.

\subsection{CARACTERIZAÇÃO DOS PRODUTOS REAGIDOS}

Com o intuito de tentar encontrar uma correlação das mudanças de mecanismos controladores durante o processo de redução, foram feitas análises de caracterização das estruturas obtidas durante e no fim do processo de redução de algumas análises.

A caracterização dos produtos após a redução foi feito por microscopia eletrônica de varredura acoplado com EDS e difração de raios-X. Assim, foi necessário a realização de ensaios de duplicata para obtenção de duas amostras para realizar a caracterização.

Para realizar a análise no microscópio eletrônico de varredura, as pelotas foram embutidas com resina de cura a frio. Após a cura, foi realizado o lixamento das mesmas até se chegar à secção central da pelota, utilizando para isso, lixas de número 180, 220, 320, 420, 600 e 1200.

Com auxilio do microscópio eletrônico de varredura é possível caracterizar as microestruturas formadas durante a reação de redução, uma vez que a microestrutura formada influencia diretamente na redução.

Para realização das difrações de raios- $X$, as pelotas foram desagregadas com auxilio de um almofariz. Em seguida, foram colocadas no suporte do equipamento e encaminhadas para as análises de difração de Raios-X. Os parâmetros utilizados foram os mesmos descritos no item 4.3.2.

Em adição, também foi realizada a quantificação das fases obtidas nas difrações de raios-X pelo método Rietveld. 


\section{RESULTADOS E DISCUSSÃO}

\subsection{CARACTERIZAÇÃO DAS MATÉRIAS PRIMAS}

Antes de se iniciar os estudos cinéticos, é importante conhecer o material no qual se irá trabalhar. Desta forma, inicialmente foram realizadas as caracterizações das três materiais primas utilizadas neste trabalho: poeira de aciaria LD, poeira de aciaria elétrica e a ferrita de zinco sintética.

\subsubsection{Poeira de aciaria LD}

5.1.1.1 Análise química

Na Tabela 6 é apresentado o resultado da análise química da poeira de aciaria LD.

Tabela 6 - Análise química da poeira de aciaria LD.

\begin{tabular}{c|c}
\hline Componentes & \% em massa \\
\hline Fe total & 46,9 \\
\hline $\mathrm{Fe}^{\circ}$ & 8,4 \\
\hline $\mathrm{Ca}$ & 23,2 \\
\hline $\mathrm{Mn}$ & 3,4 \\
\hline $\mathrm{Mg}$ & 2,1 \\
\hline $\mathrm{Si}$ & 2,0 \\
\hline $\mathrm{Zn}$ & 1,9 \\
\hline $\mathrm{Pb}$ & 0,1
\end{tabular}

Pode ser observado na Tabela 6 que o ferro é o principal elemento encontrado na poeira de aciaria LD com 46,9\%. Foi determinado que o teor de Fe metálico presente na poeira de aciaria LD é de $8,4 \%$. Também pode ser 
observado a presença de Ca (23,2\%). De acordo com Mendes $(2009)^{(13)}$, o Ca é decorrente da calcita introduzida no conversor LD ${ }^{(1)}$.

Outros elementos também foram encontrados em menor proporção, em relação ao ferro e ao cálcio, como por exemplo, Mn, Mg, Zn, Si e Pb. O Si é procedente da escória e o Mg é proveniente da escoria ou de desgaste dos refratários.

\subsubsection{Difração de Raios-X}

A Figura 32 mostra a difração de raios-X obtida da poeira de aciaria LD.

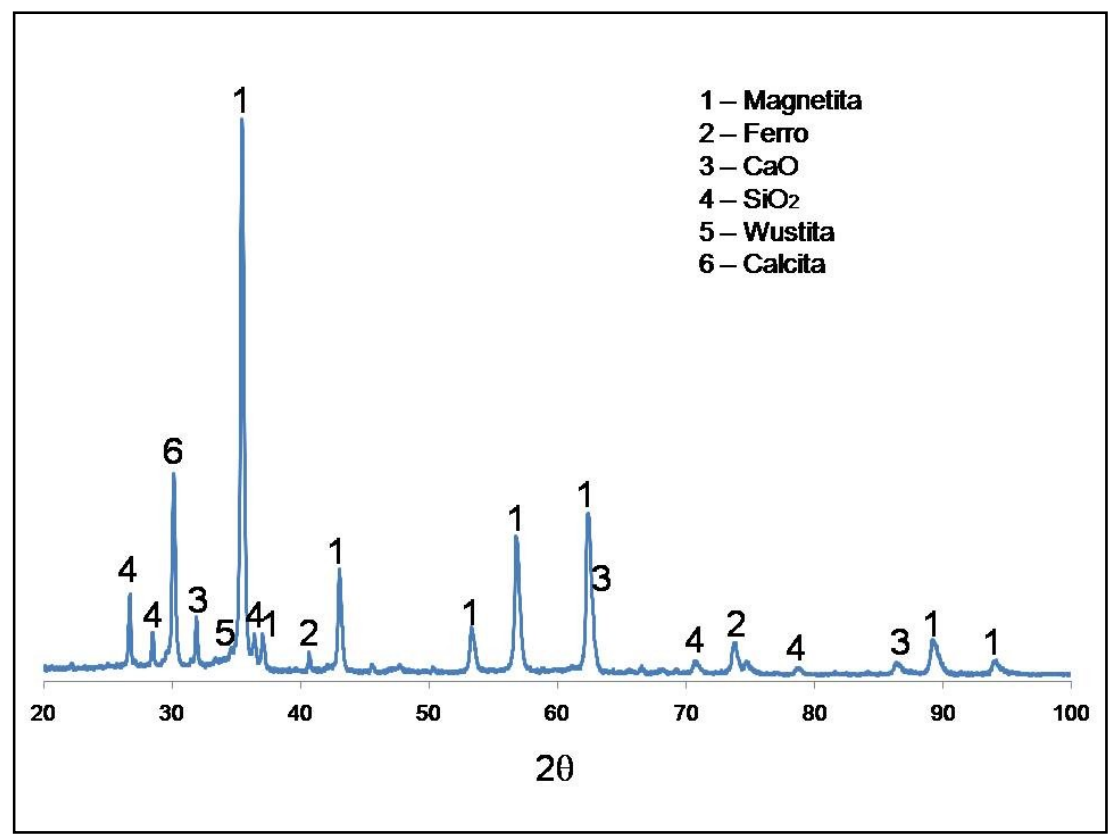

Figura 32 - Difratograma obtido da poeira de aciaria LD.

Pode ser visto que o ferro está presente na forma de wustita, magnetita e ferro metálico. Também foram encontrados picos de quartzo e calcita. De acordo com Yi et al. (2009) ${ }^{(131)}$, o $\mathrm{FeO}$ ou $\mathrm{Fe}_{2} \mathrm{O}_{3}$ são as principais fases em que o ferro pode aparecer. Já para Andrade et al. (2006) ${ }^{(4)}$ diz que o ferro está presente principalmente como wustita e magnetita, mas também na forma de ferro metálico. 
Pode-se observar também que, o cálcio presente na poeira está na forma de calcita, que está de acordo com os resultados descritos por Andrade et al. (2006) ${ }^{(4)}$, Sammut et al. (2008) ${ }^{(132)}$ e Trung et al. (2001) ${ }^{(133)}$, que também sugere que o cálcio presente na poeira está na forma de calcita.

Em adição, foi realizada a quantificação das fases utilizando o método Rietveld na poeira de aciaria LD. A quantificação das fases pode ser vista na Tabela 7.

Tabela 7 - Quantificação das fases presentes na poeira de aciaria LD pelo método Rietveld.

\begin{tabular}{c|c}
\hline Fases & $\%$ \\
\hline Magnetita & 62,6 \\
\hline Ferro & 7,4 \\
\hline $\mathrm{CaO}$ & 9,1 \\
\hline $\mathrm{Calcita}$ & 13,9 \\
\hline $\mathrm{SiO}_{2}$ & 2,3 \\
\hline Wustita & 4,6 \\
\hline
\end{tabular}

A quantificação das fases mostrou que a principal fase que contem ferro é a magnetita com $62,6 \%$. Além disso, apresentou um teor de calcita de 13,9\%.

5.1.1.3 Microscópio eletrônico de varredura

Foi obtida imagem com microscópio eletrônico de varredura e espectro de EDS da amostra de poeira de aciaria LD. A Figura 33 apresenta a imagem obtida pelo microscópio e a Figura 34 o espectro de EDS. 


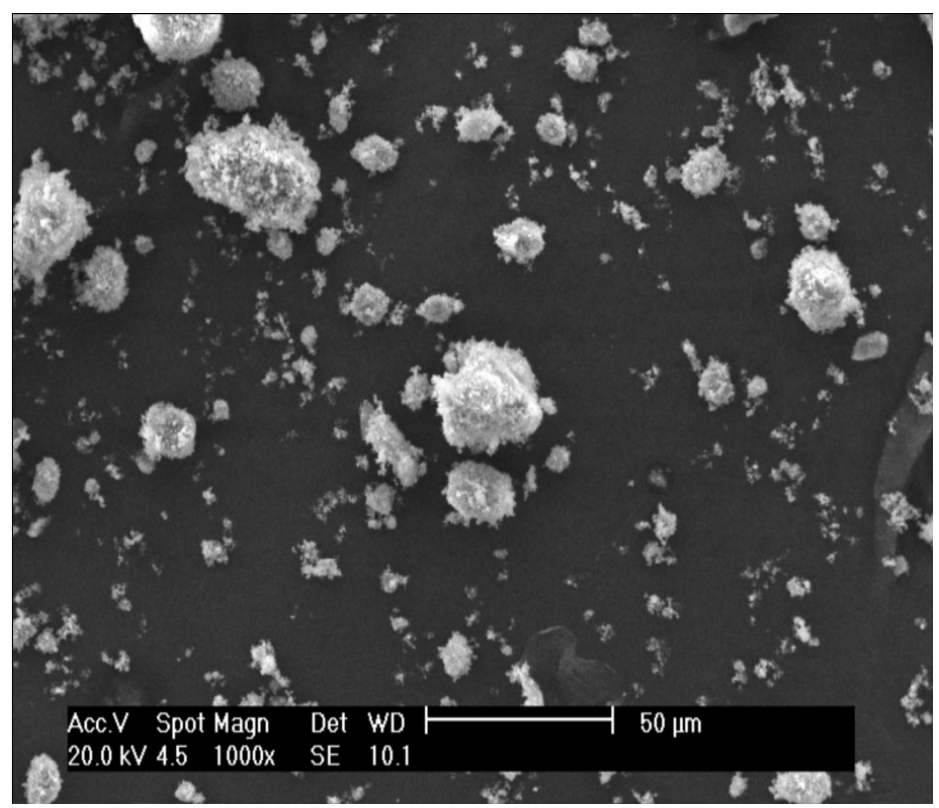

Figura 33 - Imagem de elétrons secundários obtida por microscópio eletrônico de varredura da poeira de aciaria LD.

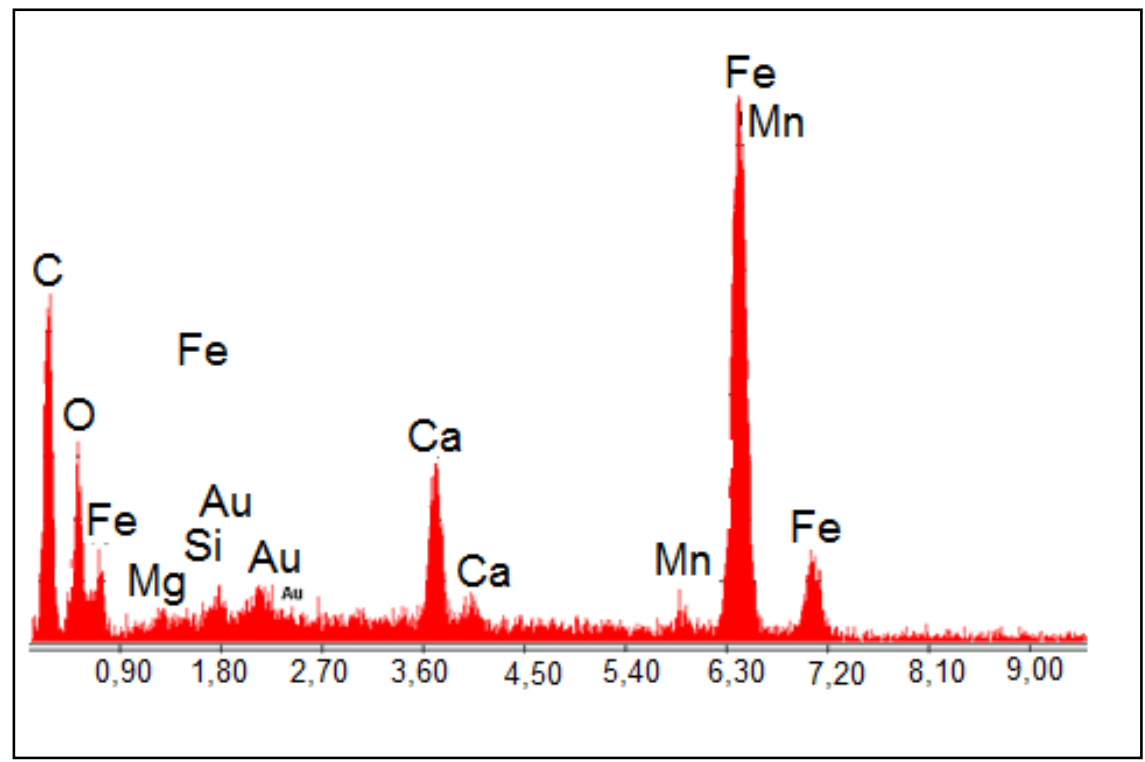

Figura 34 - Espectro de EDS da poeira de aciaria LD.

Pode ser observado que os principais picos encontrados no espectro da Figura 34 foram $\mathrm{Fe}, \mathrm{Ca}, \mathrm{Mn}, \mathrm{Mg}$ e $\mathrm{O}$. Estes resultados mostram que o ferro esta presente em maior proporção em relação aos outros elementos, como foi observado na análise química. 


\subsubsection{Análise granulométrica}

A Figura 35 mostra o resultado obtido na análise granulométrica da poeira de aciaria LD obtida pelo equipamento mastersizer 2000. A curva é apresentada na forma de porcentagem acumulada.

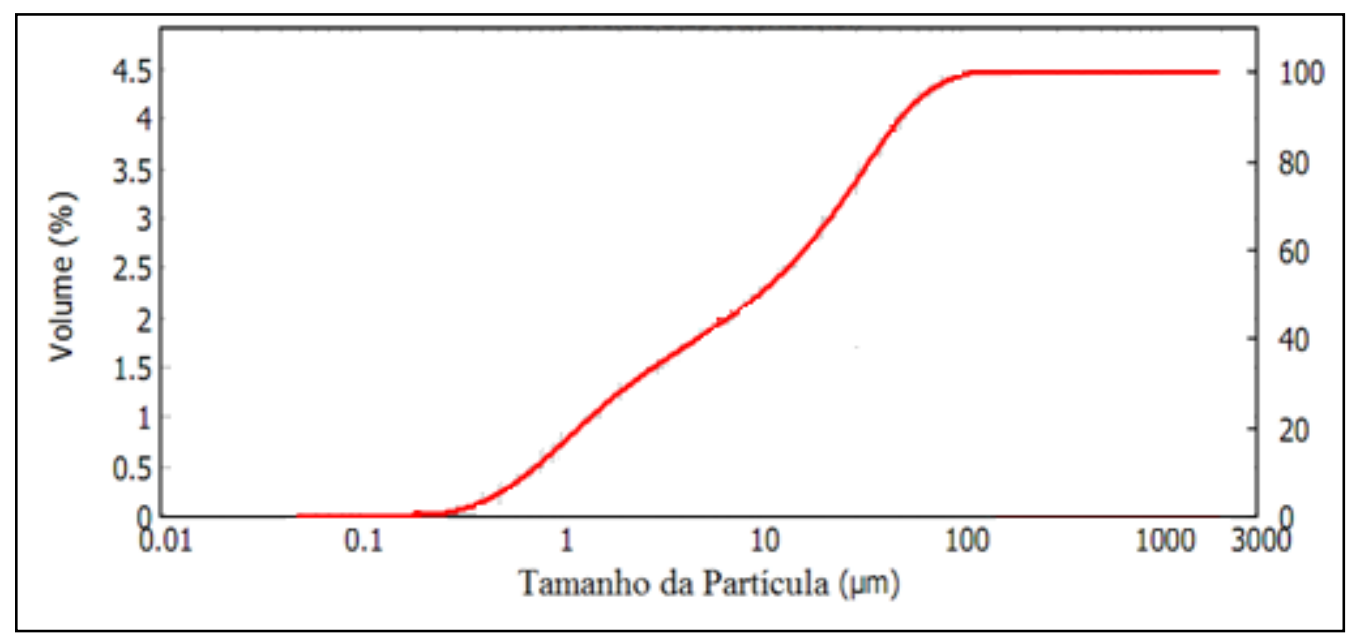

Figura 35 - Análise granulométrica da poeira de aciaria LD.

Foi notado que a distribuição granulométrica ficou entre 0,128 a $158,5 \mu \mathrm{m}$, com $98,2 \%$ menor do que $100 \mu \mathrm{m}$. Também foi observado que $50 \%$ das partículas são menores do que $10,08 \mu \mathrm{m}$.

Resultado similar ao deste trabalho foi obtido por Mikhail e Turcotte $(2008)^{(10)}$, onde encontraram todas as partículas menores do que $100 \mu \mathrm{m}$.

\subsubsection{Caracterização térmica}

Foi realizada também a caracterização térmica da poeira de aciaria LD que pode ser observada na Figura 36 . 


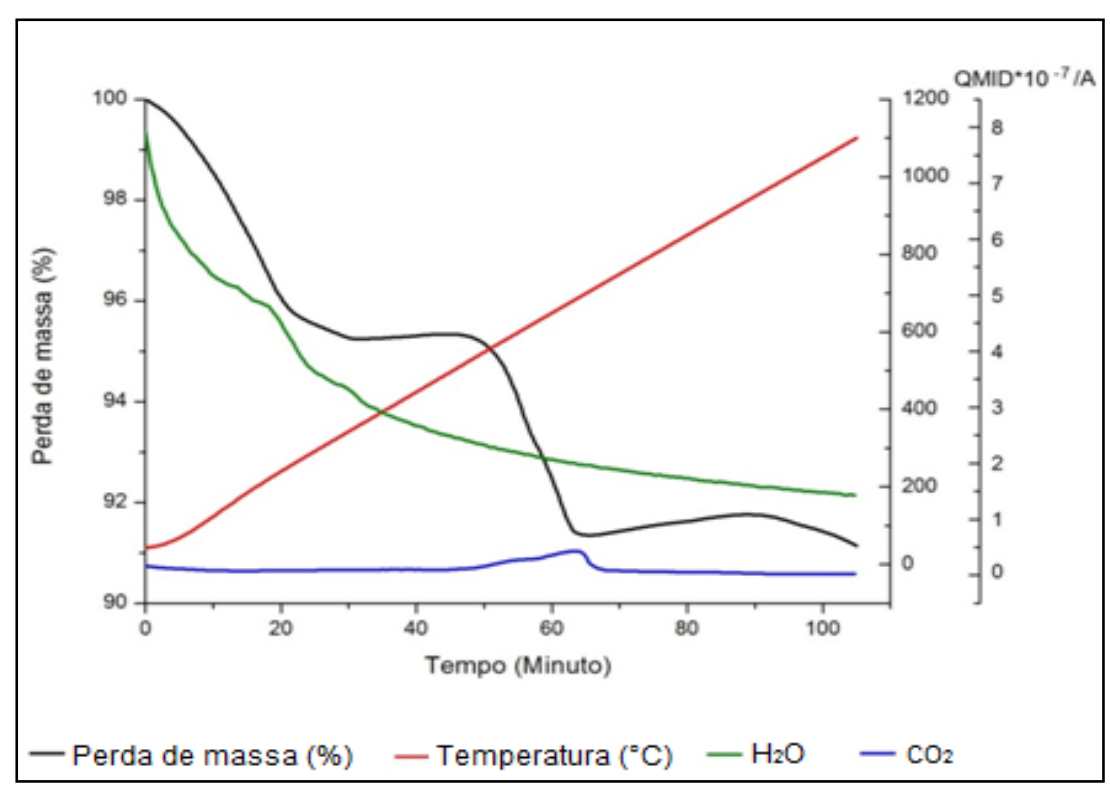

Figura 36 - Caracterização térmica da poeira de aciaria LD entre as temperaturas de 30 a $1100^{\circ} \mathrm{C}$ com atmosfera de nitrogênio.

Pode ser visto na Figura 36 que a perda de massa da poeira de aciaria LD foi de aproximadamente $8,8 \%$ entre as temperaturas de 30 a $1100^{\circ} \mathrm{C}$.

Em seguida, foi feita a curva da derivada da perda de massas $\mathrm{x}$ tempo, que pode ser observada na Figura 37.

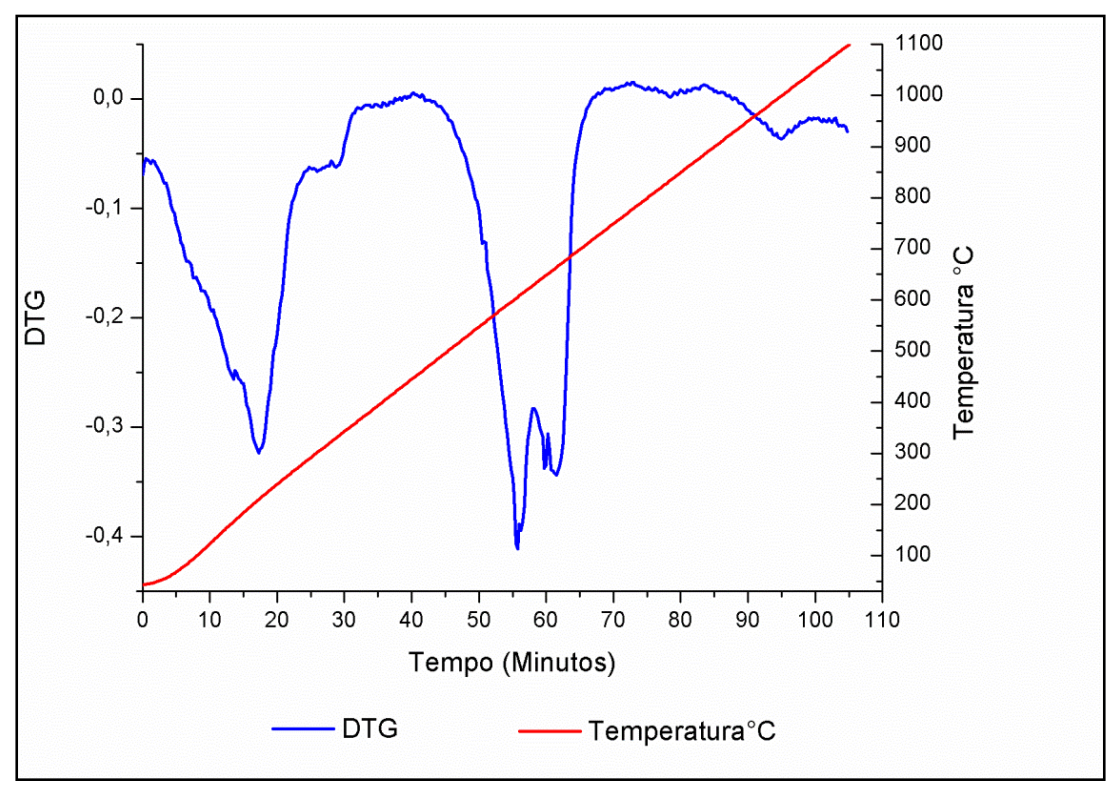

Figura 37 - Curva DTG obtida da caracterização térmica da poeira de aciaria LD utilizando atmosfera inerte. 
Nota-se na Figura 37 que a curva de perda de massas apresentou duas regiões. A primeira que ocorreu entre 50 e $280^{\circ} \mathrm{C}$ e a segunda entre aproximadamente 490 a $700^{\circ} \mathrm{C}$.

A primeira região de perda de massa esta associada à perda de água da amostra do hidróxido de cálcio presente na amostra e da água procedente da umidade atmosférica ${ }^{(10)}$.

Entre as temperaturas de aproximadamente 490 a $700^{\circ} \mathrm{C}$ ocorreu uma perda de massa de aproximadamente $4,2 \%$. Este fato pode ser devido à decomposição do carbonato de cálcio presente na poeira ${ }^{(10)}$. Outro fato que aponta esta afirmação é a presença de $\mathrm{CO}_{2}$, captado pelo espectrômetro de massa durante a análise, conforme foi mostrado na Figura 36.

5.1.2 Poeira de aciaria elétrica

5.1.2.1 Análise química

A Tabela 8 apresenta os resultados de análise química da poeira de aciaria elétrica.

Tabela 8 - Análise química da poeira de aciaria elétrica.

\begin{tabular}{c|c}
\hline Elementos & \% em peso \\
\hline $\mathrm{Fe}_{\text {total }}$ & 44,6 \\
\hline $\mathrm{Fe}^{\mathrm{O}}$ & 0,6 \\
\hline $\mathrm{Zn}$ & 15,9 \\
\hline $\mathrm{Ca}$ & 5,7 \\
\hline $\mathrm{Si}$ & 4,0 \\
\hline $\mathrm{Mn}$ & 2,0 \\
\hline $\mathrm{Mg}$ & 1,5 \\
\hline $\mathrm{Pb}$ & 1,2 \\
\hline
\end{tabular}

Pode ser observado na Tabela 8 que a poeira de aciaria elétrica é composta principalmente por ferro $(44,6 \%)$, sendo $0,6 \% \mathrm{Fe}$ metálico, e zinco $(15,9 \%)$. De acordo com Machado et al. ${ }^{(30)}$, quando a poeira de aciaria é 
proveniente da fabricação de aço carbono, o teor de zinco é entre 11,1 a $26,9 \%$. A presença de $\mathrm{Pb}$ e $\mathrm{Zn}$ na poeira faz com que este material seja

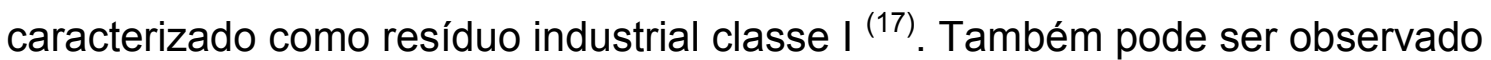
a presença de $\mathrm{Ca}, \mathrm{Si}$ e $\mathrm{Mg}$. Estes elementos podem ser procedentes da escória ${ }^{(30)}$.

\subsubsection{Difração de Raios-X}

Após a análise química, foi realizada a difração de raios- $X$ da poeira de aciaria elétrica. A Figura 38 apresenta o difratograma obtido.

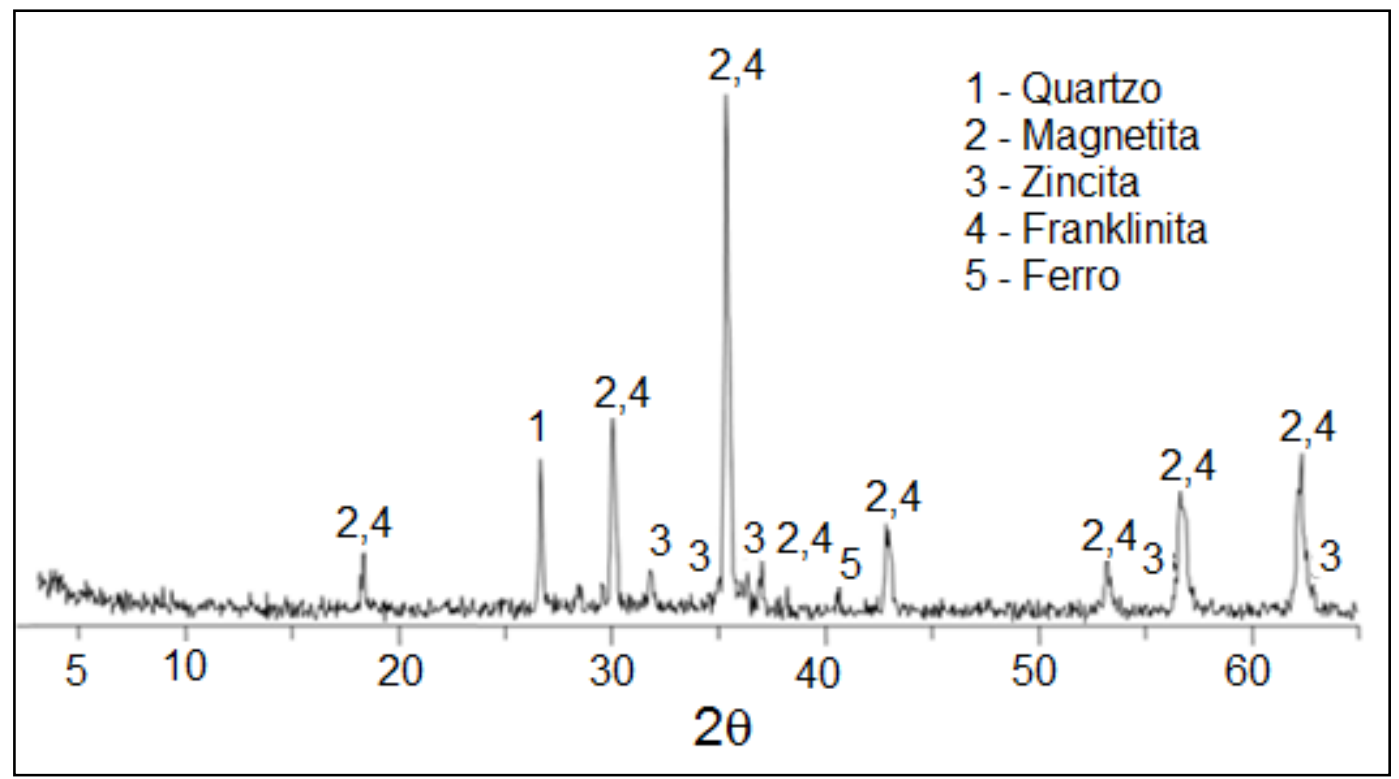

Figura 38 - Difratograma obtido da poeira de aciaria elétrica.

O difratograma mostra que as principais fases encontradas na poeira foram a magnetita, zincita, quartzo e a franklinita. Pode-se observar que o ferro está presente na forma de magnetita e ferro metálico. Além disso, também é observado que o zinco está na forma de zincita $e$ franklinita. Silva et al. (2008) ${ }^{(134)}$ diz que o ferro pode apresentar $\mathrm{Fe}_{2} \mathrm{O}_{3}, \mathrm{Fe}_{3} \mathrm{O}_{4}, \mathrm{FeO}$, $\mathrm{ZnFe}_{2} \mathrm{O}_{4}$ e ferro metálico como fases contendo ferro. No caso deste trabalho, foram identificados apenas as fases magnetita $\left(\mathrm{Fe}_{3} \mathrm{O}_{4}\right)$, ferro metálico e franklinita $\left(\mathrm{ZnFe}_{2} \mathrm{O}_{4}\right)$ como fases contendo ferro. 
Brehn (2004) ${ }^{(135)}$ realizou uma comparação entre vários trabalhos que apresentam difração de raios- $X$ da poeira da aciaria elétrica. Nesta compilação, o autor verificou que a fase $\mathrm{ZnFe}_{2} \mathrm{O}_{4}$ estava presente em todos os trabalhos.

Nyrenda (1991) ${ }^{(136)}$ complementa dizendo que quando a poeira apresenta zinco acima de $15 \%$, surge a fase $\mathrm{ZnO}$, o restante está associado principalmente com ferro, formando $\mathrm{ZnFe}_{2} \mathrm{O}_{4}$. Mantovani (1998) ${ }^{(24)}$ observou ainda em seu trabalho que o aumento do teor de zinco na poeira acarreta um aumento de picos de $\mathrm{ZnO}$.

Foi aplicado o método Rietveld de quantificação de fases no difratograma da poeira de aciaria elétrica. $O$ resultado pode ser visto na Tabela 9.

Tabela 9 - Quantificação das fases pelo método Rietveld na poeira de aciaria elétrica.

\begin{tabular}{c|c}
\hline Fases & $\%$ \\
\hline Ferro & 0,5 \\
\hline Zincita & 28,5 \\
\hline Quartzo & 6,2 \\
\hline Magnetita & 43,2 \\
\hline Franklinita & 21,6 \\
\hline
\end{tabular}

Pelo método Rietveld foi possível concluir que a principal fase presente na poeira de aciaria elétrica foi a magnetita com $43,2 \%$. Foi visto também que as fases que apresentam zinco somaram $50,4 \%$, sendo que a franklinita apresenta $21,6 \%$, ou seja, $42,8 \%$ das fases que contém zinco. Estudos apontam que 50 a $80 \%$ do teor de zinco presente na poeira pode estar na forma de zincita $(\mathrm{ZnO})$ e o restante na forma de ferrita de zinco $\left(\mathrm{Fe}_{2} \mathrm{ZnO}_{4}\right)^{\left({ }^{(3)}\right)}$.

\subsubsection{Análise granulométrica}

A análise granulométrica foi realizada utilizando o equipamento mastersizer 2000. O resultado pode ser observado na Figura 39, onde é 
apresentada a curva de porcentagem acumulada obtida para a poeira de aciaria elétrica.

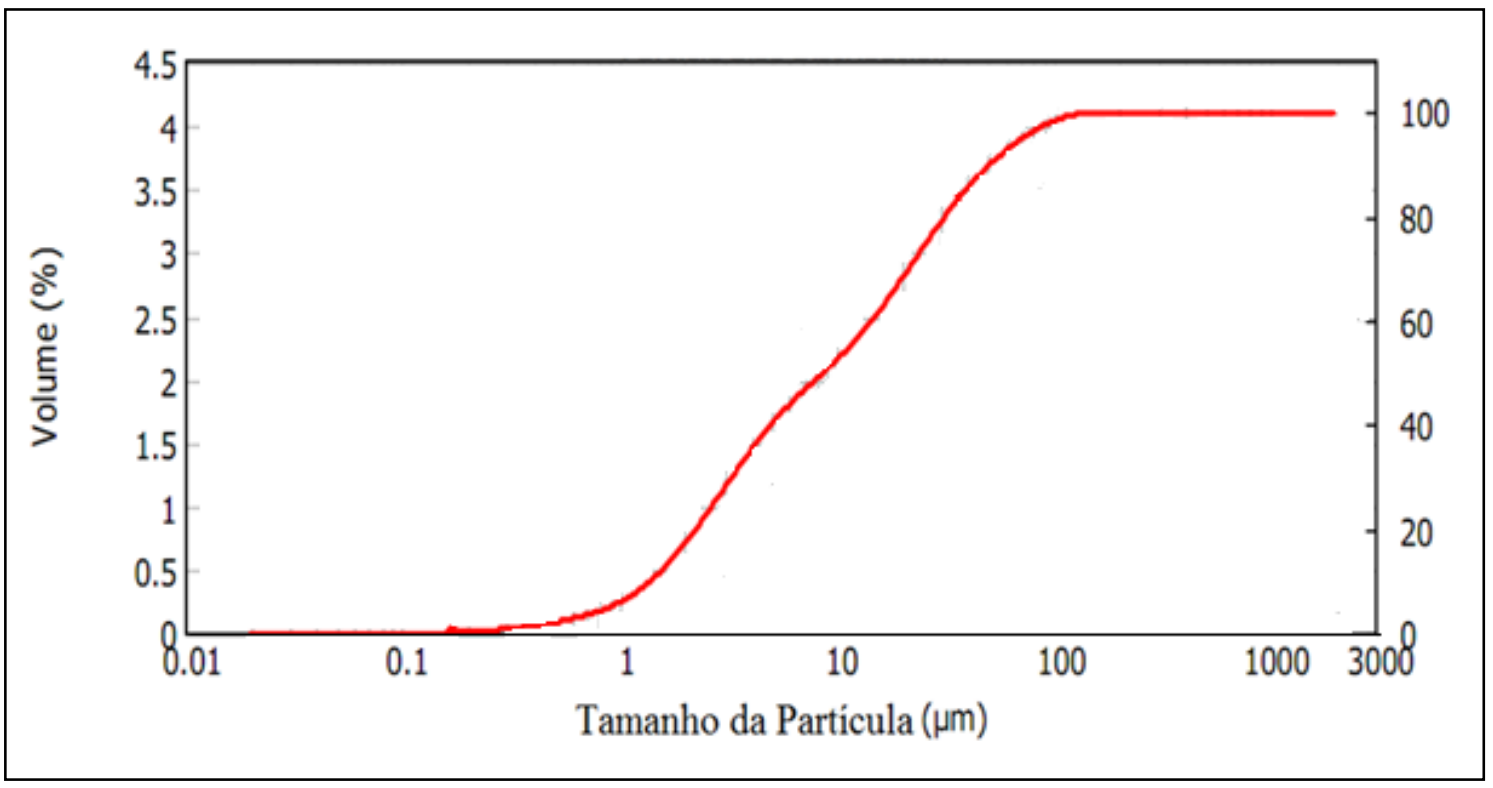

Figura 39 - Análise granulométrica da poeira de aciaria elétrica.

Foi observado pela análise granulométrica que a poeira de aciaria elétrica esta compreendida entre 0,158 a 158,48 $\mu \mathrm{m}$. Além disso, foi notado que

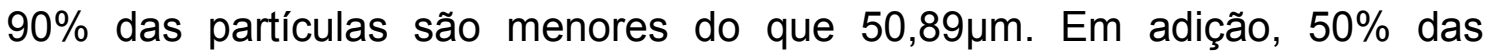
partículas menores do que $8,658 \mu \mathrm{m}$.

Resultados simulares foram obtidos por Pelino et al. (2002) ${ }^{(137)}$. Seus dados mostraram que em duas amostras diferentes foram obtidos 34 e $65 \%$ das partículas menores do que $10 \mu \mathrm{m}$.

\subsubsection{Microscópio eletrônico de varredura}

Em adição aos ensaios de caracterização, foi realizada análises de microscópio eletrônico de varredura. Na Figura 40 são apresentadas duas imagens obtidas pelo microscópio da poeira de aciaria elétrica. A Figura 40A mostra uma visão mais geral da poeira de aciaria elétrica, enquanto que na Figura 40B mostra uma imagem mais detalhada da poeira de aciaria elétrica. 


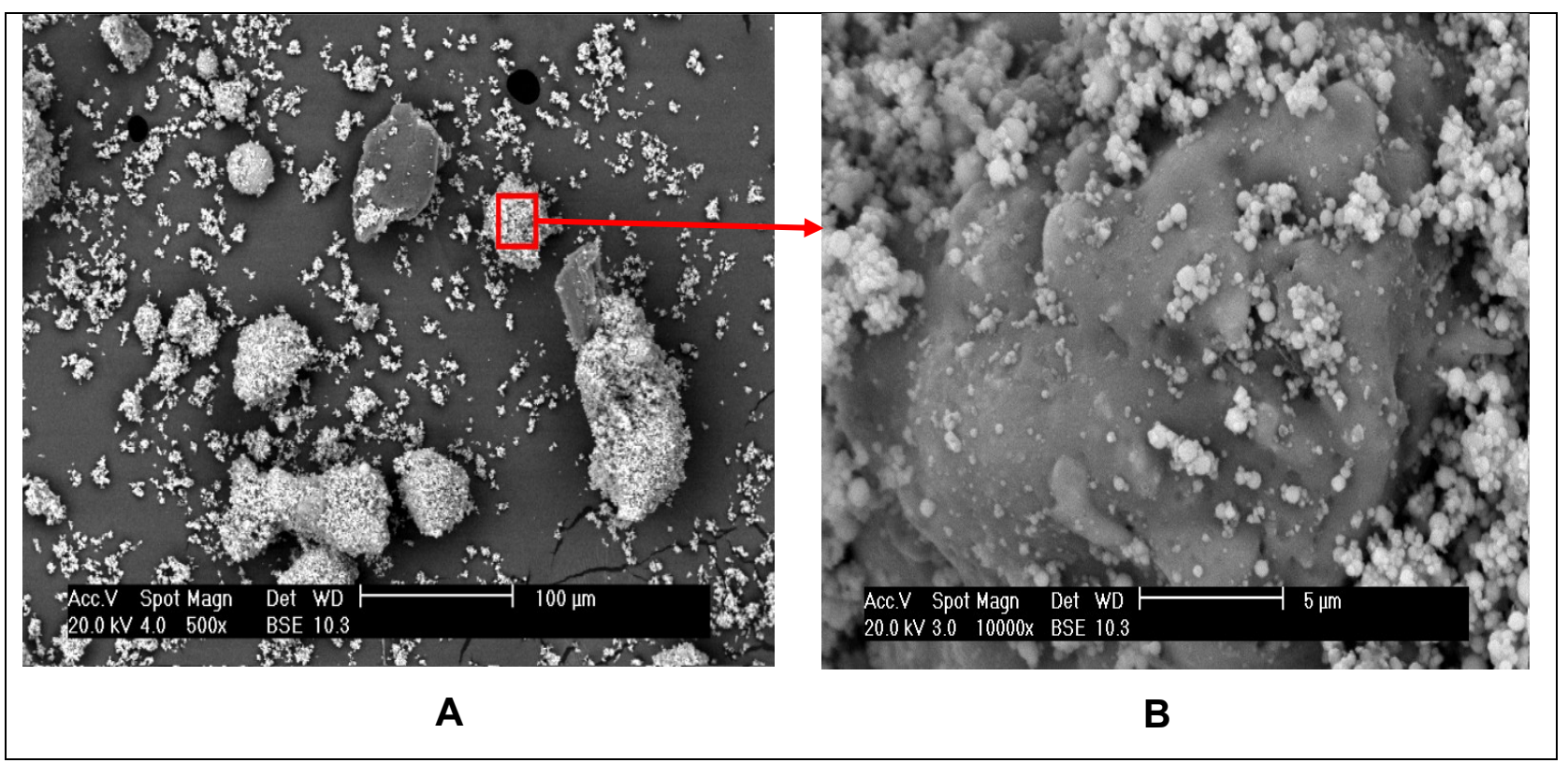

Figura 40 - Imagens de elétrons retro-espalhados obtidas por microscopia eletrônica de varredura da poeira de aciaria elétrica.

$\mathrm{Na}$ Figura $40 \mathrm{~A}$ pode ser visto que existem partículas com diferentes tamanhos. Também pode ser dito que existem partículas aglomeradas. Neste caso, pequenas partículas estão aglomeradas em partículas maiores.

$\mathrm{Na}$ Figura 40B pode ser observado que as partículas aglomeradas são menores do que $5 \mu \mathrm{m}$. Esta informação indica que os resultados obtidos pelo equipamento mastersizer 2000 estão corretos, pois a poeira de aciaria elétrica apresentou $40 \%$ das partículas menores do que $5 \mu \mathrm{m}$. Em adição, também pode ser observado que existem poucas partículas maiores do que $100 \mu \mathrm{m}$.

Também foi obtido um espectro de EDS junto com as imagens do microscópio eletrônico de varredura. A Figura 41 apresenta o espectro obtido. 


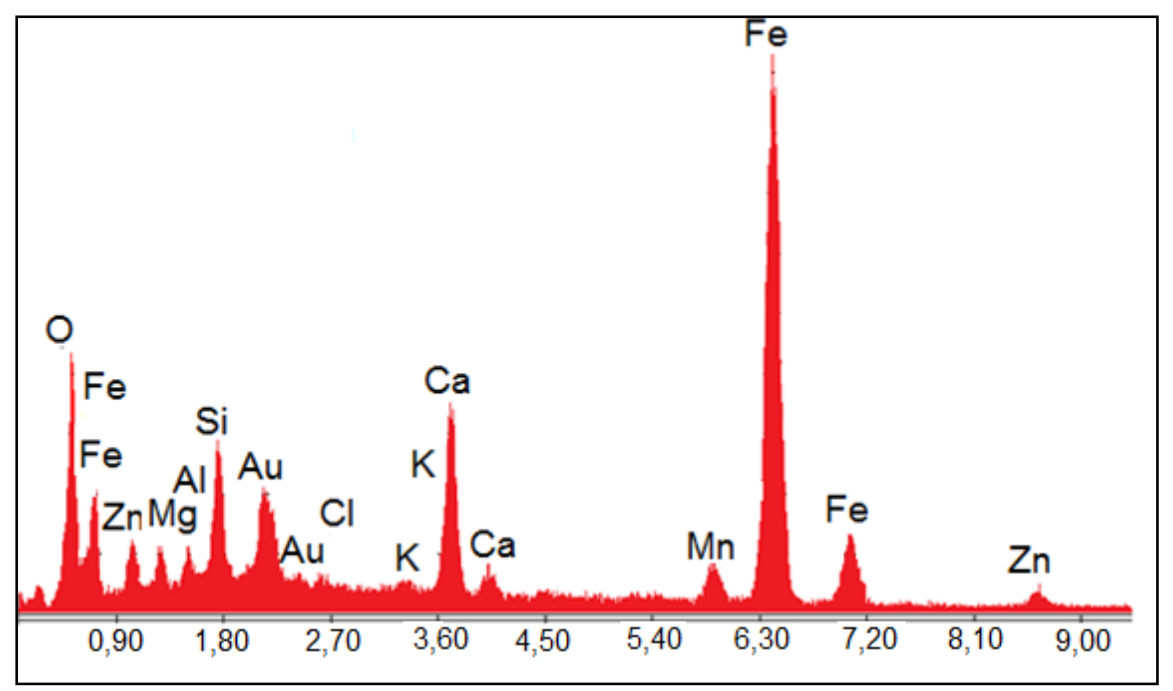

Figura 41 - Espectro de EDS obtido da poeira de aciaria elétrica.

O espectro apresenta que os principais picos encontrados foram $\mathrm{O}, \mathrm{Fe}$, $\mathrm{Zn}, \mathrm{Al}, \mathrm{Mg}, \mathrm{Si}, \mathrm{Au}, \mathrm{Cl}, \mathrm{K}, \mathrm{Ca}$ e Mn.

Estes resultados mostram que o ferro está presente em maior proporção do que os outros constituintes. O pico de oxigênio presente no espectro é procedente do óxido de ferro e zinco. O Au é procedente do recobrimento realizado na amostra.

\subsubsection{Caracterização térmica}

A Figura 42 apresenta a curva de perda de massa em função da temperatura para a poeira de aciaria elétrica. 


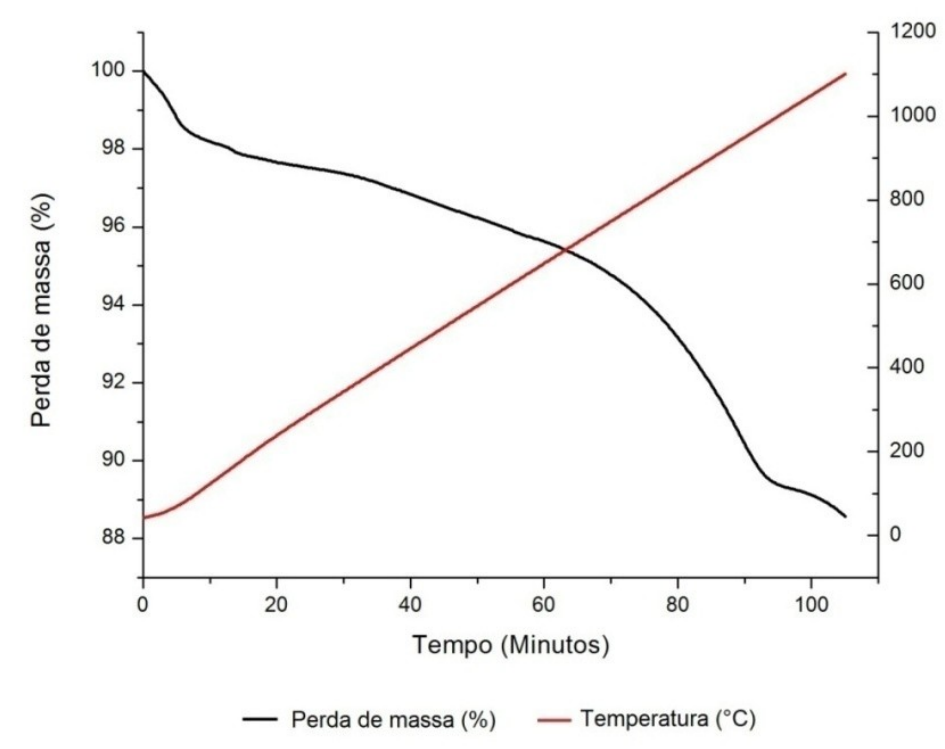

Figura 42 - Perda de massa da poeira de aciaria elétrica em atmosfera inerte.

Pode ser notado na Figura 42 que a perda de massa da poeira de aciaria elétrica entre 30 a $1100^{\circ} \mathrm{C}$ foi de aproximadamente $11,5 \%$.

Em seguida, foi feita a curva da derivada da perda de massas $\mathrm{x}$ tempo, que pode ser observada na Figura 43.

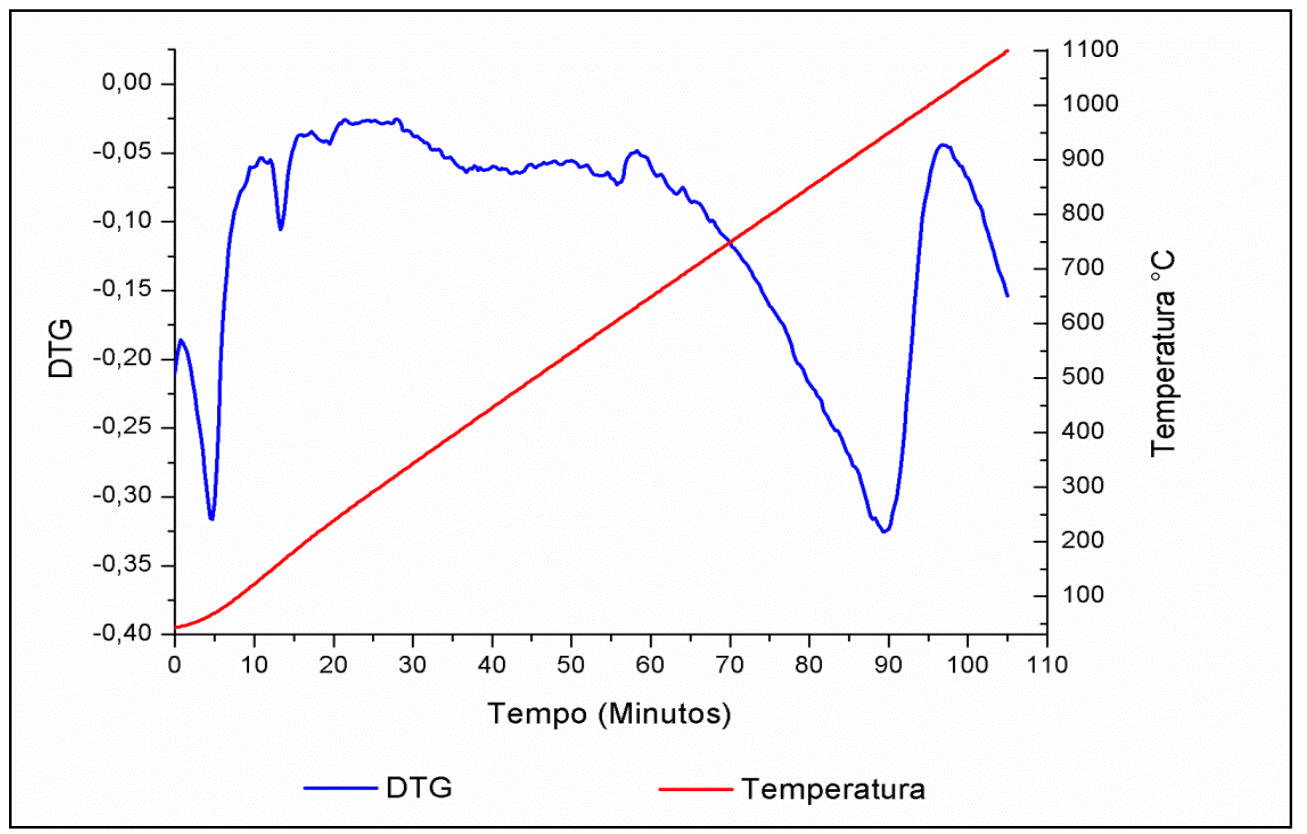

Figura 43 - Curva de DTG obtida na análise térmica da poeira de aciaria elétrica com atmosfera inerte. 
Analisando a Figura 43 foi possível concluir que entre as temperaturas de 619,4 a $1004,5^{\circ} \mathrm{C}$, a poeira de aciaria elétrica apresentou uma perda de massa de $6,4 \%$.

Pelino et al. (2002) ${ }^{(137)}$ em seu trabalho, mostrou que até a temperatura de $1000^{\circ} \mathrm{C}$ a perda de massa da poeira de aciaria elétrica estuda foi de aproximadamente $6 \%$, sendo esta perda de massa decorrente à decomposição de carbonatos, que ocorre entre as temperaturas de 600 a $800^{\circ} \mathrm{C}$. O autor também cita que a partir de $1000^{\circ} \mathrm{C}$, a perda de massas é decorrente a volatilização de metais tais como zinco e chumbo.

\subsubsection{Ferrita de Zinco sintetizada}

\subsubsection{Difração de Raios-X}

Foi realizada a síntese da ferrita de zinco. Após a síntese, foi feita a difração de raios-X do pó obtido. A Figura 44 apresenta o difratograma obtido da ferrita de zinco sintetizada.

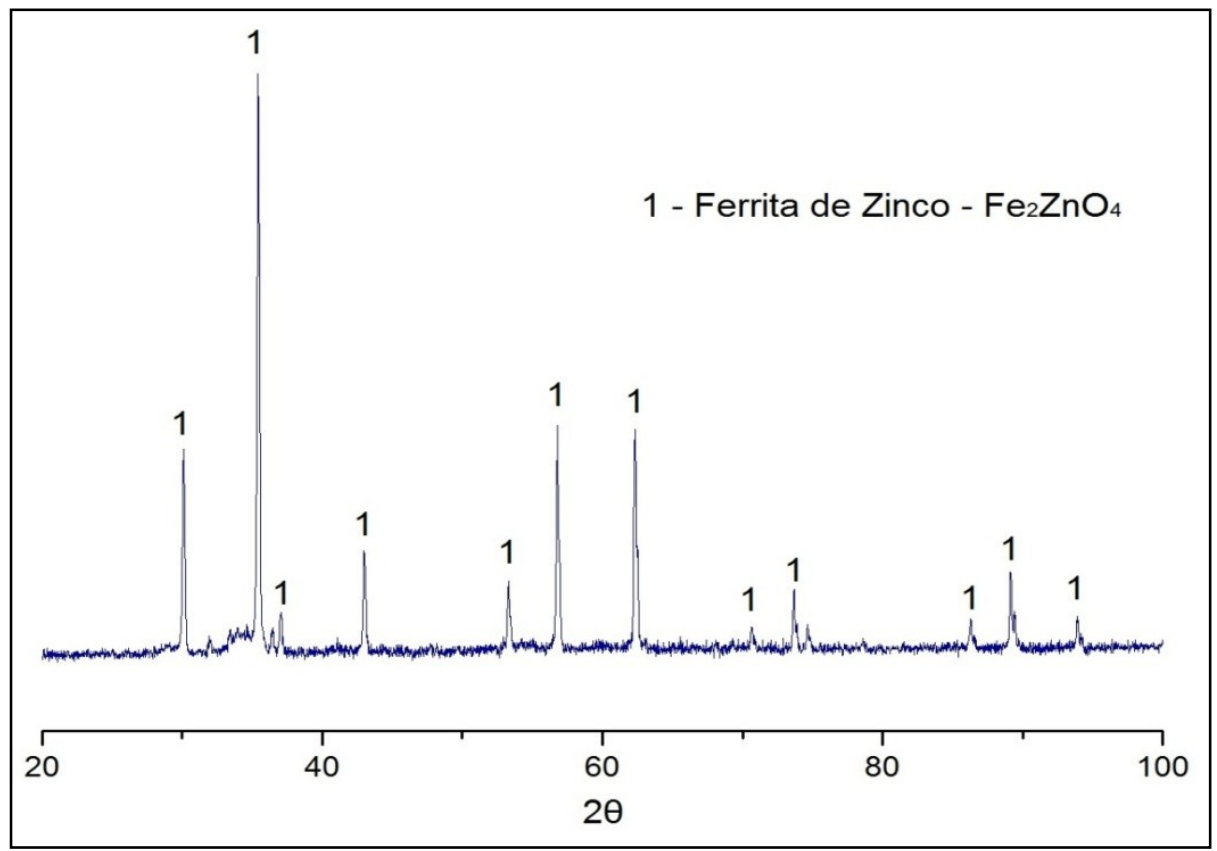

Figura 44 - Difratograma obtido da ferrita de zinco sintetizada. 
Pode-se observar no difratograma da Figura 44 que foram encontrados apenas picos de Franklinita $\left(\mathrm{Fe}_{2} \mathrm{ZnO}_{4}\right)$, comprovando que a síntese foi bem sucedida.

\subsubsection{Microscópio eletrônico de varredura}

Foram obtidas imagem por microscópio eletrônico de varredura e espectros de EDS da ferrita de zinco sintética. A Figura 45 apresenta a imagem de microscópio eletrônico de varredura e a Figura 46 o espectro de EDS da ferrita de zinco sintética.

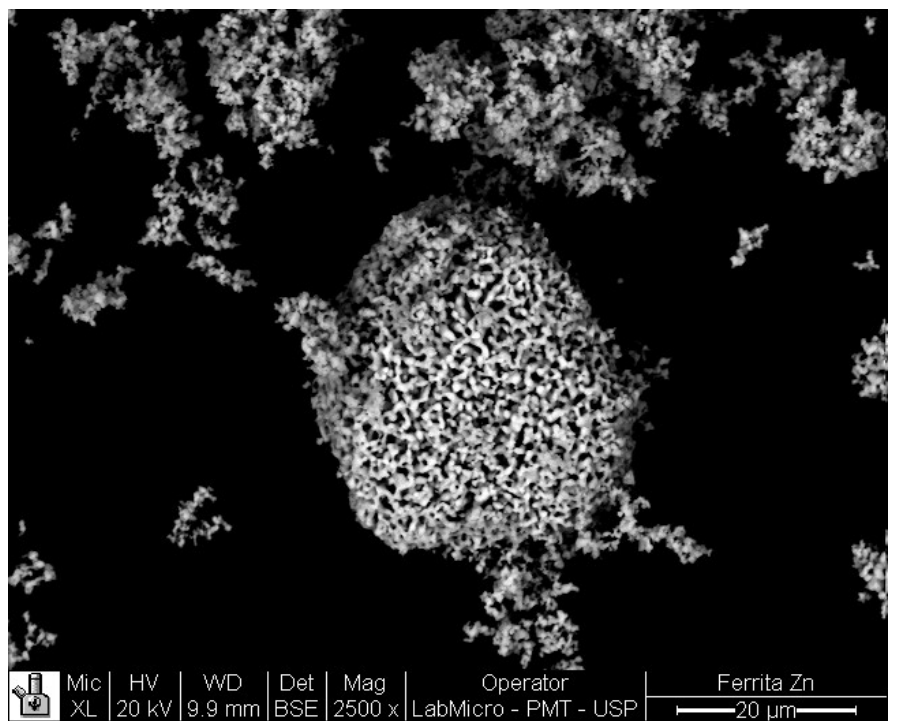

Figura 45 - Imagem de elétrons retro-espalhados obtidos por microscópio eletrônico de varredura da ferrita de zinco sintética.

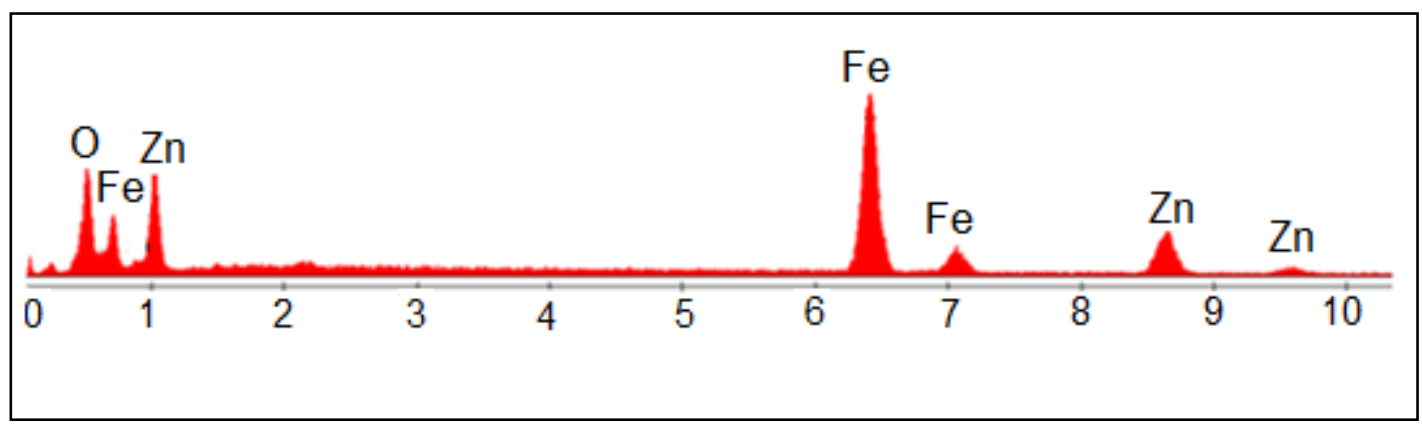

Figura 46 - Espectro de EDS da ferrita de zinco sintetizada. 
Pela Figura 45 é possível observar que as partículas de ferrita de zinco formadas na síntese apresentam um aspecto poroso. Pode-se observar através do espectro de EDS da Figura 46 que foram encontrados somente picos de Fe, $Z n$ e $O$, reforçando os resultados obtidos por difração de raios-X, onde somente foram encontrados picos de ferrita de zinco.

\subsubsection{Análise Granulométrica}

Foi realizada a análise granulométrica da ferrita de zinco sintetizada através do equipamento Mastersizer 2000. A Figura 47 mostra os resultados obtidos através da curva de porcentagem acumulada da ferrita de zinco.

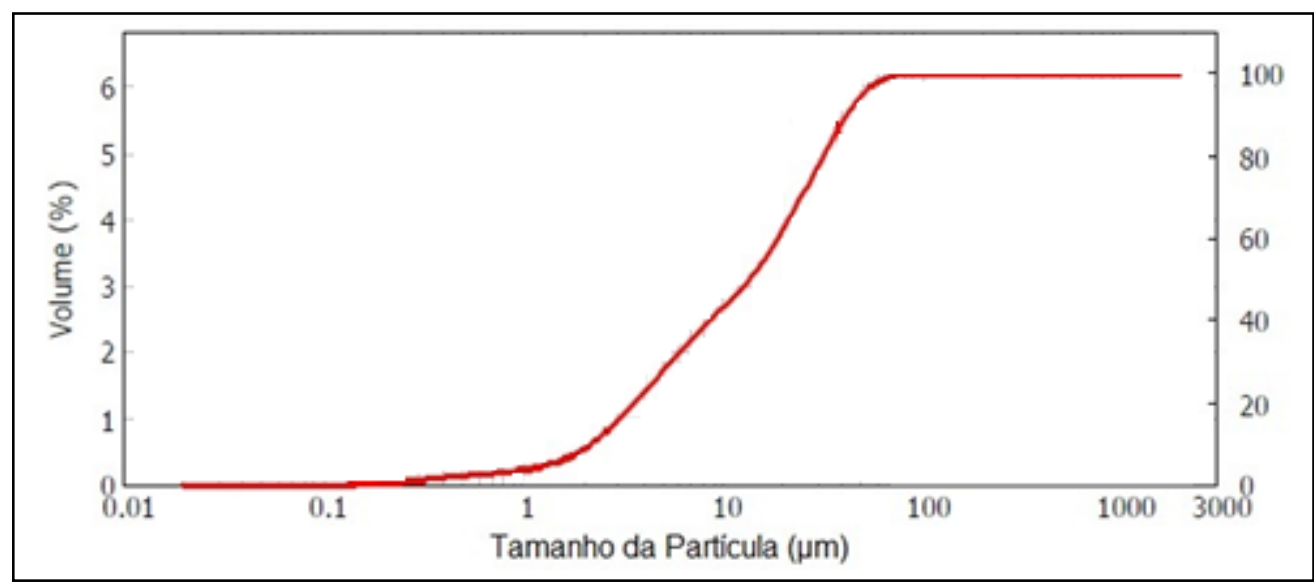

Figura 47 - Curva de porcentagem acumulada obtida na análise granulométrica da ferrita de zinco sintetizada.

A partir da Figura 47 foi observado que a faixa granulométrica da ferrita de zinco sintetizada está entre 0,138 a 91,2 $\mu \mathrm{m}$. Foi observado também que $90 \%$ das partículas estão abaixo de $42,80 \mu m$ e que $50 \%$ das partículas são menores do que $13,85 \mu \mathrm{m}$. 


\subsubsection{Porosidade das pelotas}

Antes de iniciar o capitulo de análise cinética, é importante saber a porosidade que as pelotas apresentam. Desta forma, a Tabela 10 apresenta os resultados da análise de densidade real das materiais primas utilizadas na confecção das pelotas e a densidade volumétrica das pelotas, sendo assim, possível a obtenção da porosidade das pelotas.

Tabela 10 - Análises de densidade da ferrita de zinco, poeira de aciaria LD e poeira de aciaria elétrica e porosidades das pelotas para cada material.

\begin{tabular}{c|c|c|c}
\hline & $\begin{array}{c}\text { Densidade } \\
\text { real }\left(\mathrm{g} / \mathrm{cm}^{3}\right)\end{array}$ & $\begin{array}{c}\text { Densidade } \\
\text { volumétrica } \\
\left(\mathrm{g} / \mathrm{cm}^{3}\right)\end{array}$ & $\begin{array}{c}\text { Porosidade } \\
\text { das pelota } \\
(\%)\end{array}$ \\
\hline $\begin{array}{c}\text { Ferrita de } \\
\text { zinco }\end{array}$ & 3,43 & 1,60 & 53,1 \\
\hline LD & 3,91 & 2,32 & 41,3 \\
\hline PAE & 3,51 & 1,71 & 50,3 \\
\hline
\end{tabular}

A análise de porosidade das pelotas indicaram que a pelota de ferrita de zinco é a que apresenta maior porosidade, com $53,1 \%$, enquanto que a pelota de poeira de aciaria elétrica apresentou porosidade de $50,3 \%$ e a pelota de poeira de aciaria LD foi de $41,3 \%$.

A literatura cita que a porosidade típica de pelotas de minério de ferro para alto-forno apresentam uma porosidade entre $22 \%$ e $30 \%{ }^{(138)}$. No caso das pelotas produzidas neste trabalho, não foi feita a sinterização das mesmas, desta forma, apresentando porcentagem de poros acima do que normalmente é encontra.

\subsection{ANÁLISE CINÉTICA}

Neste item, serão apresentados os resultados obtidos pela investigação cinética de redução das pelotas fabricadas com as três matérias primas. 


\subsubsection{Pelotas de poeira de aciaria LD}

\subsubsection{Redução com mistura redutora}

Testes de redução utilizando mistura redutora foram realizadas nas pelotas feitas com poeira de aciaria LD. A Figura 48 apresenta os resultados obtidos nos ensaios termogravimétricos para os diferentes fluxos de gás redutor utilizado nos ensaios.

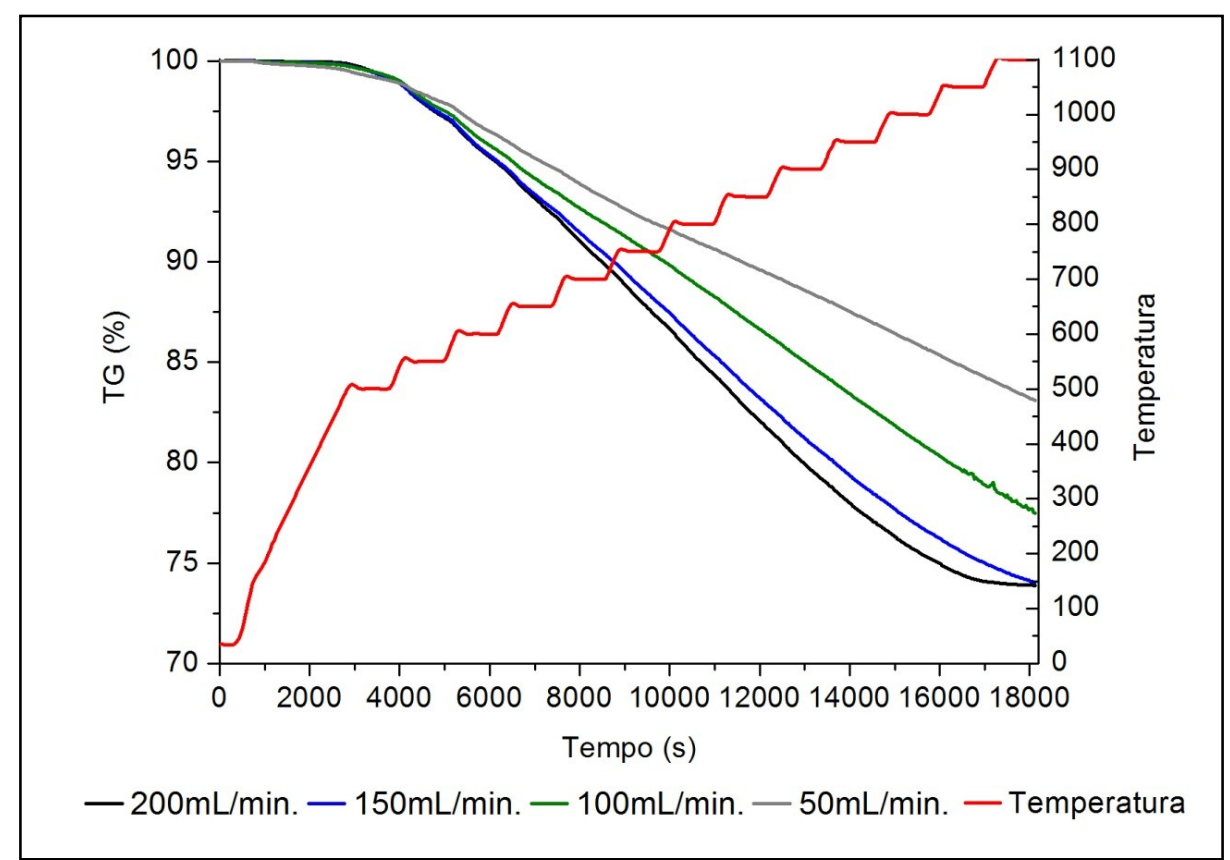

Figura 48 - Análises de perda de massa das pelotas de poeira de aciaria LD utilizando mistura redutora.

Pode ser observado na Figura 48 que o gás redutor tem influência sobre os ensaios de redução, uma vez que o aumento do fluxo do gás causou um aumento na taxa de redução re redução. Também foi observado que o tempo requerido para o fim da reação de redução foi menor com o aumento do fluxo de gás redutor.

Outro ponto observado foi que, para os fluxos de 150 a $200 \mathrm{~mL} /$ minuto, a reação chegou-se ao fim, fato que pode ser observado pela ausência de perda de massa no fim da reação. Porém, com uso de $200 \mathrm{~mL} /$ minuto foram 
encontrados os melhores dados, uma vez que com este fluxo a reação foi concluída mais rápido. Foi observado também que a perda de massa total após o fim da reação foi em torno de $26 \%$. Além disso, foi possível observar a reação de redução foi finalizada à $1050^{\circ} \mathrm{C}$, fato que pode ser comprovado pela linearidade da curva de perda de massas da Figura 48 após esta temperatura.

\subsection{Análise cinética}

Inicialmente, foram analisados os fatores de correlação das funções $d(\alpha) / d t \times f(x)$ e $g(\alpha) \times t$ citadas pela literatura. A Tabela 11 apresenta os valores de correlação destas funções.

Através da análise dos fatores de correlação apresentados na Tabela 11 não é possível distinguir as funções que podem ser possíveis controladoras da reação de redução, isto por que os valores dos fatores de correlação de cada patamar estão muito próximos uns dos outros, inviabilizando o critério da linearidade da função na pesquisa do mecanismo controlador.

A próxima etapa foi a construção das curvas de Arrhenius para todas as funções citadas pela literatura que são apresentadas na Figura 49. 
Tabela 11 - Coeficientes de correlação para as funções citadas como possíveis controladoras para a redução de pelotas de poeira de aciaria LD reduzida com mistura redutora.

\begin{tabular}{|c|c|c|c|c|c|c|c|c|c|c|c|c|c|c|c|c|}
\hline \multirow[b]{3}{*}{ Temperatura } & \multicolumn{16}{|c|}{ Funções } \\
\hline & \multicolumn{2}{|c|}{$\mathrm{A} 2$} & \multicolumn{2}{|c|}{ A3 } & \multicolumn{2}{|c|}{ D1 } & \multicolumn{2}{|c|}{ D2 } & \multicolumn{2}{|c|}{ D3 } & \multicolumn{2}{|c|}{ D4 } & \multicolumn{2}{|c|}{$\mathrm{R} 2$} & \multicolumn{2}{|c|}{ R3 } \\
\hline & Dif. & Int. & Dif. & Int. & Dif. & Int. & Dif. & Int. & Dif. & Int. & Dif. & Int. & Dif. & Int. & Dif. & Int. \\
\hline 550 & 0,99 & 0,97 & 0,99 & 0,98 & 0,99 & 0,99 & 0,98 & 0,91 & 0,98 & 0,90 & 0,98 & 0,99 & 0,98 & 0,99 & 0,99 & 0,99 \\
\hline 600 & 0,95 & 0,99 & 0,95 & 0,99 & 0,95 & 0,99 & 0,97 & 0,96 & 0,97 & 0,96 & 0,93 & 0,99 & 0,93 & 0,99 & 0,95 & 0,99 \\
\hline 650 & 0,97 & 0,99 & 0,97 & 0,99 & 0,97 & 0,99 & 0,98 & 0,98 & 0,98 & 0,98 & 0,96 & 0,99 & 0,95 & 0,99 & 0,97 & 0,99 \\
\hline 800 & 0,94 & 0,99 & 0,94 & 0,99 & 0,94 & 0,99 & 0,99 & 0,99 & 0,99 & 0,99 & 0,98 & 0,99 & 0,98 & 0,99 & 0,94 & 0,99 \\
\hline 850 & 0,98 & 0,99 & 0,98 & 0,99 & 0,98 & 0,99 & 0,99 & 0,99 & 0,99 & 0,99 & 0,99 & 0,94 & 0,99 & 0,99 & 0,98 & 0,99 \\
\hline 900 & 0,98 & 0,99 & 0,98 & 0,99 & 0,98 & 0,99 & 0,99 & 0,99 & 0,99 & 0,99 & 0,99 & 0,98 & 0,99 & 0,99 & 0,98 & 0,99 \\
\hline 950 & 0,99 & 0,99 & 0,99 & 0,99 & 0,99 & 0,99 & 0,99 & 0,75 & 0,99 & 0,99 & 0,99 & 0,99 & 0,99 & 0,99 & 0,99 & 0,99 \\
\hline 1000 & 0,99 & 0,99 & 0,99 & 0,99 & 0,99 & 0,99 & 0,99 & 0,98 & 0,99 & 0,98 & 0,99 & 0,99 & 0,99 & 0,99 & 0,99 & 0,99 \\
\hline
\end{tabular}




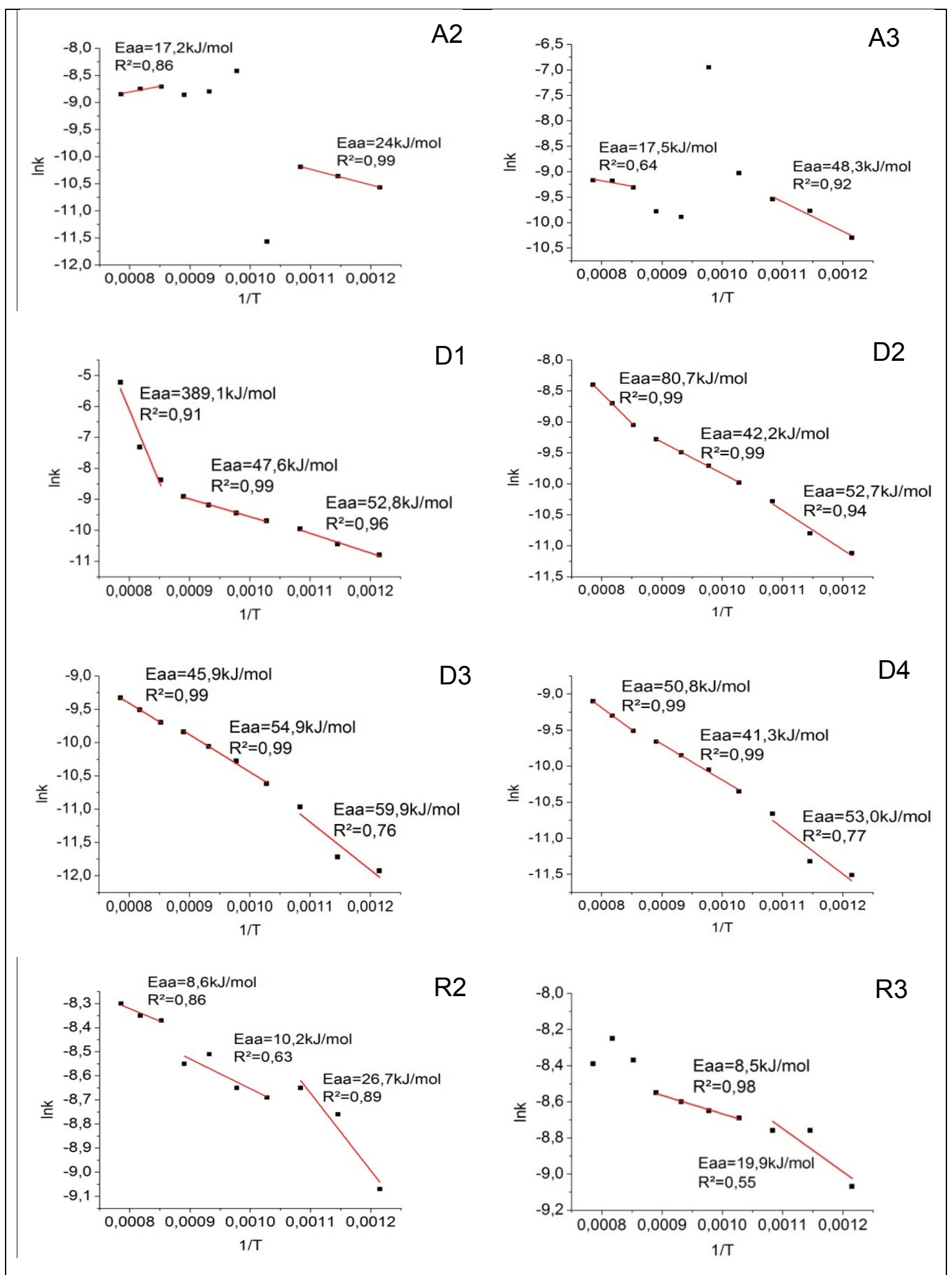

Figura 49 - Curvas de Arrhenius obtidas utilizando as equações para reações do tipo gás-sólido na redução de pelotas de poeira de aciaria LD reduzidas por mistura gasosa com fluxo de $200 \mathrm{~mL} /$ minuto. 
Pelas curvas de Arrhenius foi visualizado que a redução das pelotas de poeira de aciaria LD ocorre em três etapas. A primeira ocorre entre 550 a $650^{\circ} \mathrm{C}$. A segunda entre 700 a $850^{\circ} \mathrm{C}$ e a última entre 900 a $100^{\circ} \mathrm{C}$.

Como pode ser visto na Figura 49, ocorre uma variação nos valores de energia de ativação aparente de função para função. Assim, foi realizada uma compilação dos resultados que pode ser observado na Tabela 12.

Tabela 12 - Valores de Energia de ativação aparente obtidas para as possíveis funções controladoras.

\begin{tabular}{c|c|c|c|c|c|c}
\hline & \multicolumn{2}{|c|}{$550 \mathrm{a} 650^{\circ} \mathrm{C}$} & \multicolumn{2}{c|}{$700 \mathrm{a} 850^{\circ} \mathrm{C}$} & \multicolumn{2}{c}{900 a $1000^{\circ} \mathrm{C}$} \\
\hline Funções & $\begin{array}{c}\text { Eaa } \\
(\mathrm{kJ} / \mathrm{mol})\end{array}$ & $\mathrm{R}^{2}$ & $\begin{array}{c}\text { Eaa } \\
(\mathrm{kJ} / \mathrm{mol})\end{array}$ & $\mathrm{R}^{2}$ & $\begin{array}{c}\text { Eaa } \\
(\mathrm{kJ} / \mathrm{mol})\end{array}$ & $\mathrm{R}^{2}$ \\
\hline $\mathrm{A} 2$ & 24 & 0,99 & - & - & 17,2 & 0,86 \\
\hline $\mathrm{A} 3$ & 48,3 & 0,92 & - & - & 17,5 & 0,64 \\
\hline $\mathrm{R} 2$ & 26,7 & 0,89 & 10,2 & 0,63 & 8,6 & 0,86 \\
\hline R3 & 19,9 & 0,55 & 8,5 & 0,98 & - & - \\
\hline D1 & 52,8 & 0,96 & 47,6 & 0,99 & 389,1 & 0,91 \\
\hline D2 & 52,7 & 0,94 & 42,2 & 0,99 & 80,7 & 0,99 \\
\hline D3 & 59,9 & 0,76 & 54,9 & 0,99 & 45,9 & 0,99 \\
\hline D4 & 53 & 0,77 & 41,3 & 0,99 & 50,8 & 0,99 \\
\hline
\end{tabular}

Entre as temperaturas de 550 a $650^{\circ} \mathrm{C}$, foi observado que apenas a função A2 apresentou linearidade. Portanto, esta função pode ser a possível controladora nesta faixa de temperatura. $\mathrm{O}$ uso desta função implica em uma energia de ativação aparente de $24 \mathrm{~kJ} / \mathrm{mol}$.

Lin et al. (1999) ${ }^{(54)}$ encontrou que para a redução de $\mathrm{Fe}_{3} \mathrm{O}_{4}$ para $\mathrm{Fe}$, a mesma função controladora foi obtida. Rao (1979) ${ }^{(139)}$ também reportou que a etapa inicial de redução de óxidos de ferro é a nucleação. A nucleação é formada sobre a superfície exposta da partícula. A redução envolve a formação de um núcleo de ferro e seu crescimento sobre a fase de óxido de ferro. 0 fenômeno de nucleação e crescimento na redução de óxidos de ferro tem sido reportado por outros pesquisadores, tais como Themelis e Gauvin (1962) ${ }^{(140)}$; Hayes (1979) ${ }^{(141)}$; El-Rahaiby e Rao (1979) ${ }^{(142)}$.

Entre 700 a $850^{\circ} \mathrm{C}$, foi observado na Tabela 12 que as funções R3, D1, D2, D3 e D4 apresentaram linearidade, portanto sendo estas possíveis funções controladoras. A função R3 apresentou o menor valor de coeficiente de correlação entre as funções escolhidas $(0,98)$. Além disso, conforme critérios 
adotados neste trabalho, o valor da energia de ativação aparente encontrada para esta função é menor do que $13 \mathrm{~kJ} / \mathrm{mol}$, o que significa que esta função não se enquadra nos pré-requisitos para ser a etapa controladora.

Deste modo, pode-se observar que nesta etapa da redução (entre 700 e $850^{\circ} \mathrm{C}$ ), a reação é controlada por difusão, uma vez que as funções D1, D2, D3 e D4 apresentam fatores de correlação de 0,99. Conforme critérios adotados para identificação do valor de energia de ativação aparente, chega-se à conclusão que para esta faixa de temperatura, a energia de ativação aparente apresenta um valor de $54,9 \mathrm{~kJ} / \mathrm{mol}$.

A difusão D3 é citada como uma equação onde a reação ocorrer igualmente em todas as partes das partículas. Entretanto, pode ocorre um decréscimo na taxa de reação com o prosseguimento da reação. Este fato se deve a formação e crescimento de uma camada ao redor da partícula que dificulta a continuidade da reação ${ }^{(53)}$.

De acordo com Pineau, Kanari e Gaballah (2007) ${ }^{(68)}$, para redução de $\mathrm{Fe}_{3} \mathrm{O}_{4}$ em temperaturas superiores a $650^{\circ} \mathrm{C}$, a difusão é o mecanismo controlador. Além disso, em $700^{\circ} \mathrm{C}$ ocorre à sinterização das partículas. Quando este fenômeno ocorre, um decréscimo na porosidade e na área superficial das partículas pode ocorrer. Em adição, o crescimento de uma camada ao redor das partículas pode aparecer, atuando como uma barreira à continuidade da reação ${ }^{(143,144)}$.

Foi observado novamente que a partir de $900^{\circ} \mathrm{C}$ ocorreu uma mudança no mecanismo controlador. A partir desta temperatura, foi observado que somente as funções D2, D3 e D4 apresentaram linearidade, portanto, sendo estas funções possíveis controladoras entre 900 a $1000^{\circ} \mathrm{C}$. As três funções apresentam um fator de correlação de 0,99. Sendo assim, a energia de ativação aparente de descreverá esta etapa da reação é de $80,7 \mathrm{~kJ} / \mathrm{mol}$, procedente da equação D2.

Similar resultado foi encontrado por Pineau, Kanari e Gaballah $(2007){ }^{(68)}$, onde os pesquisadores realizaram a redução de $\mathrm{Fe}_{3} \mathrm{O}_{4}$ por hidrogênio. Os autores comentam que em $878^{\circ} \mathrm{C}$, a redução foi controlada pela função D2. 
5.2.1.1.2 Caracterização das Pelotas reagidas

Após o fim dos ensaios de redução, imagens de microscópio eletrônico de varredura (Figura 50) e espectros de EDS (Figura 51) foram obtidas nas pelotas reduzidas até o patamar de $900^{\circ} \mathrm{C}$ por mistura gasosa.

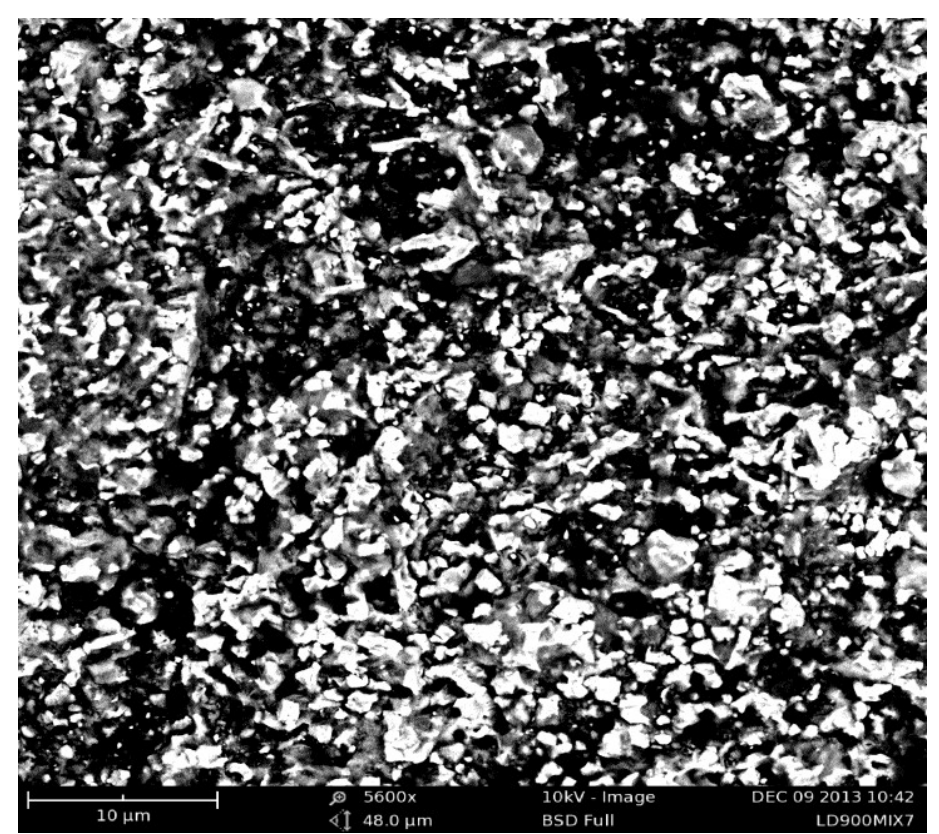

Figura 50 - Imagem retro-espalhada obtida por microscópio eletrônico de varredura da pelota de poeira de aciaria LD reduzida com mistura gasosa interrompida a $900^{\circ} \mathrm{C}$.

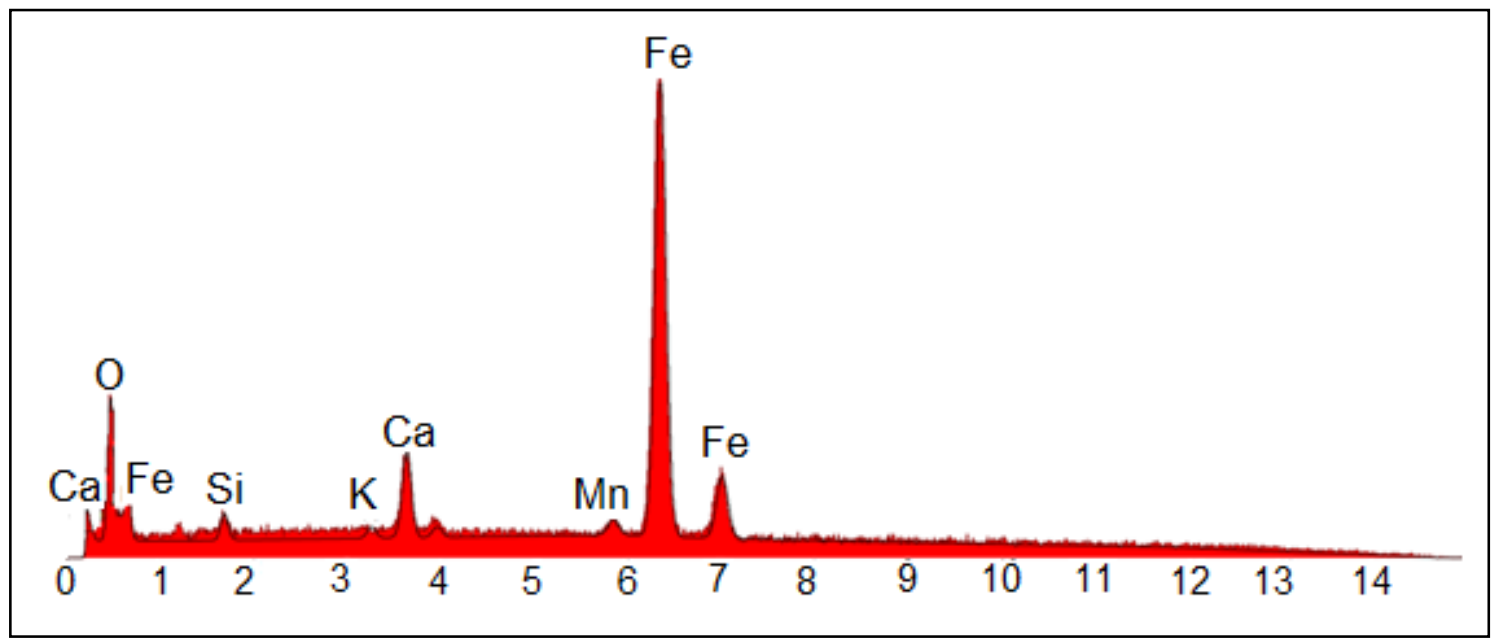

Figura 51 - Espectro de EDS obtida na região apresentada na Figura 50. 
Através da Figura 50 , pode-se observar que a $900^{\circ} \mathrm{C}$, a estrutura da pelota apresenta-se sinterizada.

Pelo espectro de EDS da Figura 51 é possível notar a predominância de ferro na amostra. Pode-se notar também a presença de picos de $\mathrm{Ca}, \mathrm{O}, \mathrm{Si}, \mathrm{Ke}$ $\mathrm{Mn}$, sendo estes provenientes da amostra inicial. O oxigênio, possivelmente é decorrente dos óxidos de cálcio e silício e da magnetita.

Foi realizada análise por difração de raios- $X$ da pelota de poeira de aciaria LD reduzida com mistura redutora. $O$ difratograma pode ser visto na Figura 52.

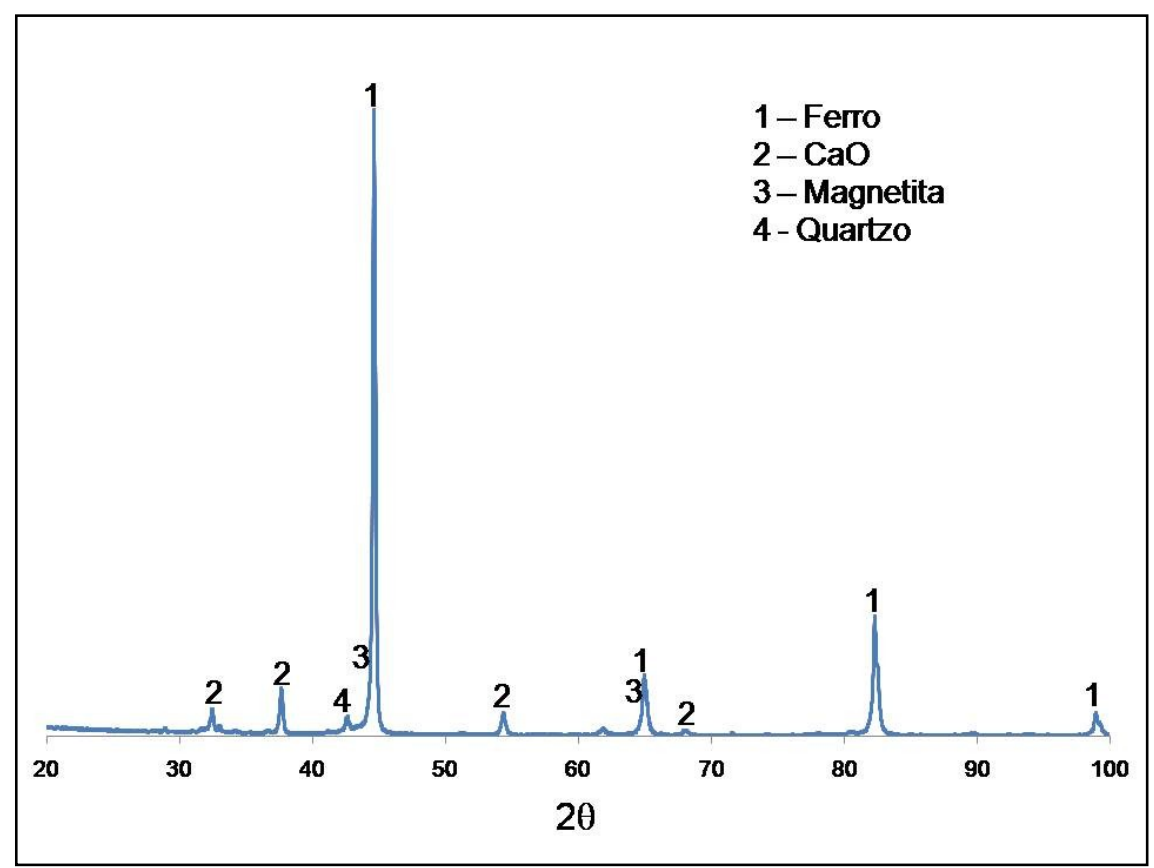

Figura 52 - Difratograma obtido da pelota de poeira de aciaria LD reduzida com mistura redutora.

O difratograma mostrou que a principal fase encontrada foi o ferro. Além disso, foram observadas a presença de outras fases, como o $\mathrm{CaO}$, quartzo e magnetita. Foi aplicado também o método Rietveld de quantificação de fases. O resultado desta quantificação pode ser observado na Tabela 13. 
Tabela 13 - Quantificação de fases pelo método Rietveld da pelota de poeira de aciaria LD reduzida com mistura redutora.

\begin{tabular}{c|c}
\hline Fases & $\%$ \\
\hline Ferro & 79,5 \\
\hline $\mathrm{CaO}$ & 20 \\
\hline Quartzo & 0,3 \\
\hline Magnetita & 0,3 \\
\hline
\end{tabular}

A quantificação das fases comprovou o que foi dito anteriormente, que o ferro está presente em maior proporção em relação às outras fases. $O$ ferro apresentou uma proporção de $79,5 \%$, enquanto que o $\mathrm{CaO}$ foi de $20 \%$, quartzo $0,3 \%$ e magnetita $0,3 \%$.

\subsubsection{Redução com gás natural simulado}

Análises utilizando gás natural simulado também foram realizadas nas pelotas feitas com poeira de aciaria LD. Os resultados dos ensaios de perda de massa das pelotas de poeira de aciaria LD reduzidas com gás natural simulado podem ser vistos na Figura 53.

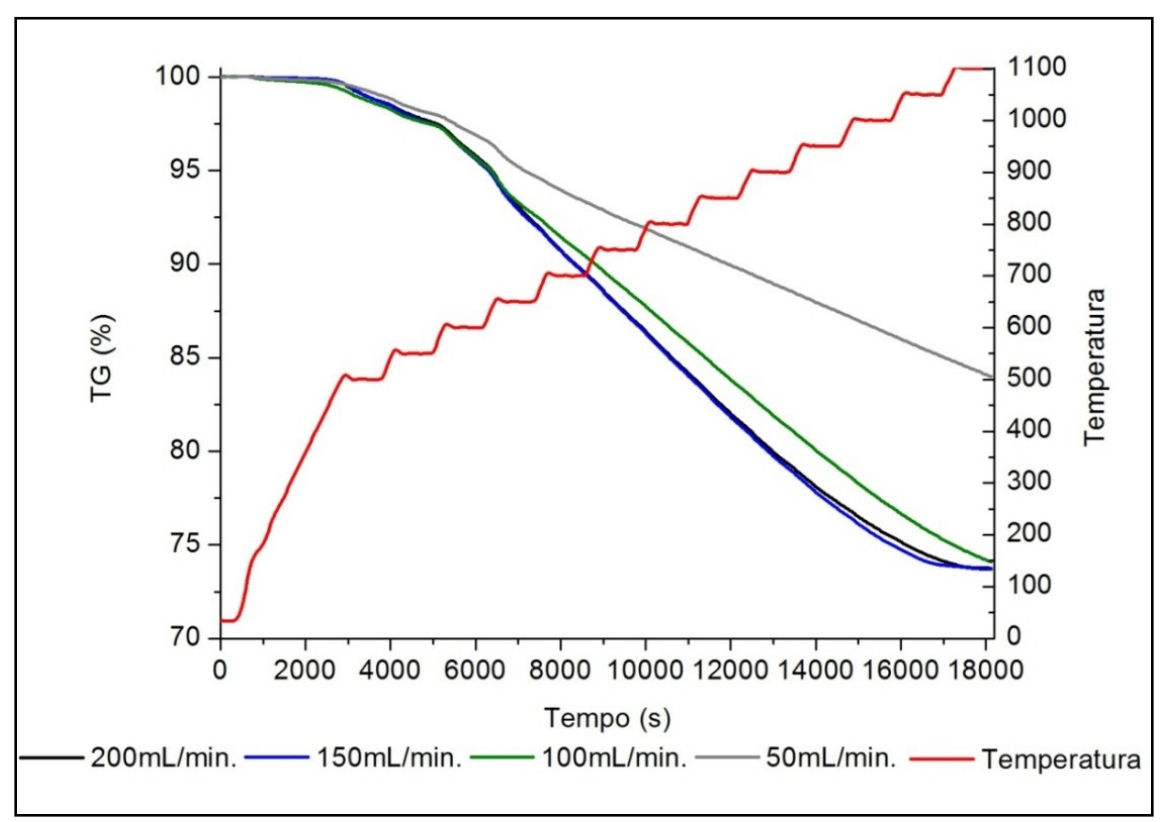

Figura 53 - Análise termogravimétrica com pelotas feitas com poeira de aciaria LD utilizando gás natural simulado como agente redutor para diferentes fluxos. 
Assim como no caso da mistura gasosa, o aumento do fluxo de gás redutor provocou um aumento na taxa de redução. Este fato pode ser comprovado pela inclinação das curvas apresentadas na Figura 53. Outro fato notado foi que para os fluxos de 150 e $200 \mathrm{~mL} /$ minuto a reação foi finalizada, sendo obtida uma perda de massa de aproximadamente $26 \%$. Para os fluxos de 50 e $100 \mathrm{~mL} /$ minuto a redução não foi completada, apresentando perda de massas menor que $26 \%$. Foi observado também que, para o fluxo de $200 \mathrm{~mL} /$ minuto, a reação foi finalizada a $1050^{\circ} \mathrm{C}$.

Pode ser visto também na Figura 53 que para temperaturas inferiores a $650^{\circ} \mathrm{C}$, a curva de perda de massa apresentou-se irregular. Este fato tem sido reportado na literatura como sendo devido à deposição de carbono procedente do CO contido na mistura redutora. De acordo com Hughes, Kam e Zadeh $(1982)^{(145)}$, a deposição do carbono pode ocorrer entre as temperaturas de 600 a $800^{\circ} \mathrm{C}$. Assim, este fenômeno inviabiliza a avaliação dos dados obtidos para temperaturas menores do que $650^{\circ} \mathrm{C}$.

Deste modo, foi realizada difração de raios-X (Figura 54) da camada externa da pelota de poeira de aciaria LD reduzida com gás natural simulado com o intuito de comprovar a deposição do carbono sobre a superfície da pelota. A difração de raios- $X$ foi realizada em uma pelota onde a análise foi interrompida na temperatura de $600^{\circ} \mathrm{C}$. 


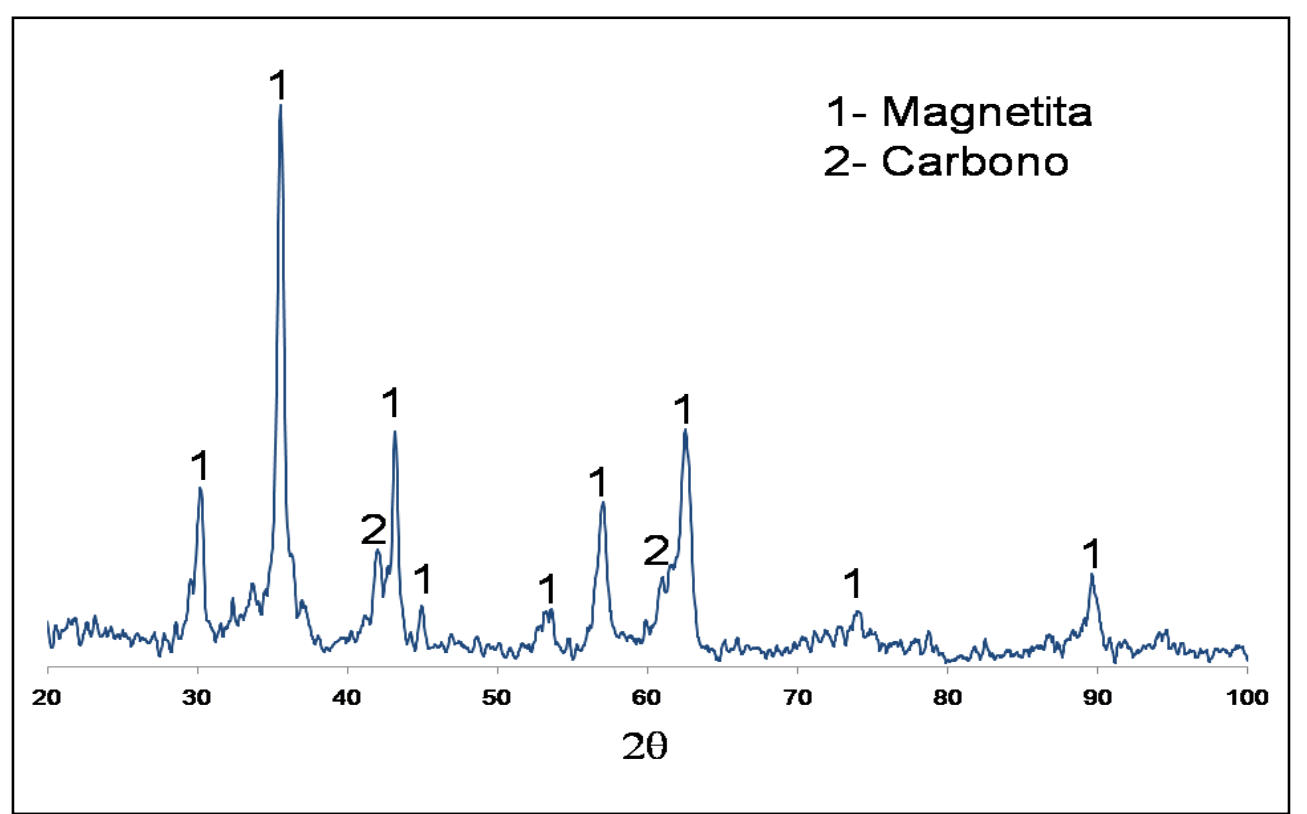

Figura 54 - Espectro de difração de raios-X obtido da camada externa da pelota de poeira de aciaria LD reduzida até a temperatura de $600^{\circ} \mathrm{C}$ com uso de gás natural simulado.

Através do espectro apresentado na Figura 54 é possível observar a presença de picos de carbono. Assim, comprovando-se que na superfície da pelota de poeira de aciaria LD houve a deposição de carbono no inicio da reação de redução. A magnetita observada no difratograma é proveniente da composição inicial da poeira.

\subsection{Análise cinética}

Inicialmente, foi feita a comparação dos fatores de correlação das funções citadas pela literatura tanto para a forma integral quanto para a diferencial, na tentativa de pré-selecionar algumas possíveis funções controladoras. Os valores dos fatores de correlação obtidos são apresentados na Tabela 14.

Notou-se que os valores de fatores de correlação estão muito próximos um dos outros, não sendo possível a pré-determinação de possíveis funções controladoras. 
Tabela 14 - Coeficientes de correlação para as funções citadas como possíveis controladoras para a redução de pelotas de poeira de aciaria LD reduzida com gás natural simulado.

\begin{tabular}{|c|c|c|c|c|c|c|c|c|c|c|c|c|c|c|c|c|}
\hline \multirow[b]{3}{*}{ Temperatura } & \multicolumn{16}{|c|}{ Funções } \\
\hline & \multicolumn{2}{|c|}{$\mathrm{A} 2$} & \multicolumn{2}{|c|}{ A3 } & \multicolumn{2}{|c|}{$\mathrm{D} 1$} & \multicolumn{2}{|c|}{$\mathrm{D} 2$} & \multicolumn{2}{|c|}{ D3 } & \multicolumn{2}{|c|}{ D4 } & \multicolumn{2}{|c|}{$\mathrm{R} 2$} & \multicolumn{2}{|c|}{ R3 } \\
\hline & Dif. & Int. & Dif. & Int. & Dif. & Int. & Dif. & Int. & Dif. & Int. & Dif. & Int. & Dif. & Int. & Dif. & Int. \\
\hline 550 & 0,96 & 0,96 & 0,95 & 0,97 & 0,98 & 0,99 & 0,98 & 0,91 & 0,96 & 0,90 & 0,95 & 0,99 & 0,98 & 0,99 & 0,95 & 0,99 \\
\hline 600 & 0,85 & 0,98 & 0,84 & 0,98 & 0,88 & 0,99 & 0,82 & 0,93 & 0,82 & 0,93 & 0,79 & 0,99 & 0,78 & 0,99 & 0,78 & 0,99 \\
\hline 650 & 0,98 & 0,98 & 0,97 & 0,98 & 0,98 & 0,99 & 0,98 & 0,936 & 0,98 & 0,94 & 0,96 & 0,99 & 0,93 & 0,99 & 0,96 & 0,99 \\
\hline 800 & 0,98 & 0,99 & 0,95 & 0,99 & 0,99 & 0,99 & 0,99 & 0,99 & 0,99 & 0,99 & 0,99 & 0,99 & 0,98 & 0,99 & 0,99 & 0,99 \\
\hline 850 & 0,99 & 0,99 & 0,98 & 0,99 & 0,99 & 0,99 & 0,99 & 0,99 & 0,99 & 0,99 & 0,99 & 0,99 & 0,99 & 0,99 & 0,99 & 0,99 \\
\hline 900 & 0,98 & 0,99 & 0,98 & 0,99 & 0,99 & 0,99 & 0,99 & 0,99 & 0,99 & 0,99 & 0,98 & 0,99 & 0,98 & 0,99 & 0,98 & 0,99 \\
\hline 950 & 0,98 & 0,99 & 0,98 & 0,99 & 0,99 & 0,99 & 0,99 & 0,99 & 0,99 & 0,99 & 0,98 & 0,96 & 0,98 & 0,99 & 0,98 & 0,99 \\
\hline 1000 & 0,98 & 0,99 & 0,98 & 0,99 & 0,98 & 0,99 & 0,98 & 0,98 & 0,98 & 0,97 & 0,98 & 0,96 & 0,98 & 0,99 & 0,98 & 0,99 \\
\hline
\end{tabular}


Partiu-se então para o segundo método, que foi o levantamento das curvas de Arrhenius que podem ser vistas na Figura 55.

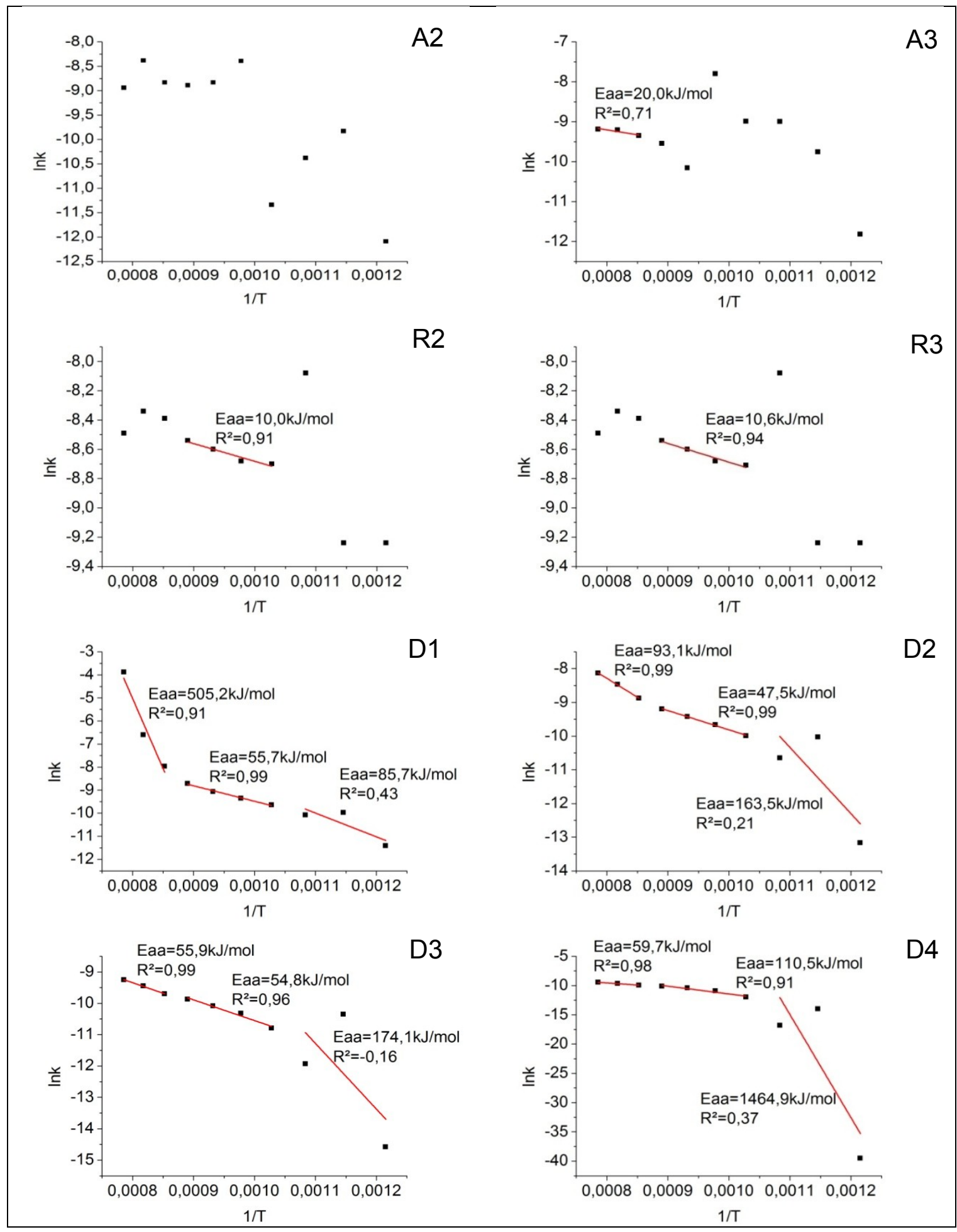

Figura 55 - Curvas de Arrhenius obtidas para a redução de pelotas feitas com de poeira de aciaria LD reduzida com gás natural simulado. 
Foi observado que a redução de pelotas de poeira de aciaria LD com gás natural simulado corre novamente em três etapas, 550 a $650^{\circ} \mathrm{C}, 700$ a $850^{\circ} \mathrm{C}$ e entre 900 a $1000^{\circ} \mathrm{C}$. Entretanto, na primeira etapa ocorreu o fenômeno de deposição de carbono sobre a superfície da pelota. Portanto, estes dados não são confiáveis, e foram descartados.

Em seguida, foi realizada uma compilação dos resultados obtidos pelas curvas de Arrhenius que pode ser vista na Tabela 15.

Tabela 15 - Energias de ativação aparente e fatores de correlação obtidos a partir das curvas de Arrhenius para a redução de pelotas de poeira de aciaria

LD reduzida por gás natural reformado.

\begin{tabular}{c|c|c|c|c|c|c}
\hline & \multicolumn{2}{|c|}{550 a $650^{\circ} \mathrm{C}$} & \multicolumn{2}{c|}{700 a $850^{\circ} \mathrm{C}$} & \multicolumn{2}{c}{900 a $1000^{\circ} \mathrm{C}$} \\
\hline Funções & $\begin{array}{c}\text { Eaa } \\
(\mathrm{kJ} / \mathrm{mol})\end{array}$ & $\mathrm{R}^{2}$ & $\begin{array}{c}\text { Eaa } \\
(\mathrm{kJ} / \mathrm{mol})\end{array}$ & $\mathrm{R}^{2}$ & $\begin{array}{c}\text { Eaa } \\
(\mathrm{kJ} / \mathrm{mol})\end{array}$ & $\mathrm{R}^{2}$ \\
\hline A2 & - & - & - & - & - & - \\
\hline A3 & - & - & - & - & 20 & 0,71 \\
\hline R2 & - & - & 10 & 0,91 & - & - \\
\hline R3 & - & - & 10,6 & 0,94 & - & - \\
\hline D1 & 85,7 & 0,43 & 55,7 & 0,99 & 505,2 & 0,91 \\
\hline D2 & 163,5 & 0,21 & 47,5 & 0,99 & 93,1 & 0,99 \\
\hline D3 & 174,1 & 0,16 & 54,8 & 0,96 & 55,9 & 0,99 \\
\hline D4 & 1464,9 & 0,37 & 110,5 & 0,91 & 59,7 & 0,98 \\
\hline
\end{tabular}

Como pode ser notado através da Tabela 15 , entre 700 a $850^{\circ} \mathrm{C}$, as funções D1 e D2 aparecem como candidatas para ser a função controladora. Foi observado também, que ambas apresentam um fator de correlação de 0,99 nesta faixa de temperatura. Tendo em mãos que ambas as funções controladoras apresentam o mesmo fator de correlação, foi aplicado o último método descrito para a determinação do valor de energia de ativação aparente que comandará esta etapa. Seguindo este contexto, foi observado que a aplicação da função D1 apresenta uma energia de ativação de 55,7kJ/mol, sendo assim, este valor o predominante neste intervalo de temperatura.

A próxima faixa de temperatura observada foi entre 900 a $1000^{\circ} \mathrm{C}$. Aplicando o mesmo método de análise, chegou-se a conclusão que as funções candidatas a controladora para esta faixa de temperatura são as funções D2 e D3, uma vez que, fatores de correlação de 0,99 foram obtidos. A energia de 
ativação aparente para esta etapa da redução é de $93,1 \mathrm{~kJ} / \mathrm{mol}$ definida pela função D2.

Um fator observado foi o aumento do valor da energia de ativação aparente com o uso de gás natural reformado com relação à mistura gasosa. Este fato está ligado à introdução de CO na composição do gás redutor. Tem sido reportado pela literatura que a introdução de $\mathrm{CO}$ em misturas redutoras contendo $\mathrm{H}_{2}$ acarreta um retardamento na reação de redução de óxidos de ferro ${ }^{(145,146)}$.

\subsection{Caracterização das pelotas reduzidas}

Imagem de microscópio eletrônico de varredura (Figura 56) foi obtida na pelota de poeira de aciaria LD reduzida com gás natural simulado. Para completar a análise, espectro de EDS (Figura 57) foi obtido na região apresentada na Figura 56.

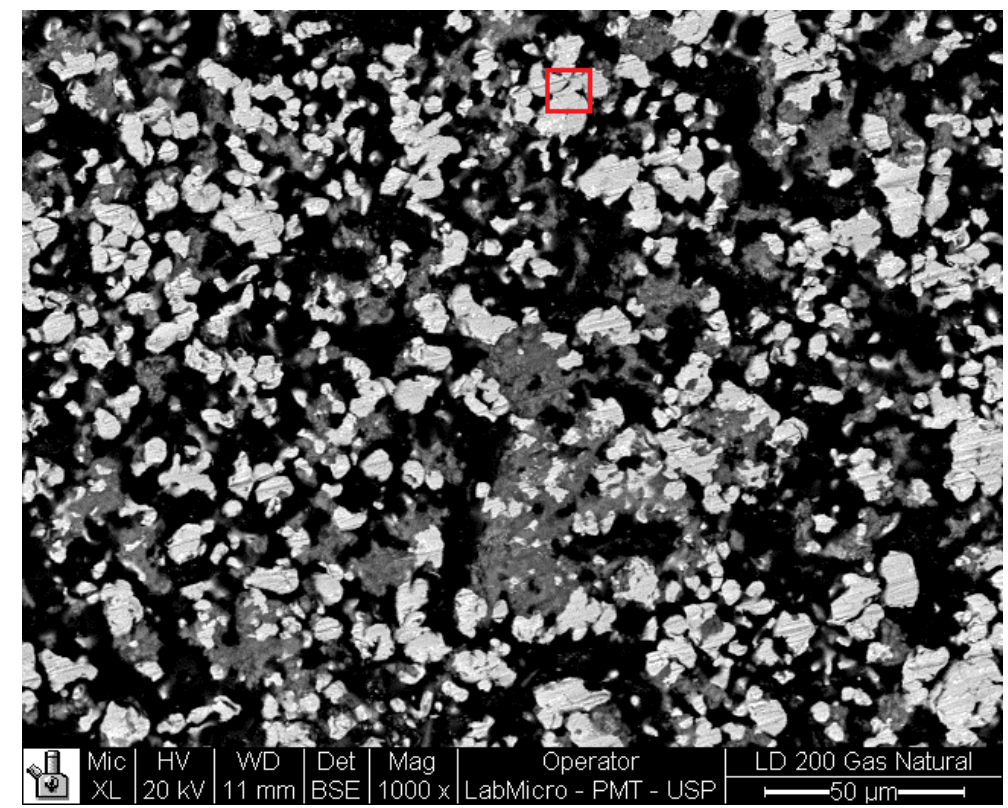

Figura 56 - Imagem obtida por microscópio eletrônico de varredura da pelota de poeira de aciaria LD reduzida por gás natural simulado com fluxo de $200 \mathrm{~mL} /$ minuto. 


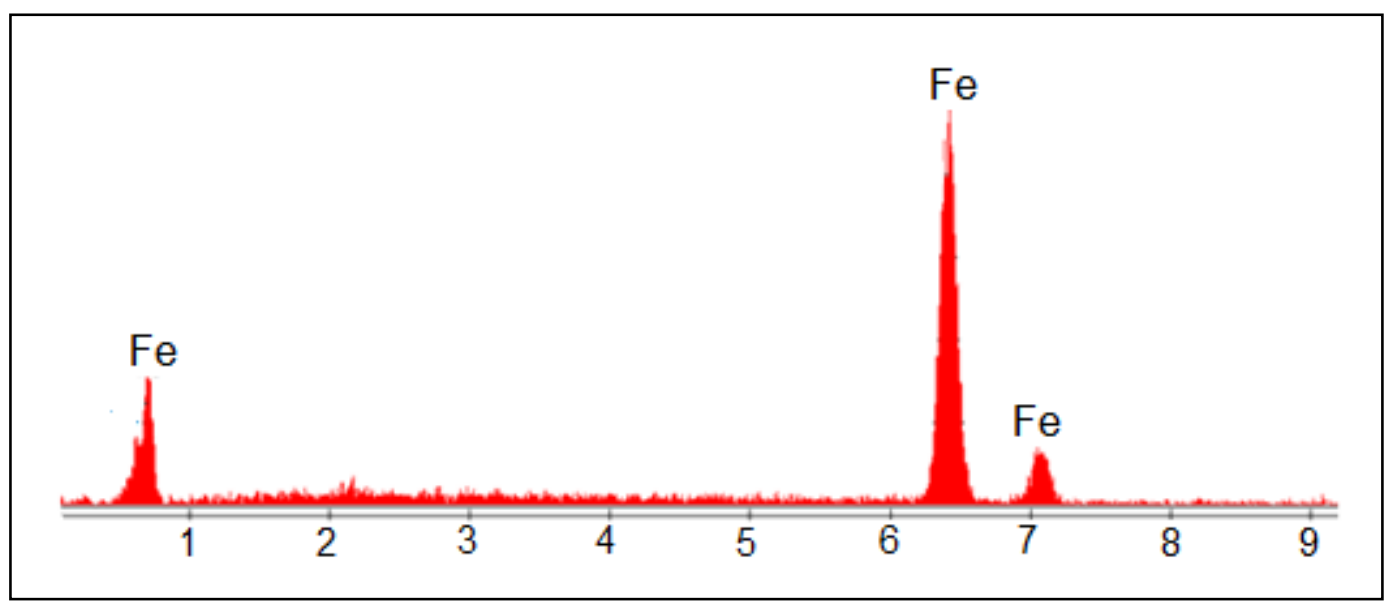

Figura 57 - Espectros de EDS obtida na pelota de poeira de aciaria LD reduzida por gás natural simulado com fluxo de $200 \mathrm{~mL} /$ minuto.

Através da imagem de microscópio eletrônico de varredura (Figura 56) pode-se observar que as partículas que constituem a pelota apresentam um aspecto sinterizado. Para complementar a análise, a Figura 57 traz o espectro de EDS da partícula que constitui a pelota, onde se pode notar que somente picos de ferro foram encontrados após a redução.

5.2.2 Pelotas de poeira de aciaria Elétrica

\subsubsection{Redução com mistura redutora}

A Figura 58 apresenta os resultados das análises termogravimétricas obtidos nas pelotas de poeira de aciaria elétrica com fluxos de 50, 100, 150 e $200 \mathrm{~mL} /$ minuto de mistura redutora. 


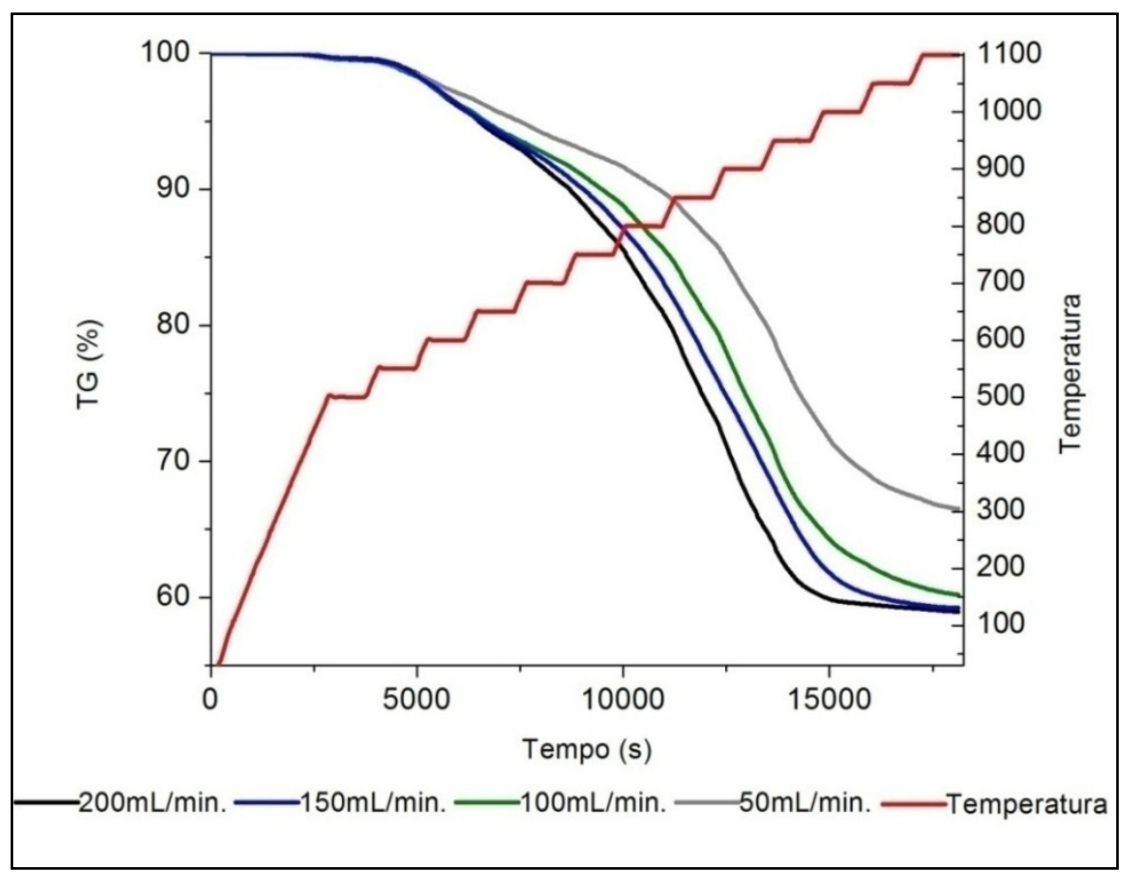

Figura 58 - Curvas de perda de massa das pelotas de poeira de aciaria elétrica em função do tempo para diferentes fluxos de mistura gasosa.

Observa-se na Figura 58 uma variação na inclinação das curvas. Quando se utilizou um fluxo de mistura de $50 \mathrm{~mL} / \mathrm{minuto}$, foi observado que a perda de massa foi de aproximadamente 34\%. É observado também que a maior perda de massa foi obtido utilizando um fluxo de mistura gasosa de $200 \mathrm{~mL} /$ minuto, onde foi obtido aproximadamente $42 \%$ de perda de massa. A perda de massa obtida para este material está associada à remoção do oxigênio dos óxidos de ferro e zinco, assim como na remoção do zinco ${ }^{(39)}$.

Outro ponto identificado foi que a reação de redução foi finalizada, no caso da utilização do fluxo de $200 \mathrm{~mL} /$ minuto, no patamar de temperatura de $1000^{\circ} \mathrm{C}$. 


\subsection{Análise cinética}

Seguindo os critérios adotados para a investigação cinética, primeiramente foi feita a comparação dos fatores de correlação para as relações $d(\alpha) / d t \times f(\alpha)$ e $g(\alpha) \times t$, que podem ser vistos na Tabela 16.

Mais uma vez, a aplicação do critério de análise dos fatores de correlação para as relações $d(\alpha) / d t \times f(\alpha)$ e $g(\alpha) \times t$ não foi bem sucedida para ajudar na interpretação dos resultados.

Foram levantadas as curvas de Arrhenius (Figura 59) para os dados obtidos na redução das pelotas de poeira de aciaria elétrica reduzidas com mistura gasosa. 
Tabela 16 - Fatores de correção obtidos para as relações $d(\alpha) / d t \times f(\alpha)$ e $g(\alpha) \times t$ para a redução de pelotas de poeira de aciaria elétrica reduzida com mistura redutora.

\begin{tabular}{|c|c|c|c|c|c|c|c|c|c|c|c|c|c|c|c|c|}
\hline & \multicolumn{16}{|c|}{ Funções } \\
\hline & \multicolumn{2}{|c|}{ A2 } & \multicolumn{2}{|c|}{ A3 } & \multicolumn{2}{|c|}{ D1 } & \multicolumn{2}{|c|}{ D2 } & \multicolumn{2}{|c|}{ D3 } & \multicolumn{2}{|c|}{ D4 } & \multicolumn{2}{|c|}{ R2 } & \multicolumn{2}{|c|}{ R3 } \\
\hline 500 & 0,52 & 0,97 & 0,63 & 0,97 & 0,73 & 0,99 & 0,73 & 0,92 & 0,82 & 0,99 & 0,61 & 0,92 & 0,6 & 0,99 & 0,6 & 0,99 \\
\hline 600 & 0,78 & 0,97 & 0,79 & 0,98 & 0,7 & 0,99 & 0,7 & 0,9 & 0,67 & 0,99 & 0,8 & 0,9 & 0,8 & 0,99 & 0,8 & 0,99 \\
\hline 650 & 0,99 & 0,97 & 0,98 & 0,98 & 0,99 & 0,99 & 0,99 & 0,93 & 0,98 & 0,99 & 0,98 & 0,93 & 0,98 & 0,99 & 0,98 & 0,99 \\
\hline 700 & 0,95 & 0,99 & 0,94 & 0,99 & 0,95 & 0,99 & 0,95 & 0,98 & 0,95 & 0,99 & 0,93 & 0,95 & 0,93 & 0,99 & 0,93 & 0,99 \\
\hline 800 & 0,53 & 0,99 & 0,97 & 0,99 & 0,97 & 0,99 & 0,97 & 0,98 & 0,97 & 0,99 & 0,97 & 0,98 & 0,97 & 0,99 & 0,97 & 0,99 \\
\hline 850 & 0,94 & 0,99 & 0,73 & 0,99 & 0,98 & 1 & 0,98 & 0,98 & 0,98 & 0,99 & 0,97 & 0,98 & 0,97 & 0,99 & 0,97 & 0,99 \\
\hline 900 & 0,98 & 0,99 & 0,97 & 0,99 & 0,99 & 0,99 & 0,99 & 0,98 & 0,99 & 0,99 & 0,99 & 0,98 & 0,98 & 0,99 & 0,99 & 0,99 \\
\hline 950 & 0,99 & 0,99 & 0,99 & 0,99 & 0,99 & 0,99 & 0,99 & 0,01 & 0,99 & 0,99 & 0,99 & 0,46 & 0,99 & 0,99 & 0,99 & 0,99 \\
\hline 1000 & 0,98 & 0,92 & 0,98 & 0,92 & 0,98 & 0,85 & 0,98 & 0,97 & 0,98 & 0,91 & 0,99 & 0,97 & 0,99 & 0,96 & 0,98 & 0,96 \\
\hline 1050 & 0,48 & 0,99 & 0,48 & 0,99 & 0,49 & 0,99 & 0,48 & 0,99 & 0,48 & 0,99 & 0,48 & 0,99 & 0,48 & 0,99 & 0,48 & 0,99 \\
\hline
\end{tabular}




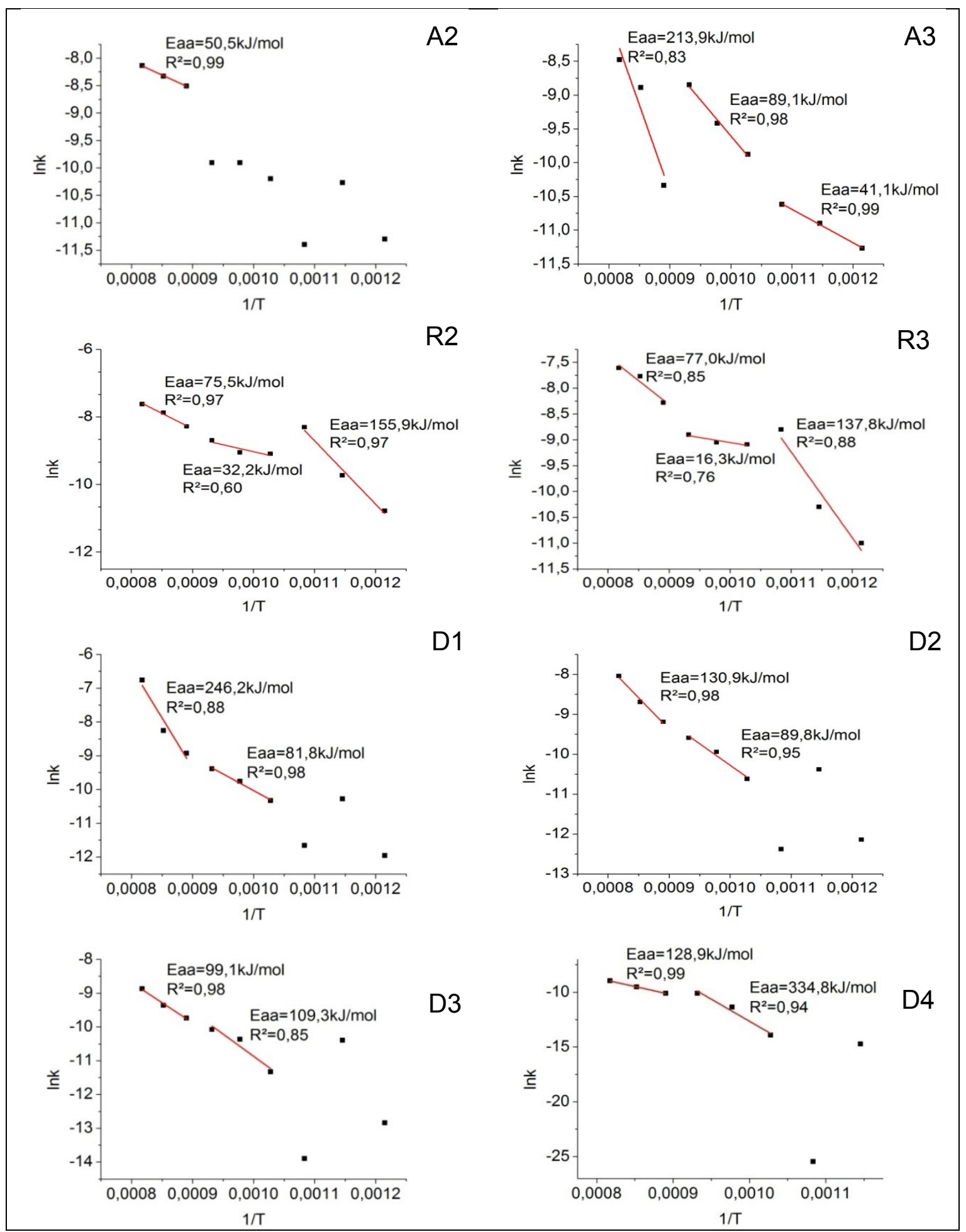

Figura 59 - Curvas de Arrhenius obtidas para a redução de pelotas de poeira de aciaria elétrica reduzidas por mistura gasosa.

As curvas de Arrhenius mostraram que a redução das pelotas de poeira de aciaria elétrica apresentaram três etapas distintas. A primeira foi entre 550 a $650^{\circ} \mathrm{C}$, a segunda entre 700 a $800^{\circ} \mathrm{C}$ e a última entre 850 a $950^{\circ} \mathrm{C}$. 
Os valores de energia de ativação aparente para cada etapa foram comparados na Tabela 17.

Tabela 17 - Compilação dos valores de energia de ativação aparente e fatores de correlação das funções utilizadas nos cálculos cinéticos para as pelotas de poeira de aciaria elétrica reduzidas com mistura redutora.

\begin{tabular}{c|c|c|c|c|c|c}
\hline & \multicolumn{2}{|c|}{550 a $650^{\circ} \mathrm{C}$} & \multicolumn{2}{c|}{700 a $800^{\circ} \mathrm{C}$} & \multicolumn{2}{c}{850 a $950^{\circ} \mathrm{C}$} \\
\hline Funções & Eaa & $\mathrm{R}^{2}$ & Eaa & $\mathrm{R}^{2}$ & Eaa & $\mathrm{R}^{2}$ \\
\hline A2 & - & - & - & - & 50,5 & 0,99 \\
\hline A3 & 41,1 & 0,99 & 89,1 & 0,98 & 213,9 & 0,83 \\
\hline R2 & 155,9 & 0,97 & 32,2 & 0,6 & 75,5 & 0,97 \\
\hline R3 & 137,8 & 0,88 & 16,3 & 0,76 & 77,0 & 0,85 \\
\hline D1 & - & - & 81,8 & 0,98 & 246,2 & 0,88 \\
\hline D2 & - & - & 89,8 & 0,95 & 130,9 & 0,98 \\
\hline D3 & - & - & 109,3 & 0,85 & 99,1 & 0,98 \\
\hline D4 & - & - & 334,8 & 0,94 & 128,9 & 0,99 \\
\hline
\end{tabular}

É observado que na primeira etapa apenas a função A3 se ajustou á reação de redução, apresentou fator de correlação de 0,99. Portanto, sendo esta função a controladora. Foi obtido um valor de energia de ativação aparente de $41,1 \mathrm{~kJ} / \mathrm{mol}$.

Na segunda etapa, foi observado que as funções A3 e D1 apresentaram uma boa linearidade, apresentando um fator de correlação de 0,98. Com isso, é dito que nesta etapa, o controle é misto. A função A3 apresentou uma energia de ativação aparente de $89,1 \mathrm{~kJ} / \mathrm{mol}$, enquanto que a função D1 apresentou uma energia de $81,8 \mathrm{~kJ} / \mathrm{mol}$. Deste modo, a energia de ativação aparente predominante nesta etapa é descrita pela função A3.

Por fim, foi visto que para a terceira etapa, duas funções apresentam-se como candidatas: A2 e D4, onde todas as funções apresentaram fatores de correlação de 0,99 . Deste modo, fica claro que nesta faixa de temperatura o mecanismo controlador é misto, apresentando a nucleação (A2) e difusão (D4) como processos limitantes. Com relação à energia de ativação aparente, foi notado que a equação por difusão é a que apresenta a maior energia $(128,9 \mathrm{~kJ} / \mathrm{mol})$, portanto, sendo esta a energia de ativação aparente global do sistema para as temperaturas entre 850 e $950^{\circ} \mathrm{C}$.

Estudos têm mostrado que a presença de impurezas, entre elas, o cálcio, são fomentadoras de núcleos. A partir da formação dos núcleos, ocorre 
o crescimento do mesmo, formando uma nova fase (ferro). Com o prosseguimento da reação, uma camada densa de ferro começa a ser formada a partir deste núcleo formado. Após a formação da camada densa, a difusão, tanto dos gases redutores quanto dos produtos gasosos é dificultada ${ }^{(96,111)}$.

Como o teor de cálcio presente na poeira de aciaria elétrica é menor do que na poeira de aciaria LD, a formação de uma camada densa de ferro será menos acentuada na primeira. Deste modo, o mecanismo de difusão não será tão preponderante quanto para a redução das pelotas de poeira de aciaria LD.

\subsection{Caracterização dos produtos reagidos}

Foram obtidas imagens por microscopia eletrônico de varredura da pelota de poeira de aciaria elétrica reduzida com mistura redutora utilizando fluxo de $200 \mathrm{~mL} /$ minutos. Para obtenção das imagens, as análises de termogravimetria foram interrompidas nos patamares de 700 e $900^{\circ} \mathrm{C}$. Também foram obtidos espectros de EDS em cada imagem.

A Figura 60 e 61 apresentam as imagens obtidas por microscópio eletrônico de varredura e o espectro de EDS, respectivamente, do ensaio interrompido na temperatura de $700^{\circ} \mathrm{C}$. 


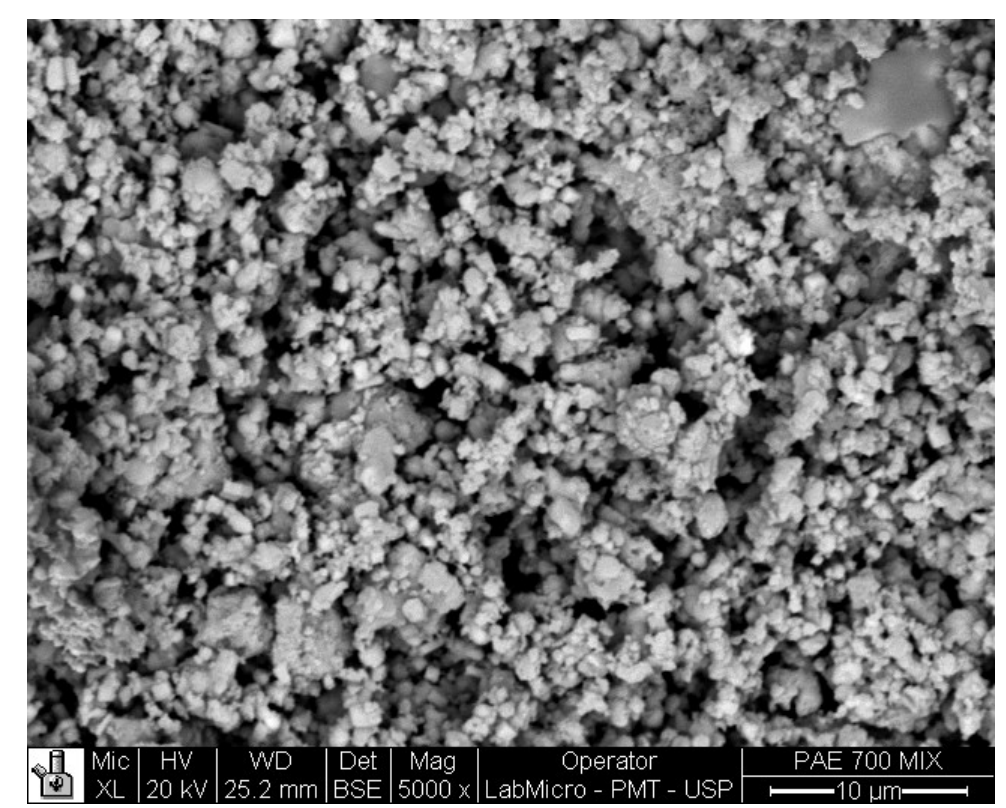

Figura 60 - Imagem de elétrons retro-espalhados obtido por microscópio eletrônico de varredura da pelota de poeira de aciaria elétrica reduzida com mistura redutora até o patamar de $700^{\circ} \mathrm{C} \mathrm{com} \mathrm{mistura} \mathrm{redutora.}$

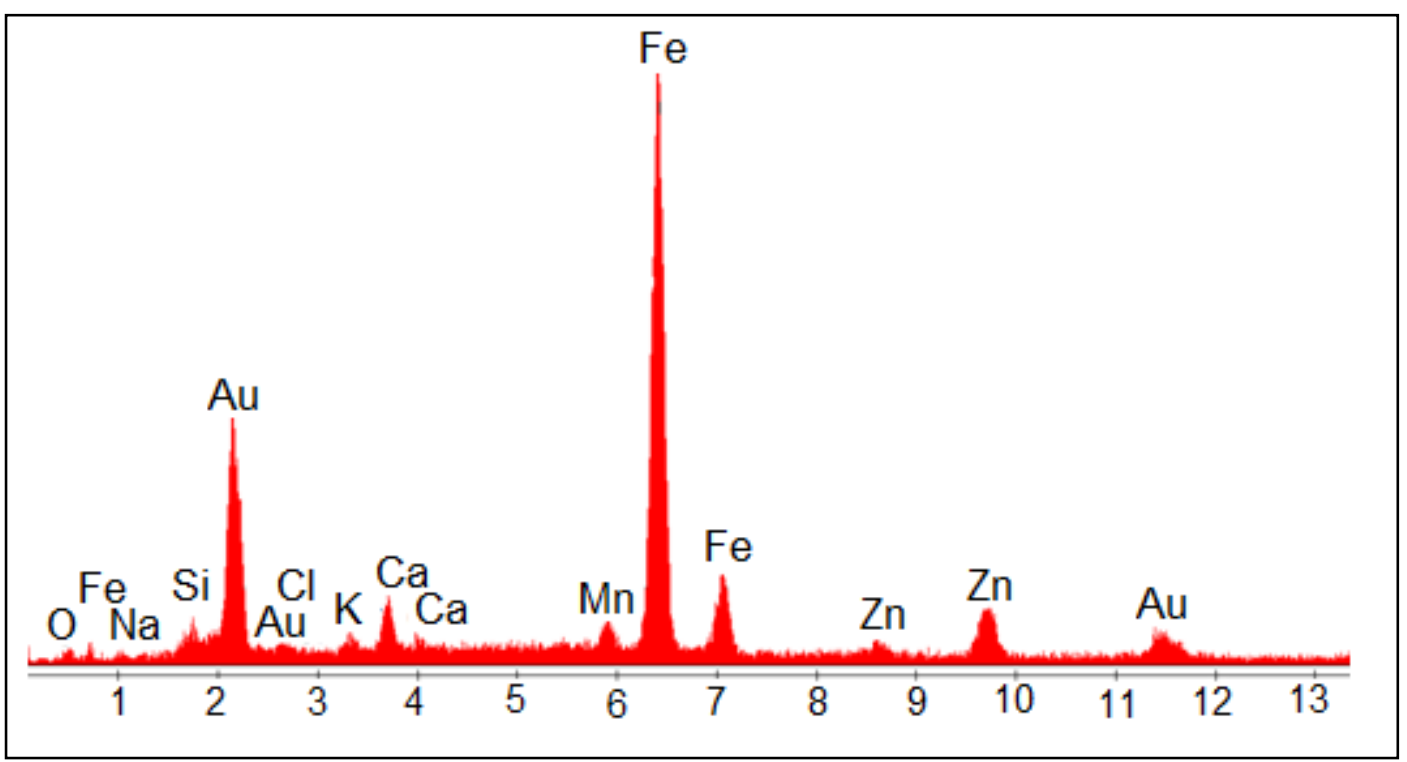

Figura 61 - Espectro de EDS da borda da pelota de poeira de aciaria elétrica reduzida com mistura redutora até o patamar de $700^{\circ} \mathrm{C}$.

A imagem apresentada na Figura 60 foi obtida na parte externa da pelota. É possível observar que as partículas ainda não apresentam um aspecto sinterizado. Através do espectro de EDS (Figura 61) é observado a presença majoritária do pico de ferro. O pico de oxigênio apresentou menor intensidade, sugerindo que a reação de redução neste ponto foi quase que completa. 
As Figuras 62 e 63 apresentam, respectivamente, uma imagem obtida por microscopia eletrônica de varredura e espectro de EDS da pelota de poeira de aciaria elétrica, onde a análise foi interrompida na temperatura de $900^{\circ} \mathrm{C}$.

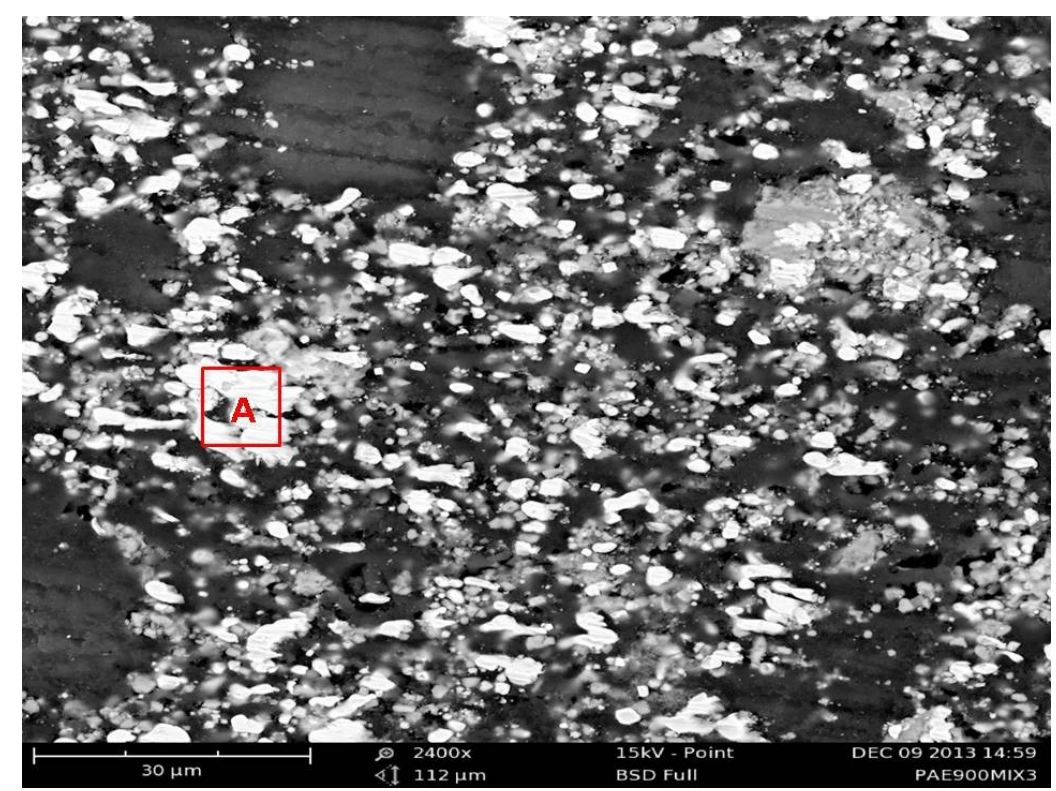

Figura 62 - Imagem de elétrons retro-espalhados obtido por microscópio eletrônico de varredura da pelota de poeira de aciaria elétrica reduzida com mistura redutora até o patamar de $900^{\circ} \mathrm{C} \mathrm{com}$ mistura redutora.

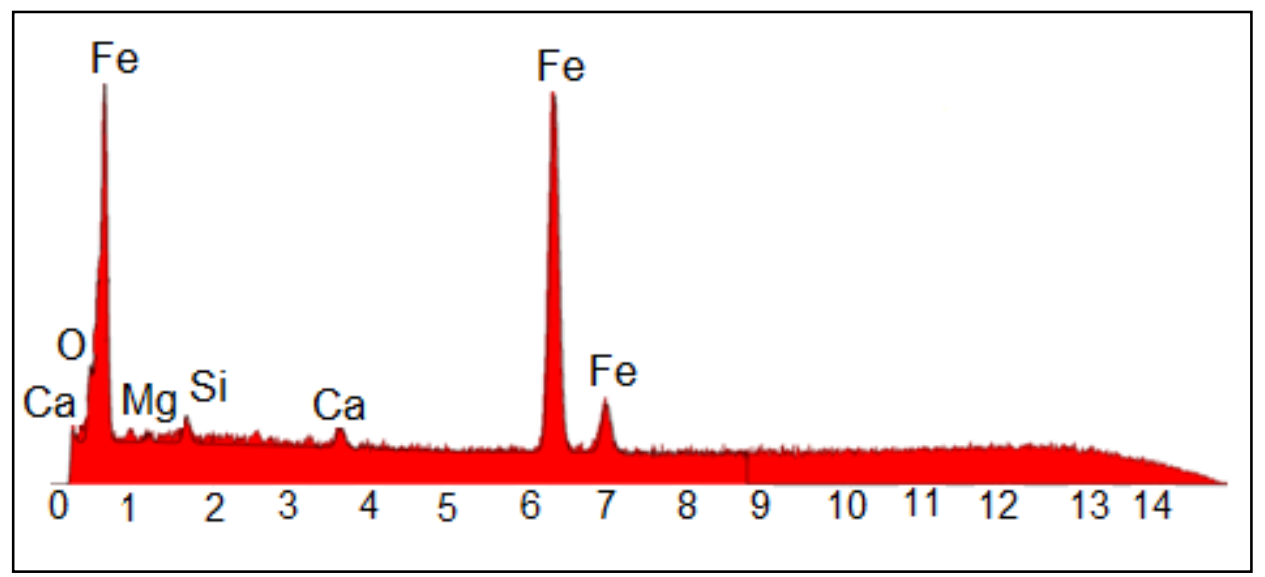

Figura 63 - Espectro de EDS obtido do ponto A da pelota de poeira de aciaria elétrica reduzida com mistura redutora até o patamar de $900^{\circ} \mathrm{C}$ mostrada na Figura 62.

É visto que na temperatura de $900^{\circ} \mathrm{C}$, as partículas presentes na pelota apresentam um aspecto sinterizado. Pelo espectro de EDS foi observado que o ferro é o elemento em maior proporção. O pico de oxigênio é provavelmente proveniente do óxido de silício remanescente da poeira. 
Quando ocorre a sinterização das partículas, uma diminuição do volume de poros é observada. Desta forma, a reação tende a ser controlada pela difusão interna dos gases redutores ${ }^{(143,147)}$.

Em seguida, foi realizada a difração de raios-X na pelota completamente reduzida. O difratograma pode ser visto na Figura 64 .

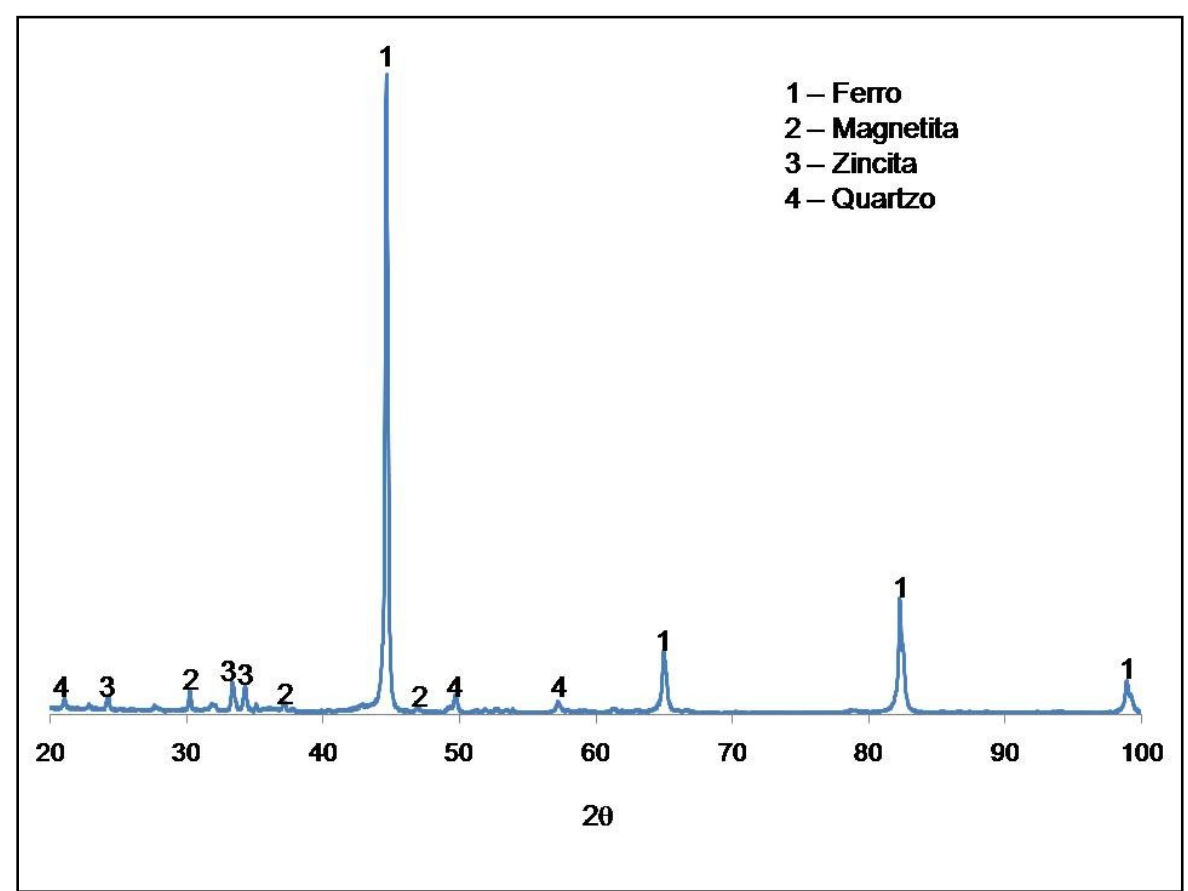

Figura 64 - Difratograma obtido na pelota de poeira de aciaria elétrica reduzida com mistura redutora com fluxo de $200 \mathrm{~mL} /$ minuto.

O difratograma mostra que após a reação, a pelota ainda apresentou picos de magnetita e zincita, além de quartzo. Porém, a fase de ferro metálico foi a fase que apresentou picos com maiores intensidades.

Foi utilizado o método Rietveld de quantificação de fases do difratograma da Figura 64. Os resultados podem ser vistos na Tabela 18.

Tabela 18 - Aplicação do método Rietveld de quantificação de fases no difratograma obtido na pelota de poeira de aciaria elétrica reduzida com mistura redutora.

\begin{tabular}{c|c}
\hline Fases & $\%$ \\
\hline Ferro & 82,8 \\
\hline Quartzo & 11 \\
\hline Zincita & 2,9 \\
\hline Magnetita & 3,3 \\
\hline
\end{tabular}


Pela quantificação das fases, foi observado que o ferro metálico foi a principal fase encontrada, com $82,8 \%$. Foram encontradas também fases de quartzo $(11 \%)$, magnetita $(3,3 \%)$ e zincita $(2,9 \%)$.

\subsubsection{Redução com gás natural simulado}

Foram realizadas as análises termogravimétricas das pelotas de poeira de aciaria elétrica utilizando gás natural simulado como agente redutor. As curvas de perda de massa versus tempo para as análises pode ser observadas na Figura 65.

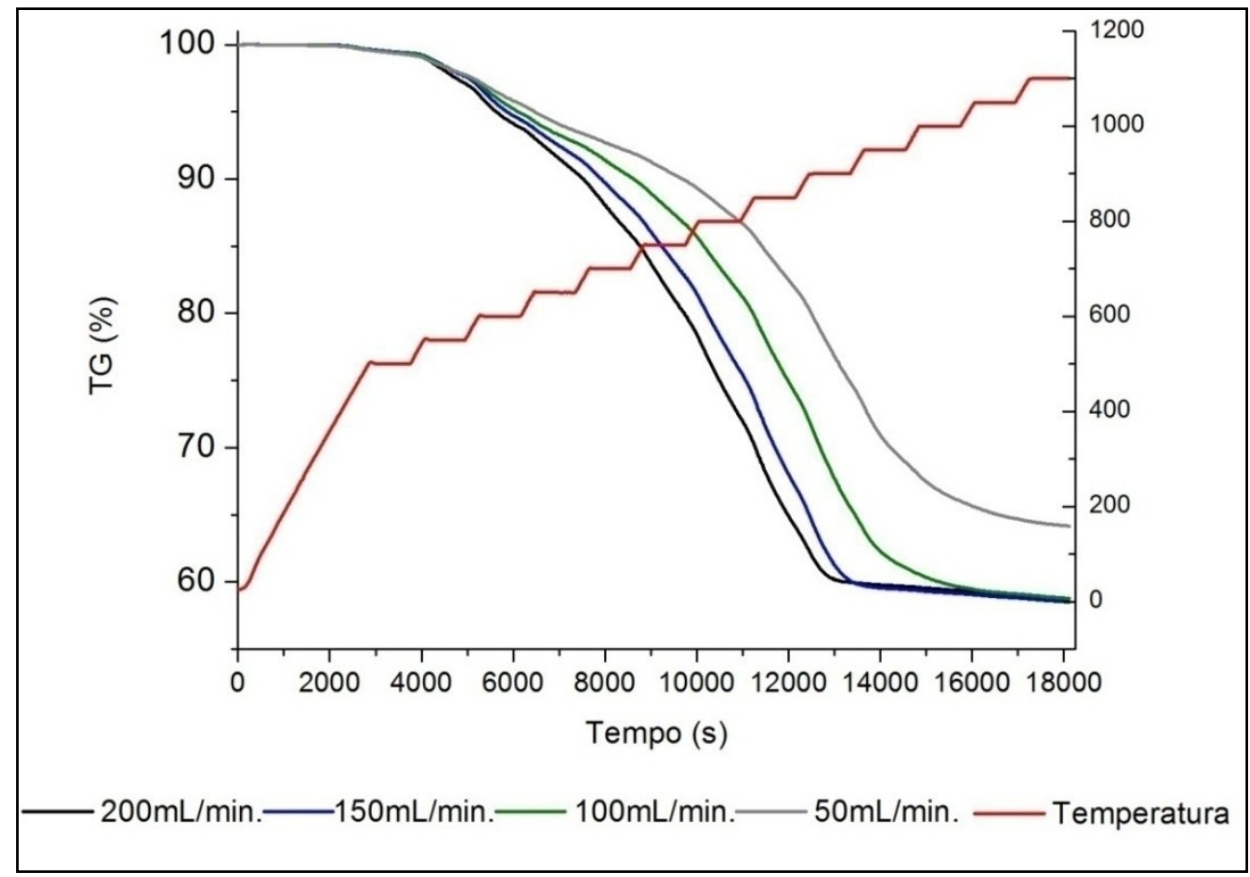

Figura 65 - Análise termogravimétrica das pelotas feitas com poeira de aciaria elétrica reduzidas com gás natural simulado para fluxos de 50,100, 150 e $200 \mathrm{~mL} /$ minuto.

As análises indicaram que a perda de massa total foi de aproximadamente $42 \%$, o mesmo valor obtido na redução com mistura gasosa.

Novamente, foi notado que no inicio da reação de redução, houve uma deposição de carbono na superfície da pelota, fato que pode ser notado com a variação da curva de perda de massas até a temperatura de $650^{\circ} \mathrm{C}$. Além 
disso, foi feita a análise com difração de raios-X com o material presente na camada externa da pelota. O difratograma pode ser visto na Figura 66.

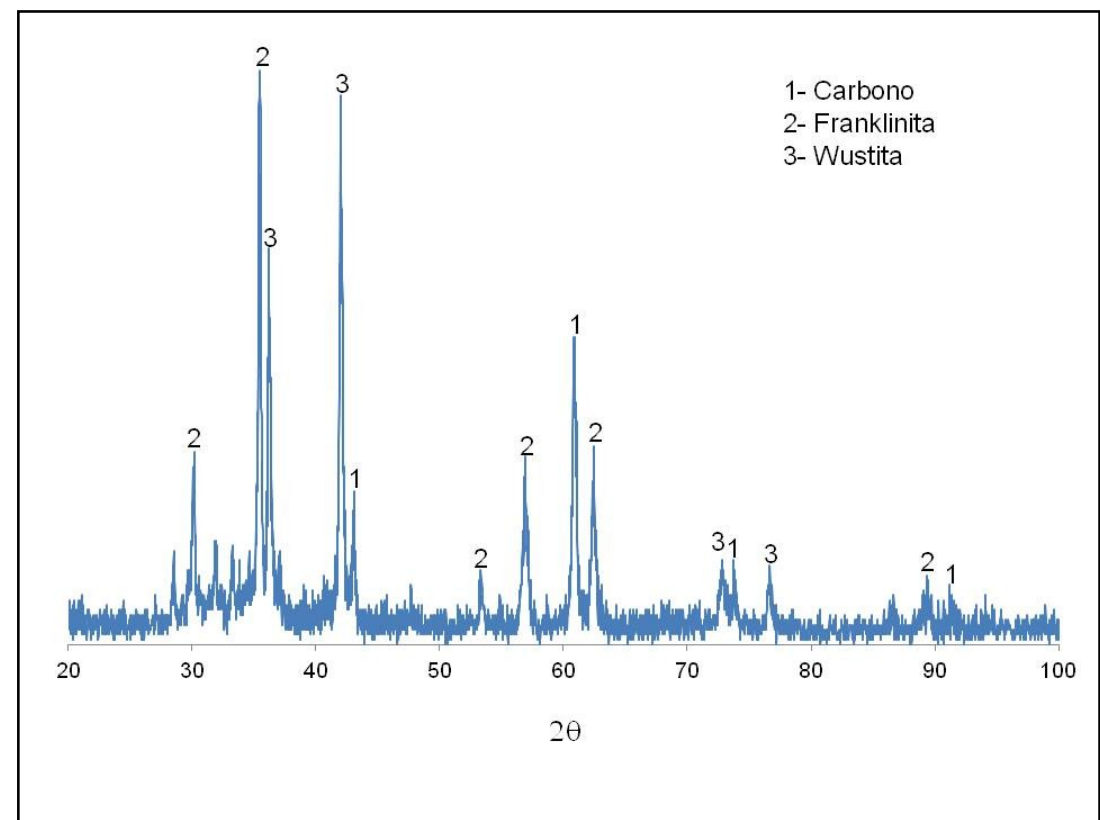

Figura 66 - Difratograma obtido na camada externa da pelota de poeira de aciaria elétrica reduzida com gás natural simulado interrompida na isoterma de $550^{\circ} \mathrm{C}$

É notado pelo difratograma há presença das fases carbono, franklinita e wustita. As fases de franklinita e wustita são procedentes da poeira de aciaria elétrica, enquanto que o pico de carbono é provavelmente procedente da deposição de carbono presente no gás redutor.

\subsection{Análise cinética}

Assim como nos outros casos anteriores, foi feita uma tentativa para predefinir funções que possam ser controladoras utilizando os fatores de correlação das relações $d(\alpha) / d t \times f(\alpha)$ e $g(\alpha) \times$ t. A Tabela 19 trás os fatores de correlação para estas relações obtidas na redução de pelotas de poeira de aciaria elétrica reduzida com gás natural simulado. 
Tabela 19 - Fatores de correção obtidos para as relações $d(\alpha) / d t \times f(\alpha)$ e $g(\alpha) \times t$ para a redução de pelotas de poeira de aciaria elétrica reduzida com gás natural simulado.

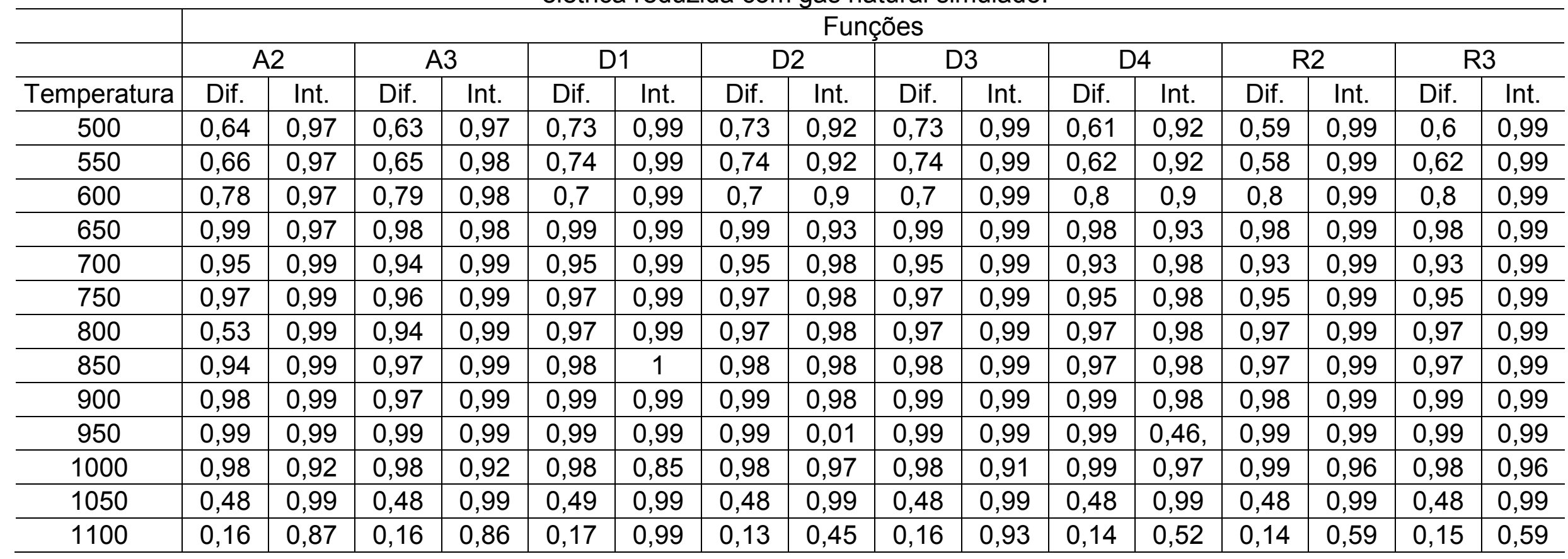


Como nas outras análises, a comparação dos fatores de correlação não indicou nenhuma função como possível controladora. Com isso, partiu-se para a análise das curvas de Arrhenius, que podem ser vistas na Figura 67.

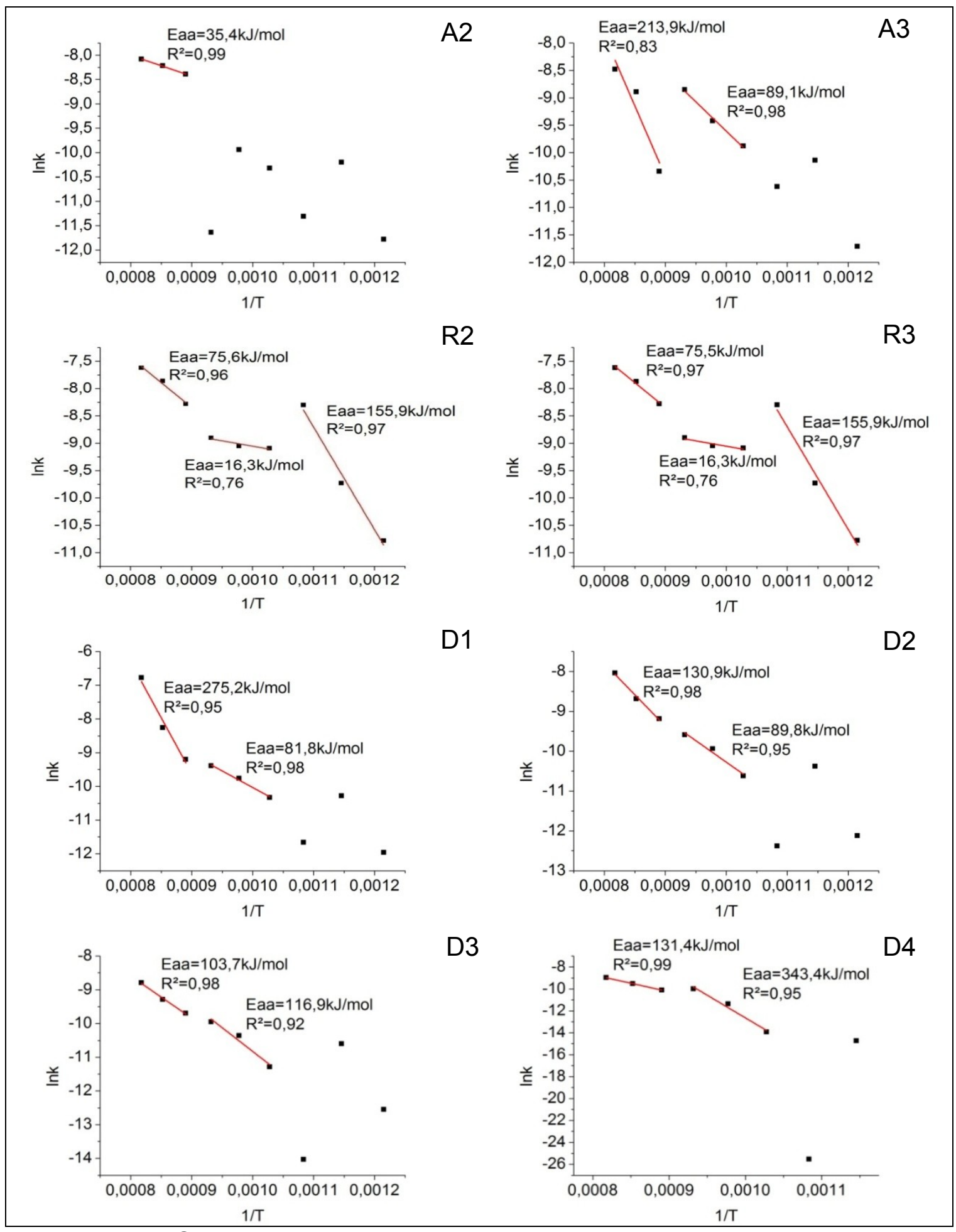

Figura 67 - Curvas de Arrhenius obtidas para a redução de pelotas de poeira de aciaria elétrica utilizando gás natural simulado. 
Em seguida, montou-se uma tabela com os valores de energia de ativação aparente obtida com o uso de cada equação para facilitar a interpretação dos dados. A compilação dos resultados pode ser vistos na Tabela 20.

Tabela 20 - Compilação dos valores de energia de ativação aparente e fatores de correlação das funções utilizadas nos cálculos cinéticos para as pelotas de poeira de aciaria elétrica reduzidas com gás natural simulado.

\begin{tabular}{c|c|c|c|c|c|c}
\hline & \multicolumn{2}{|c|}{$550 \mathrm{a} 650^{\circ} \mathrm{C}$} & \multicolumn{2}{c|}{$700 \mathrm{a} 800^{\circ} \mathrm{C}$} & \multicolumn{2}{c}{$850 \mathrm{a} 950^{\circ} \mathrm{C}$} \\
\hline Funções & Eaa & $\mathrm{R}^{2}$ & Eaa & $\mathrm{R}^{2}$ & Eaa & $\mathrm{R}^{2}$ \\
\hline A2 & - & - & - & - & 35,4 & 0,99 \\
\hline A3 & - & - & 98,1 & 0,98 & 213,9 & 0,83 \\
\hline R2 & 155,9 & 0,97 & 13,6 & 0,76 & 75,6 & 0,96 \\
\hline R3 & 155,9 & 0,97 & 16,3 & 0,76 & 75,5 & 0,97 \\
\hline D1 & - & - & 81,8 & 0,98 & 275,2 & 0,95 \\
\hline D2 & - & - & 89,8 & 0,95 & 130,9 & 0,98 \\
\hline D3 & - & - & 116,9 & 0,92 & 103,7 & 0,98 \\
\hline D4 & - & - & 343,4 & 0,95 & 131,4 & 0,99 \\
\hline
\end{tabular}

Devido à deposição do carbono, não foi possível a obtenção dos dados cinéticos para a primeira etapa de redução. A segunda etapa de redução, entre 700 e $800^{\circ} \mathrm{C}$, foi observado que a etapa de nucleação (A3) e difusão (D1) apresentam boas linearidades $\left(R^{2}=0,98\right)$, portanto, sendo o controle nesta faixa de temperatura mista. Com relação ao valor da energia de ativação aparente, verificou-se que para a nucleação, a energia de ativação aparente foi de $98,1 \mathrm{~kJ} / \mathrm{mol}$, enquanto que para a difusão, a energia de ativação aparente foi de $81,8 \mathrm{~kJ} / \mathrm{mol}$. Deste modo, conforme critérios adotados neste trabalho, a maior energia de ativação aparente é a energia global da etapa. Assim, a energia de ativação aparente para esta faixa de temperatura é a obtida com uso da equação que descreve a nucleação.

$\mathrm{Na}$ terceira etapa de redução, novamente foi observado que o controle de reação de redução foi misto, difusão (D4) e nucleação (A2), sendo estas, provavelmente, as etapas controladoras, por apresentarem maiores linearidades nos cálculos $\left(R^{2}=0,99\right)$. Os valores de energia de ativação aparente obtidos foram de $35,5 \mathrm{~kJ} / \mathrm{mol}$ para a nucleação e $131,4 \mathrm{~kJ} / \mathrm{mol}$ para a difusão. Com isso, chega-se a conclusão de que o valor da energia de ativação 
aparente para esta etapa do processo de redução foi a descrita pelo processo de difusão.

\subsection{Caracterização dos produtos reagidos}

Com o objetivo de investigar o aumento do valor de energia de ativação aparente, foram realizadas interrupções das análises durante o processo de redução. Foram obtidas pelotas reduzidas nas temperaturas de 700 e $900^{\circ} \mathrm{C}$. As imagens da microestrutura das pelotas obtidas microscópio eletrônico de varreduras podem ser vistas na Figura 68. Em complemento, foi obtido espectro de EDS da imagem obtida a $900^{\circ} \mathrm{C}$, que pode ser observada na Figura 69.

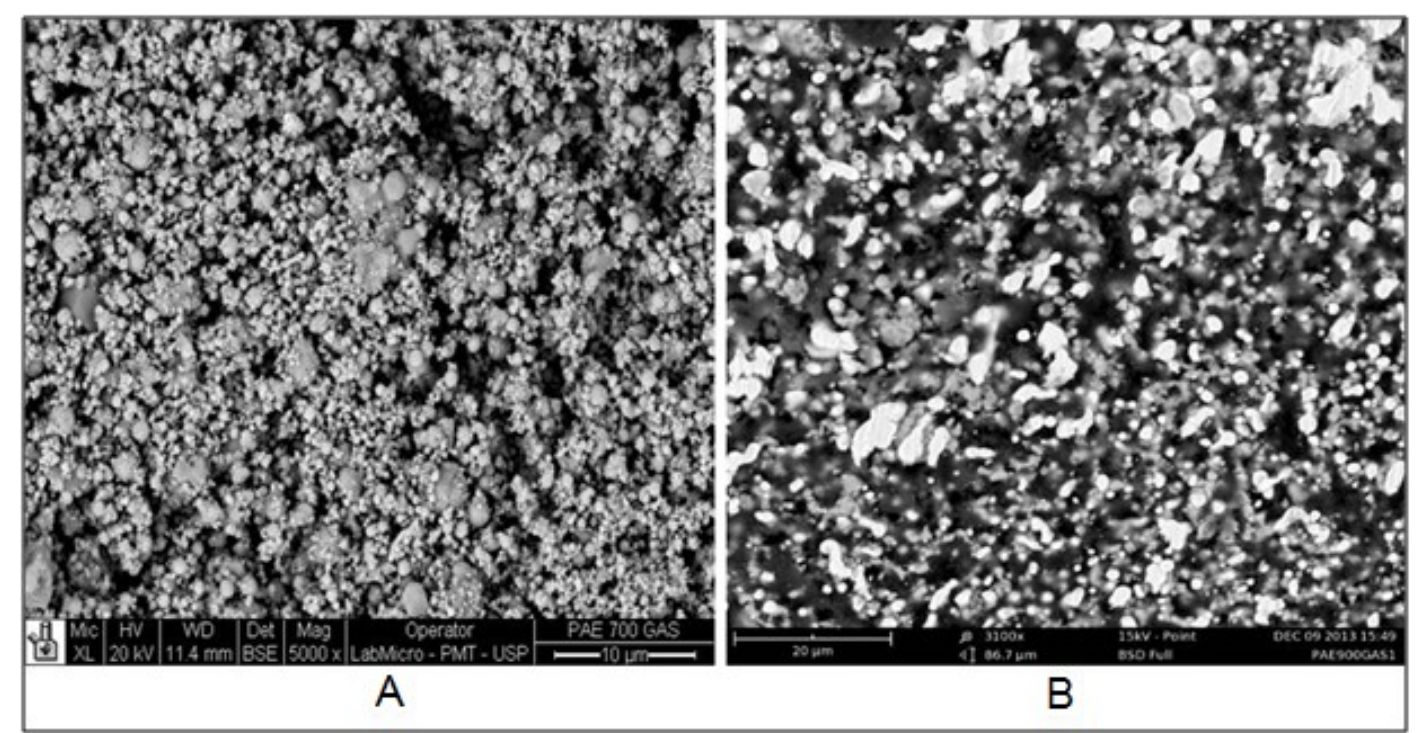

Figura 68 - Imagens de elétrons retro-espalhados obtidas por microscópio eletrônico de varredura nas pelotas de poeira de aciaria elétrica em diferentes instantes de redução. A) interrompia a $700^{\circ} \mathrm{C}$; B) interrompida a $900^{\circ} \mathrm{C}$. 


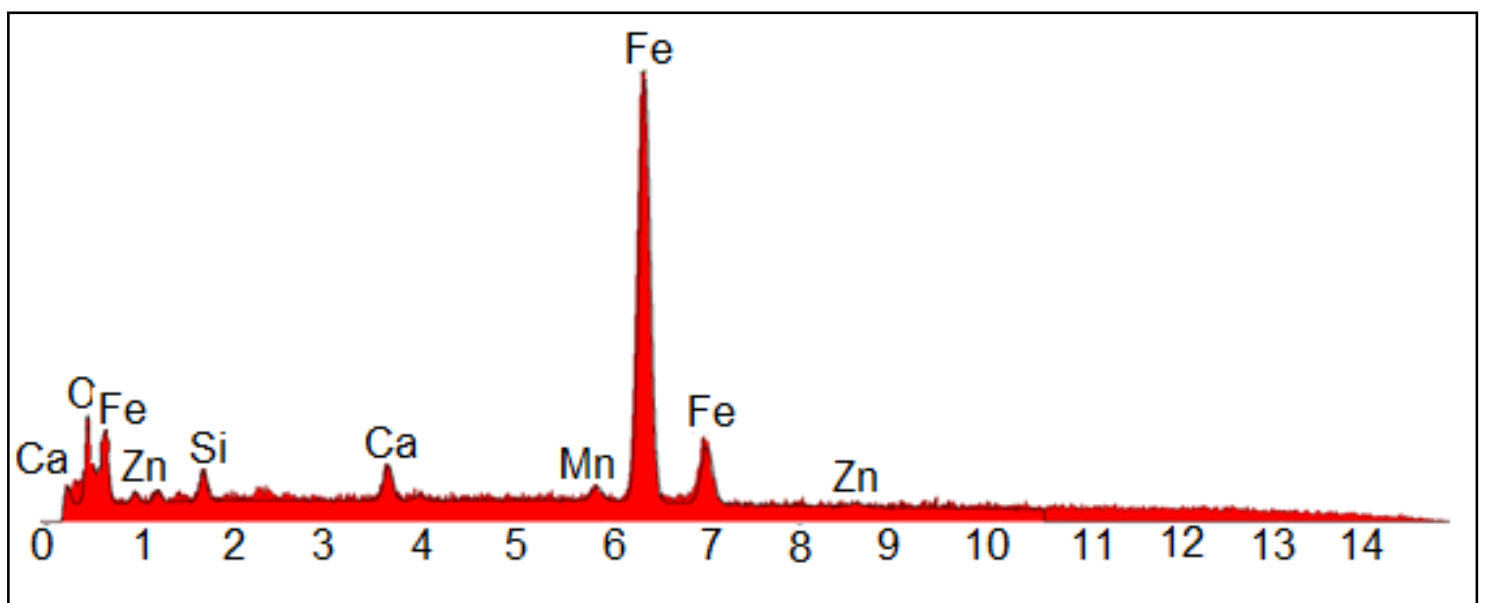

Figura 69 - Espectro de EDS obtido da região apresentada na Figura 68B.

Do mesmo modo que ocorreu quando se utilizou mistura redutora, a $700^{\circ} \mathrm{C}$ não foi observada a presença de uma estrutura sinterizada. Porém, para a temperatura de $900^{\circ} \mathrm{C}$ foi detectado que a microestrutura agora parece ser de uma estrutura sinterizada.

Em complemento a imagem obtida a $900^{\circ} \mathrm{C}$, foi obtido um espectro de EDS de toda a área apresentada na Figura 68B. O espectro mostrou que o principal elemento presente a $900^{\circ} \mathrm{C}$ é o ferro metálico. Também existem presenças de outros elementos como o $\mathrm{Zn}, \mathrm{Mn}, \mathrm{Ca}, \mathrm{Si}, \mathrm{Mg}$ e O. Estes elementos são remanescentes da composição inicial da poeira de aciaria elétrica.

\subsubsection{Pelotas de Ferrita de zinco}

\subsubsection{Redução com mistura redutora}

Inicialmente, foram realizadas as análises de redução na termobalança utilizando mistura redutora como gás redutor. As curvas de perda de massas podem ser vistas na Figura 70. 


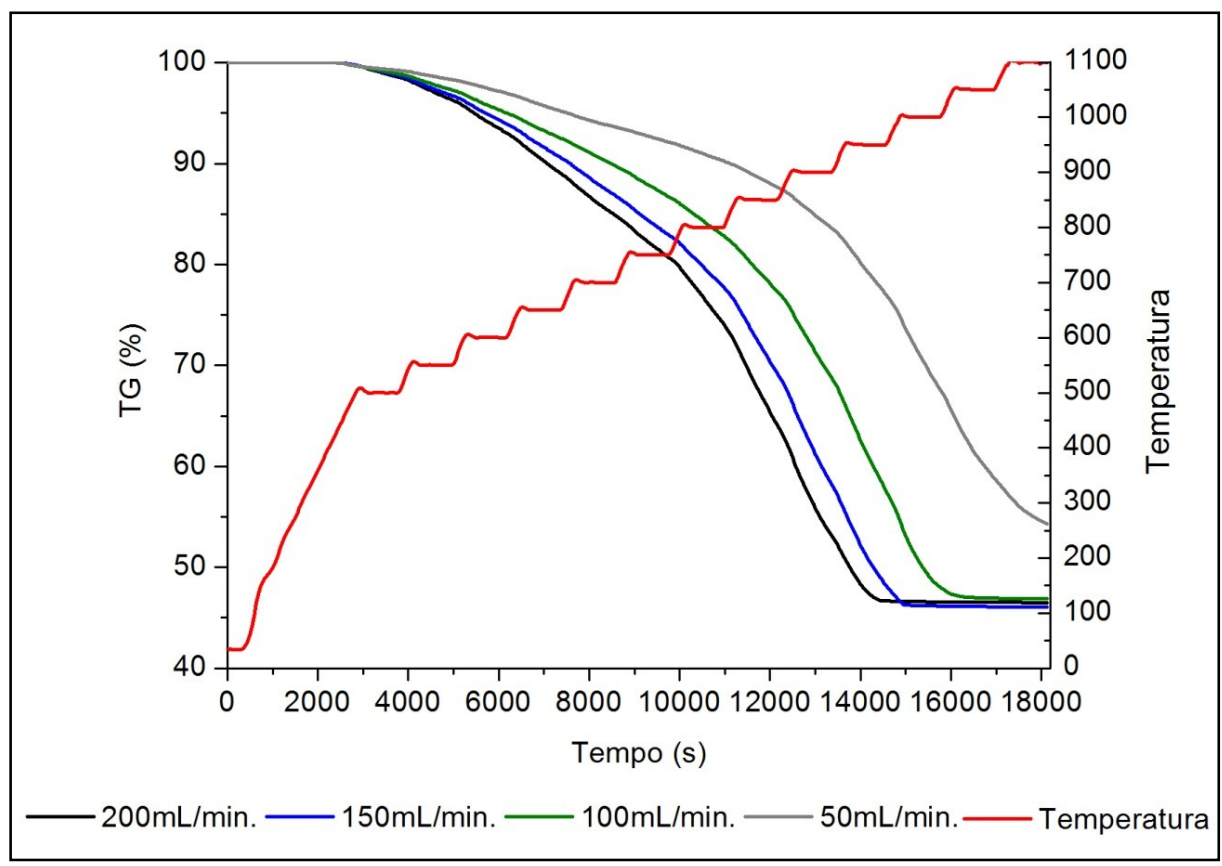

Figura 70 - Curvas de perda de massa realizada nas pelotas feitas com ferrita de zinco sintética utilizando mistura gasosa como agente redutor em diferentes fluxos.

Análogo os ensaios realizados com as pelotas de aciaria LD, o aumento do fluxo de gás redutor ocasionou um aumento na taxa de reação. Pode-se observar também que, somente para o fluxo de $50 \mathrm{~mL} /$ minuto não houve a redução total da pelota. Nos outros três fluxos (100, 150 e $200 \mathrm{~mL} /$ minuto) a reação foi finalizada, sendo obtida uma perda de massa de aproximadamente $53 \%$. Porém, com o fluxo de $200 \mathrm{~mL} /$ minuto foi observada a maior taxa de reação, uma vez que a reação foi finalizada anteriormente.

Esta perda de massa (53\%) não se refere somente à remoção de oxigênio da ferrita de zinco, mas também está incluída a eliminação do zinco ${ }^{(39)}$.

Outro fato observado foi que a reação foi encerrada na temperatura de $950^{\circ} \mathrm{C}$, fato que pode ser observado pela linearidade da curva de perda de massa após esta temperatura, ou seja, não havendo mais perda de massa. 


\subsection{Análise cinética}

Foi feita a análise dos fatores de correções das funções citadas pela literatura tanto pelo método integral quanto pelo método diferencial. A Tabela 21 apresenta os valores dos fatores de correlação encontrados para a redução de pelotas feitas com ferrita de zinco sintética com mistura redutora. 
Tabela 21 - Fatores de correção obtidos para a redução de pelotas de ferrita de zinco sintética com uso de mistura gasosa.

\begin{tabular}{|c|c|c|c|c|c|c|c|c|c|c|c|c|c|c|c|c|}
\hline \multirow[b]{3}{*}{ Temperaturas } & \multicolumn{16}{|c|}{ Funções } \\
\hline & \multicolumn{2}{|c|}{$\mathrm{A} 2$} & \multicolumn{2}{|c|}{ A3 } & \multicolumn{2}{|c|}{ D1 } & \multicolumn{2}{|c|}{ D2 } & \multicolumn{2}{|c|}{ D3 } & \multicolumn{2}{|c|}{ D4 } & \multicolumn{2}{|c|}{$\mathrm{R} 2$} & \multicolumn{2}{|c|}{ R3 } \\
\hline & Dif. & Int. & Dif. & Int. & Dif. & Int. & Dif. & Int. & Dif. & Int. & Dif. & Int. & Dif. & Int. & Dif. & Int. \\
\hline 500 & 0,65 & 0,97 & 0,73 & 0,94 & 0,86 & 0,97 & 0,55 & 0,73 & 0,55 & 0,73 & 0,73 & 0,99 & 0,73 & 0,99 & 0,73 & 0,99 \\
\hline 550 &, 94 & 0,99 & 0,81 & 0,98 & 0,94 & 0,99 & 0,94 & 0,92 & 0,94 & 0,92 & 0,91 & 0,99 & 0,92 & 0,99 & 0,92 & 0,99 \\
\hline 600 & 0,89 & 0,99 & 0,84 & 0,99 & 0,91 & 0,99 & 0,91 & 0,96 & 0,91 & 0,96 & 0,85 & 0,99 & 0,85 & 0,99 & 0,85 & 0,99 \\
\hline 650 & 0,98 & 0,99 & 0,9 & 0,99 & 0,97 & 0,99 & 0,97 & 0,98 & 0,97 & 0,98 & 0,97 & 0,99 & 0,97 & 0,99 & 0,97 & 0,99 \\
\hline 700 & 0,99 & 0,99 & 0,99 & 0,99 & 0,99 & 0,99 & 0,99 & 0,98 & 0,99 & 0,98 & 0,99 & 0,99 & 0,99 & 0,99 & 0,99 & 0,99 \\
\hline 750 & 0,99 & 0,99 & 0,96 & 0,99 & 0,99 & 0,99 & 0,99 & 0,99 & 0,99 & 0,99 & 0,98 & 0,99 & 0,98 & 0,99 & 0,98 & 0,99 \\
\hline 800 & 0,82 & 0,99 & $-0,03$ & 0,99 & 0,79 & 0,99 & 0,79 & 0,99 & 0,79 & 0,99 & 0,77 & 0,99 & 0,76 & 0,99 & 0,78 & 0,99 \\
\hline 850 & 0,99 & 0,99 & 0,98 & 0,99 & 0,99 & 0,99 & 0,99 & 0,98 & 0,99 & 0,98 & 0,99 & 0,97 & 0,99 & 0,99 & 0,99 & 0,99 \\
\hline 900 & 0,99 & 0,99 & 0,99 & 0,99 & 0,99 & 0,99 & 0,99 & 0,99 & 0,99 & 0,97 & 0,98 & 0,97 & 0,99 & 0,99 & 0,99 & 0,99 \\
\hline 950 & 0,9 & 0,98 & 0,75 & 0,98 & 0,86 & 0,95 & 0,96 & 0,81 & 0,91 & 0,67 & 0,97 & 0,99 & 0,95 & 0,87 & 0,97 & 0,91 \\
\hline 1000 & 0,81 & 0,99 & 0,92 & 0,99 & 0,84 & 0,97 & 0,82 & 0,99 & 0,83 & 0,99 & 0,81 & 0,98 & 0,84 & 0,99 & 0,82 & 0,99 \\
\hline 1050 & 0,41 & 0,99 & 0,52 & 0,99 & 0,55 & 0,97 & 0,49 & 0,99 & 0,54 & 0,99 & 0,47 & 0,98 & 0,54 & 0,99 & 0,53 & 0,99 \\
\hline 1100 & 0,14 & 0,92 & $-0,01$ & 0,91 & 0,18 & 0,98 & 0,17 & 0,63 & 0,17 & 0,8 & 0,14 & 0,99 & 0,17 & 0,72 & 0,17 & 0,81 \\
\hline
\end{tabular}


Como foi observado na tabela 15 , os valores dos fatores de correlação são semelhantes, tornando-se difícil a pré-escolha das funções controladoras. Deste modo, foram levantadas as curvas de Arrhenius (Figura 71).

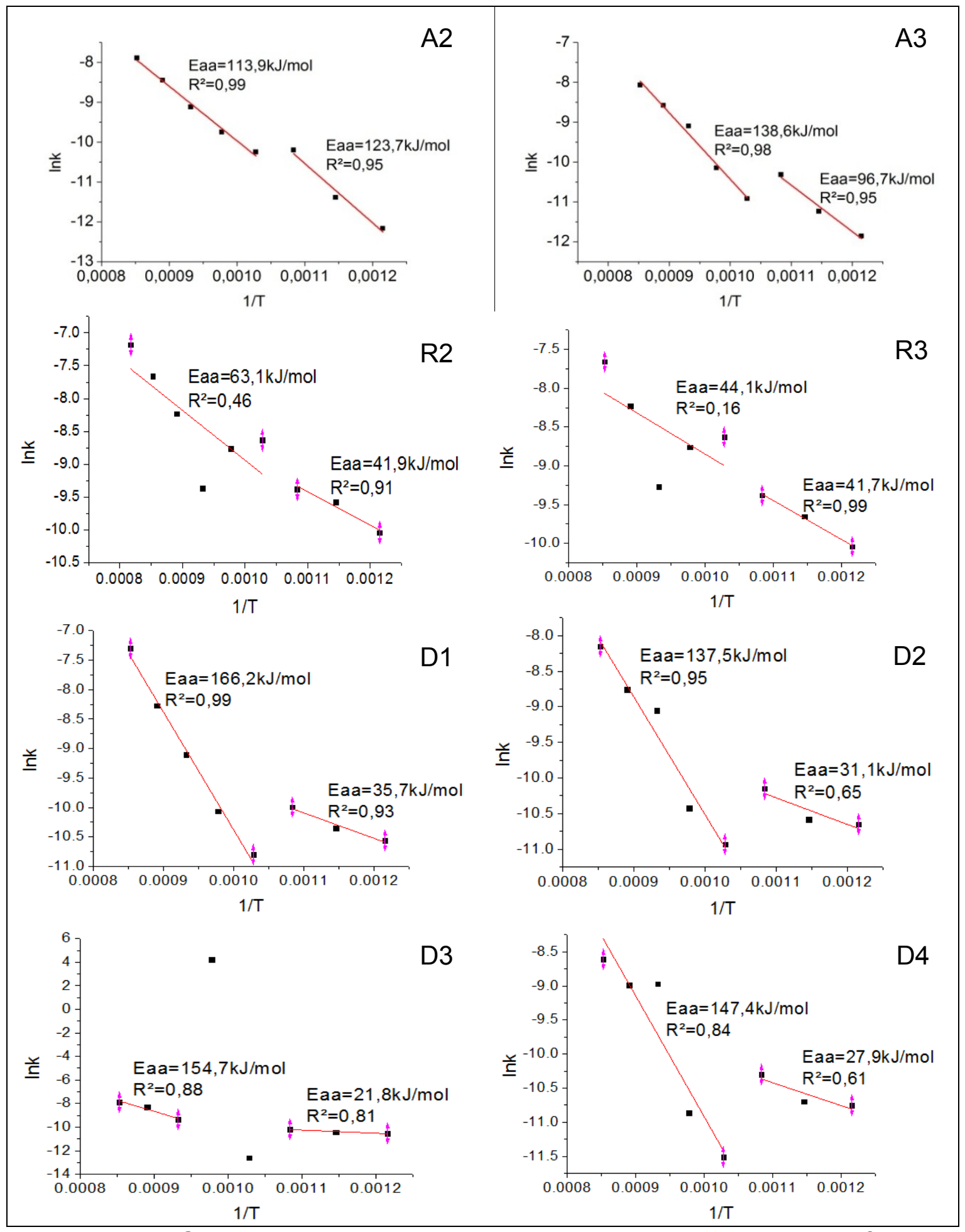

Figura 71 - Curvas de Arrhenius obtidas para a redução de pelotas de ferrita de zinco reduzidas com mistura redutora. 
Pelas curvas de Arrhenius da Figura 71, foi observado que a redução de ferrita de zinco ocorre em duas etapas: a primeira entre as temperaturas de 550 a $650^{\circ} \mathrm{C}$ e a segunda entre 700 a $900^{\circ} \mathrm{C}$.

Em seguida, uma compilação dos valores de energia de ativação aparente obtidas nas curvas de Arrhenius foi feita e estas podem ser observadas na Tabela 22.

Tabela 22 - Compilação dos valores de energia de ativação aparente e fatores de correlação obtidos nas curvas de Arrhenius para a redução de pelotas de ferrita de zinco reduzidas com mistura gasosa.

\begin{tabular}{c|c|c|c|c}
\hline & \multicolumn{2}{|c|}{$550 \mathrm{a} 650^{\circ} \mathrm{C}$} & \multicolumn{2}{c}{$700 \mathrm{a} 900^{\circ} \mathrm{C}$} \\
\hline Funções & $\begin{array}{c}\text { Eaa } \\
(\mathrm{kJ} / \mathrm{mol})\end{array}$ & $\mathrm{R}^{2}$ & $\begin{array}{c}\text { Eaa } \\
(\mathrm{kJ} / \mathrm{mol})\end{array}$ & $\mathrm{R}^{2}$ \\
\hline $\mathrm{A} 2$ & 123,7 & 0,95 & 113,9 & 0,99 \\
\hline $\mathrm{A} 3$ & 96,7 & 0,95 & 138,6 & 0,98 \\
\hline $\mathrm{R} 2$ & 41,9 & 0,91 & 63,1 & 0,46 \\
\hline $\mathrm{R} 3$ & 41,7 & 0,99 & 44,1 & 0,16 \\
\hline $\mathrm{D} 1$ & 35,7 & 0,93 & 166,2 & 0,99 \\
\hline D2 & 31,1 & 0,65 & 137,5 & 0,95 \\
\hline D3 & 21,8 & 0,81 & 154,7 & 0,88 \\
\hline D4 & 27,9 & 0,61 & 147,4 & 0,84 \\
\hline
\end{tabular}

A literatura cita que no inicio da reação de redução, a ferrita de zinco se decompõe em óxido de zinco ( $\mathrm{ZnO})$ e óxido de Ferro $\left(\mathrm{Fe}_{2} \mathrm{O}_{3}\right)$. Além disso, os mecanismos que estão envolvidos na redução da ferrita de zinco podem ser comparados aos mecanismos apresentados na redução de óxidos de ferro ${ }^{(105)}$.

Com estes conhecimentos em mãos, iniciou-se a análise cinética da redução de ferrita de zinco. Foi observado que no inicio da reação de redução, o mecanismo controlador é a reação controlada por limite de fases (R3), uma vez que foi encontrado um fator de correlação de 0,99. Para esta equação (R3) foi obtido um valor de energia de ativação aparente de $41,7 \mathrm{~kJ} / \mathrm{mol}$.

Continuando a análise cinética, a mesma interpretação foi realizada entre as temperaturas de 700 a $900^{\circ} \mathrm{C}$. Foi observado que as funções A2 e D1 são as mais indicada para esta faixa de temperatura, uma vez que foi obtido um fator de correção $\left(R^{2}\right)$ de 0,99 . Deste modo, é observado que para esta etapa de redução, o controle foi misto entre crescimento de núcleos bidimensionais e difusão unidimensionais. $O$ valor de energia de ativação 
aparente que prevalece nesta etapa é o apresentado pela equação D1, onde foi obtido o valor de $147,1 \mathrm{~kJ} / \mathrm{mol}$.

Uma hipótese para este aumento da energia de ativação aparente é a formação de uma camada densa de ferro ao redor do núcleo não reagido. Para comprovar este fenômeno, foi realizada uma análise com microscópio eletrônico de varredura acoplado com EDS na amostra reduzida há $700^{\circ} \mathrm{C}$, que pode ser observada na Figura 72.

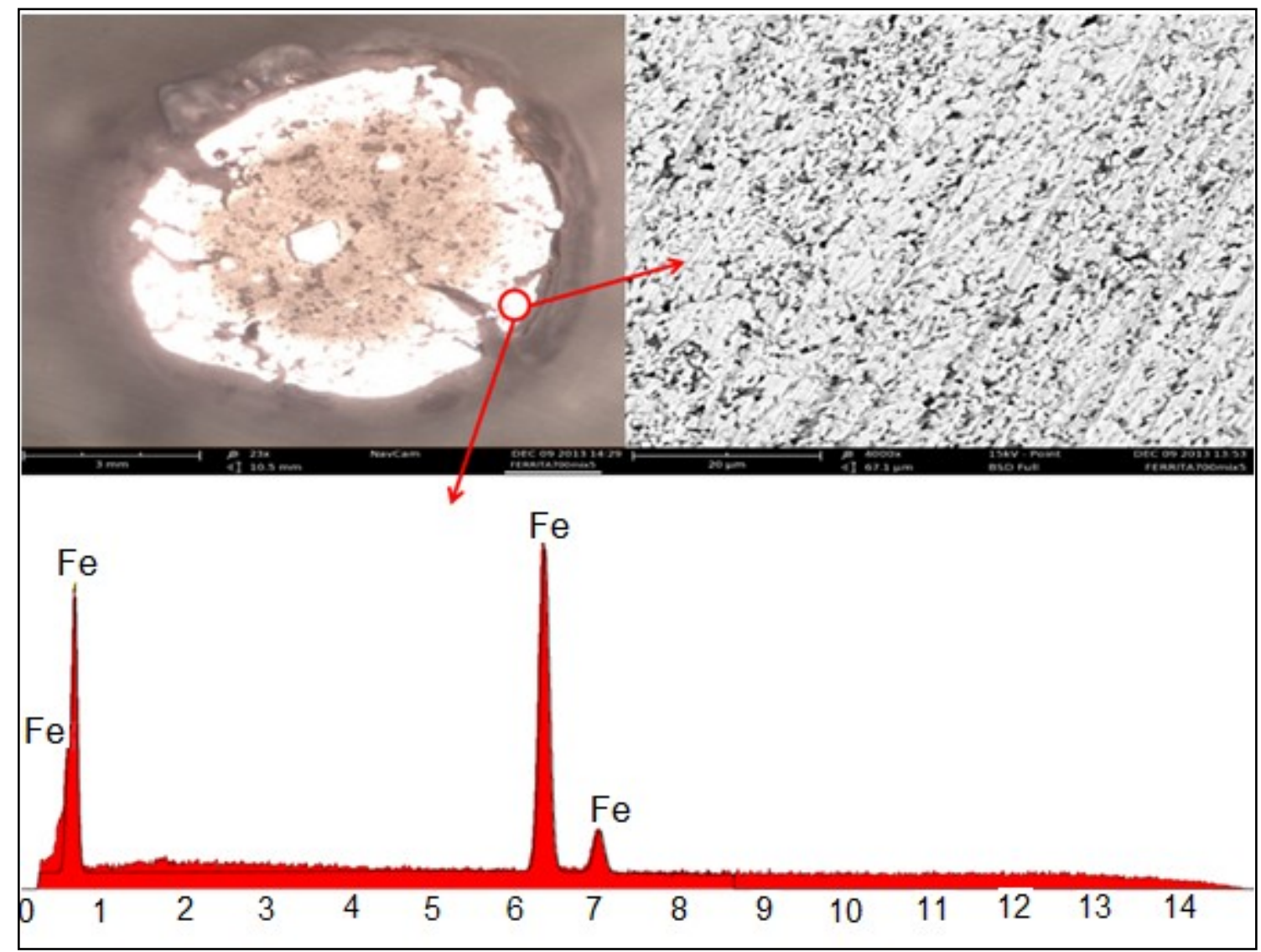

Figura 72 - Imagens obtidas por microscópio eletrônico de varredura da pelota de ferrita de zinco reduzida por mistura redutora até $700^{\circ} \mathrm{C}$.

É possível observar na Figura 72 a formação de uma camada de ferro ao redor do núcleo não reagido. A análise de difração de raios-X deste mesmo material reduzido pode ser visto na Figura 73. 


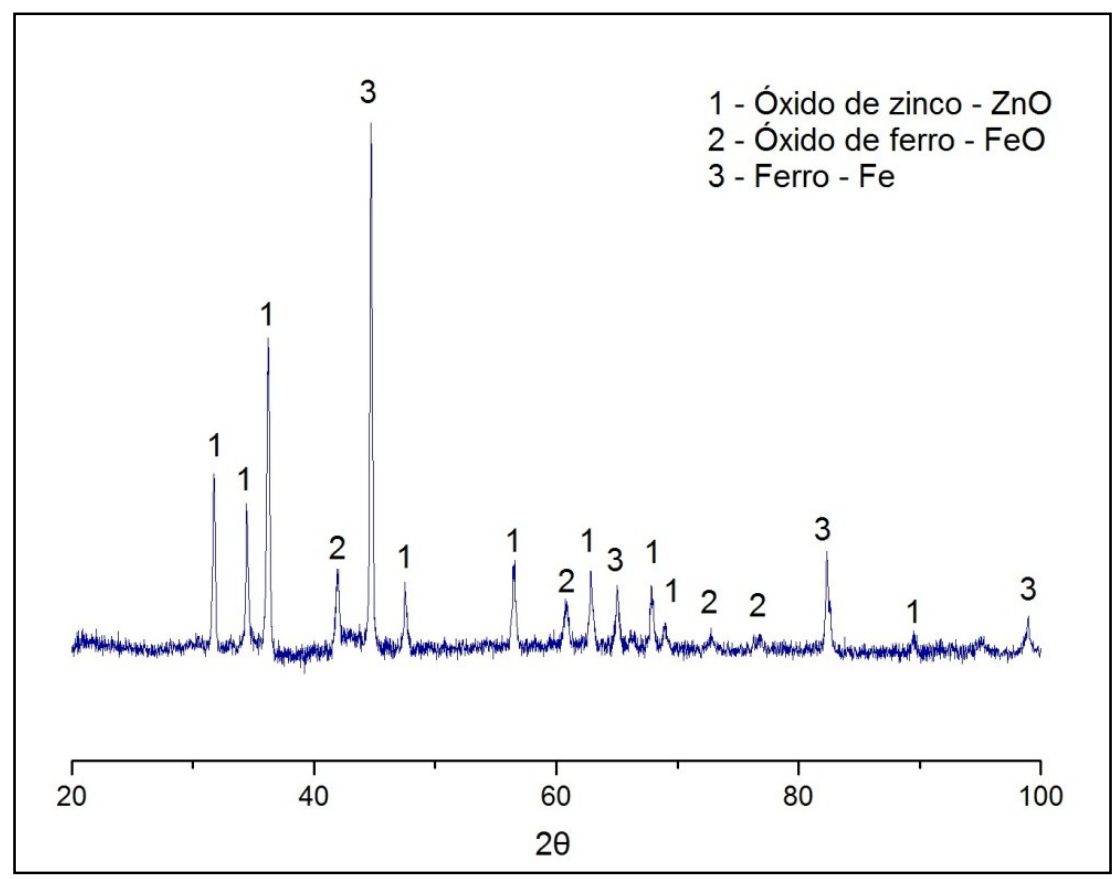

Figura 73 - Difratograma obtido da pelota de ferrita de zinco sintética reduzida até a temperatura de $700^{\circ} \mathrm{C}$ com mistura gasosa.

Pelo difratograma apresentado na Figura 73 é possível observar a presença de $\mathrm{Fe}$, óxido de zinco e óxido de ferro. O Fe, como foi observado, está situado na camada reagida da pelota. Os óxidos de ferro e zinco estão presentes na parte não reagida da pelota.

A desaceleração da reação de redução causada pela formação de uma camada reagida é uma situação corriqueira nos estudos de redução de óxidos de ferro. Esta barreira dificulta a difusão, tanto dos reagentes como dos produtos gasosos, tornando assim, a difusão a etapa limitante da reação $(148,149,150)$.

\subsubsection{Redução com gás natural simulado}

A Figura 74 apresenta a análise termogravimétrica utilizando gás natural simulado, como agente redutor, para a redução de pelotas de ferrita de zinco sintética com diferentes fluxos de gás. 


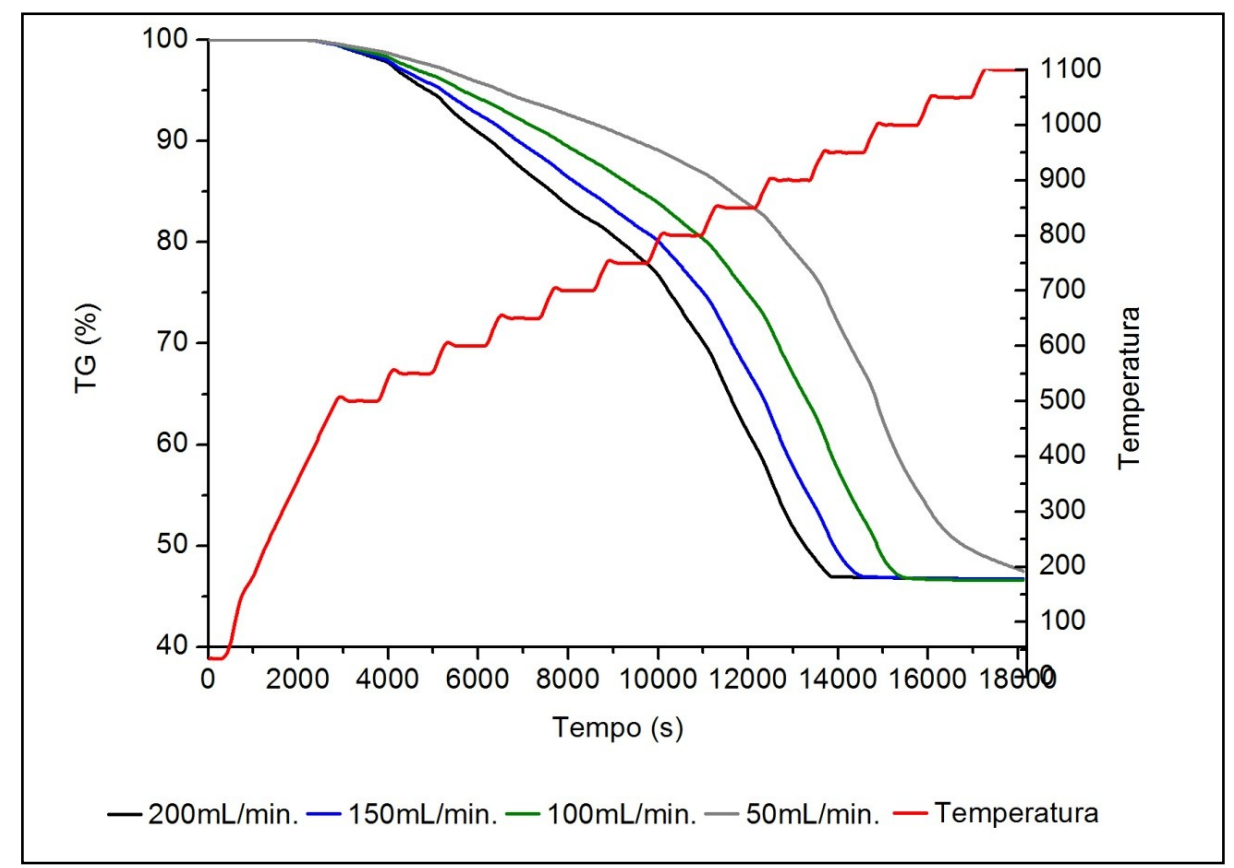

Figura 74 - Análise termogravimétrica das pelotas de ferrita de zinco reduzida por gás natural simulado para fluxos de 50, 100, 150 e $200 \mathrm{~mL} / \mathrm{minuto}$.

Assim como para as outras situações, não foi possível a escolha de possíveis funções controladoras pela análise dos fatores de correlação das funções analisadas. Os fatores de correlação para as relações $d(\alpha) / d t \times f(\alpha) e$ $g(\alpha) \times t$ obtidas para a redução de ferrita de zinco sintética reduzida com gás natural simulado são apresentadas na Tabela 23.

Em seguida, foram levantadas as curvas de Arrhenius para a redução das pelotas de ferrita de zinco reduzidas com gás natural simulado (Figura 75) com fluxo de $200 \mathrm{~mL} /$ minuto. 
Tabela 23 - Fatores de correção obtidos para a redução de pelotas de ferrita de zinco sintética com uso de gás natural simulado.

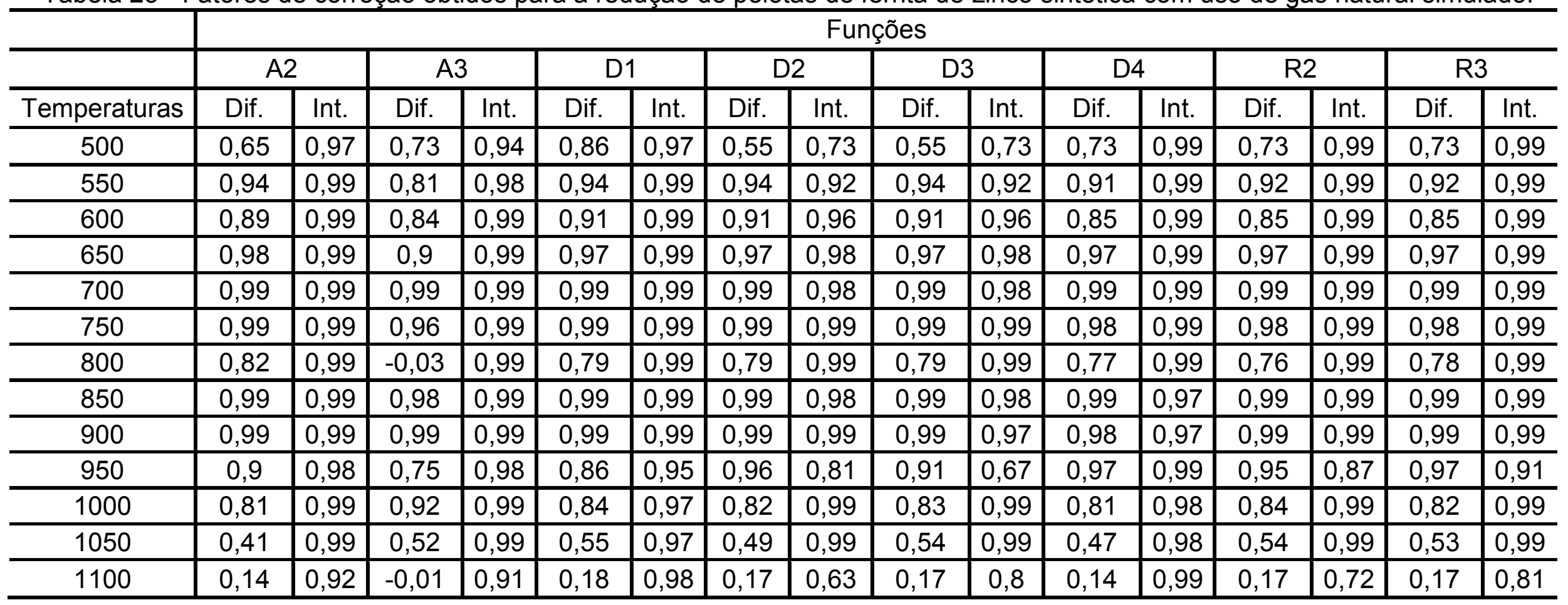




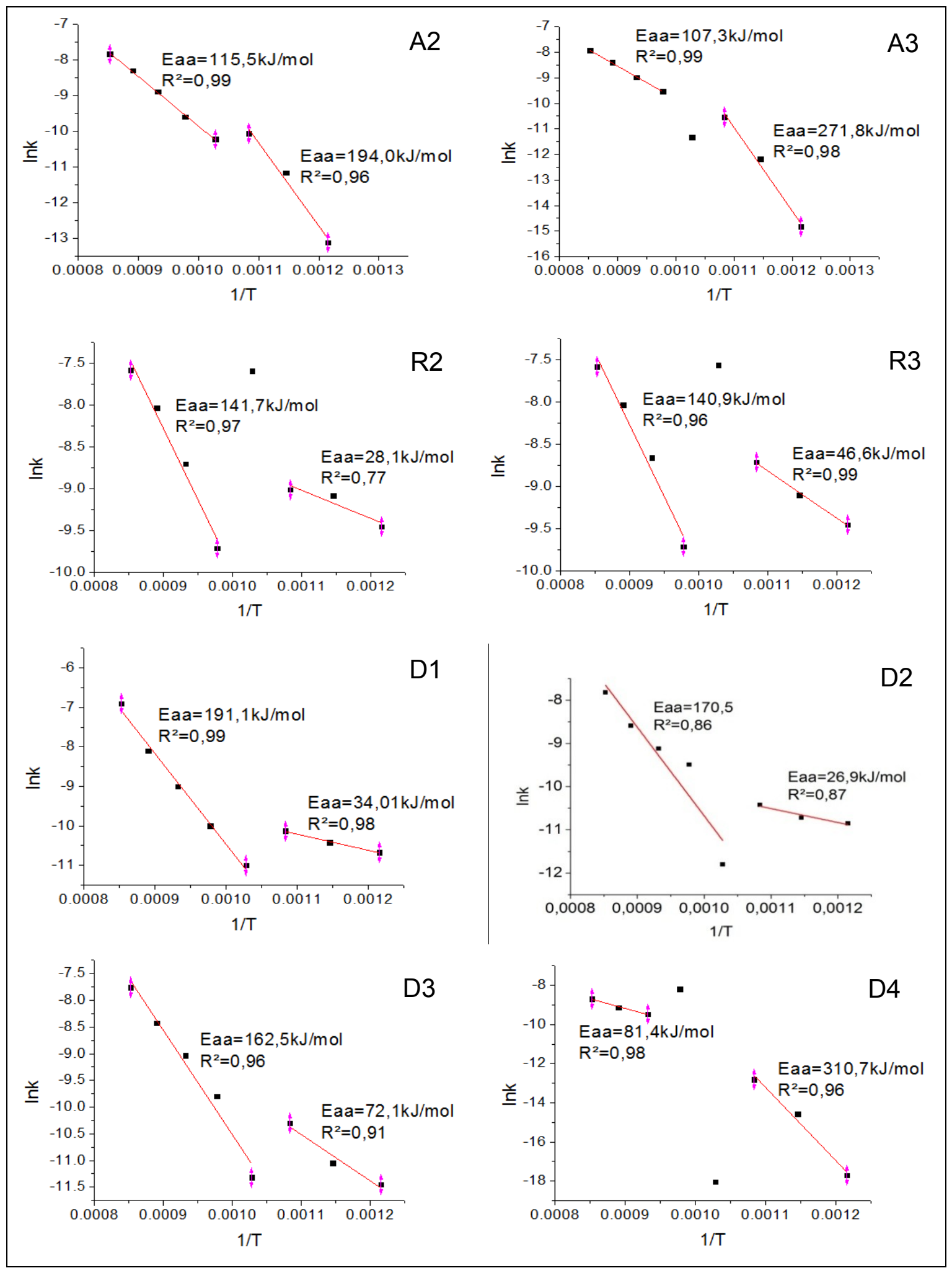

Figura 75 - Curvas de Arrhenius obtidas para a redução de pelotas de ferrita de zinco reduzidas por gás natural simulado. 
Do mesmo modo que ocorreu para a redução das pelotas de ferrita de zinco com mistura redutora, a redução com gás natural reformado, também ocorreu em duas etapas. A primeira de 550 a $650^{\circ} \mathrm{C}$ e a segunda entre 700 a $900^{\circ} \mathrm{C}$, conforme pode ser visto na Figura 75 .

Para auxiliar na interpretação dos valores de energia de ativação aparente obtidas em cada etapa, a Tabela 24 apresenta a compilação dos valores de energia de ativação aparente e dos fatores de correlação $\left(R^{2}\right)$ obtidos em cada estágio de redução para as possíveis funções controladoras.

Tabela 24 - Compilação dos valores de energia de ativação aparente e fatores de correlação obtidos nas curvas de Arrhenius para a redução de pelotas de ferrita de zinco reduzidas com gás natural simulado.

\begin{tabular}{c|c|c|c|c}
\hline & \multicolumn{2}{|c|}{$550 \mathrm{a} 650^{\circ} \mathrm{C}$} & \multicolumn{2}{c}{$700 \mathrm{a} 900^{\circ} \mathrm{C}$} \\
\hline Funções & $\begin{array}{c}\text { Eaa } \\
(\mathrm{kJ} / \mathrm{mol})\end{array}$ & $\mathrm{R}^{2}$ & $\begin{array}{c}\text { Eaa } \\
(\mathrm{kJ} / \mathrm{mol})\end{array}$ & $\mathrm{R}^{2}$ \\
\hline A2 & 194 & 0,96 & 115,5 & 0,99 \\
\hline A3 & 271,8 & 0,98 & 107,3 & 0,99 \\
\hline R2 & 28,1 & 0,77 & 141,7 & 0,97 \\
\hline R3 & 46,6 & 0,99 & 140,9 & 0,96 \\
\hline D1 & 34 & 0,98 & 191,1 & 0,99 \\
\hline D2 & 26,9 & 0,87 & 170,5 & 0,86 \\
\hline D3 & 72,1 & 0,91 & 162,5 & 0,95 \\
\hline D4 & 310,7 & 0,96 & - & - \\
\hline
\end{tabular}

É observado que entre as temperaturas de 550 a $650^{\circ} \mathrm{C}$, a função $\mathrm{R} 3$ apresenta fator de correção de 0,99 , portando sendo candidata a ser a função controladora. A energia de ativação aparente desta função para a faixa de temperatura de 550 a $650^{\circ} \mathrm{C}$ foi de $46,6 \mathrm{~kJ} / \mathrm{mol}$.

A mesma análise foi feita para as temperaturas entre 700 a $900^{\circ} \mathrm{C}$, onde foi observado que as funções A2 e D1 apresentaram valores de fator de correlação de 0,99 , desta forma, apresentando controle misto para esta faixa de temperatura. Com a aplicação da função A2 foi obtido uma energia de ativação aparente de $115,5 \mathrm{~kJ} / \mathrm{mol}$, enquanto que a função $\mathrm{D} 1$ foi obtido um valor de 191,1 kJ/mol. Deste modo, a energia de ativação aparente predominante nesta faixa de temperatura é o valor apresentado pela função D1. 


\subsection{Caracterização dos produtos reagidos}

Ao fim da reação de redução, foi realizada análise por microscopia eletrônica de varredura, juntamente com espectros de EDS da pelota de ferrita de zinco, totalmente reduzida por gás natural simulado, que podem ser vistas na Figura 76 e na Figura 77 , respectivamente.

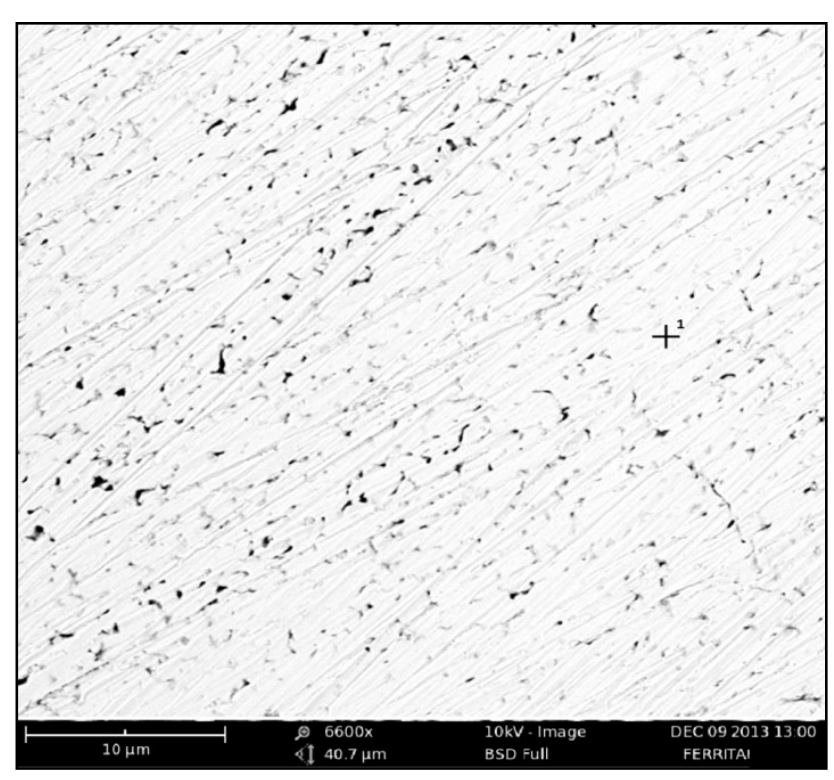

Figura 76 - Imagem de elétrons retro-espalhados obtido por microscópio eletrônico de varredura da pelota de ferrita de zinco reduzida com gás natural simulado após a completa redução.

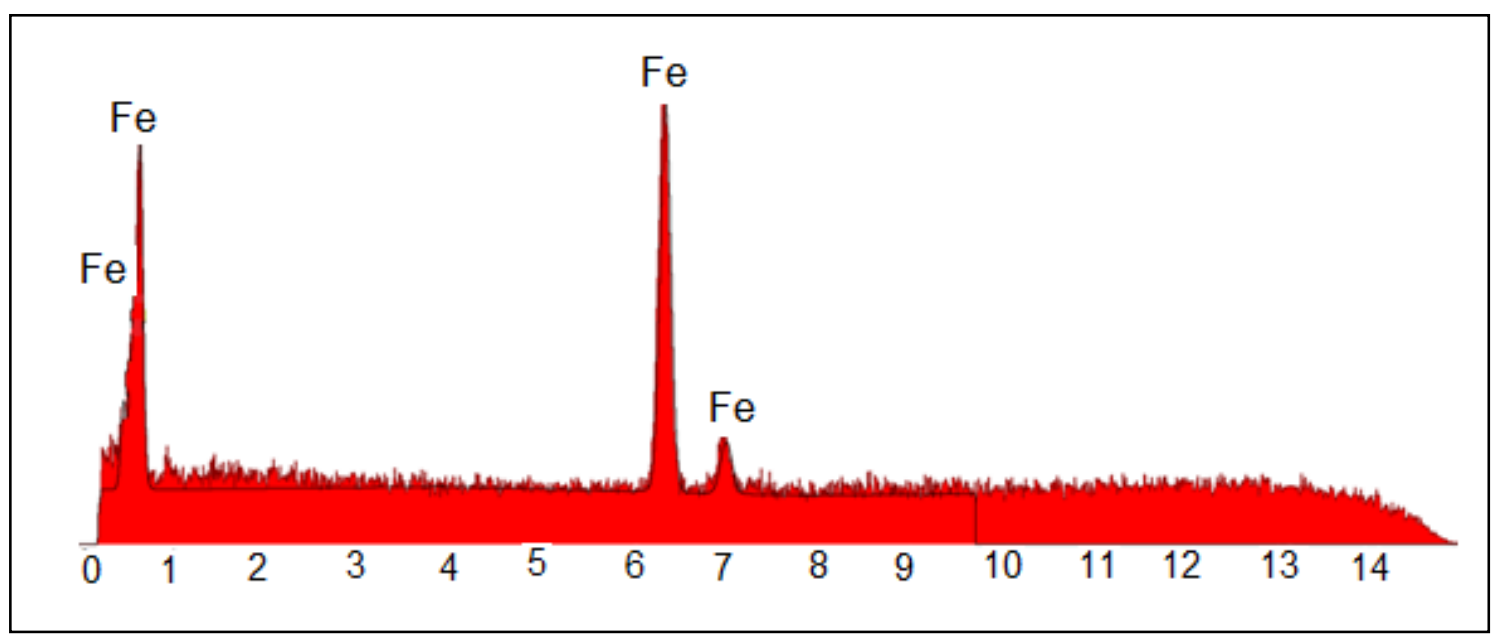

Figura 77 - Espectro de EDS da pelota de ferrita de zinco reduzida com gás natural simulado após completa redução 
É possível observar que ao fim da redução, a estrutura da pelota apresentam algumas porosidade distribuídas por toda a matriz, porém, a matriz parece ser mais densa do que a apresentada, por exemplo, pela pelota de poeira de aciaria LD.

O espectro de EDS da Figura 77, apenas picos de ferro metálico foram encontrados na pelota reduzida, ou seja, confirmando que a reação de redução foi completada.

Em seguida, foi realizada análise por difração de raios- $X$ da mesma amostra (Figura 78).

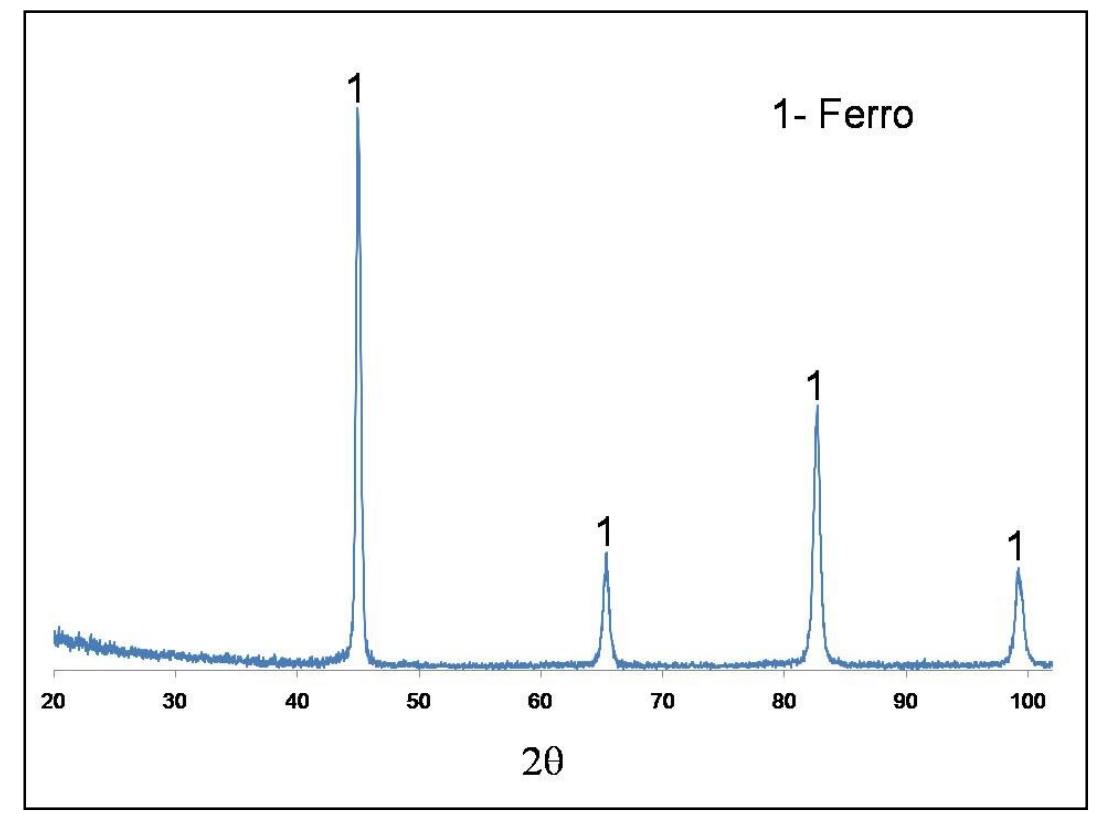

Figura 78 - Difratograma obtido da pelota de ferrita de zinco reduzida por gás natural reformado após a completa redução.

O difratograma constatada que apenas picos de ferro metálico estão presentes no produto final de reação, ou seja, todo o oxigênio e zinco foram removidos. 


\section{CONCLUSÕES}

A partir dos resultados obtidos no presente trabalho pode-se concluir que:

A poeira de aciaria LD apresentou o ferro $(46,9 \%)$ como o principal elemento, com um teor de ferro metálico da ordem de 8,4\%. Em seguida, apareceu o Ca com 23,2\%. Com relação às fases, observou-se que o ferro está presente como wustita, magnetita e ferro metálico. Também foram encontrados picos de quartzo e calcita. A distribuição granulométrica ficou entre 0,128 a $158,5 \mu \mathrm{m}$, com $50 \%$ das partículas menores do que $10,08 \mu \mathrm{m}$.

A poeira de aciaria elétrica é composta principalmente por ferro, com um teor de $44,6 \%$, onde $0,6 \%$ esta na forma de $\mathrm{Fe}^{0}$. Também apresentou 15,9\% de $\mathrm{Zn}$. Foram identificadas as fases de magnetita, zincita, quartzo e franklinita. A distribuição granulométrica situou-se entre 0,158 a $158,48 \mu \mathrm{m}$ com $50 \%$ das partículas menores do que $8,658 \mu \mathrm{m}$.

A ferrita de zinco sintetizada apresentou apenas picos de ferrita de zinco mostrando que a síntese foi bem sucedida. A granulometria está entre 0,138 a $91,2 \mu \mathrm{m}$. Foi observado que $50 \%$ das partículas são menores do que $13,85 \mu \mathrm{m}$ e apresentou um aspecto poroso.

As pelotas de poeira de aciaria LD reduzidas com mistura redutora ocorreram em três faixas de temperatura: 550 a $650^{\circ} \mathrm{C}, 700$ a 850 e 900 a $1000^{\circ} \mathrm{C}$. Na primeira, a redução teve como mecanismo controlador a nucleação, apresentando uma energia de ativação de $24 \mathrm{~kJ} / \mathrm{mol}$. No segundo estágio, o controle passou a ser controlado pela difusão. Houve um aumento da energia de ativação aparente para $54,9 \mathrm{~kJ} / \mathrm{mol}$. A última fase também foi controlada por difusão, porém, havendo um acréscimo na energia de ativação, que nesta etapa foi de $80,7 \mathrm{~kJ} / \mathrm{mol}$. 
Na redução de pelotas de poeira de aciaria LD com uso de gás natural simulado, entre as temperaturas de 700 a $850^{\circ} \mathrm{C}$, o mecanismo controlador foi por difusão. A energia de ativação aparente desta etapa foi de $55,7 \mathrm{~kJ} / \mathrm{mol}$. Entre os patamares de 900 a $1000^{\circ} \mathrm{C}$, o mecanismo controlador também foi por difusão. Porém, a energia de ativação encontrada foi de 93,1 $\mathrm{kJ} / \mathrm{mol}$. Este aumento no valor da energia de ativação foi determinado pela mudança na morfologia da pelota, uma vez que a presença de estruturas sinterizadas tendem a diminuir o volume de poros e consequentemente, dificultando $o$ fenômeno de difusão.

Para o caso da redução das pelotas de poeira de aciaria elétrica com uso de mistura redutora ocorreu em três etapas. Na primeira, o mecanismo controlador foi por nucleação, onde a energia de ativação aparente obtida foi de $41,1 \mathrm{~kJ} / \mathrm{mol}$. Na segunda etapa, foi observado um controle misto entre nucleação e difusão, onde a energia de ativação aparente que prevaleceu nesta etapa foi de $89,1 \mathrm{~kJ} / \mathrm{mol}$. Por último, houve um aumento na energia de ativação aparente para $128,9 \mathrm{~kJ} / \mathrm{mol}$. Nesta etapa, também foi obtido um controle misto entre nucleação e difusão.

A redução de pelotas de poeira de aciaria elétrica com gás natural simulado, na faixa de temperaturas entre 700 a $800^{\circ} \mathrm{C}$, foi obtido um controle misto para a reação de redução. As funções controladoras nesta etapa são descritas por nucleação e difusão. A energia de ativação aparente desta fase foi de $98,1 \mathrm{~kJ} / \mathrm{mol}$. Entre 850 a $950^{\circ} \mathrm{C}$, a reação foi controlada por difusão e nucleação, indicando um controle misto para esta faixa de temperatura. A energia de ativação aparente predominante foi de $131,4 \mathrm{~kJ} / \mathrm{mol}$.

A redução da pelotas de ferrita de zinco ocorreu em duas etapas para ambos gases redutores. Na primeira etapa, entre 550 a $650^{\circ} \mathrm{C}$, foi determinado um controle por limite de fases para as duas composições. A energia de ativação aparente encontra nesta etapa foi de $41,7 \mathrm{~kJ} / \mathrm{mol}$ para a mistura redutora e $46,6 \mathrm{~kJ} / \mathrm{mol}$ para o gás natural simulado. Na segunda etapa, foi determinado um controle misto entre a nucleação e a difusão para os dois 
casos. Foi detectado um aumento na energia de ativação aparente, que passou a ser de $166,2 \mathrm{~kJ} / \mathrm{mol}$ para a mistura redutora e $191,1 \mathrm{~kJ} / \mathrm{mol}$ para o gás natural reformado.

Após o processo de redução das pelotas de poeira de aciaria LD, elétrica e de ferrita de zinco sintética, foram obtidos teores de 79,5\%, 82,8\% e $100 \%$ de ferro metálico, respectivamente. Além disso, nos resíduos que continham zinco, este foi totalmente removido, como no caso da ferrita de zinco, ou quase totalmente removido, no caso da poeira de aciaria elétrica, que apresentou um teor final de zincita de $2,9 \%$. 


\section{REFERENCIAS BIBLIOGRÁFICAS}

1 VIEIRA, C.M.F.; ANDRADE, P.M.; MACIEL, G.S.; VERNILLI JR, F.; MONTEIRO, S.N. Incorporation of fine steel sludge waste into red ceramic. Materials Science and Engineering A, v. 427, p. 142-147, 2006.

2 MACIEL, G.S.; ANDRADE, P.M.; INTORNE, S.C. ; VERNILLI JR F. ; MONTEIRO, S.N.; VIEIRA, C.M.F. Alterações microestruturais e inertização de lama fina de aciaria em cerâmica argilosa. (em cd-rom). In: CONGRESSO BRASILEIRO DE ENGENHARIA E CIÊNCIA DOS MATERIAIS,17., Foz do Iguaçu, 2006. Anais. CBECIMat. S.L.:S.M., 2006. p. 2195-2206.

3 CUNHA, A. F.; FILHO, G. A.; JÚNIOR, A. M.; GOMES, O. C. B.; ASSIS, P. S. Aspectos técnicos da utilização da carepa gerada em processos siderúrgicos e tratada por desagregação ultra-sônica. Tecnologia em Metalurgia e Materiais, v. 3, n. 2, p. 1-5, 2006.

4 ANDRADE, P. M.; VIEIRA, C. M. F.; MONTEIRO, S. N.; VERNILLI JR, F. Recycling of Steel Sludge into Red Ceramic. Materials Science Fórum. v. 530, p. 544-549, 2006.

5 TAKANO, C.; DEODORO, J. T. C.; NASCIMENTO, R. C.; MOURÃO, M. B.; LENZ, G.; MARTINS, D. S. A reciclagem de resíduos siderúrgicos sólidos. In: SEMINÁRIO NACIONAL SOBRE REUSO/RECICLAGEM DE RESÍDUOS SÓLIDOS INDUSTRIAIS, 2000, São Paulo. São Paulo: Departamento de Engenharia Metalúrgica e de Materiais, Escola Politécnica da Universidade de São Paulo, 2000.

6 SOBRINHO, P. J. N.; TENÓRIO, J. A. S. Reciclagem da poeira e lama geradas na fabricação de aço inoxidável. Revista Escola de Minas, n. 57, v. 2, p. 121-127, 2004.

7 SZEKELY, J. A research program for the minimization and effective utilization of steel plant wastes. Iron and Steelmaker, v. 22, n. 1, p. 25-29, 1995.

8 NYIRENDA, R. L. The processing of steelmaking flue-dust: a review.

Minerals Engineering, v. 4, Nos 7-11, p. 1003-1025, 1991. 
9 Disponivel em:

http://www.acobrasil.org.br/site/portugues/numeros/estatisticas.asp?par=20141. Acesso em 15/04/2014.

10 MIKHAll, S. A.; TURCOTTE, A. M. Thermal reduction of steel-making secondary materials I. Basic-oxygen-furnace dust. Thermochimica Acta, n. 311, v. (1-2), p.113-119, 1998.

11 KELEBEK, S.; YÖRÜK S.; DAVIS, B. Characterization of basic oxygen furnace dust and zinc removal by acid leaching. Minerals Engineering, n. 17, p. 285-291, 2004.

12 EVESTEDT, M.; MEDVEDEV, A. Model-based slopping warning in the LD steel converter process. Journal of Process Control, n. 19, v. 6, p. $1000-1010,2009$.

13 MENDES, J. J. Influencia da adição da lama de aciaria a oxigênio nas características físicas e microestruturais de pelotas queimadas de minério de ferro. 2009. 79 p. Dissertação (Mestrado) - REDEMAT, Universidade Federal de Ouro Preto, Ouro Preto, 2009. p. 71.

14 HAY, S. M.; RANKIN, W. J. Recovery of iron and zinc from blast furnace and basic oxygen furnace dusts: A thermodynamic evaluation. Minerals Engineering, n. 7, v. 8, p. 985-1001, 1994.

15 SCHEELE, J. V.; JOHANSSON, M. "XYFINES a new technology for in-plant recycling of dust and sludge in metal production industries, Recycling and waste treatment in mineral and metal processing. Technical and economic aspects, I. n. 1, p. 109-118, 2002.

16 MAKKONEN, H. T.; HEINO, J.; LAITILA, L.; HILTUNEN, A.; PÖYLIÖ, E.; HÄRKKI, J. Optimisation of steel plant recycling in Finland: dusts, scales and sludge. Resources, Conservation and Recycling, n. 35, p. 77-84, 2002.

17 MANTOVANI, M. C.; TAKANO, C.; BÜCHLER, P. M. Electric arc furnace dust-coal composite pellet: effects of pellet size, dust composition, and additives on swelling and zinc removal. Ironmaking and Steelmaking, v. 29, n. 4, p. 257-265, 2002. 
18 OUSTADAKIS, P.; TSAKIRIDIS, P.E.; KATSIAPI, A.; LEONARDOU, S. A. Hydrometallurgical process for zinc recovery from electric arc furnace dust (EAFD) Part I: Characterization and leaching by diluted sulphuric acid. Journal of Hazardous Materials, n. 179, p. 1-7, 2010.

19 BEST, T. E.; PICKLES, C. A. In-flight plasma reduction of electric arc furnace dust in carbon monoxide. Canadian Metallurgical Quarterly, v. 40, n 1, p. 61-78, 2001.

20 MASLEHUDDIN, M.; AWAN, F.R.; SHAMEEMA, M.; IBRAHIMA, M.; ALI, M. R. Effect of electric arc furnace dust on the properties of OPC and blended cement concretes. Construction and Building Materials, n. 25, p. 308-312, 2011.

21 JARUPISITTHORN, C.; PIMTONG, T.; LOTHONGKUM, G. Investigation of kinetics of zinc leaching from electric arc furnace dust by sodium hydroxide. Materials Chemistry and Physics, n 77, p. 531-535, 2002.

22 GUÉZENNEC, A. G.; HUBER, J. C.; PATISSON, F.; SESSIECQ, P. ; BIRAT, J. P.; ABLITZE, D. Dust Formation by Bubble-burst Phenomenon at the Surface of a Liquid Steel Bath. ISIJ International, n. 44, v. 8, p. 1328-1333, 2004.

23 BADGER, S. R.; KNELLER, W. A. The characterization and formation of electric arc furnace (EAF) dusts. Electric Furnace Conference, 55, CHICAGO, 1997. Proceedings, p. 95-98.

24 MANTOVANI, M. S.: Caracterização de poeiras geradas em fornos elétricos a arco e seu estudo quando aglomeradas na forma de pelotas auto redutoras. São Paulo: SP. Tese (Doutorado). Escola Politécnica USP. São Paulo, 1998. p. 13, 121.

25 GUÉZENNEC, A. G.; HUBER, J. C.; PATISSON, F.; SESSIECQ, P.; BIRAT, J. P.; ABLITZER, D. Dust Formation by Bubble-burst Phenomenon at the Surface of a Liquid Steel Bath. ISIJ International, v. 44, n. 8, p. 1328-1333, 2004.

26 GUÉZENNEC, A. G.; HUBER, J. C.; PATISSON, F.; SESSIECQ, P.; BIRAT, J. P.; ABLITZER, D. Dust formation in Electric Arc Furnace: Birth of the particles. Powder Technology, n. 157, p. 2 - 11, 2005. 
27 MARTINS, F. M.; NETO, J. M. R.; CUNHA, C. J. Mineral phases of weathered and recent electric arc furnace dust. Journal of Hazardous Materials, n. 154, p. 417-425, 2008.

28 SOILIC, T.; MIOC, A. R.; STEFANOVIC, S. C.; RADOVIC, V. N.; JENKO, M. Characterization of steel mill electric-arc furnace dust. Journal of Hazardous Materials B, n. 109, p. 59-70, 2004.

29 PICKLES, C.A. Thermodynamic analysis of the selective chlorination of electric arc furnace dust. Journal of Hazardous Materials, n. 166, p. 1030-1042, 2009.

30 MACHADO, J. G. BREHM, F. A; MORAES, C. A.; SANTOS, C. A.; VILELA, A. C., CUNHA, J. B. Chemical, physical, structural and morphological characterization of the electric arc furnace dust. Journal of Hazardous Materials B, n. 136, p. 953-960, 2006.

31 TELLES, V. B. Reciclagem da poeira de aciaria elétrica na sinterização de minério de ferro visando a eliminação de zinco. 2010. 91p. Dissertação (Mestrado) - Escola Politécnica da USP. São Paulo, 2010. p 57.

32 VARGAS, A. S.; MASUERO, A. B.; VILELA, A. C. F. Investigations on the use of electric-arc furnace dust (EAFD) in Pozzolan-modified Portland cement I (MP) pastes. Cement and Concrete Research, n. 36, p. 1833-1841, 2006.

33 MENAD, N.; AYALA, J. N.; CARCEDO, F. G.; HERNÁNDEZ, A. Study of the presence of fluorine in the recycled fractions during carbothermal treatment of EAF dust. Waste Management, v. 23, n. 6, p. 483-491, 2003.

34 GRILLO, F. F.; COLETI, J. L.; ESPINOSA, D. C. R.; OLIVEIRA, J. R.; TENÓRIO, J. A. S. Zn and Fe Recovery from Electric Arc Furnace Dusts. Materials Transactions, v. 55, n. 2, p. 351 - 356, 2014.

35 LEE, G. S.; SONG, Y. J. Recycling EAF dust by heat treatment with PVC. Minerals Engineering, n. 20, p. 739-746, 2007. 
36 GRILLO, F. F. Recuperação do Zn e Fe da poeira de aciaria elétrica proveniente da produção de aço carbono. 2001. 106. Dissertação (Mestrado) - Programa de Pós-Graduação em Engenharia Metalúrgica e de Materiais, Instituto Federal do Espírito Santo, Vitória, 2011. p. 17, 18.

37 MARQUES SOBRINHO, V. P. F. Adição de poeira de aciaria elétrica em ferro gusa liquido. 2012. 104 p. Tese (Doutorado) - Escola Politécnica da Universidade de São Paulo, São Paulo, 2012.

38 SHAWABKEH, R. A. Hydrometallurgical extraction of zinc from Jordanian electric arc furnace dust. Hydrometallurgy, n. 104, p. 61-65, 2010.

39 MARROQUÍN, M. C. G. Caracterização e cinética da redução de ferrita de zinco presente em poeiras de aciaria, por misturas $\mathrm{CO}_{-} \mathrm{CO}_{2} .2008 .230$ p. Tese (Doutorado) - Pontifícia Universidade Católica do Rio de Janeiro, Rio de Janeiro, 2008. p. 62.

40 REIS, W. L. da C. Otimização da reciclagem de resíduos siderúrgicos por redução carbotermica. 2008. 147p. Tese (Doutorado) - Universidade Federal de São Carlos. São Carlos, 2008. p. 9.

41 MCCAMMON, C. A.; LIU, L.G. The effects of pressure and temperature on nonstoichiometric wüstite, FexO: The iron-rich phase boundary. Physics and Chemistry of Minerals, v. 10, n. 3 p 106-113, 1984.

42 TIERNAN, M. J.; BARNES, P. A.; PARKES, G. M. B. Reduction of Iron Oxide Catalysts: The Investigation of Kinetic Parameters Using Rate Perturbation and Linear Heating Thermoanalytical Techniques. J. Phys. Chem. B, n. 105, p. 220-228, 2001.

43 GRETZ , J.; KORF, W.; LYONS, R. Hydrogen in the steel industry. Journal Hydrogen Energy, v. 16, n. 10, p. 691-693, 1991.

44 RESTIVO, T. A. G. Redução carbotérmica de óxidos de urânio assistida por banho solvente. 2003. 106p. Tese (Doutorado) - Escola Politécnica Universidade de São Paulo, São Paulo, 2003. p.18.

45 AKTINS, P.; DE PAULA, J. Physical Chemistry, eight edition, 2006, W. H. Freeman and Company, New York. Cap 22: The rates of chemical reactions. 
46 SORENSEN, 0. T. Quasi-isothermal Methods in Thermal Analysis. Thermochimica Acta, n. 50, p. 163-175, 1981.

47 NIGEL, J. C.; ANDREW, K. G. Decomposition Reactions of Solids (An Experiment In Reviewing). Thermochimica Acta, n. 79, p. 323-370, 1984.

48 SORENSEN, O. T. Thermogavimetric and dilatometric studies using stepwise isothermal analysis and related techniques. Journal of Thermal analysis, v. 38, p. 213-228, 1192.

49 GOTOR, F. J.; MAQUEDA, L. A. P.; ORTEGA, A.; CRIADO, J. M. Kinetic analysis of solid state reactions by means of stepwise analysis isothermal (SIA) and constant rate thermal analysis (CRTA) A comparative study. Journal of Thermal Analysis and Calorimetry, v. 53, p. 389-396, 1998.

50 SRINIVASAN, N.S. Reduction of iron oxides by carbon in a circulating fluidized bed reactor. Powder Technology, v. 124, p. 28-39, 2002.

51 VISWANATH, R. P.; VISWANATHAN, B. kinetics and Mechanism of reduction of ferric oxides by Hydrogen. Trans. JIM., v. 18, p. 149-154, 1977.

52 VALIPOUR, M. S.; HASHEMI, M. Y. M.; SABOOHI, Y. Mathematical modeling of the reaction in an iron ore pellet using a mixture of hydrogen, water vapor, carbon monoxide and carbon dioxide: an isothermal study. Advanced Powder Technol., v. 17, n. 3, p. 277-295, 2006.

53 KHAWAM, A.; FLANAGAN, D.R. Solid-State Kinetic Models: Basics and Mathematical Fundamentals REVIEW ARTICLES. J. Phys. Chem. B, v. 110, p. 17315-17328, 2006.

54 LIN, Q.; LIU, R.; CHEN, N. Kinetics of Direct Reduction of Chrome Iron Ore. Journal of thermal Analysis and Calorimetry, v. 58, p. 317-322, 1999.

55 CHEN, F.; SORENSEN, O.T.; MENG, G. PENG, D. Thermal decomposition of $\mathrm{BaC}_{2} \mathrm{O}_{4} .0,5 \mathrm{H}_{2} \mathrm{O}$ studied by stepwise isothermal analysis and non-isothermal thermogravimetry. Journal of thermal analysis, v. 53, p. 397-410, 1998. 
56 MAQUEDA, L. A. P.; ORTEGA, A.; CRIADO, J. M. The use of master plots for discriminating the kinetic model of solid state reactions from a single constant-rate thermal analysis (CRTA) experiment. Thermochimica Acta, v.277, p. 165-173, 1996.

57 BROWN, M.E.; MACIEJEWSKI, S.; VYAZOVKIN, S.; NOMEN, R.; SEMPERE, J.; BURNHAM, A.; OPFERMANN, J.; STREY, R.; ANDERSON, H.L.; KEMMLER, A.; KEULEERS, R.; JANSSENS, J.; DESSEYN, H.O.; CHAO-RUI, L.; TANG, T.B.; RODUIT, B.; MALEK, J.; MITSUHASHI, T. Computational Aspects of Kinetic Analysis. Part A: The ICTAC Kinetics Project - Data, Methods and Results. Thermochimica Acta, v. 355, 125-143, 2000.

58 SZEKELY, J.; EVANS, J. W.; SOHN, H. Y. Gas-solid reaction. Academic Press, 1976, New York, Capitulo 4: Reaction of porous solids.

59 POURGHAHRAMANI, P.; FORSSBERG, E. Effects of mechanical activation on the reduction behavior of hematite concentrate. Int. J. Miner. Process., n. 82, p. 96-105, 2007.

60 POURGHAHRAMANI, P.; FORSSBERG, E. Effects of mechanical activation on the reduction behavior of hematite concentrate. Int. J. Miner. Process., v. 82, p. 96-105. 2007.

61 BESSIÈRES, J.; BESSIÈRES, A.; HEIZMANN, J.J. Iron oxide reduction kinetics by hydrogen. Int. J. Hydrogen Energy, v. 5, p. 585-595, 1980.

62 PINEAU, A.; KANARI, N.; GABALLAH, I. Kinetics of reduction of iron oxides by $\mathrm{H}_{2}$ Part I: Low temperature reduction of hematite. Thermochimica Acta, n. 447, p. 89-100, 2006.

63 SZEKELY, J.; KARATAS, C. The Reduction of Wustite Disks with Carbon Monoxide Over the Temperature Range 573 to $845^{\circ} \mathrm{C}$. Metallurgical Transactions B, v. 9B, p. 147-150, 1978.

64 BIRD, R. B.; STEWART, W. E.; LIGHTFOOT, E. N. Transport Phenomena. Second edition. John Wiley \& Sons, New York, 2002. 
65 LINA, H. Y.; CHENA, Y. W.; LI, C. The mechanism of reduction of iron oxide by hydrogen. Thermochimica Acta, n. 400, p. 61-67, 2003.

66 SOHN I.; S. JUNG, M. Effect of Metal Additions to the Reduction of Iron Oxide Composite Pellets with Hydrogen at Moderate Temperatures. Steel Research Int. v. 82, n. 12, p.1345-1354, 2011.

67 HALIM, K. S. A.; NASR, M. I.; EL-GEASSY, A. A. Developed model for reduction mechanism of iron ore pellets under load. Ironmaking and Steelmaking, v. 38, n. 3, p. 189-196, 2011.

68 PINEAU, A.; KANARI, N.; GABALLAH, I. Kinetics of reduction of iron oxides by $\mathrm{H}_{2}$ Part II. Low temperature reduction of magnetite. Thermochimica Acta, n. 456, p. 75-88, 2007.

69 MINERALOGY DATABASE. Disponível em: http://www.webmineral.com/ Acesso em 13/02/2012.

70 JUNIOR NASCIMENTO, R. C. Uma análise microestrutural sobre pelotas auto-redutoras. 1994. 334p. Tese (Doutorado) - Escola Politécnica da Universidade de São Paulo. São Paulo, 1994. p. 7, 211.

71 MAGALHÃES, F. Síntese e Caracterização de Óxidos de Ferro e Compósitos para Aplicações no Tratamento Redox de efluentes Aquosos. 2008.190p. Tese (Doutorado) - Departamento de Química - Universidade Federal de Minas Gerais, Belo Horizonte, 2008. p. 45-56.

72 PIOTROWSKI, K.; MONDAL, K.; LORETHOVA, H.; STONAWSKI, L.; SZYMANSKI, T.; WILTOWSKI, T. Effect of gas composition on the kinetics of iron oxide reduction in a hydrogen production process. International Journal of Hydrogen Energy, n. 30, p. 1543 - 1554, 2005.

73 GAVIRÍA, J.P.; BOHE, A.; PASQUEVICH A.; PASQUEVICH D.M. Hematite to magnetite reduction monitored by Mossbauer spectroscopy and X-ray diffraction. Physica B, v. 389, 198-201, 2007.

74 SHIMOKAWABE, M.; FURUICHI, R.; ISHII, T. Influence of the preparation history of $\alpha-\mathrm{Fe}_{2} \mathrm{O}_{3}$ on its reactivity for hydrogen reduction. Thermochimica Acta, v. 28, p. 287-305, 1979. 
75 WILTOWSKI, T.; PIOTROWSKI, K.; LORETHOVA, H.; STONAWSKI, L.; MONDAL, K., LALVANI, S.B. Neural network approximation of iron oxide reduction process. Chemical Engineering and Processing: Process Intensification, v. 44, p. 775-783, 2005.

76 SWANN, P. R.; TIGHE, N. J. High voltage microscopy of the reduction of hematite to magnetite. Metallurgical Transaction B, v 8, p. 479-487, 1977.

77 BAGULEY, P.; JOHN, D. H. St.; HAYES, P. C. The conditions for the formation of lath and porous magnetite on reduction of hematite in $\mathrm{H}_{2} / \mathrm{H}_{2} \mathrm{O}$ gas mixtures. Metallurgical Transaction B, v. 14, p. 513-514, 1983.

78 RAU, M. F.; RIECK, D.; EVANS, J. W. Investigation of iron oxide reduction by TEM. Metallurgical Transactions B, v. 18, p. 257-278, 1987.

79 WANG, H.; YANG, Y.; WU, B. S.; XU, J.; DING, M. Y.; WANG, H. L.; FAN, W. H.; XIANG, H. W.; LI, Y. W. Hydrogen reduction kinetics modeling of a precipitated iron Fischer-Tropsch catalyst. Journal of Molecular Catalysis A: Chemical, v. 308, p. 96-107, 2009.

80 CORNELL, R. M.; SCHWERTMANN, U. The Iron Oxides. Weinheim; New York; Cambridge; Tokyo: VCH, 1996. p. 26-33.

81 DOBBON, D. C.; LINNETT, J. W.; EAHMAN, M. M. Mössbauer studies of the charge transfer process in the system $\mathrm{Zn}_{x} \mathrm{Fe}_{3-\mathrm{x}} \mathrm{O}_{4}$. J. Phys. Chem. Solids, v. 31, p. $2727-2733,1970$.

82 CORNELL, R. M.; SCHWERTMANN, U. The Iron Oxides: Structure, Properties, Reactions, Occurrences, and Uses. $2^{\mathrm{a}}$ ed, Editora: Wiley-VCH, 2003. 664 p. p. 32.

83 POVEROMO, J. J. Iron Ores. In: The Aise Steel Foundation. (Ed.) Ironmaking, Cap. 8. Pittsburgh. p. 547 - 550, 1999.

84 CACERES, P. G.; BEHBEHANI, M. H. Microstructural and surface area development during; hydrogen reduction of magnetite. Applied Catalysis A: General, n. 109, p. 211-223, 1994. 
85 BAHGAT, M.; KHEDR, M.H. Reduction kinetics, magnetic behavior and morphological changes during reduction of magnetite single crystal. Materials Science and Engineering B, v. 138, 251-258, 2007.

86 VISWANATH, R.P.; VISWANATHAN, B.; SASTRI, M.V.C. Kinetics and Mechanism of Reduction of Ferric Oxide by Hydrogen. Trans. JIM, v 18, p. $149-154,1977$.

87 EDSTROM, J.O. The mechamisn of reduction of iron oxides. Journal of the Iron Steel Institute, p. 289-304, 1953.

88 Matthew, S. P.; Hayes, P. C. Microstructural changes occurring during the gaseous reduction of magnetite. Metallurgical Transactions B, v.21, p. 153-172, 1990.

89 REISDOERFER, E. C. Síntese e caracterização do sistema ZnO-FeO submetido à moagem de alta energia. 2008. 92p. Dissertação (Mestrado) Universidade Estadual de Maringá, Paraná, 2008. p. 20.

90 GHEISARI, M.; MOZAFFARI, M.; ACET, M.; AMIGHIAN, J. Preparation and investigation of magnetic properties of wustite nanoparticles. Journal of Magnetism and Magnetic Materials, n. 320, p. 2618- 2621, 2008.

91 ALDON, L.; JUMAS, J.C. Lithium-induced conversion reaction in wüstite $\mathrm{Fe}_{1-\mathrm{x}} \mathrm{O}$ studied by 57Fe Mössbauer spectroscopy. Solid State Sciences, v.14, n 3, p 354-361, 2012.

92 HIRAMOTO, M.; OKINAKA, N.; AKIYAMA, T. Self-propagating hightemperature synthesis of nonstoichiometric wüstite. Journal of Alloys and Compounds, n. 15, v. 520, p. 59-64, 2012.

93 GABALLAH, I.; BERT, P.; DUFOUR, L. C.; GLEITZER, C. Kinetics of The Reduction of Wustite by Hydrogen and Carbon Monoxide + Hydrogen Mixtures. Observation of trichites, Memoires Scientifiques de la Revue de Metallurgie, n 69, v. 7-8, p 523-30, 1972.

94 PESCOTT, E. R. Kinetics of the Gaseous Direct Reduction of Iron Ores in Multi-Component Gas Mixtures, British Steel, 1976. 
95 MOUKASSI, M.; STEINMETZ, P.; DUPRE, B.; GLEITZER, C. Mechanism of Reduction With Hydrogen of Pure Wustite Single Crystals, Metallurgical Transactions B: Process Metallurgy, n. 14B, v.1, p. 125-32, 1983.

96 EL-RAHAIBY, S. K.; RAO, Y. K. The kinetics of reduction of iron oxides at moderate temperatures. Metallurgical Transaction B, v.10, p. 257-269, 1979.

97 FRUEHAN, R.J.; LI, Y.; BRABIE, L.; KIM, E.J. Final stage of reduction of iron ores by hydrogen. Scandinavian Journal of Metallurgy, n. 34, p. 205-212, 2005.

98 JOHN, D. H. St.; HAYES, P. C. Microstructural features produced by the reduction of wustite in $\mathrm{H}_{2} / \mathrm{H}_{2} \mathrm{O}$ gas mixtures. Metallurgical Transactions $B$, v.13, p 117-124, 1982.

99 JOHN, D. H. St.; MATTHEW, S. P.; HAYES, P. C. The breakdown of dense iron layers on wustite in $\mathrm{CO} / \mathrm{CO}_{2}$ and $\mathrm{H}_{2} / \mathrm{H}_{2} \mathrm{O}$ systems. Metallurgical Transactions B, v. 15, p. 701-708, 1984.

100 EL MOUJAHID, S.; RIST, A. The nucleation of iron on dense wustita: A morphological study. Metallurgical Transactions B, v. 19, p. 787-802, 1988.

101 LECLERC, N.; MEUX, E.; LECUIRE, J. M. Hydrometallurgical extraction of zinc from zinc ferrites. Hydrometallurgy, n. 70, p. 175-183, 2003.

$102 \mathrm{LI}, \mathrm{Y}$.; ZHAO, J.; HE, X. Influence of oxygen pressure on combustion synthesis of zinc ferrite powders. Materials Science and Engineering B, n. 106, p. 196-201, 2004.

$103 \mathrm{KIM}$, W.; SAITO, F. Mechanochemical synthesis of zinc ferrite from zinc oxide and $\alpha-\mathrm{Fe}_{2} \mathrm{O}_{3}$. Powder Technology, n. 114, p. 12-16, 2001.

104 ANDRADE, J. M. Ferritas de cobre e zinco do tipo espinélio sintetizadas pelos métodos: hidrotermal assistido por micro-ondas, precursores poliméricos, reação no estado sólido e decomposição térmica. 2012. 122 p. Dissertação (Mestrado) - Universidade Federal da Paraíba, João Pessoa, 2012. p.8. 
105 LEE, J.J.; LIN, C.I; CHEN, H.K. Carbothermal reduction of zinc ferrite. Metallurgical and Materials Transactions B, v. 32B, p.1033-1040, 2001.

106 TONG, L. F. Reduction mechanisms and behaviour of zinc ferrite-Part 1: pure $\mathrm{ZnFe}_{2} \mathrm{O}_{4}$. Mineral Processing and Extractive Metallurgy, v. 110, n. 1, p. 14-24, 2001.

107 TONG, L. F.; HAYES, P. Mechanisms of the reduction of zinc Ferrites in $\mathrm{H}_{2} / \mathrm{N}_{2}$ gas mixtures. Mineral Processing \& Extractive Metall. Rev., n. 28, p. 127-157, 2007.

108 LIANG, M.; KANG, W.; XIE, K. Comparison of reduction behavior of $\mathrm{Fe}_{2} \mathrm{O}_{3}$, $\mathrm{ZnO}$ and $\mathrm{ZnFe}_{2} \mathrm{O}_{4}$ by TPR technique. Journal of Natural Gas Chemistry, n. 18, p.110-113, 2009.

109 RAY, H. S. Kinetics of Metallurgical Reactions. International Science Publisher. 1993. Capitulo 7: Nucleation and Growth. p.144-163. 144p.

110 JOHN, D. H. St.; MATTHEW, S. P.; HAYES, P. C. Establishment of product morphology during the initial stages of wustita reduction. Metallurgical Transactions B, v. 15, p. 709-717, 1984.

111 CHANG, M.; DE JONGHE, L. C. Whisker growth in reduction of oxides. Metallurgical Transactions B, v.15B, p. 685-694, 1984.

112 KEMPKA, A. Auto-redução de ferro esponja: Uma nova técnica para o aumento de sua qualidade. 2008. 83 p. Dissertação (Mestrado) Universidade Federal do Rio Grande do Sul, Porto Alegre, 2008. p 3.

113 Disponível em <http://www.midrex.com/uploads/documents/MidrexStats2011-6.7.12.pdf>. Acesso em 10/07/2012.

114 FEINMAN, J. Direct reduction and smelting processes. In: Wakelin, D. H. The making, shaping and treating of steel. $11^{\mathrm{a}} \mathrm{ed}$. Pittsburgh: The Aise Steel Foundation, 1999. Cap. 11, p.763-801. 
115 ARAUJO, L. A. de. Manual de Siderurgia: Produção. São Paulo: Editora Arte \& Ciências, 1997. v.1.

116 CHEELEY, R. Gasification and the Midrex direct Reduction Process. In: Gasification Technologies Conference. San Francisco. Artigo. Califórnia, 1999. Disponível em <http://www.gasification.org/Docs/Conferences/1999/GTC99260.pdf> Acesso em 23/03/2010.

117 SILVA, A. C. Simulação computacional da redução direta de minério de ferro em fornos MIDREX. 2009. 159 p. Tese (Doutorado) - REDEMAT, Universidade Federal de Ouro Preto, Ouro Preto, 2010. p. 24.

118 WEISS, B.; STURN, J.; VOGLSAM, S.; WINTER, F.; SCHENK, J. Industrial fluidised bed direct reduction kinetics of hematite ore fines in $\mathrm{H}_{2}$ rich gases at elevated pressure. Chemical Engineering Science, n. 66, p. 703-708, 2011.

119 CENTRAL Pollution Control Board. [online]. Sponge Iron Industry. Disponível em <http://www.cpcb.nic.in/upload/Newltems/Newltem_102_SPONGE_IRON.pdf>. Acesso em 06/12/2010.

120 BASAK, A.; KAWATRA, S. K. Properties and Features ff Direct Reduced Iron. Mineral Processing \& Extractive Metall. Rev., v. 28, p. 59-116, 2007.

121 SARANGI, A.; SARANGI, B. Sponge Iron Production in Rotary Kiln. Easten Economy Edition. 1 ed., 2011. p 55.

122 DASH, R.N.; DAS, C. Recent Developments in Iron and Steel Making Industry. Journal of Engineering Innovation and Research, v. 1, p. 23-33, 2009.

$123 \mathrm{GHOSH}, \mathrm{A}$.; CHATTERJEE, A. Ironmaking and Steelmaking: Theory and Practice. India: Prentice Hall, 1998. Cap. 13.

124 MARROQUIN, M. C. G.; D'ABREU, J. C.; KOHLER, H. M. Estudo cinético de formação de ferrita de zinco. In: SEMINARIO DE REDUÇÃO DE MINERIO DE FERRO E MATERIAS-PRIMAS, 36., 2006, Ouro Preto. Anais. São Paulo, ABM, 2006. p.204-212. 
125 JUNCA, E. Estudo da separação e aproveitamento da parte metálica e dos óxidos presentes no resíduo gerado no corte de rochas ornamentais. 2009. 88 p. Dissertação (Mestrado) - Escola Politécnica da Universidade de São Paulo, São Paulo, 2009. p. 38

126 ACUÑA, A.; FUENTES, C.; SMITH, C. A. Dynamic simulation of a furnace of steam reforming of natural gas. Ciencia, Tecnología y Futuro, v. 1, n. 5, p. 35-44, 1999.

127 HUSUM, P.L.; SORENSEN, O.T. Computer controlled forced stepwise isothermal analysis. Thermochimica Acta, v. 114, p. 131-138, 1987.

128 RODUIT, B.; MACIEJEWSKI, M.; BAIKER, A. Influence of experimental conditions on the kinetic parameters of gas-solid reactions -parametric sensitivity of thermal analysis, Thermochimica Acta, v. 282-283, p. 101-119, 1996.

129 PIOTROWSKI, K.; WILTOWSKIM, T.; MONDAL, K.; STONAWSKI, L.; SZYMANSKI, T.; DASGUPTA, D. Simultaneous influence of gas mixture composition and process temperature on $\mathrm{Fe}_{2} \mathrm{O}_{3}-\mathrm{FeO}$ reduction kinetics neural. Brazilian Journal of Chemical Engineering network modeling, v. 22, n. 3, p. $419-432,2005$.

130 JUNG, S.S.; LEE, J.S. In-Situ Kinetic Study of Hydrogen Reduction of $\mathrm{Fe} 2 \mathrm{O} 3$ for the Production of Fe Nanopowder. Materials Transactions, v. 50, n. 9, p. $2270-2276,2009$.

131 Yi, C.; CHEN, B., Y. WANG, C. R.; KE, J. X. Experimental Research on Reducing the Dust of $\mathrm{BOF}$ in $\mathrm{CO}_{2}$ and $\mathrm{O}_{2}$ Mixed Blowing Steelmaking Process. ISIJ International, n. 49, v. 11, p. 1694-1699, 2009.

132 SAMMUT, M.L.; ROSE, J.; MASION, A.; FIANI, E.; DEPOUX, M.; ZIEBEL, A.; HAZEMANN, J.L.; PROUX, O.; BORSCHNECK, D.; NOACK, Y.

Determination of zinc speciation in basic oxygen furnace flying dust by chemical extractions and X-ray spectroscopy. Chemosphere, v. 70, p. 1945-1951, 2008.

133 TRUNG, Z.H.; KUKURUGYA, F.; TAKACOVA, Z.; ORAC, D.;

LAUBERTOVA, M.; MISKUFOVA, A.; HAVLIK, T. Acidic leaching both of zinc and iron from basic oxygen furnace sludge. Journal of Hazardous Materials, v. 192, p. 1100-1107, 2011. 
134 SILVA, M. C.; BERNARDES, A. M.; BERGMANN, C. P.; TENÓRIO J. A. S.; ESPINOSA, D. C. R. Characterization of electric arc furnace dust generated during plain carbon steel production. Ironmaking and Steelmaking, v. 35, n. 4, p.315 - 320, 2008.

135 BREHN, F. A. Adição de óxido de zinco (ZnO) em pastas de cimento visando viabilizar a reciclagem de pós de aciaria elétrica (PAE) na construção civil. 2004. 90 p. Dissertação (Mestrado) - Universidade Federal do Rio Grande do Sul. Porto Alegre, 2004. p. 19.

136 NYRENDA R.L. The processing of steelmaking flue-dust: a review. Minerals Engeering. v. 4, n. 7, p. 1003-1025, 1991.

137 PELINO, M.; KARAMANOV, A.; PISCIELLA, P.; CRISUCCI, S.; ZONETTI,

D. Vitrification of electric arc furnace dusts. Waste Management, n. 22,

p. 945-949, 2002.

138 OLIVEIRA, V. M. ESTUDO DA POROSIDADE DE PELOTAS DE MINÉRIO DE FERRO PARA ALTOS-FORNOS ATRAVÉS DE ADSORÇÃO FíSICA. 2010. 86 p. Dissertação (Mestrado) - Universidade Federal de Minas Gerais. Belo Horizonte, 2004. p. 12.

139 RAO, Y. K.. Mechanism and the intrinsic rate of reduction of metallic oxides. Metallurgical Transactions B, v. 10B, p. 243-255, 1979.

140 THEMELIS, N. J.; GAUVIN, W. H., Mechanism of reduction of iron oxides. Canadian Mining and Metallurgical Bulletin, v. 55, p. 444-456, 1962.

141 HAYES, $P$. C. The kinetics of formation of $\mathrm{H}_{2} \mathrm{O}$ and $\mathrm{CO}_{2}$ during iron oxide reduction. Metallurgical Transactions B, v 10B, p. 211-217, 1979.

142 EL-RAHAIBY, S. K.; RAO, Y. K. The kinetics of reduction of iron oxides at moderate temperatures. Metallurgical Transactions B, v.10B, n. 2, p. 257-69, 1979. 
143 WEISS, B.; STURN, J.; VOGLSAM, S.; STROBL, S.; MALI, H.; WINTER, F.; SCHENK, J. Structural and morphological changes during reduction of hematite to magnetite and wustite in hydrogen rich reduction gases under fluidised bed conditions. Ironmaking and Steelmaking, v. 38, n. 1, p. $65-73$, 2011.

144 LIN, H. Y.; CHEN, Y. W.; LI, C. The mechanism of reduction of iron oxide by hydrogen. Thermochimica Acta, v. 400, p. 61-67, 2003.

145 HUGHES, R.; KAM, E.K.T.; ZADEH, H. M. The reduction of iron ores by hydrogen and carbon monoxide and their mixtures. Thermochimica Acta, v. 59 , p. $361-377,1982$.

$146 \mathrm{LI}, \mathrm{Q}$. J.; HONG, X. Non-isothermal kinetic model for reduction of ferrous oxide with hydrogen and carbon monoxide. Ironmaking and Steelmaking, v. 36, n. 1, p. 24-28 2009.

147 HOU, B.; ZHANG, H.; LI, H.; ZHU, Q. Study on Kinetics of Iron Oxide Reduction by Hydrogen. Chinese Journal of Chemical Engineering, v. 20, n.1, p. 10-17, 2012.

148 GABALLAH, I.; BERT, P.; DUFOUR, L. C.; GLEITZER, C. Kinetics of The Reduction of Wustite by Hydrogen and Carbon Monoxide + Hydrogen Mixtures. Observation of trichites, Memoires Scientifiques de la Revue de Metallurgie, n. 69, v. 7-8, p 523-30, 1972.

149 MOUKASSI, M.; STEINMETZ, P.; DUPRE, B.; GLEITZER, C. Mechanism of Reduction With Hydrogen of Pure Wustite Single Crystals, Metallurgical Transactions B: Process Metallurgy, n. 14B, v.1, p. 125-32, 1983.

150 WILTOWSKI, T.; PIOTROWSKI, K.; LORETHOVA, H.; STONAWSKI, L.; MONDAL, K.; LALVANI, S. B. Neural network approximation of iron oxide reduction process. Chemical Engineering and Processing: Process Intensification, v. 44, p. 775-783, 2005. 